\title{
Towards consistency of EU external policies? : a case study on the European commission
}

Citation for published version (APA):

Marangoni, A. C. M. E. (2014). Towards consistency of EU external policies? : a case study on the European commission. [Doctoral Thesis, Maastricht University]. Datawyse / Universitaire Pers Maastricht. https://doi.org/10.26481/dis.20140924am

Document status and date:

Published: 01/01/2014

DOI:

10.26481/dis.20140924am

Document Version:

Publisher's PDF, also known as Version of record

\section{Please check the document version of this publication:}

- A submitted manuscript is the version of the article upon submission and before peer-review. There can be important differences between the submitted version and the official published version of record.

People interested in the research are advised to contact the author for the final version of the publication, or visit the DOI to the publisher's website.

- The final author version and the galley proof are versions of the publication after peer review.

- The final published version features the final layout of the paper including the volume, issue and page numbers.

Link to publication

\footnotetext{
General rights rights.

- You may freely distribute the URL identifying the publication in the public portal. please follow below link for the End User Agreement:

www.umlib.nl/taverne-license

Take down policy

If you believe that this document breaches copyright please contact us at:

repository@maastrichtuniversity.nl

providing details and we will investigate your claim.
}

Copyright and moral rights for the publications made accessible in the public portal are retained by the authors and/or other copyright owners and it is a condition of accessing publications that users recognise and abide by the legal requirements associated with these

- Users may download and print one copy of any publication from the public portal for the purpose of private study or research.

- You may not further distribute the material or use it for any profit-making activity or commercial gain

If the publication is distributed under the terms of Article $25 \mathrm{fa}$ of the Dutch Copyright Act, indicated by the "Taverne" license above, 


\section{TOWARDS CONSISTENCY OF EU EXTERNAL POLICIES?}

A CASE STUDY ON THE EUROPEAN COMMISSION 
(C) Anne-Claire Marangoni, Maastricht 2014

ISBN 9789461593559

Production: Datawyse | Universitaire Pers Maastricht

Cover picture: (C) European Union, 2014 


\title{
TOWARDS CONSISTENCY OF EU EXTERNAL POLICIES?
}

\section{A CASE STUDY ON THE EUROPEAN COMMISSION}

\author{
PROEFSCHRIFT
}

ter verkrijging van de graad van doctor aan de Universiteit Maastricht, op gezag van de Rector Magnificus, Prof. dr. L.L.G. Soete, volgens het besluit van het College van Decanen, in het openbaar te verdedigen, op woensdag 24 september 2014, om 12.00 uur

door

ANNE-CLAIRE MARANGONI

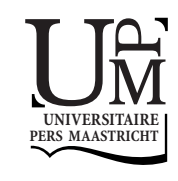




\section{Promotores}

Prof. dr. Sophie Vanhoonacker

Prof. dr. Thomas Conzelmann

\section{Beoordelingscommissie}

Prof. dr. Christine Neuhold (voorzitter)

Prof. dr. Steven Blockmans (University of Amsterdam)

Prof. dr. Tannelie Blom

Prof. Michael H. Smith (Loughborough University) 


\section{Acknowledgements}

I would like first to thank my two supervisors, Sophie Vanhoonacker and Thomas Conzelmann. Sophie spent many hours reading and re-reading my drafts, always asking the rights questions to make sense of my own research. Thomas gave me crucial feedback throughout the project, helping me to stay focused.

Second, I am indebted to the Marie Curie Initial Training Network on Interinstitutional Cooperation in the EU (INCOOP) for providing a stimulating environment outside of which I would not have written this thesis. A very special thank you goes out to Sophie Vanhoonacker and Christine Neuhold, for taking me on board and for ensuring that the research process was as smooth as possible. I have learnt a lot from you, thank you for your feedback and more importantly for all your support and kind words. I am incredibly thankful to the late Dave Allen for his unwavering support and inspiring comments. I would like to thank Mike Smith and David Spence. At our regular meetings, they commented on parts of this thesis: their advice, expertise and insights were often key throughout these three years. I would also like to thank Les Metcalfe, for stimulating exchanges on a key dimension of my research, as well as Kolja Raube, with whom it was a pleasure to work on related projects.

Third, I would like to thank a number of people who have stood by me in this process. Alexandra, Davide and the amazing "tradenees". Marie De Somer and Mathias Dobbels, my dear paranymphs, who went as far as to translate the summary of this thesis into Dutch. My parents for believing in me more than I do. Pauline, my sister, because working on our theses at the same time was quite an adventure. Clément as this book would not have been written without his unconditional support.

All errors that remain in this thesis are, as ever, the responsibility of the author alone. 


\section{Contents}

Acknowledgements $\quad 5$

$\begin{array}{ll}\text { List of tables and figures } & 10\end{array}$

$\begin{array}{ll}\text { List of acronyms } & 11\end{array}$

CHAPTER 1. AN INTRODUCTION TO THE CONSISTENCY CHALLENGE

1.1. The EU's international role 13

1.2. The consistency challenge 16

1.3. Research focus 17

1.4. State of the art 19

1.5. The relevance of the consistency question 24

1.6. Thesis outline 26

CHAPTER 2. FRAMING THE ISSUE: THE POLICY AND INSTITUTIONAL CONTEXT

2.1. The substance of external policies 27

2.1.1. The Common Commercial Policy 27

2.1.2. Development cooperation 30

2.1.3. From EPC to CFSP 31

2.2. The European Commission and external policies $\quad 34$

2.2.1. Fragmentation at the political level 34

2.2.2. Fragmentation at service level 37

2.3. Conclusion 43

CHAPTER 3. CONCEPTUAL FRAMEWORK AND METHODOLOGY $\quad 45$

3.1. Defining consistency, a challenge at several levels 45

3.1.1. A linguistic challenge, consistency versus coherence 46

3.1.2. A multidimensional challenge 48

3.2. Conceptual framework $\mathbf{5 0}$

3.2.1. How to ensure consistency? 51

3.2.2. How to assess consistency? 57

3.3. Methodology $\quad 60$

3.3.1. How to explain successful coordination? 60

3.3.2. Case studies 61

3.3.3. Process-tracing and qualitative interviews 66

$\begin{array}{ll}\text { 3.4. Conclusion } & \mathbf{7 0}\end{array}$ 
CHAPTER 4. REQUIRING CONSISTENCY: THE TREATY FRAMEWORK

4.1. The Paris Communiqué and the Single European Act 72

4.1.1. A first step, the Paris Summit Communiqué 73

4.1.2. A commitment to consistency, the Single European Act 73

4.2. From the Maastricht Treaty to the European Convention $\quad 75$

4.2.1. The Treaty on the European Union 76

4.2.2. The European Convention 79

4.3. Lisbon, the way forward 81

4.4. Conclusion $\quad 85$

CHAPTER 5. IMPLEMENTING THE CONSISTENCY

REQUIREMENT: COMMISSION INTERNAL DECISION-MAKING

5.1. Consistency, collegiality and coordination, a question of principle

88

5.2. A decentralised system $\quad 89$

5.2.1. Planning for consistency 90

5.2.2. Service-level coordination, testing the ground for a proposal 91

5.2.3. Coordination at the political level, finalizing the proposal 97

5.2.4. Conclusion 100

5.3. The Secretariat General of the Commission, the guardian angel of coordination 101

5.4. The consistency and coordination mandate of the HRVP 104

5.5. The EEAS' contribution to consistency and coordination 107

5.6. Conclusion: coordination, a renewed challenge 110

\section{CHAPTER 6. THE CONSISTENCY OF APPROPRIATE}

MEASURES AGAINST ZIMBABWE IN 2002 AND IN 2012

6.1. Introduction 113

6.2. A regime that cannot be left unpunished 114

$\begin{array}{ll}\text { 6.3. The policy framework } & 117\end{array}$

6.3.1. Cotonou, a 3-pillar agreement 117

6.3.2. Article 96 mechanism 120

6.3.3. Targeted sanctions, accounting for different objectives 121

6.4. The Commission's internal decision-making process $\mathbf{1 2 2}$

6.4.1. The adoption of appropriate measures against Zimbabwe in 2002

6.4.2. The renewal of appropriate measures against Zimbabwe in 2012 
6.5.1. Consistency between appropriate measures and foreign policy

6.5.2. Consistency of appropriate measures with development objectives

6.5.3. Consistency of appropriate measures with trade

6.5.4. Assessing consistency

6.6. The factors explaining successful coordination 142

6.6.1. The international factor

6.6.2. The Member States factor

$\begin{array}{ll}\text { 6.6.3. The nature of the decision } & 146\end{array}$

6.6.4. Bureaucratic politics 147

6.7. Conclusion

CHAPTER 7. THE CONSISTENCY OF THE 2011 COMMISSION'S PROPOSAL TO REVISE THE GSP

7.1. Introduction

7.2. Background

7.2.1. EU-DC trade

7.2.2. The EU GSP, factsheet

7.3. The policy framework

7.3.1. Policy Coherence for Development

7.3.2. Trade-development strategic documents

7.4. The Commission's internal decision-making process

7.4.1. The leadership of Trade

7.4.2. Drafting the proposal

7.5. Consistency challenges

7.5.1. Consistency between the GSP and development

7.5.2. Consistency between the GSP and foreign policy

7.5.3. Consistency between the GSP and trade policy

7.5.4. Assessing consistency

7.6. The factors explaining successful coordination $\quad 183$

7.6.1. Abiding by WTO law 183

7.6.2. Inter-institutional dynamics 184

$\begin{array}{ll}\text { 7.6.3. The nature of the decision } & 185\end{array}$

$\begin{array}{ll}\text { 7.6.4. Bureaucratic politics } & 187\end{array}$

$\begin{array}{lr}\text { 7.7. Conclusion } & 190\end{array}$ 
CHAPTER 8. CONCLUSION

8.1. A three-level framework for consistency 193

8.2. Assessing consistency 195

8.3. The factors explaining successful coordination 196

8.4. Consistency after the Lisbon Treaty 203

Annex I: Policy options for the revision of the GSP 205

Annex II: Countries no longer beneficiaries of the new GSP 207

Annex III: List of interviews 208

Exploratory interviews $\quad 208$

Interviews $\quad 208$

References $\quad 210$

$\begin{array}{ll}\text { Samenvatting } & 231\end{array}$

Valorization $\quad 235$

$\begin{array}{ll}\text { Curriculum vitae } & 239\end{array}$ 


\title{
List of tables and figures
}

\author{
List of tables
}

Table 2.1: Commission organisation $\quad 39$

Table 3.1: Dimensions of consistency challenges 49

\section{List of figures}

Figure 2.1: External policies under the Barroso II Commission 41

Figure 3.1: Coordination, successful coordination and consistency 59

Figure 3.2: Selection of case studies along the continuum of consistency 63

Figure 5.1: The chairmanship of the FAC 105 


\section{List of acronyms}

\begin{tabular}{ll} 
ACP & African, Caribbean and Pacific countries \\
CIS/ISC & Inter-service consultation \\
CCP & Common Commercial Policy \\
CFSP & Common Foreign and Security Policy \\
CSDP & Common Security and Defence Policy \\
DG & Directorate General \\
EC & European Community \\
ECJ & European Court of Justice \\
EEAS & European External Action Service \\
EEC & European Economic Community \\
ENPI & European Neighbourhood Policy Instrument \\
EPA & Economic Partnership Agreement \\
EPC & European Political Cooperation \\
ESA & Eastern and Southern Africa \\
ESS & European Security Strategy \\
EU & European Union \\
GSP & Generalised System of Preferences \\
HIC & High Income Country \\
HRVP & High Representative - Vice President of the Commission \\
MS & Member States \\
OCT & Overseas Countries and Territories \\
OECD & Organisation for Economic Cooperation and Development \\
PCD & Policy Coherence for Development \\
SG & Secretariat General of the Commission \\
SGHR & Secretariat General - High Representative \\
SPP & Strategic planning and programming \\
TEC & Treaty on the European Community \\
TEEC & Treaty on the European Economic Community \\
TEU & Treaty on the European Union \\
TFEU & Treaty on the Functioning of the European Union \\
UMI & Upper Middle Income Country \\
WTO & World Trade Organization \\
\hline
\end{tabular}





\section{CHAPTER 1.}

\section{AN INTRODUCTION TO THE CONSISTENCY CHALLENGE}

DG Internal Market wants to liberalise. DG Taxation wants to harmonise. DG Transport wants to mobilise. DG Environment wants to regulate. DG Development wants to develop. DG Enlargement wants to enlarge. DG Trade wants to trade. DG External Relations wants to talk. DG Information wants to inform. (Eppink, 2007:111)

\subsection{The EU's international role}

Few objectives have characterised European integration as much as that of an enhanced international role for the EU. The EU's own efforts towards strengthening its status as a global player, "bringing substance and presence to the foreign policy agenda" (EEAS, 2011:1), is echoed at both international (UNGA, 2011) and Member States levels (i.a. Europe Group of Foreign Ministers, 2012:1; European Council, 2010:2). In today's multipolar world, characterised by rapid changes, the wide spectrum of policies, instruments and resources on which the EU can capitalise theoretically puts it in a strong position to tackle multifaceted and global challenges (Bretherton \& Vogler, 2009:28). However, the Union has been repeatedly criticised for the insufficient consistency of its external action, which is seen in turn as jeopardising its international status.

After the Second World War, the EU started as an internal project to reconcile European nations and restore peace on the continent through economic integration. External relations have become an inevitable dimension thereof (see for instance Vimont quoted in Bindi \& Angelescu, 2012:ix). The external dimension of the European project initially consisted of the common external tariff and the association of third countries with the common market. This process has been significantly enhanced after the end of the Cold War with the association of Eastern and Central European countries and the stabilisation of the Balkans i.a. (Laursen, Vanhoonacker \& Wester, 1992:3). Building on some Member States' former colonial empires and with the specific objective to contribute to the development of the African continent (Schuman plan, 1950), the EU has progressively developed a farreaching set of external policies and instruments. The Common External Tariff and the resulting Common Commercial Policy (CCP), the front-runners of EU external action (Laursen, 2009:1), as well as the EU's Development Policy still constitute the heart of EU external relations, characterised by its economic, rather than political, rationale. The 1990s also saw the rise of EU humanitarian policy. Only in a second step and after the aborted attempt of the European Defence Community (1954), the creation of the European Political Cooperation (EPC, 1970) paved the way to the 
strengthening of political external relations. The EPC provided a loose framework to coordinate foreign policies but security and defence issues remained outside of the Treaty framework. The Maastricht Treaty (1992) eventually completed the range of external policies with the addition and the introduction in the Treaty framework of the Common Foreign and Security Policy (CFSP), the defence dimension of which was built up from the late 1990s onwards. At the same time, the EU also extended its geographical reach to new partners, for instance the neighbours of the neighbours or today's strategic partners, such as the United States, China and Russia. Depending on the situation in these countries, the EU developed instruments and policies, further broadening the scope of its external action. The triangle of core external policies constituted by the common commercial policy, development cooperation and CFSP is the policy focus of this research.

Accounting for over a fifth of world trade, providing more than half of international development and humanitarian assistance, making an important contribution to international organisations and having deployed civilian and military operations in hot spots worldwide, the EU has the potential to play an important international role (Commission, 2006b:2), in turn enabling its Member States to still play an international role:

[t]he European Union gives [its Member States] the potential to shape globalisation positively in ways even the largest of nation states cannot achieve on their own (Mandelson quoted in Bretherton \& Vogler, 2009:28).

Yet, the EU often fails to live up to the expectations created by its potential, as described in the notion of the "capability-expectations gap" developed by Hill (1993). The metaphor of the EU as an 'economic giant, political dwarf, military worm' reflects how the EU seems to fall short of exercising, in international affairs, the influence that would be commensurate with the policies, instruments and resources available (Bretherton \& Vogler, 2009:39-40; European Council, 2008:2; Commission, 2006b:6; ESS, 2003:11; European Convention, 2002f:11). ${ }^{1}$ The literature discusses several factors that weaken the EU's influence in world affairs, from the democratic deficit of the CFSP (Koenig-Archibugi, 2002) to the lack of European military capabilities (Missiroli, 2013) or the complexities of EU external representation (Blockmans \& Wessels, 2012) and the lack of a foreign policy "strategic narrative" (Biscop, 2012). The perceived inconsistency of EU external action is another such factor that is considered to jeopardise the EU's international actorness (European Convention, 2002e; Bretherton \& Vogler, 1999; Jupille \& Caporaso, 1998).

\footnotetext{
${ }^{1}$ It has been a concern at the highest level in the EU as the title of Solana's working paper presented at the Evian informal General Affairs Council “The EU's External Projection: Improving the Efficiency of Our Collective Resources" illustrates; quoted in Missiroli, 2001:2.
} 
While the Lisbon Treaty had initially seemed promising (EEAS, 2011:1), both by concluding a reform process focused on the twin goals to enhance the consistency of EU external action and EU international actorness, and by introducing farreaching institutional innovations to meet them, consistency remains a challenge until the present day. Mayer has called the gap between what the EU aims at in terms of consistency of its external action and what it actually reaches a "selfinflicted rhetorical trap" as the EU has committed itself to reaching consistency without necessarily having the ability to do so (2013:106).

This thesis raises the following overarching question: to what extent are EU external policies consistent and how can we explain such consistency (or its absence)? To answer this question, the research focuses on the European Commission. It adopts a case study approach and assesses the consistency of specific Commission proposals. First, it deals with the case of appropriate measures adopted under article 96 of the Cotonou agreement against Zimbabwe in 2002 and in 2012. A comparative pre- and post-Lisbon approach will be of particular interest to this study as the Lisbon Treaty introduced major innovations with respect to consistency. The 2011 Commission's proposal to revise the Generalised System of Preferences - under which the EU grants non-reciprocal import preferences to developing countries - is the second case. These two cases are very relevant to the study of the consistency of EU external policies as they both involve different external policy dimensions - trade, development and CFSP - and are characterised by the challenge of coordinating the different objectives and instruments of these policy domains in one Commission proposal. ${ }^{2}$ The extent to which the Commission has been successful in its attempts to adopt a proposal without internal contradictions - i.e. a consistent proposal - and why it has been successful are the main research interests of this study.

Three sub-questions are asked that will structure the two case study chapters: first, to find out how the Commission aims at consistency, second to assess the actual consistency of specific proposals and third to discuss the conditions that contributed to the success of coordination and therefore to the adoption of a consistent proposal.

The first sub-question explores how and at what levels the consistency requirement is expressed. The research identifies a three-level framework for the consistency of external policies (chapter 3). First, the Treaty framework constitutes the most general level at which the consistency requirement is expressed - the consistency of external action between trade, development cooperation and CFSP in particular. It legally requires the policy output to be consistent. Second, the policy framework specifies the general consistency requirement for a proposal taken in a particular policy area. It is by definition policy-specific and will typically vary from one case study to the other. For instance, the EU's strategic framework on human rights and democracy (2012) constitutes an instrument to streamline

\footnotetext{
${ }^{2}$ Section 3.3 discusses the case study selection and the relevance of the choices made.
} 
human rights in EU external policies and to ensure that they are consistent with human rights objectives. Overall, the policy framework provides substantial guidance to the EU's action in a particular policy area for this action to be consistent. Lastly, the research explores the Commission's internal decision-making in external policies. This third level of analysis puts into effect the consistency requirement provided for in the Treaty and in the policy framework. Decisionmaking is a necessary level to consider because it specifies how a particular institution, here the Commission, shall realise consistency on a day-to-day basis. The focus on decision-making goes hand-in-hand with a focus on coordination throughout the preparation of any Commission proposal. The Treaty framework and decision-making of the Commission provide the general framework for this research (chapters 4 and 5). This general pattern is then observed 'in action' in specific case studies (chapters 6 and 7). The case study chapters first introduce the policy framework (sections 6.3 and 7.3), further contextualising the general framework of Commission action. Sections 6.4 and 7.4 then discuss how the Commission actually implements the consistency requirement through coordination in the preparation of specific proposals.

To answer the second sub-question, the case study chapters discuss the absence or existence of contradictions between the respective primary objectives of selected Commission proposals and the policy content of these proposals to conclude on the consistency of these proposals. In the event of consistent proposals, the research concludes that coordination within the Commission has been successful.

Lastly, the third sub-question focuses on the factors that influenced the coordination process and made it more or less successful. Although the three-level framework and especially coordination throughout decision-making are important elements for the consistency of a proposal, they can never fully guarantee a consistent output. Factors, both within and outside of the Commission, weigh in, a discussion that is taken up on the basis of the empirical evidence collected in the case studies.

\subsection{The consistency challenge}

As this thesis focuses on consistency, it is important to agree on the definition of this concept. Defining consistency is a challenge per se. Lengthily dealt with in the academic literature, this exercise is complicated by the interchangeable use of the words "consistency" and "coherence" by certain scholars and practitioners, as well as by the unclear delineation of the terms consistency and coordination in policy documents. Overall, one may also note that consistency is not specific to the literature on the EU: it constitutes a topic of relevance in the field of administrative governance in general as it represents a challenge for any polity, be it at the local, regional, national or international level. 
Regarding the use of the term consistency, it is notable that consistency and coherence are often used interchangeably in the political science literature and in certain official documents. They will not be used interchangeably in this research, as they have different meanings (see section 3.1). While consistency refers to the absence of contradictions between the primary objective of an action and the different dimensions of this action, coherence goes one step further and refers to the existence of synergies between the different dimensions of a particular action. The research focuses on consistency only: it assesses the consistency of particular Commission proposals on the basis of the absence or existence of contradictions between the primary objectives and the provisions of these proposals. A focus on coherence would require assessing not only the absence of contradictions, but also the existence of positive externalities. Assessing the existence and extent of synergies would necessitate to look at the implementation of the proposals considered and to evaluate their concrete effects. The implementation phase falls however outside of the scope of this research.

A further complication is that consistency is often used together or interchangeably with coordination. Such a use of the terms confuses a political objective (consistency) with an instrument to achieve this objective (coordination). The thesis therefore defines consistency (or its absence) as the possible outcome of various activities, such as coordination, by different actors. While the use of these terms will be disentangled further in the following chapters, it is important to note here that the way in which a consistent policy outcome is or is not achieved in the EU through various coordination instruments in particular constitutes a major dimension of this research (see chapter 3).

\subsection{Research focus}

Consistency is an overall challenge, which is neither specific to the EU nor to external policies. But the consistency of EU external action has been at the top of the political agenda since the mid 1970s and was in particular extensively discussed by the European Convention. Consequently, this section defines the exact research focus and motivates the choice for its policy scope (EU external policies), its institutional focus (the European Commission) and the phase of decision-making it is looking at.

First, this research is defined by its focus on EU external policies. "External action" is the most common and generic expression used in the Lisbon Treaty (article 16.6 TEU, art. 18.4 TEU, Chapter 1 of title V TEU, art. 21.3 TEU). The EU's external action is manifold and covers a wide range of policy areas: external policies proper - such as external trade, development cooperation and the Common Foreign and Security Policy - and the external aspects of internal policies - such as the external dimension of the Common Agricultural Policy. The scope of the study does not include the latter. The research looks into the 'hard core' of EU external 
action, the three classical external policies of the EU namely external trade, development cooperation and CFSP. The focus is on the existence or absence of contradictions in concrete proposals between the respective primary objectives of the proposals and actions taken on these three dimensions.

Second, the institutional focus of the research is narrowed down to one institution, the European Commission, and the consistency challenge within this institution. ${ }^{3}$ This choice is motivated by several reasons. To start, since the Single European Act (1987), the Commission has always been given special responsibility for ensuring the consistency of the EU's action. The Treaties successively provided that the Council Presidency and later the Council should cooperate with the Commission to ensure consistency. The Lisbon Treaty reaffirms the Commission's responsibility for consistency (article 21.3 TEU). Its mandate is even strengthened by the creation of the double-hatted position of High Representative-Vice President of the Commission (HRVP). Indeed, the consistency of EU external action is one of the key responsibilities of the HRVP. Under the hat of Vice-President of the Commission, the emphasis is put on consistency within the Commission and the Treaty provisions explicitly refer to the coordination of external policies within the Commission (article 18.4 TEU). In this context, the Lisbon Treaty further sharpens the consistency challenge. Creating the European External Action Service (EEAS) to support the HRVP, the new Treaty has added an actor to the EU's institutional architecture, thereby complicating institutional dynamics. Yet, the EEAS also exercises part of the consistency mandate (Gaspers, 2008:34; see also for instance Duke, 2008; Lieb \& Maurer, 2007). Although external to the Commission, in specific circumstances, the EEAS plays an important role in the Commission's internal decision-making in the adoption of Commission proposals, as will be discussed in chapter 5. Lastly, with regard to policy substance, the focus on the European Commission is justified by its important contribution to external action (see section 2.1). In the field of external trade, one of its exclusive competences, the Commission has an exclusive right of initiative and negotiates with trade partners within the limits set by Member States. In the field of development cooperation, a complementary competence of the EU, the Commission initiates the Union's policy to the extent that it does not prevent Member States from exercising their competence. The Commission also programs and implements most of EU development instruments. The Commission's tradition and expertise in these two policy areas make it a very important actor of the Union's external action, all the more so since there exist strong policy interlinkages between economic external policies (trade and development) and the CFSP. The Commission's tradition and expertise also explain the decision to fully associate the Commission with European Political Cooperation back in the early 1980s (Nuttall, 1992). Today, in the field of CFSP, the Commission has a right to ask questions as well as to submit proposals jointly with the HRVP to the Council. The Commission also derives influence in this

\footnotetext{
${ }^{3}$ As opposed to consistency as a challenge between different institutions, for instance between the Commission and the Council or between the Commission and the European Parliament. However, the Commission takes decisions in a complex institutional framework: consequently, other institutions' influence - the Council or the Parliament's notably - will be considered as well.
} 
policy field from its authority over the EU budget. ${ }^{4}$ In addition, through its Service for Foreign Policy Instruments, the Commission implements the CFSP budget, the crisis response and prevention measures financed under the Instrument contributing to Stability and Peace, the electoral observation missions under the European instrument for Democracy and Human Rights, and the Kimberley Process certification scheme. It also works to prevent the trade in goods that could be used for capital punishment or torture, and prepares and implements sanction proposals. $^{5}$

As a third element, this research is also defined by its focus on a specific phase of the policy cycle. It studies the preparation of Commission proposals up to their adoption by the College. Under regular circumstances, the preparation of any Commission proposal is divided into two phases. The first phase is called strategic planning and programming (SPP). In a second step, concrete policy proposals are prepared by Commission services for their adoption by the College. Evidently, in the case of crisis decision-making, the first phase - SPP - is missing. The research focuses on these first two steps within the Commission and explores the Commission's decision-making process (as the third level of the conceptual model developed above). This focus leaves out the discussion and possible adoption of the proposal by other institutions and the implementation phase of the decision. The Commission's pivotal role in the early stages of the development of policies, giving a direction to EU action, provides an additional justification for the research focus on this institution. If the European Commission has an important role in the first steps of the development of policies, the implementation of EU decisions is the responsibility of the Member States - the Commission only supervises this phase. Despite its institutional focus, this research does not imply that other institutions such as the Council or the European Parliament will not be considered at all; they influence the Commission's decision-making, a factor that will be discussed in the following chapters.

\subsection{State of the art}

As has already become clear, there exists a large body of scholarship dealing with the consistency challenge both at a general level and at the level of EU external action. This section first reviews the existing literature, exploring how consistency has been addressed so far and second outlines the added value of the research. In doing so, three strands of the literature will be referred to.

First, consistency is an overall challenge in public administration that is not specific to the EU. Consequently, consistency often appears as an underlying objective of governmental action in the public administration literature. It usually

\footnotetext{
${ }^{4}$ The "EU as a global player" chapter of EU budget amounts to €9.6 billion in 2013, including instruments such as the Development Cooperation Instrument or Humanitarian aid for instance.

${ }^{5}$ http://ec.europa.eu/dgs/fpi/about/index_en.htm
} 
refers to the avoidance of contradictions and/or the creation of synergies between policies (Jordan \& Schout, 2006:ix; Mc Lean Hilker, 2004:4; Schout, 1999:6). This strand of literature mainly discusses the reasons why consistency may be a challenge - referring to organizing principles of public administrations or to particular administrative behaviours (see i.a. Peters, 2010; Simon, 1997; Hammond, 1986). In particular, horizontal specialisation - or the definition of sectoral responsibilities - is the traditional organising principle in public administrations. Pros and cons of this organising principle have already been discussed extensively in the literature (Stevens \& Stevens, 2001:166-168 \& 196197; Simon, 1997:30; Coombes, 1970:109). If specialisation provides for the expertise needed by decision-makers, it also leads to institutional fragmentation and thus to policy fragmentation with its inherent risk of inconsistency of the policy output. Coping with institutional and policy fragmentation is challenging. For instance, today the consistency of national economic policies is a topical issue. Different dimensions and objectives need to be taken into consideration and coordinated to design a sustainable economic policy - such as employment, social policy, education, industrial and competitiveness policies, competition law and fiscal provisions. Each of these policies is the preserve of a particular member of the government and the corresponding ministry with particular objectives. Overcoming this sectoral fragmentation to address cross-policy issues is "the eternal problem (...) in governance" (emphasis in the original, Perri et al., 2002:9 quoted by Jordan \& Schout, 2006:32), all the more so since most issues today require an action on multiple dimensions (see for instance Peters, 2001:373-378). This literature also focuses on how public administrations tackle the consistency challenge, with a clear focus on coordination (Dimitrakopoulos \& Passas, 2003; Schout, 1999; Alexander, 1993; Mintzberg, 1979). It explores instruments used to ensure coordination in the framework of both national administrations and international organisations (Peters, 2010:203; Pollitt, 2003:35; Wollmann, 2003; Schout, 1999:6-8; Simon, 1997:113; Alexander, 1993). ${ }^{6}$ The overall objective to produce a contradiction-free policy output may be met in national public administrations, for instance, through strategic planning, the definition of overarching objectives and the setting up of services with a coordination mandate (see for instance Morisse-Schilbach, 2005). Aiming at the same objective, international organisations may also encourage the diffusion of best practices in specific areas, as the case of 'policy coherence for development' illustrates (see for instance Mc Lean Hilker, 2004).

The second strand of literature deals specifically with the consistency challenge in the context of the EU. In particular, the consistency challenge in the EU has arisen

\footnotetext{
${ }^{6}$ Different categorisations of coordination instruments exist in the public administration literature, ranging from modes of governance (hierarchy, network and market; Jordan \& Schout, 2006:15-16; Wollmann, 2003:595-596) to March \& Simon's distinction between coordination through programming and coordination by feedback (1958 in Van de Ven, Delbecq \& Koenig, 1976:323; Hage, Aike \& Marrett, 1971:860-861) and Mintzberg's ideal types (hierarchies, behaviour, standardisation of worker skills, standardisation of work outputs and mutual adjustment (1998:3-7).
} 
from the pillarized structure of EU external action - formally until the Lisbon Treaty - materialised by the coexistence of two sets of actors with different powers and two decision-making processes (Nuttall, 2005; Stetter, 2004; Schmalz, 1997; Timmermans, 1996). ${ }^{7}$ The case of sanctions practically illustrates the dichotomy of EU external policies (Buchet de Neuilly, 2003; Schmalz, 1997). Typically, the political decision on sanctions is adopted in the CFSP framework but the decision implementing the sanctions is adopted under the Community framework. Chapter 3 will present the debate on the definition of consistency and of its different dimensions.

One can distinguish two directions in the EU literature. On the one hand, there are those scholars who focus on consistency as provided for in the Treaties. The dichotomy between economic and political external relations has important institutional consequences and challenges the overall consistency of EU external action (Smith, 2006; Spence, 2006c; Allen, 2002:51; Smith, 2001; Schmalz, 1998; Allen \& Smith, 1994). In particular, accounts of Treaty changes indirectly talk about the risks associated with the duality of EU external action and EU attempts to tackle them (i.a. Laursen (ed.), 2012; Duke, 2011a; Laursen (ed.), 2009; Portela \& Raube, 2008; Raube, 2007; Laursen (ed.), 2006; Smith, 2001a; Laursen (ed.), 2002; Nuttall, 2000; Schmalz, 1998; Krenzler \& Schneider, 1997; Nuttall, 1992; Laursen \& Vanhoonacker (eds), 1992). They discuss the strengthening of the consistency requirement in the Treaties, including the protection of the delineation between former EC external policies and CFSP (Hillion \& Wessel, 2009; Dashwood, 2008; Van Ooik, 2008), as well as the institutional provisions contained in the Treaty to realise the consistency requirement (Duke, 2011a; Bosse-Platière, 2009; Cremona, 2008; Bonavita, 2008; Smith, 2001a; Nuttall, 2000; Wessel, 2000; Duke, 1999; Schmalz, 1998; Krenzler \& Schneider, 1997; Timmermans, 1996). For instance, the entry into force of the Lisbon Treaty has triggered early assessments of its consistency-related innovations, notably the double-hatted position of the HRVP and the EEAS (see for instance European Parliament, 2013; Eckes, 2013:28-35; Blockmans \& Hillion, 2013; Helwig, Ivan \& Kostanyan, 2013; Duke, 2012; Marangoni, 2012; Rüger, 2012; Duke, 2011b).

On the other hand, in an attempt to conceptualise the EU's role in foreign policy (Jupille \& Caporaso, 1998) and to assess the extent to which the EU has actually become an international actor (Bretherton \& Vogler, 2006), the scholarship considers consistency or coherence as an important explanatory factor. The model developed by Jupille and Caporaso for example identifies four criteria of EU actorness: recognition, authority, autonomy and cohesion. For the fourth criterion to be met, the EU must be "able to formulate and articulate internally consistent policy preferences" (emphasis added; Jupille \& Caporaso, 1998:214). Consistency is also a defining element of actorness in the model developed by Bretherton and

\footnotetext{
${ }^{7}$ See the discussion on the choice, in the Maastricht Treaty, of the temple or pillar structure over the tree structure in Laursen, Vanhoonacker \& Wester, 1992:16.
} 
Vogler (2006). The two authors identify a different set of criteria - opportunity, presence and capability - but the last criterion, capability, requires in their view coherence and consistency $(2006: 24,30)$. Bretherton and Vogler have a specific understanding of consistency and coherence (2006:30): consistency "indicates the degree of congruence between the external policies of the Member States and of the EU" (an aspect which is referred to as vertical consistency later in this study; see chapter 3) while coherence "refers to the level of internal coordination of EU policies" (horizontal consistency in the terms of this study). ${ }^{8}$ In both the models of Jupille/Caporaso and Bretherton/Vogler, consistency constitutes a central criterion of EU actorness. The concern of scholars with the issue of consistency is also echoed in some official documents, the wording of which always emphasises the great expectations associated with consistency - such as effectiveness, credibility and legitimacy (Marangoni \& Raube, 2014; see section 1.5).

The third strand of literature specifies the instruments and approaches to consistency used by the EU. As outlined in the general public administration approach, coordination is a central instrument in the EU in general and in the Commission in particular. This strand of EU literature assesses the Commission's internal operations, rules of procedures and specific responsibilities for coordination (Hartlapp, Metz \& Rauh, 2012; Miglioli, 2009; Spence, 2006a \& 2006b; Kassim, 2006 \& 2004b; Christiansen, 2001; Nugent, 2001; Cini, 1996). The focus on administration and processes, characteristic of the public administration literature, has progressively gained more importance in European studies. Institutionalism puts the emphasis on decision-making at the political and administrative levels, aiming to explain actors' behaviour as a function of their institutions (see for instance Hall \& Taylor, 1996). The "administrative turn" of European studies signals the new focus on day-to-day decision-making and the role of bureaucracies therein to study European governance (Trondal, 2007:961). It led to the development of a new strand of literature on EU institutions in general, and on the Commission in particular, and on the extent to which institutions matter (ibidem). The literature does not only discuss the Commission in general, its position in the institutional triangle and its powers (Nugent, 2001; Cini, 1996) or its dealing with a particular policy area such as external policies (Smith, 2006). Addressing the lack of account for the institution's internal dynamics (Hartlapp, Metz \& Rauh, 2012), a growing body of the literature also focuses on the Commission's internal functioning, giving a more (Eppink, 2007) or less controversial account thereof (Spence (ed.), 2006; Dimitrakopoulos (ed.), 2004; Kassim, 2004b). The consistency challenge and coordination issue have progressively taken centre-stage (for instance Kassim, 2004c, Christiansen, 2001; Cram, 1994). In an article published in

\footnotetext{
${ }^{8}$ What these authors call "coherence", in reference both to the pillar structure (2006:32) and to "aspects of the operation of the Commission" - notably the fragmentation of external policy-making between several Directorates-General (2006:33), actually corresponds to the use of the term 'consistency' in this study.
} 
1994, Metcalfe developed a coordination scale, building on the different meanings of coordination in public administrations (Metcalfe, 1994). Kassim, Wright and Peters further contributed to the literature on coordination in the EU by elaborating on coordination of EU affairs in Member States while another strand of literature was dealing with the coordination of EU and Member State actions (Kassim, Peters \& Wright, 2001 and 2000; Jordan \& Schout, 2006:4).

The EU literature also assesses the consistency of EU action in a particular country or geographical area (for instance Sicurelli, 2008) or in a particular policy domain (see for instance De Jong \& Schunz, 2012 on energy security and climate change; Laakso et al., 2007 on article 96 of the Cotonou agreement; Bretherton \& Vogler, 2008 on external fisheries policy; Carbone, 2008 on policy coherence for development or Elgström \& Pilegaard, 2008 on the negotiation of the European Partnership Agreements). These studies identify the relevant actions taken by the EU and/or Member States in one country or in one area and qualitatively discuss the existence or absence of contradictions between these actions. However, there are hardly any extensive empirical studies on the consistency of one particular policy proposal on the basis of a careful examination of the decision-making process. Hartlapp, Metz and Rauh (2012) outline the importance of looking at Commission internal dynamics to explain which substantial policy positions the Commission takes.

This research considers that the public administration literature - in particular its focus on coordination - is relevant to discuss consistency. The study aims to contribute to the literature on the consistency of the EU's action by taking one step back and by looking at the content of particular Commission's proposals. This research also aims to contribute to the literature on the EU by developing a comprehensive framework to study consistency, reflecting on the levels at which the consistency requirement is expressed and detailing how the Commission puts into effect the consistency requirement, as well as by assessing consistency in concrete cases. While the present study builds on the literature on Treaty provisions related to consistency, it complements this research strand by adding two levels of analysis. First, it discusses how policy frameworks specify the Treaty framework for consistency and how they provide substantial guidelines for Commission action. Second, it explores the Commission's internal decision-making process in external policies in general and in specific case studies. The research discusses how different interests are aggregated in the Commission's decisionmaking and how decision-making shapes the policy output. It argues that this is a necessary step in explaining why consistency of EU external policies is present or absent. The case studies provide an opportunity to explore the interaction between the three levels of the conceptual framework in concrete situations with the objective to assess the consistency of particular Commission's proposals. 


\subsection{The relevance of the consistency question}

The focus on consistency comes from the acknowledgement of the lack of international lever of the EU. As we have seen, at least part of the EU's unfulfilled potential is explained by the inconsistency of its external action. Consistency has a positive connotation and is understood by practitioners as a stepping-stone to an enhanced international actorness. Consistency is generally expected to lead to effectiveness, legitimacy and credibility, as illustrated in particular by the Laeken declaration and the debates of the European Convention (European Convention 2002c, 2002d, 2002e and 2002f). The expectations created by consistency explain why this topic has received so much attention and illustrate its continued relevance when discussing EU external action (Marangoni \& Raube, 2014).

First, the link between consistency and the effectiveness of one's action is emphasised by both scholars and practitioners. External policies are formally divided but substantially interdependent: the effectiveness of the whole depends on the consistency of external policies (Gebhard, 2011:109-113; Portela \& Raube, 2009:3; De Baere, 2008:220; Vanhoonacker, 2007:145; Missiroli, 2001:4). The search for consistency is seen as "a prerequisite for effective government" (Gauttier, 2004:24). Significantly, the wording of the Treaty sees consistency and effectiveness as systematically interrelated:

The Union shall have an institutional framework which shall aim to promote its values, advance its objectives, serve its interests, those of its citizens and those of the Member States, and ensure the consistency, effectiveness and continuity of its policies and actions (emphasis added, article $13 \mathrm{TEU}$ ).

The Member States shall work together to enhance and develop their mutual political solidarity. They shall refrain from any action which is contrary to the interests of the Union or likely to impair its effectiveness as a cohesive force in international relations (emphasis added, article 24.3 TEU).

The Council and the High Representative of the Union for Foreign Affairs and Security Policy shall ensure the unity, consistency and effectiveness of action by the Union (emphasis added, article 26.2 TEU).

Similarly, the consistency-effectiveness link was central during the Convention debates. With the objective to increase EU effectiveness, the Convention outlined the current state of affairs, inconsistency, and the consequence thereof, namely Europe not always weighing much in international affairs (European Council, 2001:21, 23; Missiroli, 2001:49). The EU's international influence is seen as conditional on it becoming a "strong, effective and efficient player on the international scene", which in turn would require a consistent external action and a "properly coordinated use of all instruments, [both] economic and political" (European Convention, 2002e:2-3). The effectiveness of the EU's action also calls for "the best possible use of the collective resources available to [the EU]" to reach its objectives and to make a difference (Missiroli, 2001:2). If a policy contradicts 
another policy, it also means that resources allocated to both policies are wasted (Vanhoonacker, 2007:145).

Second, consistency is expected by practitioners to lead to legitimacy. It legitimises on the one side EU objectives and actions - by ensuring that they do not contradict one another - and the decision-making process on another side (Portela \& Raube, 2009:4). A consistent external action is more legitimate than an inconsistent external action because such an action considers the cross-policy nature of any issue and discusses the different dimensions thereof. A consistent external action is also more legitimate than an inconsistent action because the process that produces it articulates the interests and objectives of the actors concerned, what Vivien Schmidt calls the legitimacy of the "throughput" (2013). Efforts to aim for consistency throughout the decision-making in turn legitimizes the outcome, which is seen as the result of a coordinated exercise, as opposed to a decision steered, unilaterally, by one particular actor and its specific objectives.

Third, the Convention discussion paper on EU external action states that ensuring consistency is necessary to be a credible player, "capable of projecting itself" (Missiroli, 2001:2) on the international stage (European Convention, 2002f:2). To the extent that the EU is not perceived as a self-contradictory actor and that it respects its proclaimed commitments, but also that its action is effective and legitimate, these characteristics account in turn for the credibility and trustworthiness of an actor (Gaspers, 2008:20; Vanhoonacker, 2007:146). Meeting the consistency requirement is expected to ensure that the objectives and priorities identified are actually pursued and taken into consideration in the decision, in turn making the EU's commitment to comprehensive and global objectives credible.

However, could consistency also be a vice? This question is hardly ever raised even though it is clear that consistency may come at a price (Parkes, 2011). First, institutions and services may actually adopt a reactive posturing against the permanent quest for consistency. Decision-making rules aiming at producing a consistent output constrain the freedom of institutions or services that are supposed to follow specific steps. Not all institutions or services are equally equipped to cope with these constraints and some of them may feel at disadvantage, which in turn could lead them to adopt a reactive or blocking position in decision-making. Certain services may also consider that they do not need the input of others to prepare a proposal, thus adopting the same reactive posturing in the process. Second, the rules requiring consistency may actually slow down the decision-making process. Their lifting would a contrario speed it up or introduce more flexibility, a quality that is sometimes also needed for an international actor to respond to a particular situation. Lastly, too important a focus on consistency could also be read as a waste of resources. The operational steps towards consistency - for instance convening a series of meetings to discuss the different options to address an issue, or preparing studies before a decision is taken to discuss the impact of this decision on different policies - are time-consuming and require important human resources as well as expertise. This could over-stretch 
the already limited resources of EU institutions or of a particular service of the Commission for instance.

In conclusion, consistency is expected to trigger a positive snowball effect. This positive causality explains the EU's continuous efforts to ensure and enhance consistency, as evidenced most recently by the Lisbon Treaty. The recurrent efforts also outline the EU's perception that it has failed to satisfactorily address the consistency challenge so far.

\subsection{Thesis outline}

This study consists of seven substantive chapters. Chapter 2 introduces the general context of EU external policies, their dichotomy and the organisation of the Commission in its dealing with external policies. The third chapter provides the conceptual framework of this research. It first defines the key concept, consistency, its different dimensions and their implications for the research design. Then, it discusses how to ensure consistency, how to operationalize the consistency requirement and how to measure consistency. Based on this conceptual underpinning, the chapter comes to an informed case selection. The Treaty framework (chapter 4) is the first level at which the EU seeks to ensure consistency. The Treaty framework provides legal guidelines on consistency between external policies at the most general level, in particular between trade policy, development cooperation and CFSP. It also specifies the consistency mandate of particular institutions such as the Commission, but without defining how the Commission should ensure consistency in particular. Chapter 5 introduces the Commission's internal decision-making process in external policies in general. It identifies consistency responsibilities within the Commission and reviews the procedural guidelines for the drafting of Commission proposals that seek to put the consistency requirement into practice. Chapters 6 and 7 contain two detailed empirical case studies. They show first how, within the limits set by the Treaty framework, the policy framework provides a policy-specific consistency requirement. Second, the case studies discuss the concrete implementation of coordination mechanisms in the Commission's decision-making process. Third, the case studies assess the actual consistency of Commission proposals and present factors that were found to be conducive or detrimental to such consistency. Finally, the concluding chapter 8 reflects on the utility of the three-level framework to discuss consistency. It also discusses on a more general level the external and internal factors that have an impact on decision-making, thereby influencing the success of coordination in producing a consistent output. 


\section{CHAPTER 2.}

\section{FRAMING THE ISSUE: THE POLICY AND INSTITUTIONAL CONTEXT}

The task [of governing the EU] is not easy. The step-by-step integration, which has characterised the [EU's] development, has tended to slice policies into sectoral strands, with different objectives and different tools; over time the capacity to ensure the coherence has diminished (...). The [EU] institutions and the Member States must work together to set out an overall policy strategy. For this purpose, they should (...) refocus the Union's policies and adapt the way the institutions work... (Commission, 2001d: 28)

To discuss the consistency objective of the EU, this chapter introduces EU external policies and their institutional context within the Commission. It does not aim at providing an exhaustive description of the EU's different external policies but points to the characteristic elements of their coexistence and interaction. The first section discusses the main characteristics of the three external policies - common commercial policy, development cooperation and CFSP - on which this study focuses. By so doing, it outlines the potential for contradictions amongst them and consequently the challenge to consistency. The second section introduces the institutional framework of external policies within the Commission. It explores who does what within the institution. It identifies the DGs responsible for the development of the trade policy, development cooperation and CFSP, outlining the evolution in the Commission's dealing with external policies over time at both political and service levels.

\subsection{The substance of external policies}

This first section focuses on the three distinct external policies that are arguably the most important components of EU external action - the common commercial policy, development cooperation and the CFSP. The section successively discusses the main characteristics of each external policy and its evolution. Adopting a historical approach, it will also elaborate on the changes introduced by the Lisbon Treaty in each policy area.

\subsubsection{The Common Commercial Policy}

The Common Commercial Policy (CCP) is one of the founding external policies of the EU. As Member States chose to establish a customs union (European Economic Community Treaty), the CCP and a Common External Tariff (CET) were regarded as a "logical corollary" (Niemann, 2012:205). Indeed, it was essential to establish a 
common policy regarding Member States' commercial relations with the rest of the world. The Treaty of Rome provided for explicit policy-making in external economic relations. It granted the Community the authority to set out, negotiate and enforce all aspects of trade relations with the rest of the world through the common external tariff, common trade agreements with partners and the uniform application of trade instruments across the Member States (article 3(b) and articles 110-116 Treaty of Rome; Niemann, 2012:205; Smith, 2006:313). Over time, the position of CCP has been asserted as the EU has grown to become a major trade player internationally. Today it represents a market of more than 500 million consumers, merchandise exports amounting to €1,686.8 billion and imports to $€ 1,791.7$ billion in 2012 (Commission, DG Trade, 2013:46-49). The size of its market explains its position as the leader in world trade, as well as the lever that the EU may have over its partners (Meunier \& Nicolaïdis, 2006).

Substantially, the CCP is defined by its objectives and its scope. First, according to the Treaties, the CCP shall contribute to the development of world trade, to the progressive abolition of restrictions on international trade and on foreign direct investment, and to the lowering of customs and other barriers (preamble and article 131 TEC now article 206 TFEU). The Lisbon Treaty brought the CCP under the single heading on EU external action (title V TEU). "Encourag[ing] the integration of all countries into the world economy, including through the progressive abolition of restrictions on international trade" is one of the general objectives of EU external action (article 21.2(e) TEU). Bringing trade under this general heading also means that the CCP must contribute to and abide by the other common principles and objectives of the EU's external action (article 21.2 TEU), such as the promotion of democracy and human rights. This may in turn politicise trade (Cremona, 2006:30). Second, the scope of the CCP has evolved over time. In particular, with the changing international trade agenda, new issues raised new competence questions for the Community/Union. Although poorly defined in the Treaty of Rome (Niemann, 2012:207), following disputes between the Commission, the Council, Member States and the Parliament, the rulings of the European Court of Justice (ECJ) has progressively specified and expanded the scope of the CCP. For instance, in its opinion 1/94, the ECJ considered that both the Community and Member States were jointly competent to conclude international agreements under the General Agreement on Trade in Services and Trade-Related Intellectual Property Rights. Treaty revisions also expanded the scope of CCP. For instance, since the Lisbon Treaty, services, intellectual property and investment now also fall within the exclusive competence of the Community (article 207.1 TFEU).

The CCP is one of the most integrated policy areas where the Union has exclusive competence (article 3 TFEU). First, the role of the European Commission is very important as it has the exclusive right of initiative. The Council gives a mandate to the Commission to open negotiations with third countries, in which the Commission acts as the sole negotiator, It does so however in close consultation with the article 207 committee composed of representatives of the Member States 
(article 133 TEC now article 207 TFEU). The nature of the competence and the fact that trade is a traditional policy area for the Union are reflected in the high profile of the Trade Commissioner and of DG Trade. This position is also reinforced by the importance of the Union as a trade power and the potential leverage on partners that it might entail (Vanhoonacker, 2011:80 \& 2005:71). Second, the Council gives a mandate to the Commission to open negotiations. As a co-legislator, together with the EP, the Council adopts international agreements, by qualified majority voting in principle (Vanhoonacker, 2011:81). Certain areas still require unanimity, signalling national sensitivities, even though these areas have been reduced over time. Today, they include "agreements in the fields of trade in services, commercial aspects of intellectual property and FDI (...) where such agreements include provisions for which unanimity is required for the adoption of internal rules" but also trade in cultural and audiovisual services as well as in social, education and health services under specific circumstances (article 207.4 TFEU). Under the Lisbon Treaty, Member States have also retained the right to conclude agreements in the fields of trade in services and commercial aspects of intellectual property rights (Niemann, 2009:209). Besides these formal rules constraining the Commission's power, national interests influence also informally the Commission's internal decisionmaking process. The Commission considers concerns raised by Member States because its proposal will ultimately have to be approved by the Council and because individual Member States attempt to influence the internal drafting process by getting in touch with officials in charge of a dossier (interview 4). Third, in addition to the Commission and the Council, the European Parliament has acquired new powers in the CCP. Having complained for a long time about its exclusion from decision-making in the CCP, its role has been strongly enhanced by the Lisbon Treaty. It has obtained co-decision rights on measures implementing the CCP (article 207.2 TFEU), its consent is required for trade agreements (article 218.6(a) TFEU) and its role has been augmented with regard to the negotiations of trade agreements (article 207.3 TFEU). Lastly, in the post-Lisbon era, a new service has been set up, the EEAS, but trade is excluded from its remit.

In conclusion, trade is one of the oldest and most integrated policy areas of EU external action. With the entry into force of the Lisbon Treaty, the objectives of the CCP have been brought under the common set of objectives of the EU's external action. Trade does not have a trade-related purpose only. The implications of trade relations with third countries for other policy areas or its contributions to the objectives of other areas are recognised in an attempt to enhance the consistency of EU external action overall. The role of the Commission is central in CCP decisionmaking. The Trade Commissioner and DG Trade are prominent actors within the Commission given the nature of the competence and the lever that trade gives the Union in world affairs. 


\subsubsection{Development cooperation}

Historically, development cooperation can also be traced back to the Treaty of Rome. Building on colonial ties existing between some Member States (Belgium, France, Italy, the Netherlands, and later on the United Kingdom and Portugal) and non-European countries and territories, the Treaty of Rome provided for cooperation in this field (articles 131-136 TEEC). In contrast with the integrated CCP framework, the TEEC referred to the association of overseas countries and territories (OCTs) with the aim to promote their economic development. The Treaty of Rome established a small foreign aid programme, to complement bilateral policies of the Member States. The parallel existence of a development policy managed by the Commission and of bilateral development policies of the Member States thus has become a defining feature of EU external relations in this field (Carbone, 2012:229-230). Given the location of former colonies, the development policy mostly concerned African, Caribbean and Pacific countries (ACP). With the decolonisation process and in the absence of a reform of the Treaty of Rome, separate international agreements were concluded to adapt development cooperation to the reality of the newly independent countries (the Yaoundé Convention in 1963, the Lomé Convention in 1975 and its various successor agreements, and finally the Cotonou agreement concluded in 2000). In an effort to become a more influential global actor, the EU expanded the geographic reach of its development policy over time. Development policy thus went beyond its original ACP focus to include Latin America and Asia, as well as the Mediterranean and Central and Eastern Europe (Carbone, 2012:230-231). The Maastricht Treaty introduced a new section on development policy, specifying objectives, procedures and implementation, which has become a very important dimension of EU external action over time (Title XX). Today, the EU and its 28 Member States are the world's largest donor of official development aid (€55.2 billion in 2012; Commission, Devco, 2013:10) and are committed to improving the effectiveness of their action in favour of those developing countries most in need.

The central objectives of development policy have been broadened in the treaties. In the Treaty of Rome, the objective of the association of overseas countries and territories was "to promote the economic and social development of the countries" and "to establish close economic relations between them and the Community as a whole" (article 131 TEEC). With the generalisation of the concept of policy coherence for development (PCD), the scope of activities deployed significantly expanded and resulted in "a multidimensional understanding of the concept of development" (Carbone, 2012:230). Bridges were built between development cooperation and a number of sectors such as trade, agriculture, fisheries, environment and climate change, social policies, security, migration, information society, research and innovation, transport and energy (Commission, DG Devco-EuropeAid, n.d. c \& 2012d). Today, poverty reduction is the central objective of development cooperation (article 208.1 TFEU). In addition, "foster[ing] 
the sustainable economic, social and environmental development of developing countries with the primary aim of eradicating poverty" is one of the general objectives of EU external action under the Lisbon Treaty (article 21.2(d) TEU) i.e. an objective to which any EU policy shall contribute. Development cooperation takes place within the framework defined by this set of general objectives and principles. In particular, the development policy also contributes to developing and consolidating democracy and the rule of law, human rights and fundamental freedoms as already emphasised in article 177 TEC and reaffirmed in the set of common objectives of EU external action in the Lisbon Treaty (article 21 TEU).

As regards the separation of powers between the Member States and supranational players, development cooperation is not an exclusive but a complementary competence. The Union has "the competence to carry out activities and conduct a common policy" but that "competence shall not result in Member States being prevented from exercising theirs" (article 4.4 TFEU). In other words, EU and Member States' development policies exist alongside each other. Within the Commission, the exercise of this competence is highly fragmented both along geographical lines and depending on the phases of the policy cycle - with the implementation of development policies in the partner countries constituting the backbone of the activity of former EC delegations. Under the Lisbon Treaty, the exercise of the competence is even more fragmented than before as a new division of labour had to be defined between the Commission and the newly created EEAS. The EEAS gives strategic direction for the development policy while DG Devco is now in charge of programming and implementing most EU development instruments (see section 2.2). Since the Maastricht Treaty, the European Parliament and the Council adopt the measures necessary for the implementation of development cooperation in accordance with the ordinary legislative procedure (article 212.2 TFEU). Historically, the Parliament has exercised little control over the implementation of development policy. However, it exchanges views with the Commission on the topic. Besides, its budget authority constitutes an important control tool over this policy given the importance of financial instruments in that policy domain.

In conclusion, the framework of development policy has evolved since the initial provisions contained in the Treaty of Rome. Over time, development cooperation has increased its prominence in the EU's external action, expanding both the range of its activities and its geographical scope.

\subsubsection{From EPC to CFSP}

The third dimension of EU external action is the Common Foreign and Security Policy. The original emergence of a European foreign and security policy stricto sensu outside the Treaty framework and separately from trade policy and development cooperation illustrates the fundamental dichotomy that characterises EU external action. The Treaty of Rome introduced a fundamental distinction in 
external policies between the "'in' and 'out' of bounds to the European Community": external policies in matters where the EC had internal competence were allowed but not in matters relating to diplomatic and security issues (Winn \& Lord, 2001:21). Consequently, external policies were to focus on economic aspects while, reaching to the sovereignty of nation states, foreign, security and defence policies remained excluded from the Treaty of Rome. In the context of the Cold War and after the failure to create a European Defence Community (1954) and a European Political Union (Fouchet Plan, 1962), Member States created the European Political Cooperation (EPC) in 1970 to cooperate on foreign policy issues (Nuttall, 2000:14). It was only in 1987, with the entering into force of the Single European Act, that the EPC was given a Treaty basis. As a purely intergovernmental framework, the EPC allowed for the incremental development of foreign policy coordination amongst Member States - yet excluding security and defence-related issues (Nuttall, 2006). The fall of the Berlin wall (1989) ultimately created a new international situation and the Maastricht Treaty (1993) tried to upgrade the loose form of foreign policy cooperation to a fully-fledged Common Foreign and Security Policy (CFSP). Against the background of the Yugoslav crisis and uncertainties about a continuing US engagement in Europe, the successor of the EPC addressed the rising importance of security issues for the EU and the pressing need for the EU to formulate common positions on issues of foreign and security policy. The security and defence dimension of CFSP was given shape in the Treaty of Amsterdam, with the creation of the European Security and Defence Policy (ESDP; article 17.1 and 17.2 TEU). Operational since 2003, the ESDP aims at ensuring the security of the Union and refers to humanitarian and rescue tasks, peacekeeping tasks and tasks of combat forces in crisis management. Under the proviso that Member States contribute military capabilities, the EU may deploy military crisis management operations worldwide. Since Lisbon, ESDP is now known under the acronym CSDP (Common Security and Defence Policy, article 42 TEU).

International security, international cooperation, the development of democracy and rule of law, and the respect for human rights and fundamental freedoms were listed under article 11.1 TEU as the specific objectives of CFSP before Lisbon. These objectives were meant to define the scope of the CFSP attributions (De Baere, 2008:101-102). Yet, some of the objectives could not be clearly demarcated from, in particular, development cooperation objectives, thus illustrating linkages with other external policies (De Baere, 2008:107). For instance, the issue of dual-use goods, economic sanctions or human rights conditionality are cases of policy overlap. In the Lisbon Treaty, these objectives are now listed under article 21.2(a), (b) and (c) TEU: they are part of the general objectives of EU external action. The provisions specific to the CFSP refer to these general objectives (article $23 \mathrm{TEU}$ ) and so do the provisions specific to the CSDP (article 42 TEU).

The sensitive nature of foreign and security policy explains the intergovernmental nature of this competence (article 2.4 TFEU). Contrary to the 
Common Commercial Policy, Member States retain their power in this policy area and take decisions by unanimity. The Commission was initially only consulted if EPC affected the European Economic Community's work (EEC) while being excluded from foreign policy meetings (Nuttall, 2006:345; Vanhoonacker, 2005:79). The London Report (1981) provided for the full association of the Commission with EPC issues "at all levels" because of the interaction between the EPC and the external relations of the EEC. It was also an acknowledgment of the Commission's expertise in this area. This provision remained in the TEU until Lisbon. From 1981, the Commission was linked to the COREU system and the position of European Correspondent was set up within the institution to coordinate its input to foreign and security policy.

The distinction between Community external policies and the EPC was given an institutional form in the Maastricht Treaty, the former governed by first pillar procedures and rules, while the latter became the CFSP and constituted the second pillar. Although formally the Maastricht Treaty introduced a single institutional framework, decision-making remained strongly differentiated because of the sensitivity of the CFSP. Likewise, the role of the Commission remained limited compared to that in Community external policies. In contrast to the first pillar, it only received a co-right of initiative. It was sharing this right with Member States and hardly ever actually made use of it.

The Lisbon Treaty radically changed the position of the European Commission in the field of CFSP. With DG Relex - before Lisbon in charge of CFSP - being transferred to the EEAS - a service outside of the Commission - the dynamics in the design of CFSP have changed much. The HRVP - also Vice-President of the Commission - with the support of the EEAS, contributes to the development of CFSP (article $27 \mathrm{TEU}$ ) and puts it into effect (articles 24.1 and $26 \mathrm{TEU}$ ). Article 30 TEU provides for a limited role of the Commission in CFSP: the Commission shares a right to ask questions and to submit proposals to the Council on CFSP with the HRVP (see section 5.2.3).

Over the years, the importance of the EPC and then of the CFSP slowly but progressively increased. It became a policy of the Union in its own right. However, the nature of the competence and the resulting institutional arrangements and choices made in terms of decision-making distinguish it strictly from CCP and development cooperation. The traditional dichotomy between economic external relations (CCP and development policy) and political external relations (EPC and then CFSP) is a constitutive element of the Union's external action (De Baere, 2008:219). At the same time, it is an artificial dichotomy given the many interdependencies between policies (Nuttall, 1992:24).

In conclusion, this overview of the three external policies on which this study focuses explains how the consistency challenge came to the fore. Even before the creation of the single institutional framework, consistency has constituted the guiding principle that has held 'external policies' together as a system (Portela \& Raube, 2009:8; Dashwood, 2008:70-103). Ensuring consistency - i.e. the absence of 
contradictions - between different policies has always been seen as a necessary condition for the EU to capitalise on its potential and realise its objectives. It is striking to note that, despite its varying roles in the different external policies, the Commission has been co-responsible for ensuring consistency since the Single European Act. To discuss this responsibility, the next section now turns to the Commission's dealing with external policies, exploring the institution's organisation and internal division of labour.

\subsection{The European Commission and external policies}

[B]reaking those [Chinese walls] down and getting the DGs to talk to each other in the preparation of policy (...) is the single most important area of improvement. (Meacher quoted by Jordan \& Schout, 2006:3)

Following the discussion of the CCP, development cooperation and CFSP and of the characteristics of these external policies, the focus of this section is on the internal structure of the European Commission. Within the Commission, the responsibility for external policies is fragmented. This fragmentation results from the organising principle of specialisation that exists both at the political (allocation of Commissioners' portfolios) and at the service level (Directorates-General, DGs). Fragmented organisation and compartmentalised policy-making challenge the consistency of the policy output. This challenge has become even more acute with the expansion of Commission activities over time and the proliferation of departments. Already in 1979, the Spierenburg report ${ }^{9}$ had argued that the Commission's internal fragmentation was jeopardising consistency and identified coordination between the different actors as both a necessity and a challenge. Consequently, it recommended i.a. merging several DGs into a limited number of units related to the same sector to facilitate coordination between these units and to enhance the consistency of the EU's external action (Spierenburg, 1979: para.32). Building on an historical approach, this section explores and discusses the way in which decision-making in external policies is organised within the Commission, first at the political level, second at service level. In particular, it will emphasise the changes introduced by the Lisbon Treaty as they have an impact on the consistency challenge.

\subsubsection{Fragmentation at the political level}

At the political level, the definition of Commissioners' portfolios reflects the different dimensions of external policies, their relative salience and the rise of new

\footnotetext{
${ }^{9}$ After the name of Dirk Spierenburg, the chair of a committee set up in 1978 to review the Commission's working methods and draw up proposals that might lead to their improvement.
} 
concern. This sub-section gives an historical overview of the evolution of Commissioners' portfolios with a special emphasis on post-Maastricht era, outlining in particular how the trade, development and external relations portfolios are handled.

Development and trade were Commissioners' portfolios from the early days of the European project, but the portfolio of external political relations was created in the 1990s only. The reorganisation of Commissioners' portfolios paralleled the rising importance of external political relations as well as the creation of CFSP by the Maastricht Treaty. President Santer (1995-1999) restructured the portfolios in 1995 along both functional and geographical considerations, increasing to five the number of Commissioners responsible for external policies and in turn fragmenting the political management of external policies:

- Sir Leon Brittan, Vice-President, was in charge of external relations with industrialised countries and of economic external relations,

- Manuel Marin, Vice-President, in charge of Southern Mediterranean, Middle and Near-East, Latin America, Asia and North-South Cooperation,

- Hans van den Broek, in charge of relations with Eastern and Central European Countries, New Independent States, Mongolia, Turkey, Cyprus, Malta, European countries and CFSP (the responsibility for CFSP and human rights was also shared by the Commission's President),

- Joao de Deus Pinheiro, in charge of the African, Caribbean and Pacific Countries, South Africa and Lomé agreements,

- Emma Bonino, in charge of the European Community Humanitarian aid Office (Warin, 1997:18).

This allocation of portfolios on a mixed basis aimed at ensuring consistency across geographical areas as each Commissioner was responsible for all the dimensions of the relations with specific regions. However, the result was not satisfactory and led to successive re-organisations under the Prodi and Barroso Commissions (Gauttier, 2004:33).

Since 2000, consistency and coordination have remained the major concern of the internal re-organisation of the Commission (Prodi Commission 2000-2004 and Barroso Commissions since 2004). In that respect, despite internal turf wars and concerns for Commissioners' independence, the Commission Presidents Prodi and Barroso took advantage of the Amsterdam and Nice Treaties, which had increased their powers to reorganise the Commission in an attempt to enhance coordination amongst external relations portfolios. The Declaration 32 annexed to the Treaty of Amsterdam relating to the organisation and the operation of the Commission noted "the desirability of bringing external relations under the responsibility of a VicePresident". However, this recommendation was not followed - until the creation by the Lisbon Treaty of the position of High Representative-Vice President, who has a coordination mandate of external policies within the Commission. Nevertheless, under the Prodi Commission, to support Treaty developments that outlined the 
interdependence between the different external policies, a group of external relations Commissioners - and their corresponding DGs - was set-up. It included the Commissioners for external relations (Chris Patten), enlargement (Günter Verheugen, a new portfolio), development and humanitarian aid (Poul Nielsen) and trade (Pascal Lamy). The Commissioner for external relations took the lead of the 'Relex group of Commissioners', to provide an overall coordinating role (Smith, 2006:31; Gauttier, 2004:33). The creation of the position of High Representative (HR) for the CFSP in 1999 and Javier Solana's appointment (1999-2009) arguably introduced an additional, external, difficulty to the consistency challenge within the Commission: how to balance the political clout of the HR with the more technical role of the Commission in external policies (Duke, 2011:26)?

From 2004 to 2009, the portfolios of the Relex Commissioners were divided along the same lines as above. President Barroso himself chaired the Relex group of Commissioners, which counted four Commissioners: Trade (Peter Mandelson between 2004 and 2008 and then Catherine Ashton between 2008 and 2009), external relations and the European Neighbourhood Policy (Benita FerreroWaldner), enlargement (Olli Rehn), and development and humanitarian aid (Louis Michel and then Karel de Gucht). The second Barroso Commission (2009-2014) was organised differently as a consequence of the new institutional arrangements created by the Lisbon Treaty. First, to protect Community-type policies, the ENP was moved to the enlargement portfolio immediately before the entry into force of the Lisbon Treaty. The purpose of this move was to avoid that it would fall under the responsibility of the double-hatted Commissioner for external relations. Second, the new position of High Representative-Vice President (HRVP, Catherine Ashton) reconciled in one person both sides of the EU's external policies, as the HRVP is responsible for both Foreign Affairs and Security Policy and for external relations within the Commission. Within the Commission, under her 'Vice President hat', the HRVP has a central coordinating role. Catherine Ashton, as first VP of the Commission, was responsible for external relations and "within the Commission (...) for coordinating other aspects of the Union's external action" (article 18.4 TEU). This coordination mandate was supported by the coordination requirement contained in the mission letters sent by the Commission's President to the Commissioners for Development, Enlargement and International Cooperation (President of the Commission, 2009b). Third, formally, the Relex group of Commissioners still exists but has proved less useful (Interviews 4, 5, 6 and 13). In practice, it was still chaired by President Barroso although he had tasked the HRVP to chair it (Blockmans, 2011:11). In addition to the HRVP in charge of external relations, the Relex group of Commissioners counted five Commissioners: Development ${ }^{10}$ (Andris Piebalgs), Trade (Karel de Gucht), Enlargement and the ENP

\footnotetext{
${ }^{10}$ Before the Lisbon Treaty, the Commissioner for external relations represented the Commission at the Council. After the entry into force of the Lisbon Treaty, the Commissioner for Development now represents the Commission at the Council.
} 
(Stefan Füle), International Cooperation, Humanitarian Aid and Crisis Reaction (Kristalina Georgieva) and Economic and Financial Affairs (Olli Rehn).

In conclusion, the responsibilities of different political actors in the Commission are clearly divided in theory. The reality is less clear-cut however. There tend to be substantial overlaps between the portfolios of different Commissioners. Consequently, the Commission has emphasized the need for consistency between portfolios, to be achieved through different instruments as will be further discussed in chapter 5 .

\subsubsection{Fragmentation at service level}

Over time - as shown in table 2 - the Commission has developed a substantial bureaucratic machinery to back up its action in external policies (Smith, 2006:320). There are currently 33 DGs within the European Commission. The emphasis in this sub-section will be put on the DGs that are primarily in charge of external action and the evolution of their organisation over time. Yet, one should keep in mind that these DGs are not the only DGs dealing with external policies, as the responsibilities of 'internal' DGs are often characterised by a strong external dimension as well internal DGs however fall outside the scope of this study.

Dealing with external policies has constituted an organizational challenge for the Commission. Trade and development have been Commission portfolios since the beginning of European integration. Staff numbers (see table below) illustrate the continued importance of these two DGs. However, the nature of EPC led to a specific institutional arrangement. The EPC was dealt with by the 'EPC unit' within the Secretariat General of the Commission, as opposed to a normal DG as in other portfolios such as trade and development (Nuttall, 2006:353). The choice to put EPC under the Secretariat General is explained by the position that the SG occupies within the Commission. Indeed, the Commission's input to EPC was coming from several services and the SG was in the best position to coordinate it (ibidem). Besides, the Deputy Secretary General under whom the EPC fell was not only the Commission's representative in the political committee (dealing with EPC-related issues) but also in COREPER, thus maximising the "Commission's role as a bridge between EPC and Community frameworks" (ibidem). Only in 1993, after the entry into force of the Maastricht Treaty and the creation of CFSP, the EPC unit was transformed into a Directorate General (at the same level as any other Commission DG) - DG IA (Smith, 2006:314).

Until the Santer Commission, the key DG in the field of external relations was DG I in charge of the Common Commercial Policy. DG IA was created under the Delors Commission of 1993-1995 after the entry into force of the Maastricht Treaty, and was made responsible for external political relations. Under the Santer Commission, external economic relations were reorganised on a geographical basis between DG I, DG IA and DG IB, with DG IA continuing to cover political relations (Smith, 2006:314). While DG I was reporting to Sir Brittan (Commission for 
external economic policies), DG IA and DG IB were reporting to Commissioner van den Broek (Commissioner for external relations). The mismatch between Commissioners' portfolios and DGs' attributions added to the confusion and the competition between services, all the more since the North-South cooperation part of DG IB was actually also reporting to a third Commissioner, Manuel Marin (Commissioner for Development and Cooperation). DG I was known by the abbreviation DG Trade and DG IA and IB by the abbreviation DG Relex.

DG Relex also underwent internal changes. With the gradual institutionalisation of CFSP, DG Relex adapted its own structure. A separate Commission CFSP directorate was created in DG Relex when the Amsterdam Treaty established the position of HR and the position of CFSP counsellor was created, with responsibility for overseeing the Commission's input into CFSP, CFSP project management and the management of EU special representatives. Besides, the European correspondent's unit was responsible for coordinating the Commission's policy input into CFSP and ensuring effective Commission participation in the exchange of views and information between Member States done through COREUs, cipher and ESDP-net messages (Spence, 2006c:373 and 375-376). These services and positions are often referred to as examples of coordination within the Commission on external policies: if they indeed exemplify intra-institutional coordination efforts, they are centred on CFSP-related issues rather than crosscutting external policies.

Additional DGs or offices were also created in the field of external action for humanitarian aid, enlargement and the implementation of EU external aid programmes. First, a specific office, ECHO (European Commission Humanitarian Office), was set up in 1992 and became the DG for Humanitarian Aid in 2004, before integrating civil protection in 2010 (Commission, ECHO, n.d.). ECHO was given the horizontal responsibility to manage humanitarian actions in the event of natural disasters or exceptional events requiring swift response (ibidem). The setting up of a separate office for humanitarian aid reflected not only efficiency concerns and the willingness to be responsive to the growing number of humanitarian crises but also the aim to pursue neutral objectives in crisis situations that political considerations should not distort. Upon its creation, ECHO was first placed under the joint responsibility of the Commissioner for external relations and the Commissioner for Cooperation and Development (ibidem). Between 1995 and 1999, a separate Commissioner for humanitarian aid was appointed. Between 1999 and 2010, ECHO fell under the responsibility of the Commissioner for Development, until Kristalina Georgieva was appointed Commissioner for International Cooperation, Humanitarian Aid and Crisis Response. Second, in 2001, the Prodi Commission saw the creation of DG Enlargement under the responsibility of the Commissioner for Enlargement. Third, DG EuropeAid was also created in 2001 under the responsibility of the Commissioner for Development for the implementation of EU external aid programmes. Table 2.1 below illustrates the fragmentation of the Commission, on both a geographical and a functional basis. 
Table 2.1: Commission organisation (after Spence, 2006b:131; Lewis, 2012; Commission, 2013 and own compilation)

Santer Commission (1995-1999) Prodi Commission (1999-2004)

External relations: CCP and relations with North Trade (DG Trade)

America, the Far East, Australia and New Zealand

(DG I)

External relations: Europe and the New

External relations (DG Relex)

Independent States, CFSP and external missions

(DG IA)

External relations: South. Mediterranean, Middle and Near East, Latin America, South and South-

East Asia and North-South Coop. (DG IB)

Development (DG VIII)

Development and Humanitarian aid (DG

Development, EuropeAid and ECHO)

Enlargement and ENP (DG Elarg)

Barroso I Commission (2004-2009)

Barroso II Commission (2009-2014)

Trade (DG Trade)

Trade (DG Trade, 533 staff)

External relations and European Neighbourhood External relations/European External Action

Policy (DG Relex)

Service* $^{*} 3,500$ staff $)$

( ${ }^{*}$ outside of the Commission)

Foreign policy instruments

(73 staff)

Development (DG Dev and EuropeAid)

Development and Cooperation (EuropeAid and DG

Devco, 1184 staff)

Enlargement (DG Elarg)

Enlargement and ENP (DG Elarg, 273 staff)

Humanitarian Aid (DG ECHO)

International cooperation, humanitarian aid and crisis response (DG ECHO, 211 staff)

It would be misleading to think that any particular external policy is managed by a single DG. The complexities of internal organisation are best illustrated by the case of development policy. Development policy is characterised by a very fragmented structure. Before the Lisbon Treaty, the management of aid was first divided along geographical lines: DG Development was focusing on ACP countries, DG Relex on non-ACP countries and DG Enlargement on pre-accession aid for candidate countries. The responsibility was also divided according to the policy cycle: DG Development was focusing on designing development policy while implementation 
was the responsibility of another DG, EuropeAid. This had led to criticisms about the compartmentalisation of methods and geographical inconsistencies (Vanhoonacker, 2005:76).

With the entry into force of the Lisbon Treaty, the situation has become more complex. As a major institutional innovation in the field of EU external action, the new Treaty created the European External Action Service (see figure 2.1 below). As a result, certain services and instruments were transferred from the Commission to the new diplomatic service. These were DG Relex, CFSP/CSDP instruments and some elements of DG Development. Other DGs with an external policy responsibility were not affected to the same extent. DG Trade and DG Enlargement remained outside of the EEAS - although the integration of all external DGs was an option debated (Vanhoonacker \& Reslow, 2010:8; Duke, 2009:218-221; Avery et al., 2007:88-89; Grevi \& Cameron, 2005:12-13; European Convention 2003). Evidently nevertheless, there exist strong policy linkages between the EEAS on the one side and the trade, development and enlargement portfolios (interview 6) on the other. At the same time, despite the obvious complementarity between policies the Lisbon Treaty also created competition between the Commission and the EEAS. For instance, in 2009, the Commission President transferred the control of the European Neighbourhood Policy Instrument (ENPI) from the former Commissioner for external relations (merged into the HRVP) to DG Enlargement to protect Commission competences and prevent the transfer of the ENPI to the EEAS (Stoss, 2011:2). Tensions were also visible when portfolios such as trade and humanitarian assistance strongly reaffirmed their independence from the EEAS. 


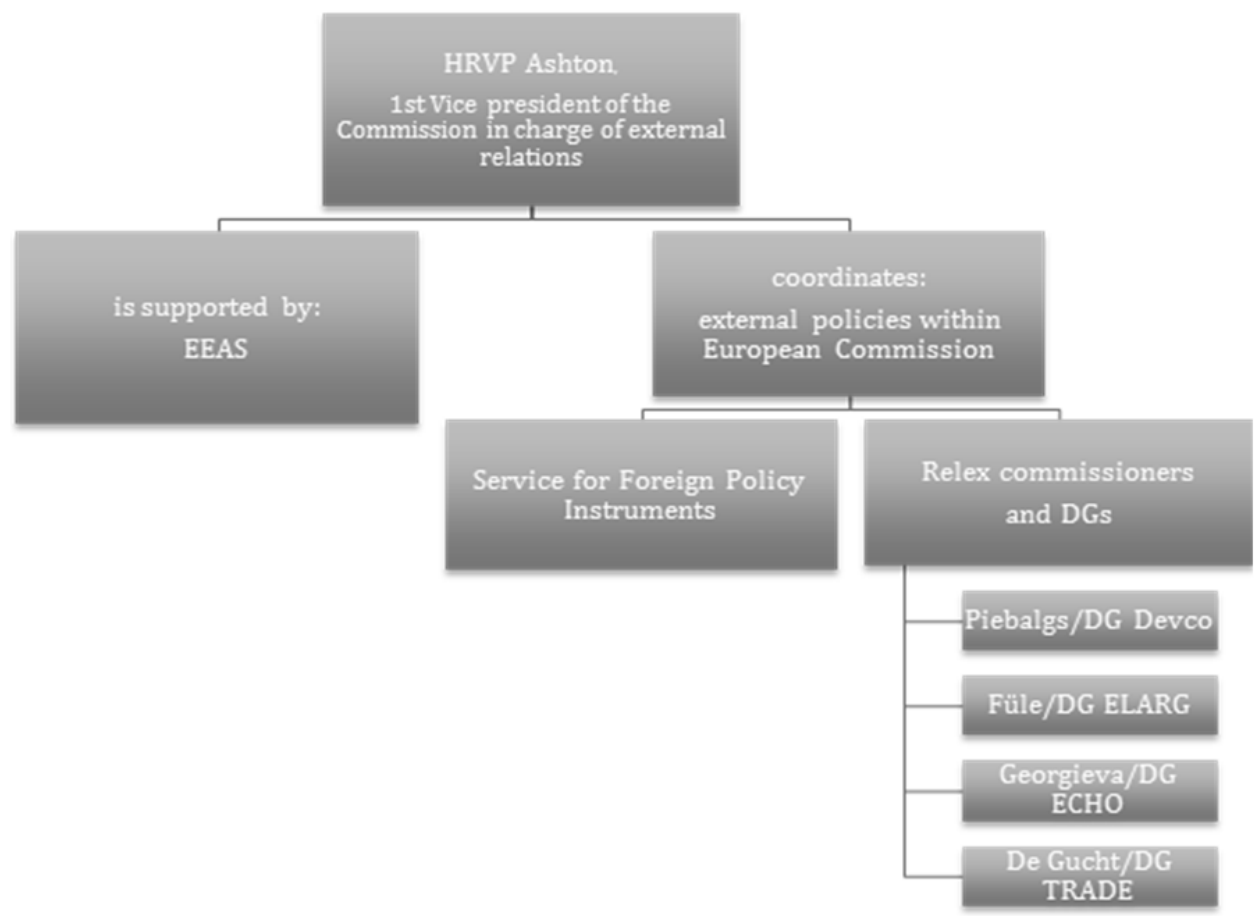

Figure 2.1: External policies under the Barroso II Commission

Besides institutional competition, the Lisbon Treaty has also led, in the field of development cooperation, to institutional changes within the Commission and to a reorganisation of policy-making. Some elements of the former DG Development were transferred to the new diplomatic service. DG Development and DG EuropeAid were merged to form DG Development and Cooperation-EuropeAid (DG Devco), which became operational on 3 January 2011. Putting both policy programming and implementation under the same umbrella, the merger aims to enhance the consistency of the EU on development cooperation (one DG, one voice, one single contact point for stakeholders). However, DG Devco does not decide on development policy on its own. It is responsible for designing development policy and for establishing thematic programmes. Its geographical desks are in charge of implementation (Duke, 2012:58). The EEAS is responsible for the programming of development instruments and looks at regional strategies (European Parliament, DG for external policies, 2013:49-50). New working habits need to develop between Commission DGs (here Devco) and the newly created EEAS.

Since April 2010, another new service has been set up, the Service for Foreign Policy Instruments (FPI, ex A3 unit of DG Relex). It directly reports to the HRVP and was created by the Commission to coordinate policies with the EEAS (European Parliament, 2013:56). This service has a very important portfolio: it is in charge of 
the financial and operational implementation of CFSP, the instrument for stability, the industrialised countries instrument, election observation missions, press and public diplomacy (Service for Foreign Policy Instruments, 2013). It is also responsible for regulatory instruments such as CFSP sanctions within the areas of competence of the European Commission, the Kimberley process ${ }^{11}$, and the prevention of trade in goods that could be used for capital punishment or torture (ibidem). Despite its importance, it is a service and not a fully-fledged DG and its dependence on other DGs (for instance on DG Devco for administrative or IT matters) may create difficulties. The link with the Commission is both obvious and difficult. Substantially, the mandate of the FPI links it to the Commission. However, the service appears on the organisation chart of the EEAS because it directly reports to the HRVP and it is located in the same building as the EEAS.

The EU is no exception to the challenge of fragmentation in public administration (see section 1.4) because, as a polity, the EU is a "system of interacting parts" (Hall \& Taylor, 1996:6; see also Stevens \& Stevens, 2001:145) and cannot be considered as a unitary actor (Allison \& Halperin, 1972:43). The literature generally considers that the challenge is even more acute at the EU level than in national administrations (Peters \& Wright, 2001:158). ${ }^{12}$ The general consistency challenge also characterises individual institutions within the EU system, including the European Commission, which is the central focus of this research:

[T] he assumption is that the Commission is a fundamentally fragmented body, driven by the bureaucratic politics of inter-DG rivalry within which Commissioners either play no role or simply exacerbate existing cleavages and tensions (Smith, 2003:140).

As ministries at the national level, the European Commission is organised by the specialisation principle. Specialisation happens horizontally - between the different services or Directorates General - and vertically - between administrative (the DGs) and political (Commissioners and cabinets) actors. Consequently, the Commission is best described as a collection of services that have each a sectoral expertise and agenda. Their mere coexistence is expected to lead to frictions (March \& Simon, 1958:117; Allison \& Halperin, 1972; Mintzberg, 1983; Alexander, 1993:333; Christiansen, 1997:78). In conclusion, in Cram's words, the Commission is a "multi-organisation" (Cram, 1994:196) the decision-making of which is "strongly biased by the horizontal organisational structure of the [institution]" (Trondal, 2007:963,968). "Firewalls between sectors are high and often impermeable" (Peterson, 1997:5 quoted by Jordan \& Schout, 2006:12), an issue further complicated by inter-institutional dynamics. Consequently, there is a felt

\footnotetext{
11 The Kimberley Process aims at stopping the trade in conflict diamonds and ensuring that these do not finance rebel movements and attempts to destabilise legitimate governments (Kimberley Process.,n.d. a). ${ }^{12}$ See Jordan \& Schout, 2001 for a discussion on the reasons that explain why the consistency challenge reaches such an unprecedented level in the EU.
} 
need for a joint decision-making framework to deal with this situation of potential conflict and risk of inconsistency.

\subsection{Conclusion}

In conclusion, the "danger of fragmentation" has been repeatedly recalled, not least under the Prodi Commission by the Commission's President himself and Chris Patten, the then-Commissioner for external relations. ${ }^{13}$ Because of the substantial "indivisibility of external policies" (Patten quoted by Missiroli, 2001:49),

[the actors responsible for the different external policies] should be engaged not in trench warfare but in a common enterprise to ensure that the world's largest trading group also makes its presence felt politically (Patten quoted by Missiroli, 2001:44).

Ideally, the EU should build on its different external policies and instruments, which are mutually reinforcing.

Within the Commission, responsibilities have grown larger, more complex and more sensitive. Portfolios have increased in number and in scope. Different actors, both political and administrative, are expected to work together as well as to work with outsiders (the EEAS) in the post-Lisbon era. More often than ever, accounts of the structure of the Commission to manage external policies outline bureaucratic rivalries and the difficulties created by the autonomy of DGs and the political independence of Commissioners (see for instance Smith, 2006:325; Spence, 2006c:372). Overall, the major change following the entry into force of the Lisbon Treaty is that DG Relex has been integrated into the EEAS, outside of the Commission. This causes a particular coordination difficulty since coordination was one of the main responsibilities of DG Relex within the Commission: the institution had to re-think how to ensure consistency (interviews 2, 3, 4, 5, 7 and 13), a point to which the next chapter turns.

\footnotetext{
${ }^{13}$ Patten, 2000: "A European Foreign Policy: ambition and reality" and Prodi, 2000: "Plenary Session of the European Parliament”, reproduced in Missiroli, 2001:Annexes A and C.
} 



\section{CHAPTER 3.}

\section{CONCEPTUAL FRAMEWORK AND METHODOLOGY}

This research is concerned with understanding how the European Commission ensures the consistency of its policy output and with assessing it. Chapter 2 has presented the policy and institutional context that creates the consistency challenge. Because consistency is considered a sine qua non of EU international actorness, it has become a focus of both practitioners' and scholars' attention. In order to assess the consistency of the policy output, this study first needs to identify the levels at which the consistency requirement is expressed. As a first step, this chapter aims at defining the terms and at explaining the conceptual and methodological choices of this research. The first section undertakes to define the key concept of the study, consistency. The second section answers the question of how to study consistency. It identifies and introduces the three-level framework that has been developed by the EU to realise the consistency objective. The first level consists of the Treaty framework, the second one of the policy framework while the third level refers to Commission internal decision-making. The next chapters will systematically elaborate on the relevance of these levels for the EU's external action in general and in particular for the case studies. Lastly, this chapter justifies methodological choices made in this research. First, it presents the chosen case studies and shows the relevance of the cases to assess the consistency of the Commission's policy output. Second, it discusses the process-tracing approach and justifies the use of qualitative interviews as a key data source.

\subsection{Defining consistency, a challenge at several levels}

Legal scholars and political scientists, but also practitioners, have extensively elaborated on the concept of consistency. The scholarship is replete with definitions. This illustrates the interest and the centrality of consistency, which is not only a theoretical or an abstract concern but does also raise policy-relevant questions (for an overview, see for instance Duke, 2011a; Portela \& Raube 2009). However, as mentioned before, the definition exercise is complicated by the coexistence and interchangeable use of several terms - consistency and coherence. It is further blurred by the existence of different interpretations of the word consistency - one of them being specific to the EU and the construction of its external action (Nuttall 2005) - and of different dimensions of the consistency challenge. This section is the first, necessary step in the definition of the conceptual framework and of the methodology of this study. It discusses the definition of 
consistency, distinguishing it from the word coherence, and introduces the different dimensions of the consistency challenge.

\subsubsection{A linguistic challenge, consistency versus coherence}

As already pointed out in the first chapter, defining consistency is complicated by the interchangeable use that is sometimes made of the words consistency and coherence. Despite the importance of the concept of "consistency" in the Treaty, the word can only be found in its English version. There is no equivalent in many other EU languages. Their versions of the Treaty use only the equivalent of the word coherence - for instance in French 'cohérence', in German 'Kohärenz', in Italian 'coerenza', in Spanish 'coherencia', in Portuguese 'coerência', in Dutch 'samenhang' and in Danish 'sammenhæng'. Besides, even the English version of official documents sometimes refers to "consistency", sometimes to "coherence", while sometimes both words are used interchangeably. This sub-section defines both concepts and explains the choice to focus on consistency in this research. It then refines the definition by discussing the different dimensions of consistency.

Both consistency and coherence are difficult to define: often, they are defined only negatively, id est by the absence, respectively, of inconsistency and of incoherence. An interchangeable use of both words in some documents further adds to the confusion.

On the one hand, in the legal literature, there is a consensus on the distinction between coherence and consistency. According to lawyers, coherence and consistency cannot be used interchangeably because they have different meanings and different implications (see for instance Bosse-Platière, 2009:28; Hillion 2008; Gauttier 2004; Tietje 1997). Hillion defines coherence as "beyond the assurance that the different policies do not legally contradict each other, a quest for synergy and added value in the different components of EU policies" (Hillion, 2008:17). Gauttier follows the same line in considering that coherence is more about synergy than about avoiding contradictions (Gauttier, 2004:23). Tietje argues that the general level of coherence of an action depends on the level of consistency of the individual sub-actions, id est the absence of contradictions between the different sub-actions, and on the creation of synergies, or externalities, between these subactions (Tietje, 1997:213). This means that the concept of "coherence" goes beyond the concept of "consistency". Consistency means an absence of contradictions between the different dimensions of an action and the primary objective of this action, while coherence requires the creation of synergies between the different dimensions of an action in addition to the absence of contradictions. The final effect is more than the sum of the effects of sub-actions. Typically, the word coherence is used in the field of development. "Policy coherence for development" refers to a strong political focus on development and the creation of synergies between different actions - and not only to the absence of contradictions between policies to pursue development-related objectives. 
On the other hand, the political science literature often uses the two words coherence and consistency interchangeably to avoid unnecessary "linguistic pedantry" (Nuttall, 2005:93). For instance, Gaspers systematically uses the word "coherence" to define "consistency". He defines "institutional consistency" as "the coherence of the policy-making approaches of the Council and the Commission and of the different sub-structures within these two institutions towards the same issue" (Gaspers, 2008:21). Similarly, from a practitioner's point of view, as revealed by exploratory interviews and policy papers published by specialised organisations, the distinction is not clear-cut (exploratory interviews 5, 6, 7 and interview 1; see for instance Box and Koulaïmah-Gabriel, 1996, Gual, 1995).

Nevertheless, certain policy-oriented papers provide elaborate definitions:

Policy coherence (...) involves the systematic promotion of mutually reinforcing policies across government departments and agencies creating synergies towards achieving the defined objective (DAC poverty guidelines 2001 quoted by Mc Lean Hilker, 2004:4).

Policy coherence means different policy communities working together in ways that result in more powerful tools and products for all concerned. It means looking for synergies and complementarities and filling gaps, between different policy areas to meet common and shared objectives (DAC journal of development cooperation, 2002 quoted by Mc Lean Hilker, 2004:4).

These definitions emphasise the goal-oriented nature of coherence (towards achieving the defined objectives) and the creation of synergies between policy instruments across sectors as underlined by the legal definition, while focusing on coordination to put the coherence requirement into effect and achieve policy coherence. Some practitioners draw the line between the output and the process. In their views, coherence is applicable to policies once they have been adopted while consistency is understood more as an instrumental concept. It refers to the procedures followed to adopt a policy, to the mechanisms to avoid contradictions and to the continuity of objectives of a certain policy over a period of time (exploratory interview 5). Interviews have also revealed that the reference to consistency or to coherence depends on the nationalities of the respondents. This creates a particular difficulty for the empirical research: there might be an inconsistent use of concepts by the researcher and by the interviewees. All the interviews conducted therefore started with questions on the definition of concepts to ensure a common understanding of and a focus on what this research defines as consistency.

This research will systematically use the concept of consistency. By using the concept of consistency, this research focuses on the absence or existence of contradictions between the primary objective of an action and the different dimensions of this action. It is more feasible to assess the consistency of Commission proposals than their coherence. Indeed, as defined in the legal literature, coherence would require to assess not only the absence of 
contradictions, but also the existence of positive externalities (Bosse-Platière, 2009:28). Such a discussion goes beyond the scope of this thesis. The same line of reasoning also led the European Court of Justice to focus on the concept of consistency in its case law on ex-article 47 TEU (C-91/05 Commission v. Council; Commission, Legal Service 2008). The Court did not base its ruling on the concept of coherence because it does not have the political remit to decide on the opportunity for synergies between policies, since this is left to the political appreciation of decision-makers. In addition, assessing the existence and extent of synergies would also require to consider the implementation of the proposals studied and evaluate their concrete consequences, a dimension that falls outside the research scope. Studying the difficulties in achieving consistency and the conditions under which consistency is achieved also allows, in a second step, drawing inferences about the difficulties of achieving consistency.

Krenzler and Schneider define consistency as

a "coordinated (...) behaviour (...) where comparable and compatible methods are used in pursuit of a single objective and result in an uncontradictory (foreign) policy" (1997:134).

Their definition highlights three characteristics of the concept of consistency. First, it posits that the policy output should be contradiction-free. Second, the definition outlines the goal-oriented nature of consistency, namely the realisation of a particular objective, which in turn constitutes the benchmark against which to assess the existence or absence of contradictions. Lastly, Krenzler and Schneider emphasise the centrality of coordination in achieving consistency: consistency and coordination are not the same, but coordination is an instrument of decisionmaking aiming to reach consistency. Coordination is an organising theme of decision-making, which puts into effect the consistency requirement. Consequently, it will constitute a key dimension of this research. In particular, coordination instruments in the Commission's internal decision-making process - both the responsibilities of the actors involved in decision-making and the concrete rules of procedure - are understood as central when considering how the Commission, in the case studies, articulates different external policies to avoid contradictions between them and a particular objective.

\subsubsection{A multidimensional challenge}

The definition of consistency as discussed above focuses on a policy output that is free of contradictions. Such contradictions may arise from different sources, all linked to the characteristics of EU external action as discussed in chapter 2. The literature breaks down the consistency challenge into four dimensions. As shown in the table below, these dimensions include vertical, horizontal, institutional and external challenges (Portela \& Raube, 2008:3; Nuttall, 2005:96-107). 
Table 3.1: Dimensions of consistency challenges

\begin{tabular}{lll}
\hline Dimension & Definition & Examples \\
\hline Vertical & $\begin{array}{l}\text { Between different levels of } \\
\text { administration/governance }\end{array}$ & The EU v. member states \\
Institutional & Between organizations & Commission v. Council \\
& Between branches of an organization & DG Trade v. DG Development \\
Horizontal & Between different policies & CCP v. development policy \\
External & $\begin{array}{l}\text { Between one's action and the perception } \\
\text { of one's action by a } 3^{\text {rd }} \text { player }\end{array}$ & $\begin{array}{l}\text { The EU v. its clientele; the EU v. } \\
\text { third countries }\end{array}$ \\
\hline
\end{tabular}

First, vertical consistency challenges refer to the articulation between different levels of governance. Vertical inconsistency arises from contradictions between the action of the EU and actions of Member States. It occurs for instance when the EU sets ambitious targets for official development aid (ODA) while its Member States include in the total ODA controversial elements such as the schooling of migrants' children. Another example is France inviting Mugabe to attend the French-African Summit in 2003 despite the EU's sanctions against Mugabe's regime.

The second institutional dimension consists of two types of challenges. It refers to inter-institutional conflicts - tensions between different organizations e.g. between the European Commission and the European External Action Service or between the Commission and the Council of the EU. For instance, in the ECOWAS case (C-91/05), Commission and Council were opposed as to which instruments could be adopted in the fight against small arms and light weapons. The Commission argued that it was falling under the Cotonou agreement while the Council argued that it was falling under the remit of CFSP. Institutional consistency challenges also stem from intra-institutional conflicts - tensions between the different branches of an organization - for instance between different DirectoratesGeneral of the European Commission or between the political and administrative levels.

Third, horizontal consistency challenges are linked to the tensions that may arise between different policy areas; it is a challenge to ensure horizontal consistency either between the different dimensions of an action. The tensions between the reciprocity requirement in the liberalisation of trade and the protection of developing countries' markets in the negotiation of the Economic Partnership Agreements are a topical example. Evidently, it is difficult to distinguish between horizontal and institutional consistency: how institutions are organised and how they work together with other institutions has consequences on the content of the policies adopted. 
Lastly, external consistency challenges refer both to an actor's capacity to present itself as acting consistently and to the way the partners of this actor perceive its action. For instance, the EU delegation at the G20 summit in March 2010 counted two Presidents, the President of the European Council and the President of the European Commission. This arrangement may have confused the other participants in the summit.

Overall, consistency is defined in this study as a specific quality of a policy output, in the sense that the different dimensions of a policy proposal do not contradict the primary objective of that proposal. The different types of consistency challenges discussed above point at different sources of contradictions: different levels of governance, different institutions or the different objectives of different policies. The inter-institutional consistency challenge is beyond the research scope as the case studies deal with the drafting of Commission proposals. Nevertheless, it will be marginally dealt with when dynamics of cooperation between different institutions (the Commission, the Council, the EEAS and the European Parliament) are relevant for the case studies as, in practice, the Commission generally aims at presenting a proposal that is acceptable to the other institutions (Kassim \& Menon, 2004:26). The vertical dimension of the challenge - the absence of contradictions between the actions of the EU and the Member States - will not be addressed as it mostly concerns the implementation phase, a phase of the policy cycle that is outside the scope of this research. The external dimension was indirectly touched upon in section 1.5 dealing with the partners' perceptions of the EU as an international actor and the discussion of the expectations created by consistency, but it is not central in this thesis either. As defined in section 1.3, the emphasis of the current study will be put on the horizontal challenge (across external policies) within the Commission (intra-institutional consistency) with the aim to assess the consistency of particular proposals adopted by the European Commission. In order to assess the consistency of policy proposals, this chapter now asks how to study consistency (conceptual framework) before introducing the methodology for this research.

\subsection{Conceptual framework}

As outlined already, consistency is a multidimensional concept that is potentially influenced by many factors. Thus, it does constitute a phenomenon difficult to study and a complex challenge to address. At what levels does the EU in general and the Commission in particular aim for consistency? Besides the general and policyspecific consistency requirement, provisions implementing this requirement are contained in Commission decision-making with the objective to guarantee the actual consistency of the policy output. This section introduces the three levels at which the consistency requirement is expressed in the EU. The Treaty framework, the policy framework and Commission decision-making all aim at achieving a 
consistent policy output. The present study will therefore focus on these different levels. Taken together, efforts at these three levels may or may not lead to a consistent policy output. Such outputs will then be studied, assessed and explained in the case studies. Section 3.2.1 discusses the three levels, while section 3.2.2 deals with the question of how to assess consistency.

\subsubsection{How to ensure consistency?}

Consistency is sought at different levels. This research identifies three complementary levels:

1. The Treaty framework,

2. The policy framework,

3. Decision-making in external policies and in specific case studies.

The EU expresses the consistency requirement at these three levels, in this order, from a general level through the Treaty provisions to the specific policy framework and the more concrete steps to take at the decision-making level. The section now introduces the discussion on the levels, which will be elaborated on in more detail in the next chapters. Chapter 4 will elaborate on consistency-related provisions in the Treaty framework while chapters 6 and 7 will specify the policy framework for each case study. Chapter 5 will present decision-making in external policies in general, which will be further detailed in the case studies chapters on the basis of the drafting of the selected proposals (chapters 6 and 7).

\section{The first level, the Treaty framework}

At the more general level, the Treaty framework defines consistency as one of the guiding principles and objectives of EU action. Tietje considers it as a constitutional principle of the EU's legal order (Tietje, 1997:214). The Treaty framework does not only proclaim a general consistency principle, it also details the different dimensions of consistency (horizontal, institutional and vertical, see section 3.1) and reaffirms the centrality of all of them. The consistency of EU external action in particular occupies a central position in both the TEU and the TFEU today (Treaty on the Functioning of the European Union, see chapter 4; Nuttall, 2005:98-100). Besides requiring consistency, the Treaty framework realises this obligation to a certain extent by specifying the consistency mandate of particular actors in the EU. For instance, the Council and the Commission, assisted by the HRVP, are responsible for the consistency of EU external action (article 21.3 TEU), while the HRVP has a particular consistency mandate for external policies within the Commission (article 18.4 TEU). In addition, the TEU also aims to ensure consistency by providing for the unity of EU external action. The Lisbon Treaty creates a single title on external action (title V) and introduces a set of common principles and objectives that guide external action (article 21.2 TEU). These principles and objectives include the consolidation and support to democracy, the rule of law and 
human rights, or the promotion of social and environmental development of developing countries. Any external policy shall work toward these general objectives - and not only towards its own, specific objectives. Overall, the Treaty framework constitutes the first and most general level where consistency is aimed at. It is a constant, static element of the consistency framework applicable to external action in general. A more detailed elaboration on the Treaty provisions on consistency will follow in chapter 4.

\section{The second level, the policy framework}

A policy framework consists of strategies, policy concepts and policy guidelines that define the substantial content of EU action in a particular policy area. This level specifies the general commitment to consistency of external action contained in the Treaty framework.

While the Treaty framework provides general guidelines for EU external action, the policy framework specifies how consistency between different objectives in a given policy area should be achieved. This level defines the substantial implications of the general consistency requirement by detailing the different policies or dimensions to take into consideration when legislating on a particular topic. For instance, when legislating on the Generalised System of Preferences (GSP), the Commission has to take into consideration not only the trade-related imperatives of import preferences but also the trade-development nexus as well as the general concept of policy coherence for development. Combined, these orientations set a frame for the Commission's action. However, the proliferation of such frameworks - there are over 60 strategies for instance in different policy fields that may partially overlap - may also be a challenge for consistency (Jordan \& Schout, 2006:12).

Overall, the policy framework aims at providing a comprehensive approach by identifying overarching objectives and detailing the contributions of individual actions thereto. Because this second approach is by definition policy-specific, it differs from one case study to the other and consequently will be dealt with in the case study chapters (see chapters 6 and 7).

The third level, the Commission's internal decision-making process in external policies

Coordination is one of the golden words of our time. Offhand, I can think of no way the word is used that implies disapproval. But what does it mean? (Wildavsky quoted by Alexander, 1993:329)

The research takes one step further to explore how proposals are actually adopted by the Commission in a particular policy area. Constituting "a uniform system of rules to govern all individual official decisions and actions" (Coombes, 1970:106), 
the Commission's internal decision-making process defines how Commission proposals are prepared up to their adoption by the College. ${ }^{14}$ Given the internal fragmentation of the Commission, a focus on decision-making aims to explore what happens inside the "black box" of this institution.

To address the consistency challenge in their study on the effect of EU membership on national administrations, Dimitrakopoulos and Passas refer to the "coordination imperative" (2003:442). The French and British paradigms of coordination in EU affairs - consisting of coordination meetings, a culture of diffusion of information and the establishment of arbitration mechanisms illustrate how Member States adapt their administrations to contribute substantially to EU decision-making that cut across policy boundaries (Dimitrakopoulos \& Passas, 2003:442-443). The "coordination imperative" results from the need to overcome the institutional and horizontal fragmentation discussed above and the associated difficulty to develop consistent policy proposals across the range of sectoral responsibilities. Actors need to be coordinated or to coordinate their decisions to make sure that "different policy dimensions or objectives do not impede, frustrate or negate one another" (Metcalfe, 1994:278).

Besides the general requirement for consistency in EU primary and secondary law, public administrations have set up instruments to put into effect the consistency requirement. In particular, they consist of coordination instruments that aim at aggregating often-competing interests or different positions and in turn at enhancing the consistency of the policy output. Such instruments may take different forms. For instance, at the national level, France has set up a specific structure to coordinate its European policy: the Secrétariat général des affaires européennes (SGAE) (Morisse-Schilbach, 2005:115). An administration de mission, its rationale and overarching objective are the coordination of the French European policy and the definition of France's position on EU policy. The Secretariat does not have a sectoral competence but covers all policy domains of the TEU and TFEU (with the exception of CFSP) and coordinates the positions of the different ministries to produce a consistent policy. The SGAE is only one illustration. The same efforts are deployed at the EU level, specifically within the Commission to avoid contradictions between different external policies as will be discussed in more detail in chapter 5 . It is for instance the aim of the inter-service consultation by which all DGs concerned by a proposal are consulted ex ante, for their positions on the proposal to be taken into consideration in the drafting. It is also the rationale behind the coordination mandate for external policies within the Commission of the HRVP (Jordan \& Schout, 2006:5). Whenever and wherever the consistency challenge has been raised, the Union's classical answer to this challenge or to the "mismatch" between policy consistency and the existing internal capacities was to pay more attention to coordination (Eberlein \& Kerwer, 2004:122 quoted by Jordan

\footnotetext{
${ }^{14}$ Decision-making is the "horizontal process of bargaining, coalition formation and compromise among actors"; Allison quoted by Hammond, 1986:380.
} 
\& Schout, 2006:5). The Commission is no exception to this trend: it addresses the consistency concern precisely by putting the emphasis on coordination throughout decision-making. This PhD research takes the same approach: it understands coordination as an instrumental concept towards consistency (Radin, 2003:611; Duke, 1999:1). Coordination and consistency are not the same: coordination aims at ensuring the consistency of the decision taken but consistency may or may not be the outcome of coordination.

Coordination remains an elusive concept despite the existence of a plethora of definitions (see for an overview: Jordan \& Schout, 2006:40-43; Peters \& Wright, 2001:156; Alexander, 1995:3-6; Alexander, 1993:330-331). Definitions refer to different "objectives (e.g. avoiding day-to-day conflict or producing longer-term strategy), tasks (simple or complex), environments (tightly or loosely coupled) and mechanisms (coercion or voluntary cooperation)" (Jordan \& Schout, 2006:40). This research adopts Wollmann's definition of coordination:

[Coordination is the] attempt to optimize the (...) consistency of political decisions and policy implementation across policies [to overcome the sectoral fragmentation of policies and to achieve comprehensive and holistic responses to complex problems], across actors and stakeholders [to accommodate their often-conflicting interests] and across levels [to overcome the vertical fragmentation of policies and actors] (Wollmann, 2003:594).

This definition merges two aspects of coordination. It refers first to the goaloriented nature of coordination, presenting coordination as an instrument to ensure the consistency of decisions. Contradictions between norms, actors and instruments are avoided through the aggregation of competing demands inside an institution (a point also made by Kassim, 2001:87-88 and Simon, 1997:190-191 for instance). Second, Wollmann also outlines the process dimension of coordination. Coordination is the principle that underlies the drafting of any Commission proposals: internal decision-making brings together actors who are concerned by a particular proposal so that their positions are taken into consideration in the drafting (see also March \& Simon quoted by Hage, Aiken \& Marrett, 1971:860). Coordination cannot be understood as a given of decision-making. It is a point of permanent attention throughout the internal decision-making process. It constitutes a continuous effort to bring together different actors and different levels of governance across the broad range of policies in an effort to produce a consistent output, which in turn is expected to ensure the effet utile of the Union's external action as a whole (Dashwood, 2008:96).

The third level of analysis identified in this research consequently leads to an examination of the interaction between the subparts of the Commission with a focus on the coordination of sectoral concerns and of different positions and preferences. Such investigation will contribute to explain how coordination is working in the Commission, and which factors make it successful, so that a consistent policy outcome is adopted. Because the existence of a legal commitment 
to consistency does not actually guarantee consistency, the importance to focus on decision-making in general and primarily on coordination is acknowledged in the literature and in Commission official documents:

The quality and consistency of the Commission's and its departments' work depend on effective coordination at the earliest possible stage, not only between all the departments concerned but also with anyone outside the Commission who is affected. (emphasis added; Commission, n.d.a)

In that light, this research provides a detailed and comprehensive analysis of arrangements and instruments for coordination. Internal decision-making assigns responsibilities, prescribes roles and defines procedures (see Commission, 2010i). For instance, the Secretary-General of the Commission is responsible to "help to ensure political consistency by organising the necessary coordination between departments" (article 20 Commission 2010i) and the Relex group of Commissioners contributes to the coordination of the work of the Commission (article 18 Commission, 2010i). Inter-service consultations are the process by which departments contribute to the drafting of a proposal and their contributions are taken into consideration ("Cooperation and coordination between departments", article 23 Commission, 2010i).

Besides the formal rules, the role of informal efforts of coordination should not be underestimated. Although the distinction between the two categories is sometimes blurred, the empirical research of this thesis has revealed how much informal and formal efforts are mutually reinforcing (see for instance Brie \& Stölting, 2012:19-20; interviews 4 \& 5). Firstly, informal coordination may take place outside formal decision-making whenever it precedes the discussion of any proposal (interview 5), as well as within the formal decision-making process. Either way, it increases the effectiveness thereof, eases the negotiations and reduces the transaction costs. Second, informal coordination gives the opportunity to continuously try to bring different positions closer together, thereby introducing flexibility in a complex system (Daase, 2009:298) and helping to cope with institutional changes (Reh, 2012:66).

Although a very important element of Commission decision-making, informality lacks an agreed definition (see for instance Helmke \& Levitsky or Harsh quoted by Christiansen \& Neuhold, 2012:4; Christiansen, Foellesdal \& Piattoni, 2003:6). Overall, the distinction between formality and informality builds on three characteristics. Where formal institutions are defined as explicit, external and enforceable, informal institutions are defined a contrario as implicit, internal and not enforceable (Daase, 2009:290). Practically, there exists a price for the actor who does not respect the informal steps of decision-making or an informal agreement reached during decision-making: informality works via social obligation. The price ranges from disapprobation to social isolation and a less-off position in a later negotiation (Brie \& Stölting, 2012:20; interview 5). 
Additional elements need to be considered to better understand informality and the distinction between formal and informal rules. First, informal negotiations are often said to take place behind closed doors and, consequently, to lack transparency. This is not a defining characteristic of informality for two reasons. Formal decision-making is not as transparent as most believe it is, although it follows precise rules. For instance, the membership of Commission inter-service groups is very open. When an inter-service group is set up, the membership is decided and formalised in a registration form, but any DG can always apply later, or can simply come and go (interview 5). Besides, informal decision-making is not as hidden as most believe it is. It is often very obvious during a formal negotiation that several actors have been pre-negotiating informally (outside of the formal setting, sometimes even with a different membership) as they move quicker to a solution in the formal setting (interview 5). Second, the membership of informal meetings is not explicitly defined (Conzelmann, 2012:232). It depends on personal contacts established by actors leading a particular negotiation and remains open because not all the implications of a given decision are necessarily known in advance (Reh, 2012:68; interview 5). Thirdly, information about the informal sphere is limited, because meetings are not open to public scrutiny and because outcomes of informal negotiations are not necessarily officially notified. Lastly, decisions binding on outsiders are the product of the formal sphere only: decisions in the informal sphere are binding only on the participants involved in informal decision-making (ibidem).

There is no clear boundary between formal and informal processes, both are part of the decision-making process and constrain individuals' actions (Daase, 2009:296). They should therefore not be thought of in binary terms as they coexist and are often co-dependent. They mutually reinforce each other in a political system characterised by organizationally independent but functionally dependent services. The discussion of Commission decision-making in chapter 5 will not be structured along the informal/formal dichotomy but the case studies will illustrate the mutually reinforcing nature of informal and formal decision-making.

Overall, Commission internal decision-making is the third level at which consistency is sought. With its focus on coordination, it constitutes the implementation of the commitment to consistency in the drafting of a particular proposal. But the outcome will depend on the use actors choose to make of the instruments that are available to these ends (interview 46). The general characteristics of decision-making for external policies will be presented in more detail in chapter 5 and specifically discussed in particular case studies (chapters 6 and 7).

In conclusion, this section has identified the three levels at which the EU requires and implements consistency. They constitute the complementary layers of a pyramid going from the general consistency requirement provided for in the Treaty framework, to the specification of this requirement by the policy framework 
in a particular policy area, to its realisation in the Commission's decision-making process in the field of external policies.

\subsubsection{How to assess consistency?}

So far, this chapter has defined the consistency concept and how consistency was approached in this research. But how to assess the consistency of a particular policy output? The research adopts a qualitative assessment approach to assess the consistency of particular proposals.

A proposal will be considered to be consistent when there is no contradiction between the primary objective and the rest of the provisions of this proposal, as opposed to a situation where the content of a particular proposal contradicts the primary objective of this proposal. Consequently, the research adopts a qualitative approach. The first analytical step to take is to establish the presence or absence of contradictions by looking at the content of the proposal. The discussion of the potential contradictions between the different objectives or dimensions of a Commission proposal outlines the different research directions. Inherent tensions between different objectives or dimensions as well as a comparison between the different options available to the Commission contribute to the assessment. Indeed, this initial step outlines the elements most likely to be contradictory in the light of the constraining effect of the Treaty and policy frameworks that, ex ante, require coordinating certain objectives and dimensions in order to avoid contradictions in the actual proposal. Then, the research qualitatively assesses the existence or absence of contradictions in the actual provisions of the proposal against the primary objective of a proposal, which provides the benchmark against which to assess consistency. Indeed, as stated above, consistency does not mean that all three dimensions - trade, development cooperation and CFSP - have necessarily an equal weight and that there cannot be a hierarchy of objectives: the definition of consistency used in this research starts from the idea of a 'primary objective'. This necessarily implies that there can be (and usually is) a certain hierarchy between objectives and policy areas. A consistent action then serves to reach a particular primary objective through the use of different policy instruments. The assessment builds on the wording of the selected proposals and discusses it in the light of the primary objective pursued by the Commission.

Assessing consistency is not a binary choice - consistency or inconsistency but a matter of degree. The discussion on the existence or absence of contradictions, within a proposal, between the primary objective of this proposal and its provisions, therefore needs to be refined. Different degrees along the consistency/inconsistency continuum are defined as follows:

1. High consistency: a proposal is highly consistent when all its provisions fully support and further strengthen the primary objective(s) that this proposal sets; 
2. Medium consistency: a proposal reaches a medium degree of consistency when its provisions do neither contradict the primary objective(s) nor significantly add to its (their) achievement;

3. Low consistency: low consistency qualifies a situation in which none of the provisions of a proposal contradict the primary objective(s) but a few jeopardise its secondary objective(s);

4. Inconsistency: a proposal is inconsistent when there is a contradiction between its primary objective and its provisions.

This scale will be applied in the case study chapters to assess the degree of consistency reached in each proposal.

Once the degree of consistency has been established, the research aims to explain the absence or existence of consistency. If the Treaty and the policy frameworks for consistency are a given, the outcome of decision-making in particular cases is the unknown dimension. The Commission's decision-making process focuses on coordination as emphasised above but coordination and consistency are not synonymous. Although the definition of coordination establishes that the objective of coordination is a consistent policy output, consistency may or may not be the outcome of coordination efforts. The mere presence of institutional and procedural tools for coordination does not guarantee that consistency is systematically the outcome of the process. It is only when the output is consistent that the research concludes that there has been successful coordination, while coordination has failed if the policy output is inconsistent. In addition, as established above, the research considers that there are three degrees of consistency: low, medium and high. It follows that coordination may be limitedly, moderately or fully successful. The degree of the success of coordination depends on the degree of consistency reached:

1. Coordination is fully successful when the policy output is highly consistent;

2. Coordination is moderately successful when the output reaches a medium degree of consistency;

3. Coordination is limited successful when the output reaches a low degree of consistency;

4. Coordination fails when the policy output is inconsistent (figure 3.1). 


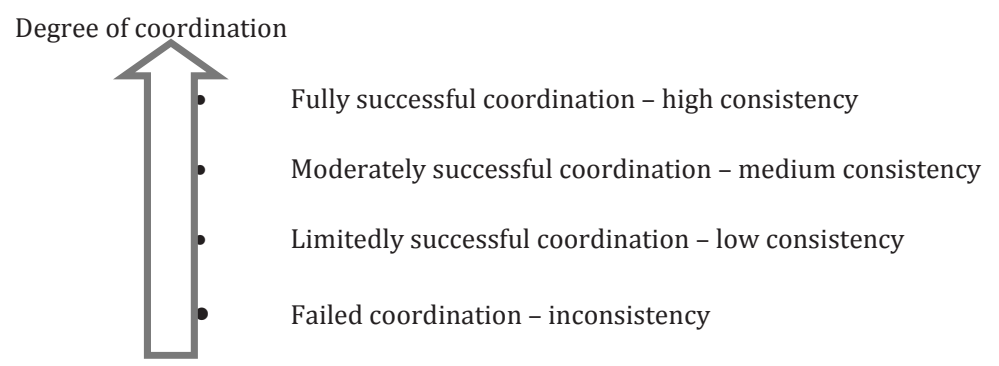

Figure 3.1: Coordination, successful coordination and consistency

In turn, this research will aim at explaining the degree of success of coordination.

This approach for assessing consistency is clearly distinct from two alternative approaches that have been suggested in the scholarship, namely to either assess consistency on the basis of the perceptions of third actors, or to assess consistency on the basis of the existence of coordination instruments. The first approach, in particular advocated by Peters (n.d.:6), focuses on external consistency, the perception of consistency by third actors. This option requires to identify the clientele of one's action and to study its perception of the consistency of the action. Article 11.3 TEU in particular goes in this direction:

The European Commission shall carry out broad consultations with parties concerned in order to ensure that the Union's actions are coherent and transparent. (emphasis added)

Specific instruments of EU decision-making - such as public consultations and impact assessments - build on this logic. For instance, evaluation reports commissioned by DG Devco partly rely on this option. They consult stakeholders of EU development policy and enquire about the perceived degree of consistency of this policy. Methodologically however, this option presents several shortcomings. It is a challenge to define exactly the clientele of a particular policy. Besides, evaluations do not provide specific criteria or benchmarks against which to assess the consistency of a policy. Respondents form their own opinion of what defines a consistent policy, state whether they perceive EU development policy as consistent and may in certain consultations elaborate on their answers. To summarize, it is challenging first to identify the clientele of a policy and second to ensure that everyone applies the same set of criteria to evaluate consistency. These methodological shortcomings explain why this option will not be systematically pursued.

A second approach for assessing consistency might have been to look at the existence of more or less encompassing means of coordination. Such an approach is for instance suggested in Metcalfe's "coordination scale", outlining the different degrees of coordination in a national administration (1994). Metcalfe identifies 
nine degrees from independent decision-making to the existence of a central strategy. Metcalfe's scale is a bottom-up Gullman scale: a higher level of coordination can only be reached provided that the lower level(s) of coordination are met already. A priori, the scale constitutes an instrument to measure the degree of coordination reached within a particular administration. However, the scale does not mean that a higher degree of coordination is always necessary (Jordan \& Schout, 2006:41). This is a limiting factor in terms of operationalisation for this research. These looser or tighter forms of coordination address different situations, depending on their degree of complexity: loose forms of coordination are suitable for simple tasks while more tightly integrated systems aimed at the management of more controversial and/or encompassing tasks (Jordan \& Schout, 2006:11). In addition, the scale does not define either what constitutes successful coordination (Schout, 1999:8). Consequently, the research will not use Metcalfe's scale.

In conclusion, the discussion of consistency is based on a qualitative assessment of the existence or absence of contradictions in the text of Commission proposals against the primary objectives of these proposals, and will be explained after a careful examination of the drafting of these proposals, within the substantial limits set by the Treaty and the policy frameworks.

\subsection{Methodology}

\subsubsection{How to explain successful coordination?}

As discussed above, methodological choices were made about consistency and coordination. They imply that consistency is not the systematic outcome of coordination. It is only when coordination is successful that the policy output is consistent. Hence, the explanatory ambitions of the present research have to focus on the conditions under which coordination is successful.

A principal decision is through which approach this question should be addressed. One option is a hypothesis-testing design, in which a number of factors that are derived from the literature would be 'tested' for their relative explanatory power. It is however difficult to identify ex ante all the factors that have an influence on the outcome of coordination and this research strategy bears the risk of not being comprehensive. Consequently, a second option will be chosen in which the conditions under which coordination is successful will be identified inductively from the case studies. Discussing the cases, building on the results of expert interviews and the triangulation of the empirical findings of the case studies contribute to identify the conditions under which coordination is successful. By carefully decomposing each step of the drafting of the selected proposals, the research uncovers the different determinants of the decision-making process that in turn influenced how the choices were made within the Commission. Consequently, this research adopts a process-tracing approach. This will allow to 
reach the high level of empirical detail that is required to identify the primary objective of each proposal and to discuss the way potential tensions with these primary objectives are resolved and the success of coordination (Yin, 1989:17).

This approach towards explaining consistency requires both a careful selection of case studies and a thorough method to unearth detailed empirical evidence. The process tracing conducted for this research required the use of qualitative interviews as a key data source. These two aspects - first, case studies and their selection, and second, process tracing and interviews - are explained in the next two steps.

\subsubsection{Case studies}

Case studies allow scholars to get a "reasonably good knowledge of nearly all factors influencing a political decision" (Dür, 2008:563). Case studies are a valuable method to "closely examine the hypothesized role of causal mechanisms (...) and (...) [to address] causal complexity" (George \& Bennett, 2005:48). In this research, cases will help to explore Commission decision-making and to reflect on the implementation of the consistency requirements. Because evidence from multiple cases is more compelling, and in order to avoid the risk of uniqueness or "artifactual conditions surrounding [a] case", the research will use a multiple-case design (Yin, 1989:53, 61). The case studies chosen for this research pose specific consistency challenges, while at the same time dealing with the same principal problem, namely the way in which the trade, development and foreign policy dimensions of an action can be reconciled in the pursuit of a particular objective. The cases are also of strong political relevance and provide the opportunity to follow the development of a specific Commission's proposal in great empirical details. The research will study two cases, the case of appropriate measures against Zimbabwe in 2002 and in 2012, and the 2011 Commission's proposal to revise the Generalised System of Preferences.

\section{Case selection}

The literature on case studies elaborates extensively on the several options to select cases as the case selection risks introducing an important bias in the results of the research (George \& Bennett, 2005:61). Case selection in the present study is primarily based on two criteria, which are the variations of the dependent variable and the topicality of the issue.

The variation of the dependent variable, here consistency, has been the first selection criterion. This approach helps to identify which variables are necessary or sufficient conditions for the selected outcome (George \& Bennett, 2005:62). Exploratory interviews were conducted between September and December 2010 with EU officials and practitioners to have a better understanding of the cases most relevant for the study of the consistency challenge of EU external action. The 
expectations as to the (in-)consistency of particular proposals revealed by these interviews and by the general knowledge and communication on the EU's action at that time constituted the first selection criterion. ${ }^{15}$ Interestingly, interviewees emphasised that there were, in their views, no cases that they would qualify as fully consistent or inconsistent. Indeed, it appears that consistency/inconsistency is a matter of degree between the two extremes - which in turn explains why the research did not adopt an extreme case approach. The case studies will actually test the expectations projected by the interviewees on the basis of the precise definition of consistency adopted here and its application to the cases selected.

The second selection criterion is the topicality of the issues. Through the exploratory interviews and in the literature, topical cases were identified that are considered to be representative of the challenges ahead of the EU. Topicality ensures that the case studies are linked to the EU's international actorness and its ability to "do something" to address a particular (international) concern. Consequently, this second criterion for case selection adds to the relevance of the cases for the research (George \& Bennett, 2005:145).

From both considerations, two cases were selected: the appropriate measures under article 96 of the Cotonou Agreement against Zimbabwe and the 2011 Commission's proposal to revise the Generalised System of Preferences. The first case will actually be subdivided into two with a focus on the 2002 Commission's proposal to adopt appropriate measures against Zimbabwe and its 2012 proposal to renew such measures. Based on the exploratory interviewees, the adoption of appropriate measures against Zimbabwe in 2002 was expected to reach only a very low degree of consistency - because of the criticism of the double standard applied by the EU in the case of the activation of article 96. The renewal of appropriate measures against Zimbabwe in 2012 was expected to be an intermediary case on the scale of consistency. Finally, the reform of the Generalised System of Preferences was expected to constitute the most consistent case under research here (figure 3.2).

\footnotetext{
${ }^{15}$ Another option would have been to select cases on the basis of the independent variables. However, it appears that it is difficult to define ex ante what independent variables influence consistency.
} 


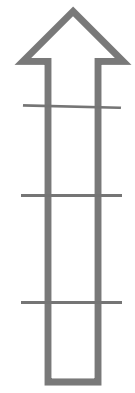

2011 Commission proposal to revise the GSP

2012 Commission proposal to renew appropriate measures under art.96 Cotonou against Zimbabwe

2002 Commission proposal to adopt appropriate measures under art.96 Cotonou against Zimbabwe

Figure 3.2: Selection of case studies along the continuum of consistency

The research will test these preliminary assessments by conducting a detailed analysis of the Commission's proposals. The case-study approach leaves the possibility to correct initial assessments as to the degree of consistency of the Commission's proposals in question.

The two cases were initially thought to illustrate the challenge between of coordinating two dimensions of an action only but, after preliminary research, they appear to combine the three core dimensions (trade, development cooperation and CFSP) of EU external action. The cases differ as regards lead departments and the involvement of several DGs, and are therefore characterised by different institutional dynamics - elements that did not constitute selection criteria though.

Cases are also defined by a particular timeframe. Although consistency has been a concern for forty years now, the timeframe of this research will be more limited. Over the last decade, the domain of external policies has rapidly changed. The consistency issue has regained momentum with the Lisbon Treaty and the new ambitions attached to the EU's external action. The period covered in this study runs from 2001 to 2012. 2001 was chosen as starting point because it inaugurates a decade of self-reflection of the EU on its decision-making processes and the implications of institutional arrangements for its policies. Ten years after the Intergovernmental Conference leading to the Maastricht Treaty, the EU came to realise that its institutions and procedures were putting at risk its international status (Commission, 2001d). The 2001 White Paper on EU governance illustrates this concern particularly well. It addresses the growing criticism towards EU decision-making by calling for a revision of institutional processes (Commission, 2001d:7). The White Paper recognises coherence as a key requirement for the EU to qualify for good governance, outlining the challenge that it constitutes for the EU and the risk that incoherence would jeopardise EU action (Commission, 2001d:10). This diagnostic was followed-up by the European Convention (2002-2003). The Convention focused on consistency to improve EU decision-making and linked it to the concern of EU international actorness (see section 1.3) (European Convention, 2002c). The period covered in this study ends in 2012, three years after the 
entering into force of the Lisbon Treaty. This decade-long timeframe allows the research to have a broader view of the evolving legal, institutional and political dynamics in relation to the case studies, as well as to the consistency challenge.

\section{Case relevance}

The first case study relates to the 2002 Commission's proposal to adopt appropriate measures under article 96 of the Cotonou agreement against Zimbabwe and to the 2012 proposal to renew appropriate measures against Zimbabwe. To what extent is this case relevant to the research project?

The framework of the relations between the EU and ACP countries, the Cotonou agreement, articulates foreign policy, development objectives and trade concerns. The integration of these different dimensions illustrates the importance of consistency but also the challenge that it may represent. Indeed, in article 96 - the "sanction mechanism" of the Cotonou agreement - the tension between the different dimensions is most stark for several reasons. Article 96 can be activated when a partner is in breach of the rule of law, human rights or democratic principles. This sanction mechanism aims to re-balance the different dimensions of the Cotonou agreement: it is "not an instrument for foreign policy goals to the detriment of [other] objectives (...) but an instrument directed at consistency since its utmost aim is to harmonise [different] goals" (Laakso et al., 2007:36). The horizontal challenge to consistency (the risk of contradictions between the different dimensions) is doubled by an institutional challenge. Article 96 implicitly requires the involvement of different institutions - Commission and Council in 2002; Commission, EEAS and Council in 2012 - because of the nature of the competence. The literature has rather focused on the negotiation of the Cotonou agreement than on the implementation of article 96. However, a series of discussion papers by the European Centre for Development Policy Management (ECPDM) constitutes a useful source (Mackie \& Zinke, 2005), as well as an evaluation study by Laakso et al. on coordination and coherence of article 96 (Laakso et al., 2007). This research project aims to contribute to the study of article 96 specifically against Mugabe's regime in Zimbabwe.

Article 96 has been activated several times against ACP partners but Zimbabwe constitutes the most emblematic case. There has been "a before and an after Zimbabwe" in the use of article 96 measures (interview 17). Systematically mentioned by interviewees, Zimbabwe is the country against which appropriate measures were in place the longest, between 2002 and 2012. ACP countries have criticised the inconsistency of EU action under this article.

Article 96 measures likewise constitute a relevant case study as regards the institutional focus of this research on the Commission. Until 2011 and the setting up of the European External Action Service, the Commission was in the lead on article 96. In 2012, the Lisbon Treaty had led to an adaptation of decision-making. The proposal, still adopted as a Commission proposal, was prepared by the EEAS in 
association with DG Devco. The specificities of the new decision-making process and of the position of the EEAS vis-à-vis the Commission are introduced as a comparative element. Consequently, the case of appropriate measures against Zimbabwe will actually be subdivided into two sub-cases, namely the 2002 Commission's proposal to adopt appropriate measures under article 96 of the Cotonou agreement against Zimbabwe and the 2012 proposal to renew the appropriate measures. This reflects the very different institutional set-ups prevailing at the time the decisions were taken. The two proposals also reflect two different logics behind appropriate measures. If in 2002 the focus was primarily put on human rights violations, the 2012 proposal illustrates the EU's reengagement strategy in Zimbabwe, which had started in 2009 (Giumelli, 2013:31).

The second case study explores the Commission's proposal to revise the Generalised System of Preferences (GSP). Again, the question of the relevance of the case for this research arises. The GSP is the flagship of EU trade policy with developing countries and the revision adopted in 2012 aims at a more effective outcome in terms of development objectives. The system of preferences does not only illustrate the articulation between trade and development, but also between these two areas and foreign policy. Foreign policy objectives come in through the general withdrawal mechanism (in the event of violations of human rights, labour conventions or fisheries agreement) and the GSP+ arrangement in which political conditionality is central. The GSP has also been used as an instrument of foreign policy when for instance in the event of the flooding in Pakistan in 2010 the debate on the granting of trade preferences to the country was heavily political. The granting of preferences was not only to provide a form of economic assistance to the country - as illustrated by the fact that measures granting the preferences were actually implemented 18 months after the flooding and not immediately after. The EU used the granting of trade preferences to signal its strategic interest in a closer collaboration with Pakistan. Overall, the GSP is another illustration of the articulation between trade, development and foreign policy. The consistency of the system is a question raised in several provisions of the scheme and a central objective of the revision.

\section{Structure of the case studies}

The above-mentioned case studies aim at answering the following questions: to what extent are EU external policies consistent and how can we explain this? How and at which levels is the consistency requirement expressed? To what extent is the policy output consistent? Under which circumstances is coordination successful? The case studies chapters (chapters 6 and 7) will be organised as follows. After having set the scene, each chapter will first turn to the policy framework, which further specifies the general provisions of the Treaty framework (discussed in chapter 4). This level of analysis consists of the guidelines and policy principles that constrain the substantial choices made by the Commission in the drafting of 
particular proposals (sections 6.3 and 7.3). As a second step, the case studies chapters turn to the decision-making process - on the basis of the general decisionmaking process introduced in chapter 5 - and elaborate on how the consistency requirement is actually implemented in the drafting of concrete proposals (sections 6.4 and 7.4). The case studies chapters then turn to the assessment of the consistency of the Commission's proposals (sections 6.5 and 7.5). Lastly, they discuss the conditions under which coordination is successful and the policy output consistent (sections 6.6 and 7.6).

\subsubsection{Process-tracing and qualitative interviews}

This research explains the consistency of specific Commission proposals by looking at the decision-making process and the success of coordination in the drafting of the proposals. In the absence of earlier work on the case studies selected, it will do so i.a. by adopting a process tracing approach, conducting qualitative interviews and direct observation through an internship. The research explores the drafting of Commission proposals to better explain the outcome of the drafting phase.

Process tracing as a method "attempts to identify the intervening causal process - the causal chain and causal mechanism - between an independent variable (or variables) and the outcome of the dependent variable" i.e. steps by which causes affect outcomes (George \& Bennett, 2005:206). This research explores the finer details of decision-making within the Commission: describing and characterising key steps in the drafting process permits a substantial analysis of the policy output (Collier, 2011: 824). Evidence needed for this research cannot be found in textbooks: only process tracing allows the researcher to develop a very detailed knowledge of decision-making of a particular policy proposal "to cover all steps of a causal process" (Dür, 2008: 563). The following paragraphs elaborate on the collection of specific empirical evidence and on the triangulation of this evidence with documentary analysis and direct observation. Process tracing contributes to several research objectives, including: "(a) identifying novel political and social phenomena and systematically describing them; (b) evaluating prior explanatory hypotheses, discovering new hypotheses, and assessing these new causal claims; (c) gaining insight into causal mechanisms (...)" (Collier, 2011: 824). The study of crosscutting policy initiatives aims at identifying key actors, analysing institutional procedures and mechanisms throughout the drafting of proposals in the field of external policies and discussing the factors that contribute to or hinder their consistency. Careful description is fundamental in identifying causal inference (Collier, 2011: 824).

Qualitative semi-structured expert interviews were an important element of the research strategy. Although the institutional focus of the research is on the Commission, interviews were not only conducted with Commission officials, but also with officials of the European External Action Service, the Council and the Permanent Representations of Member States. Interviewees were selected on the 
basis of their position, because they were/are either working on consistency and coordination - as revealed by the title of their position and the name of their units, or as indicated by other interviewees - or because of their expertise in either case study. Identifying relevant contacts over the period from 2001 onwards has proven particularly challenging. Recommendations made by some interviewees themselves and the annual editions of the EU institutions registry have helped to some extent. However, a few officials who had worked on topics of interest for this research project had left the Commission. Others were not working on these dossiers anymore and either refused to be interviewed or had only a partial memory of the institutional dynamics. Often, they referred back to other contacts and to specific (internal) documents.

Overall, 58 interviews have been conducted. An effort was made to meet the officials working on the different dimensions of each case study. Most interviews took about one hour, with the shortest lasting half an hour and the longest one taking two hours. In a limited number of cases, interviews were followed up by an exchange of emails on specific, technical details. In addition, three interviews were conducted by phone (interviews 14, 33 and 44) and ten were conducted by email (due to the impossibility to schedule a meeting; exploratory interviews 2 and 3 , and interviews $12,15,16,18,22,23,24$ and 29). In one case the interviewee agreed to answer questions $\mathrm{s} /$ he would select in an email because the topic was too sensitive (interview 24). All interviewees were guaranteed anonymity in order to allow them to speak openly. In the majority of cases, interviewees agreed to be recorded provided that only the researcher would use the transcript of the interview. For reasons of political sensitivity, one interviewee asked not to be recorded when answering one particular question and a few interviewees added additional remarks at a later stage off the record. Whenever agreed upon, the transcript was sent to the interviewee. The persons in question took this opportunity to add factual and interpretative elements that were missing in their answers, but also sometimes to delete elements of their answers that were too sensitive.

Interviews aimed at discussing first the consistency and coordination challenges, and secondly decision-making in general and in particular cases. The research strategy was to let the interviewees describe their experience in the first person narrative with as little intervention as possible. Two sets of questions were prepared for the interviews. The first set focused on the consistency of EU external action and the coordination challenge within the Commission in general while the second one was case-study-specific. Both were to some extent adapted on the spot depending on the direction interviewees took to answer questions. Question lists were sent in advance to interviewees upon request (less than 10 cases). They systematically included the following questions:

- How would you define consistency?

- Do you consider that consistency is a challenge for the EU/the EU's external policies? Why (not)?

- Is consistency a concern in your daily job? Why (not)? 
- A priori, would you say that the EU's external policies are consistent or inconsistent?

The first question on interviewees' definition of consistency addressed the difficulty raised above on the interchangeable use of the words consistency and coherence. It ensured a common understanding of the key concept throughout the interviews and a focus on consistency as defined in this research. The second type of questionnaire - case-study-specific - focused on decision-making and coordination instruments. In the first part of the interviews, interviewees were generally keen on providing background information on the importance of consistency, of the challenge it constituted in their work and on assessing EU attempts to tackle this challenge. They were encouraged to develop their insights from their backgrounds and areas of expertise. In the second part of the interviews, the different factors and dimensions of the decision-making process were discussed in as much detail as the interviewees could recollect. The general way of asking questions made it easier for interviewees to discuss practical examples of difficulties, mistakes and weaknesses. More technical questions helped tracing the specifics of decision-making and the drafting phase of a particular proposal.

Overall, interviews are key to collect extremely detailed empirical evidence. They are instrumental in exploring the institutional dynamics and to learn about the reality of decision-making, confronting the description of these instruments with their actual use. The method however also has its weaknesses (Fielding, 2003:6-8, 10, 26-28). Respondents may only be partially truthful or have forgotten the details of an episode. Coordination efforts are a difficult topic to explore as they are often informal and confidential. Besides, interviewees did not necessarily realise that some elements of decision-making they were involved in were actually of relevance for this study. Depending on their responsibilities, their position or their personal analysis of a situation/policy decision, interviewees may emphasise certain elements and present a biased version of the cases. The use of interviews also introduces an inter-personal, subjective, element in the research process. The interviewees' own evaluation of policy-making and the subsequent interpretation by the researcher make replication hardly possible. Validity is a common concern in case study research (Yin, 1989:41). Nevertheless, interviews are a valuable source of information, also because they may compensate for insufficient access to (internal) documents. They often remain the only way to get an insight into policymaking. To address the weaknesses of this approach, the research never relied on the data collected during one interview only but the findings were triangulated. Numerous interviews were conducted describing and discussing the same instances of policy making.

Reconstructing the formal phase of coordination was a challenge as many officials who were involved in the drafting process of a specific proposal had changed positions or even left the Commission. Several interviewees also emphasised their only partial recollection of the process as in some cases ten years had passed since they had been working on the dossier in question. As a result, 
most interviewees only mentioned the different elements of ISC in general: circulation of the draft proposal, exchange of comments on that draft via CIS-net ${ }^{16}$ at both DG- and then cabinet-levels. To address this challenge, the results of interviews were cross-referenced by documentary analysis. The following sources were examined: EU primary and secondary legislation, Commission communications and staff working papers, organisational charts and budgets, as well as internal documents whenever available. ${ }^{17}$ Certain internal documents were made available by interviewees themselves. These proved particularly helpful as they provided an insider's view on the problem and on the attempts to address it. Interviews were also informed by existing studies on institutional procedures and mechanisms in the political system of the EU, studies on the consistency and coordination of EU external policies and academic literature on the case studies.

Lastly, the research is also based on direct observation. I interned at the European Commission for 5 months between March and July 2012. For ethical reasons, I did not work on a dossier directly related to my research or in the unit of the Secretariat General of the Commission responsible for the coordination of external policies (the F3 unit "Coordination of External Policies"). Instead, DG Trade offered me a position in the F3 unit "Tariff and Non-Tariff Negotiations and Rules of Origin". The mandate of this unit is very much horizontal as it systematically deals with technical barriers to trade and rules of origin in trade negotiations with partners of the EU and regional groupings. Besides the operational knowledge I gained of a specific trade domain, my internship in a sectoral DG gave me a unique experience not only as regards the technicalities of coordination but also as concerns the substance targeted by coordination efforts. In particular, I had the opportunity to observe different cases of inter-service consultation (ISC) - both purely within the Commission and between the Commission and the EEAS - and thus to familiarize myself with the requirements and the specific instruments of ISC. Lastly, this internship also confirmed the risk inconsistency constitutes for the EU's action and, consequently, the relevance of the consistency concern for the Commission as a whole, as well as the relevance of the focus on coordination adopted by this research.

\footnotetext{
${ }^{16} \mathrm{CIS}$-net is the electronic platform that serves to circulate Commission proposals to all actors within the Commission.

${ }^{17}$ For instance, in the case study on Zimbabwe, the collection of evidence was a difficult process. Indeed, formal coordination on a proposal prepared in a crisis situation is actually not very much formalised, it does not use the same instruments as in the regular decision-making process. In particular, coordination meetings in this type of situation take a more flexible format than in the case of a proposal requiring a durable coordination effort (see section 5.2.2). Besides, the reference of the inter-service consultation on the 2002 Commission's proposal to adopt appropriate measures is not in CIS-net anymore. To palliate this weakness, the case study was consequently based on interviews, which were triangulated with data on other steps of article 96 procedure (opening and conclusion of the consultations, see Commission 2001a \& 2001c; Council 2002b, 2002d, 2002e, 2002f, 2002g, 2002h, 2001a, 2001b \& 2001c).
} 


\subsection{Conclusion}

This chapter has discussed the definition of consistency, a concept characterised by its multiple dimensions and interpretations. The focus of the research on horizontal consistency within the Commission was specified (section 3.1). Section 3.2 defined the conceptual framework of the research and raised the question of how to best study consistency. It identified the different levels at which consistency is sought: the Treaty framework, the policy framework and the Commission's decisionmaking process in external policies. In turn, these levels structure the following chapters. The last section set out the methodology applied in this research project. A case study approach was chosen and the selection of the cases - the appropriate measures under article 96 of the Cotonou agreement against Zimbabwe and the 2011 proposal to revise the Generalised System of Preferences - was explained. The first case is subdivided into two, the 2002 proposal to adopt article 96 measures and the 2012 proposal to renew such measures. Lastly, this section has justified the added value of process-tracing and qualitative interviewing for the project. The next chapter deals with the first level at which the consistency requirement is expressed, the Treaty framework, and the impact it has on the consistency of external policies. 


\section{CHAPTER 4.}

\section{REQUIRING CONSISTENCY: THE TREATY FRAMEWORK}

This chapter discusses the Treaty framework and its provisions with regard to the consistency of EU external policies. As set out in chapter 2, external policies - both substantially and in the way the Commission deals with them - constitute a very specific policy area. This policy area has very much evolved over time and a consistency challenge has thus emerged. Treaty changes have accompanied these evolutions in general, one of the prime objectives being to address the consistency challenge. The Treaty framework constitutes the first of the three levels identified in the previous chapter - Treaty framework, policy framework and Commission internal decision-making in external policies - that aims to ensuring the consistency of the policy output. The Treaty framework is the first and most general level at which consistency is sought. It applies to EU external action as a whole. This is why this level is dealt with in a separate chapter (as opposed to being dealt with under the case studies chapters). Historically, the Treaty framework is also the first level developed by the EU to tackle the consistency challenge. In turn, decision-making puts in practice the consistency requirement within institutions as discussed in chapter 5 (but also between institutions), whereas the policy framework specifies this same requirement for particular policy areas (as discussed in the case study chapters 6 and 7).

Implicitly, the EU's Treaties refer to the risk of inconsistency and of contradictions that may exist at several levels. The different dimensions of the consistency challenge - vertical, horizontal, inter- and intra-institutional (see section 3.1) - can all be found back in the Treaties. For instance, article 24.3 TEU calls for vertical consistency between EU and Member States' actions when it requires Member States to “support the Union's external and security policy actively and unreservedly in a spirit of loyalty and mutual solidarity and [to] comply with the Union's action in this area". Article 21.3 TEU for instance evokes the risk of contradiction that exists between the different areas of EU external action and hence calls for horizontal consistency. Also, the logic behind the creation of the double-hatted position of HRVP is the recognition of the risk of inter-and intra-institutional inconsistency. The HRVP is tasked with coordination between institutions - in that case between the Council and the Commission - and within a particular institution - as witnessed by its coordination mandate for external policies within the Commission (article 18.4 TEU). Overall, the objective of ensuring the consistency of external policies thus occupies a central position in the Treaty.

While the Lisbon Treaty further strengthens the commitment to the consistency of EU external action, consistency is evidently not a new concern in this 
policy area. Since the creation of the European Political Cooperation (EPC) in 1970, the consistency issue has progressively taken centre stage. Politicians and scholars have discussed the possible remedies to the de facto division of external policies the division between political cooperation on one side and Community external policies on the other side - and to the risk of contradictions between different external policies. As a "constitutional principle" (De Baere 2008), consistency aims at managing the interface between different external policies (Nuttall, 2005:95). The refrain of consistency may be identified in all Treaties since 1987. In purely quantitative terms, the number of references to consistency has clearly increased over time. Qualitatively, consistency-related provisions have also been further specified, in an effort to bring the different external policies closer together and to put into effect the general consistency requirement. The measures to achieve consistency have thus shifted from political arrangements to Treaty-based institutional arrangements and task allocations. However, Treaty provisions do not specify how to implement the requirement and leaves it to individual institutions, such as the Commission, to make the necessary arrangements and define their rules of decision-making to put consistency into practice - an issue on which chapter 5 will focus.

Adopting a historical approach, this chapter provides an overview of the development of the Treaty-based consistency requirements. It highlights the steps taken to enhance consistency and the increasing importance of the concept. From the first reference to consistency in the Paris Summit Communiqué of 1974 to the renewed framework for consistency in the Lisbon Treaty, the chapter identifies three periods - from 1974 to the Maastricht Treaty, from the Maastricht Treaty to Lisbon, and the post-Lisbon Treaty era - to discuss consistency-related provisions in the Treaties. After the emergence of the consistency concern in the Treaties, the Maastricht Treaty (1993) constitutes the first turning point as it establishes a single institutional framework for EU external policies. The third period starts with the Lisbon Treaty (Dec. 2009), in which the consistency of EU external action is strengthened, not least with the introduction of a number of institutional innovations, specifying and aiming at implementing the consistency requirement.

\subsection{The Paris Communiqué and the Single European Act}

Ensuring consistency in external action has progressively emerged as a priority of the EU. This section analyses when and how the consistency challenge was first recognised and studies the initial attempts to implement it. As the external dimension of the European project gained prominence, the need to include a clear obligation of the European institutions to safeguard the consistency of external policies was quickly understood as a sine qua none for the EU to deploy an effective external action. The risk of contradictions existed not only between political and economic external relations, but also between trade and development cooperation. 
However, the recognition of consistency in the mid-1970s reflects an interpretation of consistency specific to the EU: the consistency challenge was understood as resulting from the dichotomy between economic and political external relations rather than the banal meaning of contradictions between different policies.

\subsubsection{A first step, the Paris Summit Communiqué}

The final Communiqué of the meetings of heads of Government of the Community in Paris (1974) is the first document that explicitly recognised the consistency challenge:

\footnotetext{
Recognising the need for an overall approach to the internal problems involved in achieving European unity and the external problems facing Europe, the Heads of Government consider it essential to ensure progress and overall consistency in the activities of the Communities and in the work of political cooperation [emphasis added] (Paris Communiqué, 1974).
}

It acknowledged both the problem - the risk of inconsistency or the assumed inconsistency - and its source - the division between external activities of the Community and political cooperation. Because the EPC was running in parallel to the Community external policies and driven by Member States, the focus was on the horizontal dimension of consistency - across policies - as well as on its vertical dimension - between the EU and Member States. In addition, as EPC fell outside of the Community framework, the focus was initially on the political arrangements rather than on institutional mechanisms to ensure consistency at the European level. Remedies to inconsistency were not enshrined in the Treaty but were the result of a pragmatic approach by the institutions themselves to manage the coexistence of both sets of external policies (Duke, 2011a:24).

Although very general, the provision of the Paris Summit Communique recognised the potential problem, the source of the problem and the need to address it. It paved the way for the introduction of a commitment to consistency in the Treaty.

\subsubsection{A commitment to consistency, the Single European Act}

The Single European Act (SEA) provides for the first reference to consistency in a Treaty, making it a priority for EU external policies. Prior to the SEA, consistencyrelated considerations remained very much at the level of general political objectives. Consistency meant "the obvious - ensuring that the EPC and the Community did not cancel or contradict each other's actions - but it also implied that there should be a distinction between EPC and the activities of the Community so that they did not contaminate one another" (Duke, 1999:7). With the introduction of consistency in the Treaty, the commitment took a more binding form. 
The SEA formally recognises the increasing interaction between the EPC and the Community and brings together these two competing systems (Nuttall, 2000:21). It proclaims Europe's intention to act with consistency in its Preamble:

Aware of the responsibility incumbent upon Europe to aim at speaking ever increasingly with one voice and to act with consistency and solidarity in order more effectively to protect its common interests and independence (emphasis added).

It introduced, for the first time, a commitment to consistency across both types of external policies in article 30.5:

The external policies of the European Community and the policies agreed in European Political Cooperation must be consistent (emphasis added).

At the same time, "[while] being 'single' in the literal sense of the word [because it dealt with both EC and EPC in the same legal instrument] the SEA codified the dualism between Community and EPC by separating both within two distinct titles" (Schmalz, 1998:423). ${ }^{18}$ Thus, the dualism of external action as the structural cause of potential inconsistency in the EU was enshrined in the structure of the Treaty. In addition, although article 30.5 referred to the horizontal dimension of consistency (consistency between external policies), it is interesting to note that in the same article the focus was still very much on the vertical dimension of consistency, consistency amongst Member States ("the High Contracting Parties") and between Member States and the Community.

Besides a general recognition of the need for consistency, the SEA also conferred the responsibility for ensuring the observance of the commitment to consistency on the Council Presidency and the Commission. As stipulated in Article 30.5:

The Presidency and the Commission, each within its own sphere of competence, shall have special responsibility for ensuring that such consistency is sought and maintained.

Those actors had been chosen for their respective roles in EPC and EC external policies. The Council Presidency had been preferred over the Council because, other than the High Contracting Parties, the Council did not have a role per se in the EPC. The aim was to create a clearer operational responsibility (Nuttall, 2000:182). Regarding EC external policies, the Commission was co-responsible for consistency not only because of its expertise and central role in trade policy and development cooperation, but also because it was "fully associated with the proceedings of

${ }^{18}$ Sanctions for instance illustrate how Community instruments may be used to pursue EPC policies and at the same time the potential for frictions between the 2 types of external policies. Nuttall shows for instance how, in the case of sanctions against the Soviet Union in February 1982, the absence of consensus in EPC made national measures impossible while action was taken under the Community framework (Nuttall, 1992:262). 
Political Co-operation" (article 30.3). This stipulation already required the Commission to work towards consistency between EC external policies and EPC. ${ }^{19}$ The Commission's responsibility for consistency has remained in the Treaties since then.

Finally, Article 30 of the SEA defined coordination as the most obvious means to ensure consistency:

2.(a) The High Contracting Parties (...) ensure that their combined influence is exercised as effectively as possible through coordination (...). [emphasis added]

In sum, following up on the recognition of the need for consistency in the Paris Summit Communiqué, consistency was first introduced as a legal requirement in the SEA and has remained in the Treaties since then. These first references to consistency reflect the risk of contradictions that results from the parallel existence of two types of external policies - EC external policies and EPC - that are each characterised by a specific set of actors with varying powers and by a particular type of decision-making. The most remarkable progress from the Paris summit to the SEA is the introduction of a formal responsibility to act in a consistent manner, the clarification of responsibilities, and the identification of coordination as a prime measure to achieve consistency. However the consistency requirement introduced by the SEA mostly relates to vertical consistency between the activities of the member states and those of the EC.

\subsection{From the Maastricht Treaty to the European Convention}

With the Maastricht Treaty, consistency took centre-stage. The centrality of consistency in the TEU from Maastricht onwards results from the enhancing of EU foreign policy with the creation of the CFSP. Before 1992, the EPC was not more than an empty shell while the CFSP substantially enhanced EU foreign policy. Consequently, the risk for contradictions with other external policies became stronger than before. Besides, the strengthening of consistency-related provisions a requirement for the EU "to attain its objectives" (article $\mathrm{C}$ ) - responds to the call for an enhanced global role for the EU and the effectiveness of its external action (Smith, 2001:171). With the creation of the pillar structure, including all external policies under a single institutional framework, "the nature of consistency shifted subtly (...) with less emphasis upon consistency amongst the Member States and greater emphasis being paid to consistency in the external policies of the Community" (Duke, 1999:5).

\footnotetext{
${ }^{19}$ The same logic was also behind the full association of the Commission with the CFSP in the Maastricht Treaty.
} 


\subsubsection{The Treaty on the European Union}

The Maastricht Treaty or Treaty on the European Union (TEU) reformed the general architecture of EU external action. In an attempt to tone down the "duopolistic procedure" characterising EU external policies, it introduced a single institutional framework for the EC and the Common Foreign and Security Policy (CFSP). The latter replaced the EPC and constituted the so-called second pillar of the new Treaty (Krenzler \& Schneider, 1997:137; Stetter, 1997:722; Best, 1994:2021). Marking a "giant leap forward in the call for consistency" (Quinn, 2012: 49), the TEU reaffirmed the consistency requirement, introduced new instruments to achieve this objective and specified the mandate to ensure consistency.

The TEU requires EU external activities to be consistent. Two dimensions were referred to in the Treaty. First, the Union was aiming at horizontal consistency:

The Union shall in particular ensure the consistency of its external activities as a whole in the context of its external relations, security, economic and development policies (article 3 TEU).

This new wording in the Treaty departed from the traditional dualistic presentation of the EU's external policies. Instead of referring to the "external policies of the EC" on one side and to the "policies adopted by the EPC" on the other side (article 30.5 SEA), article 3 TEU focused on the unity of the Union's external action: for the first time, the Union was committed to ensure the consistency of "its external activities as a whole". The distinction between the two types of external policies was not made explicit in the Treaty article anymore, though it was still apparent at the end of the article, which listed the security, economic and development aspects of external activities. The inherent potential for conflict would be strengthened with the introduction of the defence dimension by the Amsterdam Treaty (Duke, 2011a:26). Consistency-related provisions in the TEU did not only mean that there should not be any contradictions between policies. It also meant that all policies should be treated equally, not any one at the expense of another, thereby playing down the distinction between political (CFSP) and economic (EC) external relations. Article 47 TEU provided Community external policies with a shield against any encroachment from the second pillar (Dashwood, 2008:70):

(...) nothing in this Treaty shall affect the Treaties establishing the European Communities or the subsequent Treaties and Acts modifying or supplementing them.

Based on this understanding of consistency - limited to preventing CFSP from encroaching upon EC competences - the European Court of Justice had a restricted mandate to actually ensure compliance with the consistency principle but affirmed the protection of Community competences against any encroachment from Union competences in the much-commented ECOWAS case (case C-91/05; see De Baere, 
2008:189). ${ }^{20}$ Second, the Union was also aiming at vertical consistency, i.e. consistency between EU action and Member States action. To that aim, article 11.2 TEU recalled the loyalty principle for the EU and its Member States to cooperate sincerely towards the implementation of EU law.

To ensure consistency, the Maastricht Treaty provided for the following. First, the TEU introduced a single institutional framework for EU action:

The Union shall be served by a single institutional framework which shall ensure the consistency and the continuity of the activities carried out in order to attain its objectives while respecting and building upon the acquis communautaire (emphasis added, article $\mathrm{C}$ TEU, later article 3 of the Nice Treaty).

The single framework brought together the two sets of external policies: trade and development as well as foreign policy. However, the impact of the innovation on consistency was disputable: although "single" on paper, the framework was only an umbrella for different sets of policies, the so-called pillars (Best, 1994:19; Laursen, Vanhoonacker \& Wester, 1992:16). As a matter of fact, the TEU institutionalised the compartmentalization of external policies. EC external policies constituted the first pillar and the CFSP the second one, each characterised by different objectives and different decision-making processes (Nuttall, 2000:183). CFSP, replacing EPC, was incorporated into the second pillar of the EU and as such became part of the single institutional framework (Duke, 2002:488).

Second, the TEU introduced new legal instruments within the CFSP pillar to coordinate the Union's external action addressing the vertical consistency concern in particular (see for instance Allen \& Smith, 2002:99). The Maastricht Treaty created joint actions and common positions (articles 14 \& 15 TEU), which the Amsterdam Treaty complemented with common strategies (article 13 TEU). By defining a policy towards a country, a region or an issue, and coordinating EU and Member States' efforts to achieve a particular objective, these instruments were

\footnotetext{
20 In this case, the ECJ ruled out putative encroachment on Community competences. The case opposed the Commission to the Council on the instruments that it was possible to adopt in the fight against small arms and light weapons (SALW) (see for instance Dashwood, 2008:98-99; De Baere, 2008:179-180). Arguing that the Cotonou agreements covered action in that area of SALW, the Commission had concluded a regional indicative programme (a traditional programming instrument under Cotonou) for West Africa giving support to conflict prevention and good governance and announcing particular support in the field of SALW. For the Council, the fight against SALW was not a Community objective as per articles 2 and 3 TEC but clearly an EU objective as per article 11 TEU i.e. preserving peace and strengthening international security; it had adopted a CFSP measure to give financial assistance to the ECOWAS in the field of SALW. The Commission challenged the Council's decision on the basis that it was infringing article 47 as it affected Community competences. The Court, considered that, even if a measure simultaneously pursued a number of objectives or had several components, without one being incidental to the other, this measure could not be adopted on the basis of the TEU when it was also falling under a competence conferred by the TEC, thus protecting Community competences against an encroachment from Union competences.
} 
expected to ensure vertical consistency. The latter instrument also aimed at improving horizontal consistency in the EU's approach to a country or a region. ${ }^{21}$

Thirdly, the TEU also specified the responsibility to ensure consistency. It introduced a distinction, depending on "whether it [was] a question of consistency between the policies of the Union and the Community or the Union and the Member States" (Krenzler and Schneider, 1997:136):

\begin{abstract}
The Union shall in particular ensure the consistency of its external activities as a whole (...). The Council and the Commission shall be responsible for ensuring such consistency. (Article 3 TEU)

The Member States shall support the Union's external and security policy actively and unreservedly in a spirit of loyalty and mutual solidarity. The Member States shall work together to enhance and develop their mutual political solidarity [addendum from the Amsterdam Treaty]. They shall refrain from any action which is contrary to the interests of the Union or likely to impair its effectiveness as a cohesive force in international relations. The Council shall ensure that these principles are complied with. (Article $11 \mathrm{TEU}$ )

The Council shall take the decisions necessary for defining and implementing the common foreign and security policy on the basis of the general guidelines adopted by the European Council. It shall ensure the unity, consistency and effectiveness of action by the Union. (Article 13 TEU)
\end{abstract}

These provisions call for several remarks. First, the Council and the Commission were to ensure the consistency of external activities as a whole (horizontal consistency) but the Council only was responsible to ensure consistency in the field of CFSP generally speaking and in "external and security policy" between the Union and the Member States (vertical consistency, respectively in articles 13 and 11). Second, the Council's responsibility was a change from the SEA, which had entrusted the responsibility to ensure consistency to the Presidency. This change, according to Simon Nuttall, transformed "an obligation of ensuring compliance into one of merely observing it" (2000:182). At the same time, given the principle of the six-monthly rotation of the presidency, the conferral of responsibility to a collective and permanent body introduced more stability for ensuring consistency. Both the Council and the Commission have remained responsible for ensuring the consistency of the Union's external action, each in accordance with its respective powers in external policies, until now (Timmermans, 1996:67). In addition, from the Amsterdam Treaty onwards, article 3 TEU specified that they should "cooperate to this end" but without giving the operational details of this cooperation (Wessel, 2000:1151).

Overall, the introduction of a legal commitment to consistency did not actually guarantee consistency. It was still difficult to know "how to make institutions [act consistently], how to pull the strands of policy together into a whole; and finally how to resist attempts from within the EU or externally to promote division" (Duke,

\footnotetext{
${ }^{21}$ Common strategies did not prove a very successful instrument. Only three such strategies have been adopted (on the Mediterranean region, on Ukraine and on Russia).
} 
2011a:21). The TEU focused very much on horizontal consistency and tried new institutional answers to the consistency issue. Throughout the $1990 \mathrm{~s}$ and the revisions of the TEU at Amsterdam and Nice (Laursen (ed.) 2006; Laursen (ed.) 2002), the rationale was to enhance the consistency of the Union's external action to make it "play a role in the world commensurate with its responsibilities and its potential" (Duke, 2002: 483; Conference of the Representatives of the Governments of the Member States, 1996: part A). External policies were over time strengthened and new external policies such as security cooperation were added, running in parallel to one another, thereby enhancing the consistency challenge. Despite the attempt to address this challenge by the Treaties, "the effect was fragmentation rather than [consistency] and fear of contamination rather than interaction" (Schmalz, 1998:427).

\subsubsection{The European Convention}

The decision to convene a Convention on the Future of Europe was partly motivated by hopes that progress would be made in the long-lasting quest for consistency. A careful reading of Convention documents - in particular from the two working groups of the Convention on external action (group VII) and on defence (group VIII) - reveals the centrality of the issue and the political efforts to tackle it.

The Laeken declaration (2001) opened the reform process by affirming the centrality of consistency. It raised the consistency issue twice, first in the context of the organisation of Union competences and its relation to that of the Member States (sub-section on "A better division and definition of competence in the European Union"), and second in the context of institutional and decision-making efficiency sub-section on "More democracy, transparency and efficiency in the EU" (Cremona, 2011:56). The first annex to the Laeken declaration on the future of the European Union, under the section dealing with "Challenges and reforms in a renewed Union", specifically asked "How a more coherent common foreign policy and defence policy [should] be developed" (European Council, 2001: 22-23). The same annex also asked: "How should the coherence of European foreign policy be enhanced? How is synergy between the High Representative and the competent Commissioner to be reinforced?" The wording was interesting here since it singled out the CFSP - a very specific external policy - while using the very generic term "foreign policy" when referring to external action largo sensu. It is also interesting to note the traditional opposition between the two sides of the EU's external policies in the issue of the division between the High Representative and the Commissioner for external relations and the underlying coordination issue between the different external relations portfolios within the Commission.

The sheer number of references to consistency in Convention documents illustrates the many different dimensions of the consistency issue. Consistency may be a vertical problem between the EU and its Member States when the two sides 
are not conveying the same message: "Could the Union speak, in a wider range of international organisations with one voice, or with a common message, or with better coordination?" (European Convention, 2002f). It may also be an institutional challenge, either between institutions (typically between the Council and the Commission) or even within institutions (for instance within the Commission between its different directorates-general). The European Convention was for instance calling for "ways of improving internal coordination [within the Council, the Commission and the European Parliament] of policies and actions that [were] relevant for the EU's international relations" (ibidem). Horizontal consistency, across external policies, is also challenging. Here the European Convention asked "how to ensure the (consistency) of the Union's action and coordinate all instruments at its disposal (including development aid, humanitarian action, financial assistance, trade policy)" (European Convention, 2002c, 2002d \& 2002f). Lastly, the external dimension of consistency refers to the way the EU's external action is perceived by outsiders. This explains why the European Convention was called on to clarify the Union's external representation for instance (European Convention, 2002c). The answer to inconsistency needed to address all the dimensions of the problem.

Besides the necessity to reaffirm the consistency commitment, the Convention opened up new ways to put into effect the commitment. The Working Group VII on "External Action" of the Convention focused on new institutional arrangements to enhance the consistency and made the following recommendations:

- To abolish the pillar structure in EU external action;

- To group in a single section of the Treaty the articles which would cover the different aspects of EU external action, while keeping different arrangements for different external policies;

- To define a single set of principles and objectives of EU external action (the WG actually drafted such a set of principles and objectives);

- To strengthen the hierarchy of actors and norms and to create a specific External Action Council thereby strengthening strategic guidance of external policies (the European Council should define EU strategic objectives and interests, while the External Action Council would be responsible for the implementation of these strategic objectives and interests);

- To enhance consistency between institutions, for instance by merging the roles of the High Representative for CFSP and the Commissioner responsible for external relations and by making the High Representative one of the VicePresident of the Commission;

- To enhance consistency within each institution, for instance by creating a specific External Action Service, chaired by the High Representative and by establishing a focal point within the Commission, possibly the VicePresident, to coordinate all external issues; 
- To enhance consistency at the level of services for instance thanks to the establishment of the European External Action Service (European Convention, 2002a).

This section will not discuss any further the proposals of the Convention as its product, the Constitutional Treaty, was not ratified. The Lisbon Treaty has however taken over the proposed provisions on consistency.

\subsection{Lisbon, the way forward}

The Lisbon Treaty, in setting a reformed and lasting institutional framework, improves our capacity to fulfil our responsibilities (...). It will bring increased consistency to our external action. (European Council 2007a)

The Lisbon Treaty has become, even before its entry into force, the "benchmark for measuring whether the hopes [with regard to consistency of the Union's external policies] that were raised in Laeken have been met" (Gaspers, 2008:20). Although it might still be too early to assess the effects that the new Treaty has on the consistency of external policies, the IGC was aiming with the Lisbon Treaty "to strengthen the Union's profile as a credible international actor ... [by overcoming] the inconsistencies associated with the intergovernmental-communautaire dualism of EU foreign policy", the existence of different external policies and their potentially divergent objectives and "the persistence of distinct and often rather divergent national foreign policy" (ibidem). After the failure of the Constitutional Treaty, the 2007 IGC restated the call for enhanced consistency of external action and the Lisbon Treaty strengthens the consistency framework (Laursen (ed.) 2012).

First, the new Treaty reaffirms the commitment to consistency. After Lisbon, the European Union is based on two Treaties, the Treaty on the European Union and the Treaty on the Functioning of the European Union (TFEU). Overall consistency between policies and actions or activities as a general objective is proclaimed twice in the Lisbon Treaty, once in article 13 TEU and once in article 7 TFEU:

The Union shall have an institutional framework which (...) ensure[s] the consistency, effectiveness and continuity of its policies and actions. (article 13 TEU)

The Union shall ensure consistency between its policies and activities, taking all of its objectives into account (...). (article 7 TFEU)

In addition, article 21.3 TEU specifically provides for (horizontal) consistency of EU external action, "between the different areas of external action and between 
external action and other policies". ${ }^{22}$ Lastly, the principle of vertical consistency is also recalled in article 24.3 TEU.23

Second, the new Treaty proclaims the unity of external action. It formally abolishes the old pillar structure ${ }^{24}$, which in theory makes the "pillar reading" of the consistency challenge disappear. Yet, the Union still rests on two Treaties, the TEU and the Treaty on the Functioning of the European Union. The former EC external policies are to be found in the TFEU, while CFSP is still the object of a specific chapter and of specific provisions in the TEU (Cremona, 2003:1353). Besides, the abolition of the pillar structure has not implied a complete harmonization of procedures (see for instance Koehler, 2010:61; De Baere, 2008:209). Furthering the unity of external action and aiming at its consistency, the Treaty creates a single Title (Title V) on the "General provisions on the Union's external action and specific provisions on the CFSP". Integration is also realised by the choice of the singular word "action" instead of the plural "activities" or "policies" in the wording of Title V, of chapter 1 of Title $V$ and article 21 TEU for instance.

Third, the unity of external action is reinforced by the introduction, for the first time in the Treaties, of a single set of principles and objectives (article 21 TEU) that any external policy shall comply with (Chapter 1 of Title $V$ and article 205 TFEU). These principles come in addition to the general objectives of the Union proclaimed in article 3 TEU.

1. The Union's action on the international scene shall be guided by the principles which have inspired its own creation, development and enlargement, and which it seeks to advance in the wider world: democracy, the rule of law, the universality and indivisibility of human rights and fundamental freedoms, respect for human dignity, the principles of equality and solidarity, and respect for the principles of the United Nations Charter and international law. (...)

2. The Union shall define and pursue common policies and actions, and shall work for a high degree of cooperation in all fields of international relations, in order to:

(a) safeguard its values, fundamental interests, security, independence and integrity;

(b) consolidate and support democracy, the rule of law, human rights and the principles of international law;

(c) preserve peace, prevent conflicts and strengthen international security, in accordance with the purposes and principles of the United Nations Charter, with the principles of the Helsinki Final Act and with the aims of the Charter of Paris, including those relating to external borders;

(d) foster the sustainable economic, social and environmental development of developing countries, with the primary aim of eradicating poverty;

(e) encourage the integration of all countries into the world economy, including through the progressive abolition of restrictions on international trade;

\footnotetext{
22 The principle of horizontal consistency could already be found in article 3 of the Nice Treaty but the wording of the Lisbon Treaty is slightly different.

${ }^{23}$ The implicit reference to vertical consistency could already be found in article 11.2 of the Nice Treaty but the wording of the Lisbon Treaty is slightly different.

${ }^{24}$ Article 13 TEU does not refer to a single institutional framework but to 'an institutional framework'.
} 
(f) help develop international measures to preserve and improve the quality of the environment and the sustainable management of global natural resources, in order to ensure sustainable development;

(g) assist populations, countries and regions confronting natural or man-made disasters; and

(h) promote an international system based on stronger multilateral cooperation and good global governance. (article $21 \mathrm{TEU})^{25}$

The principles do not constitute a novelty in substance but their presentation does (Gaspers, 2008:37). The existence of a single set is in line with the de-pillarization and further materialises the fact that all policies belong to the same legal order (De Baere, 2008:205). In an effort to ensure consistency, Treaty provisions on specific external policies include a standard clause recalling that any external policy "shall be conducted within the framework of the principles and objectives of the external action of the Union". The TFEU builds on the single set of objectives and principles. First, Article 7 TFEU successfully "incorporate[s] a set of horizontal objectives into all Union policies (external policies included) and operating alongside the more general Union objectives of Article 3 TEU" (Cremona, 2008:30). Second, TFEU provisions specific to certain external policies such as the Common Commercial Policy (article 206 and 207.1) and development cooperation (article 208.1) recall the general objectives of external policies contained in the TEU. However, Cremona notes the broad wording of the general principles and objectives that may result in inconsistency at a specific policy level (Cremona, 2011:77). The criticism is not specific to this single set of principles and objectives, as the wording of principles and objectives is usually highly political. Nevertheless, the single set of principles and objectives under Title $\mathrm{V}$ constitutes "one of the potentially most influential innovations in terms of increasing the horizontal and institutional consistency" of EU external relations (Gaspers, 2008:36) as it confers unity to the EU's external action and illustrates the integration of policies realised by the Lisbon Treaty (Cremona, 2003:1349; Cremona, 2004:566-568; Jordan \& Schout, 2006:ix). ${ }^{26}$ These objectives and principles "will bind European institutions and Member States - at least within the framework of the Union - when formulating and implementing intergovernmental and communautaire aspects of EU foreign policy" (Gaspers, 2008:36).

Fourth, in addition to the Council and the Commission, also the double-hatted High Representative of the Union for Foreign Affairs and Security Policy (HRVP) and the EEAS now have responsibilities in this respect:

The Council and the Commission, assisted by the High Representative of the Union for Foreign Affairs and Security Policy, shall ensure consistency [between the different areas of the Union's external action and between these and its other policies] and shall cooperate to

\footnotetext{
25 This set of objectives mirrors the one recommended by the European Convention (European Convention, 2002a).

${ }^{26}$ Dashwood discusses the adverse effects of the absence - until the Lisbon Treaty - of identity of objectives between the two pillars (2008:83).
} 
that effect. (article $21.3 \mathrm{TEU}$ )

[The High Representative] shall ensure the consistency of the Union's external action. (article 18.4 TEU)

The Council and the High Representative of the Union for Foreign Affairs and Security Policy shall ensure the unity, consistency and effectiveness of [CFSP] by the Union. (article 26 TEU)

The HRVP position and the EEAS will be discussed in more detail in the following chapter as they are two of the key actors with respect to the consistency of EU external action. The basic responsibility for the consistency of external action still rests with the Council and the Commission - the Commission is however not fully associated with CFSP anymore ${ }^{27}$ - which are supported in this task by the HRVP (article 21.3 TEU). As a bridging position between the Commission and the Council, the HRVP constitutes a key element in the quest for consistency: (s)he has an explicit responsibility for the consistency of the Union's external action (article 18.4 TEU) and (s)he is him-/herself assisted by the EEAS. As previously, the responsibility for consistency in the field of CFSP is specific: it lies with the Council and the HRVP (article 26 TEU). The reference to the General Affairs Council and to the newly created Foreign Affairs Council (FAC) specifies the role of the Council in ensuring consistency (article 16.6 TEU):

The General Affairs Council shall ensure consistency in the work of the different Council configurations... [The Foreign Affairs Council shall] ensure that the Union's action is consistent. (article 16.6 TEU)

The General Affairs Council exercises a special coordinating role in general. In its foreign affairs formation, the Council deals with the whole of the EU's external action (notably CFSP, development and trade). ${ }^{28}$ Compared to the General Affairs Council, the refocused mandate of the FAC makes it a new instrument to work at the integration of external policy objectives. The responsibility of the FAC is strengthened by the fact that it is chaired by the HRVP - but not when commercial policy is on the agenda (see section 5.2.3).

Fifth, in addition to the absence of contradictions, consistency also means protecting TFEU-type competences against CFSP and vice versa (Van Ooik, 2008:407):

The implementation of the common foreign and security policy shall not affect the application of the procedures and the extent of the powers of the institutions laid down by the Treaties for the exercise of the Union competences referred to in articles 3 to 6 of the TFEU.

Similarly, the implementation of the policies listed in those Articles shall not affect the

\footnotetext{
27 This change in the Treaty provisions should not, however, lead the observer to overestimate the Commission's contribution to CFSP in the pre-Lisbon era.

${ }^{28}$ Before the Lisbon Treaty, external relations were dealt with by the GAERC (General Affairs and External Relations Council). Separating the two responsibilities of the GAERC, the Lisbon Treaty replaced this formation with two new Council formations, GAC (General Affairs Council) and FAC (Foreign Affairs Council).
} 
application of the procedures and the extent of the powers of the institutions laid down by the Treaties for the exercise of the Union competences under this chapter. (article 40 TEU)

Rewording ex-article 47 and going further than the ECJ jurisprudence, Lisbon introduces a "mutual non-affectation clause" (Elsuwege, 2010:1002). Consistency has long referred to the need to protect the Commission's competence in external relations and to organise its collaboration with other actors. The Lisbon Treaty now extends the protection given by the consistency requirement to CFSP against any encroachment from a TFEU policy. To prevent any case of "constitutional erosion" (Timmermans, 1996:62), Member States felt that it was necessary to equally protect former EC policies and CFSP (Van Ooik, 2008:407; Timmermans, 1996:66). Pursuant to article 40 TEU (ex-article 47), the implementation of the CFSP shall respect Union powers laid down in the TFEU, and - conversely - the implementation of TFEU policies shall respect CFSP powers. The "default Community preference" has come to an end" (Duke, 2011a:17).

Lastly, the importance of the Treaty framework depends on the existence of a guardian of the Treaty that has jurisdiction over the consistency requirement. As opposed to the pre-Lisbon situation, the European Court of Justice now has jurisdiction over the consistency principle (Court of Justice, 2009:2; Hillion, 2008:31). However, enforcing this requirement might be complex. It might actually even be challenged by article 40 TEU, which extends the Court's jurisdiction for "policing the borderline between CFSP and other Union policies" (De Baere, 2008:189). Following the same logic as the far-reaching ECOWAS case law, in the first prominent cross-Treaty legal basis dispute, the Advocate General Bot argues that an EU action that "pursues one or more of the objectives referred to in article 21(2)(a) to (c) TEU, in particular the objective of preserving peace and strengthening international security, must be regarded as falling within the sphere of the CFSP" (C-130/10, point 64). This reintroduces within the apparently unified external action the distinction between CFSP and the other external policies (Eckes, 2013:15). Such a reading of the new Treaty provisions might go against the spirit of Lisbon and its efforts to enhance the consistency of EU external action. ${ }^{29}$

\subsection{Conclusion}

In conclusion, consistency has been a concern throughout the history of the Treaties. As from the late 1980 s onwards, Treaty provisions reflect a constant efforts towards establishing an enhanced framework for the consistency of EU external action. Because it considered that it had not satisfactorily addressed the consistency challenge, the EU engaged in a reform process in 2001. From the

\footnotetext{
${ }^{29}$ For a discussion on the non-contamination clause of article 40 TEU and the ECJ's interpretation on the boundaries between CFSP and non-CFSP fields, see Blockmans \& Spernbauer, 2013.
} 
Laeken declaration and the Treaty establishing a Constitution for Europe to the 2007 Inter-Governmental Conference mandate and the Lisbon Treaty, this reform process brought consistency further to the fore. The Lisbon Treaty strengthens once again the consistency requirement and introduces significant - policy, legal and institutional - changes to put into effect the requirement. While these changes were initially received positively (European Council, 2001: annex I), it remains to be seen whether they will actually enhance consistency or create new challenges to consistency.

Consistency has been described as "a legal procedural obligation to be followed by political action" (Portela \& Raube, 2009:4) and by institutional innovation. The Treaty framework is important to achieve consistency as it provides the legal framework for external policies. As such, it binds institutions in their decisionmaking and has an impact on the substance of any decisions, as is illustrated in the case studies. However, the Treaty framework is not enough to ensure consistency: it needs to be backed up by bold political willingness and practical arrangements to ensure that any external policy contributes to the consistency of the EU's external action (Missiroli, 2001:44).

On paper, the Treaty constitutes a forceful response and aims high (Gaspers, 2008:46; interviews 4, 46 and 49 i.a.). In practice, l'essai doit être transformé: the legal requirements shall be specified and principles shall be actually implemented (Cremona quoted by Portela \& Raube, 2008:14-16). The Treaty framework does not specify in details how to ensure consistency. The policy background has grown increasingly dense and institutional dynamics have been made more complex not least with the creation of the EEAS by the Lisbon Treaty (chapter 2). The consistency mandate of the Commission has become more important but also more difficult in practice. For consistency not to remain at a declaratory level, exploring how the Commission fulfils its mandate is one of the objectives of this research. It is a necessary step to assess how the Commission concretely ensures consistency, building on a pre- and post-Lisbon comparison, and to assess the actual consistency of Commission proposals. This is the point to which the next chapter now turns: it discusses how the Commission puts the consistency requirement in practice in the field of external policies. 


\section{CHAPTER 5.}

\section{IMPLEMENTING THE CONSISTENCY REQUIREMENT: COMMISSION INTERNAL DECISION-MAKING}

What happens is not chosen as a solution to a problem but rather results from compromise, coalition, competition and confusion among government officials who see different faces of an issue. (Allison, 1971:708)

This chapter introduces the Commission's internal decision-making process. Chapter 4 has discussed the Treaty framework that seeks to achieve consistency at the most general level. ${ }^{30}$ But this requirement is not a sufficient condition to actually ensure the consistency of EU external policies. In this respect, the fragmented way in which the Commission is organised - in particular as regards its external policy activities in the field of trade, development and the CFSP - poses a specific challenge (see chapter 2 ). In order to achieve consistency, the respective Treaty provisions need to be put into effect through coordination during the decision-making process at various levels. Therefore, this chapter focuses on the Commission's internal decision-making process and explores how the institution seeks to achieve consistency in its decisions. ${ }^{31}$ Instead of focusing on the implementation phase as much of the literature, this research takes a step back and opens up the black box of policy-making. It explores how a Commission proposal in the field of external policies is prepared and adopted. This chapter aims at identifying and assessing the tools at the disposal of the Commission to coordinate potentially conflicting positions and to produce a consistent policy output. To do so, it relies on qualitative interviews and on the analysis of internal documents such as rules of procedure. The actual use of these tools will then be discussed in the case studies (sections 6.4 and 7.4).

This chapter is structured as follows: the first section elaborates on the links between the concern for consistency, the collegiality principle and coordination. The second section discusses in detail the Commission's internal rules of procedure and the role played by the different actors within the Commission in the drafting of any proposal. In particular, as a result of the entry into force of the Lisbon Treaty,

\footnotetext{
30 The second level of analysis, the policy framework, specifies the consistency requirement in particular policy areas. Because it is by definition policy-specific, it will be dealt with in the case studies themselves.

31 This chapter is a revised and extended version of a book chapter that was published under the title "Coordination of External Policies: Organisational and Procedural Frameworks of Consistency within the European Commission"; in Boening, A. B., Kremer, J.-F. and A. van Loon (eds., 2013), The EU: A Global Power in the Making? Europe's Present and Future Role in a Changing World (Berlin Heidelberg: SpringerVerlag), vol.I, pp.37-54.
} 
this section elaborates on the adaptation of the Commission's inter-service consultation mechanism to include the EEAS. The process takes place under the supervision of the Secretariat General of the Commission (SG), which ensures that the coordination requirement is implemented (third sub-section). The fourth and fifth sub-sections discuss the two major innovations introduced by the Lisbon Treaty, the double-hatted position of High Representative-Vice President and the European External Action Service. Their working relationships with and within the Commission are relevant elements to consider in the field of external policies given their mandates. However, it appears that these new actors have not provided ready-made solutions in their first years of existence. Including new actors in the decision-making process has disrupted existing coordination routines, raising a new coordination challenge, and consequently has required the adaptation of coordination procedures.

\subsection{Consistency, collegiality and coordination, a question of principle}

Collegiality and coordination are organising themes of the Commission's work. The centrality of these principles seems to stand in contrast with the frequent portrayal of the Commission as a collection of feudal fiefdoms (Davignon, 1995). Despite the fragmentation that characterises the Commission, proposals are adopted by the institution as a whole and thus in theory result from an agreement among all actors. Internal decision-making ensures that the policy output is acceptable to any actor within the Commission. However, collegiality and coordination are necessary but not sufficient conditions to ensure that coordination is actually successful and policy outputs consistent.

Enshrined in the Treaty and in the Commission's working methods (art. 17.6(b) TEU; art. 1 Commission, 2010i; Commission, n.d. a), collegiality underlies every effort of services and cabinets to produce a decision that reflects the agreement of all actors (Commission, 2004a:2; Cini, 1996:154; Noël, 1962:9). Commission proposals are collegiate decisions: they are adopted by the Commission as a whole, not by individual services. Securing the agreement of all actors is not only a formal requirement- i.e. the decision is not only rubber-stamped by the College - but a substantial sine qua non for decision-making. The Commission President emphasises the "importance of working together to develop policies in a collegiate, cross-cutting way", to which coordination precisely refers (emphasis added; President of the Commission, 2010d:2). Yet, "the structure of the Commission - it is modelled on a hierarchical French-style bureaucracy - and the different cultures of the DGs have complicated horizontal relations" (Jordan \& Schout, 2006:99). Where different objectives or different approaches to the same issue may conflict, horizontal relations need to be encouraged by specific instruments (Nuttall, 2005:97). 
In turn, coordination within the European Commission is the practical corollary of the collegiality principle:

The quality and consistency of the Commission's and its departments' work depend on effective coordination at the earliest possible stage, not only between all the departments concerned but also with anyone outside the Commission who is affected. (emphasis added; Commission, n.d. a)

As defined in section 3.1.3, coordination is "the attempt to optimize the (...) consistency of political decisions (...) across policies (...), across actors and stakeholders and across levels" (Wollmann, 2003:47). Prima facie, coordination might be met with resistance on the part of services (interview 9). Nevertheless, documents on internal procedures emphasise the importance of coordination and its contribution towards consistency:

Maintaining focus, (consistency) and a sense of clear priorities within an enlarged Commission requires effective co-ordination and better preparation of what the Commission does. (...) Attention will be directed towards (...):

(a) promoting a culture of cooperation where coordination is a matter for everyone, starts early and is focused increasingly on substance rather than form; (...)

(c) ensuring a high level of (consistency) and quality for the documents. (emphasis added;

Commission, 2004a:8)

Individual services likewise underline the centrality of coordination between sectors and the necessity to develop crosscutting approaches to certain issues (see for instance Commission, DG Trade, n.d. a:28). Collegiality and coordination are thus organising themes of the Commission and of its internal decision-making that aim at ensuring the consistency of its policy output. Post-Lisbon, these principles go beyond the Commission's boundaries. Indeed, in external policies, the Commission's decision-making process now includes the EEAS, a service created outside of the Commission that yet participates in the drafting of Commission proposals (see section 5.2.4). Collegiality and coordination are therefore not limited to the Commission but present an inter-institutional dimension as well. The next section turns to the specifics of Commission internal decision-making.

\subsection{A decentralised system}

Decision-making ensures that coordination happens systematically during the drafting of any proposal to avoid one-sided decisions in a fragmented institutional environment (Spence, 2006b:150). Coordination is a guiding principle at the strategic level - throughout the Strategic Planning and Programming exercise of the Commission - and in the regular decision-making process. Even if a few changes occurred in the internal decision-making process following the entry into force of 
the Lisbon Treaty, Commission decision-making remains largely unchanged. The coordination responsibility is decentralised as it is "everyone's job" (interview 14) to ensure that coordination happens throughout the preparation of any proposal.

\subsubsection{Planning for consistency}

Strategic Planning and Programming (SPP) is the first step towards coordination and a requirement to address internal fragmentation (Commission, 2004a:3-5; Kassim, 2006:85). ${ }^{32}$ It emphasises the importance of consistency and coordination for the credibility of the institution and the quality of its output (Commission, 2010c:8-9; Commission, 2005c:11-13). SPP aims at defining a work programme by setting out clear political priorities, building on the contributions from the different services and ensuring that they do not contradict each other. ${ }^{33}$

SPP is "organised around an annual policy cycle, with an early identification of priorities, the aim of which is to strengthen the SG's coordinating role, enabling it to intervene at an earlier stage, encouraging DGs to cooperate even before proposals have been drafted, convening meetings of officials and cabinet members, and arbitrating in inter-departmental disputes" (Kassim, 2006:83). The Commission's Work Programme and Political Programming team of the SG coordinates this substantial exercise. The SG filters the services' contributions on the basis of the respective portfolios, timing or policy package. This role ensures that crosscutting issues are addressed in a coordinated and timely manner and that all the relevant actors are brought together from the outset (Commission, 2010a:4-5; interview 5). The SPP exercise is supported by an administrative network, the network of SPP correspondents, present in each DG (interview 12). Given its participation in policymaking, the EEAS has been included in the SPP network and also has an SPP correspondent (interview 12).

Under the Prodi Commission and the first Barroso Commission, five-year strategic objectives were identified by the Commission upon entering into office: they constituted the overarching political message that the College wanted to convey and the objectives against which its actions would be assessed (President of the Commission, 2000; Commission, 2005c). The yearly orientation debate of the College defined priorities and objectives of the Commission for each following year (Commission, 2004a:4). Services were informed by the Secretary-General of the

\footnotetext{
32 The emphasis is not here on strategies adopted in certain policy areas or for certain regions such as the EU counter-terrorism strategy, EU 2020 or EU strategy for Africa for instance. It is on the efforts to strategically plan the Commission's work in the short- and long-term in the wide range of its attributions.

${ }^{33}$ Naturally, a sudden crisis cannot be included in the management plan; still, when it is needed, the Commission (and the EU) responds to unexpected situations. Generally speaking, the response fits into the general framework of the EU's action because it pursues the same objectives and principles of action as planned activities. Yet, the consistency of the response depends on the crisis, its causes, its effects and the level of public attention (interviews 4, 5 and 9).
} 
conclusions and made proposals to translate orientations into specific operations, on the basis of which the annual policy strategy was adopted. This document was discussed by the Commission, the European Parliament and the Council. The Commission's work programme for the following year was then prepared to translate policy strategy into a concrete action plan and a set of deliverables (Commission, 2004a:3-4). The work programme was the result of several months of prioritisation and negotiations between DGs, combining bottom-up - with indicative lists of proposals drafted by each DG - and top-down procedures - with choices made by senior management and Commissioners (Commission, 2004a:4-5; Jordan \& Schout, 2006:52-53). In turn, annual management plans, adopted by each DG, described how DGs planned their activities and contributed to the priorities set by the Commission.

For the first time in September 2010, SPP followed a new course (Commission, 2004a:7; interview 12). The preparation of the Commission's Work Programme now starts with contributions from DGs and the EEAS ${ }^{34}$, which are centralised and analysed by the 'Commission's Work Programme and political programming team' of the SG (interview 12). The SG filters the contributions. The next step consists of bilateral meetings between the President's cabinet and the SG on the one side and cabinets and DGs on the other side. They discuss the inclusion of initiatives in the Commission's Work Programme, the formation of packages, and possible cooperation between DGs. In parallel, the President delivers the State of the Union speech in September each year. The Commission's Work Programme is then finalised following meetings at DG and head of cabinet level and eventually adopted by the College. The President's political guidelines - endorsed by the College in several seminars - and the multiannual strand of the Commission's Work Programme have replaced the 5-year strategic objectives (interview 12).

\subsubsection{Service-level coordination, testing the ground for a proposal}

Coordination is also a guiding principle of the regular decision-making process. Commission rules of procedures are replete with references to coordination, which takes different forms, including: checks and balances, information-sharing and consultation requirements. ${ }^{35}$ Inter-service consultation (ISC) constitutes the central mechanism by which any proposal is drafted (see i.a. Kassim, 2006:75-102; Spence, 2006a:25-74 \& 2006b:128-155).

\footnotetext{
${ }^{34}$ The EEAS contributes to the work programme initiatives prior to their being presented for adoption by the Commission or jointly by the Commission and the HRVP (Commission, Secretariat General, 2011:7).

${ }^{35}$ For instance, see section III of Commission 2004a on "Coordinating and preparing the work of the Commission":8-12; see also Annex 2 "Principles governing working relations between the members of the Commission, their cabinets and the services of the Commission" and Article 23 "Cooperation and coordination between departments" in Commission, 2010i-b.
} 
Regarding particular proposals, horizontal coordination starts early in the policy-making and informally. Article 23.1 of the Commission's rules of procedure provides that:

In order to ensure the effectiveness of Commission action, departments shall work in close cooperation and in coordinated fashion from the outset in the preparation and implementation of Commission decisions.

The central actor is the lead DG or chef de file, which brainstorms about the proposal. As provided for in article 23 of the Commission's rules of procedure:

2. The department responsible for preparing an initiative shall ensure from the beginning of the preparatory work that there is effective coordination between all the departments with a legitimate interest in the initiative (...).

3. Before a document is submitted to the Commission, the department responsible shall, in accordance with the implementing rules, consult the departments with a legitimate interest in the draft text in sufficient time.

Despite the existence of checks and balances to avoid unilateral decisions, evidently, the lead DG enjoys strategic advantage in this first phase. ${ }^{36}$ Indeed, it decides on the initial extent of coordination to prepare a particular proposal (article 23.2 Commission 2010i). The lead $\mathrm{DG}^{37}$ in general and each policy officer for the proposal he/she is in charge in particular are responsible for coordination and thus also for consistency (interview 14). Since often a proposal has a crosscutting nature, the lead DG consults the other concerned DGs, according to certain predefined rules (see section 5.3). However, while they shape coordination, services may also challenge it as much is left to their discretion. As they decide on the extent of coordination (Spence, 2006b:129, 149-150), they could in theory choose not to include any other DG in the drafting. In practice however, this is hardly ever the case (interviews 5, 8 and 10).

In this still informal phase, the lead department informs other departments of the proposal, the planned approach and the likely stages. The first steps taken are informal until the draft proposal is circulated via CIS-net (see below). The extent of coordination depends on several factors. First, it depends on the political weight of the lead DG and its resources (Spence, 2006b:129, 149-150). The political

\footnotetext{
${ }^{36}$ In the preparation of a proposal, the German Mitzeichnungspflicht for instance - the obligation to get the signature of every service or official concerned by a specific issue at ministerial level - formally constrains the discretionary powers of the lead service (interview 46). Such a sanction mechanism does not exist at EU level.

37 The lead DG is the sectoral DG that is responsible for the initiation and drafting of a proposal, which falls under its portfolio. The decision on who is the lead DG might prove controversial and the SG may have to arbitrate. In particular cases and on the request of the President, the General Secretariat may take the lead itself. Under these circumstances, the Secretariat General has to rely on the input provided by services (since it does not itself have the required technical policy expertise). The correlative risks to the quality of the proposal are usually considered a disincentive (interview 7).
} 
sensitivity (or the potential for conflict) of the proposal is the second factor. Lastly, the extent of coordination also varies with the perceived existence of a "legitimate interest" to be consulted i.e. the extent to which the issue/policy is considered to be of a crosscutting nature. This defines the number of DGs concerned and the intensity and modalities of coordination (Miglioli, 2009:31; Nugent, 2001:243). The intensity of consultation also depends on whether the consulted DGs are interested in participating in the exchange and whether they are responsive. Overall, the lead DG enjoys strategic advantages in the process. It has the sectoral expertise, fixes the first position on the issue with the first draft and has full discretion on which other DGs to involve (Hartlapp, Metz \& Rauh, 2012:5 \& 2010:10). Defining who participates in the early stage of the policy-making has consequences on the definition of the problem, the definition of policy options and preference formation, thus pulling the decision in a particular direction (see for instance Miglioli, 2009:17-19, 29; Nugent, 2001:242-243). Nevertheless, practitioners emphasise that, usually, the lead DG does consult other DGs (interviews 5, 7, 8 and 10; for a contrasting view see Miglioli, 2009:31). It is indeed in the interest of the lead DG, as " $[\mathrm{t}]$ he department responsible shall endeavour to frame a proposal that has the agreement of the departments consulted". A proposal that integrates different points of view is more likely to be accepted than a proposal that does not (article 23.7 Commission, 2010j; interview 5). At this stage, drafting and coordination overlap, as the draft should ideally integrate the various objectives and approaches of different services (Spence, 2006b:147; interviews 8, 9 and 11). This enriches the drafting phase and facilitates agreements at later stages of decision-making. Political actors have identified priorities and defined strategies but they are generally not involved at this stage, except for the lead DG that supervises the drafting phase and except in the case of major or disputed proposals.

On proposals of particular political significance, exchanges between services are paralleled by an impact assessment. Impact assessments aim at "identify[ing] likely consequences of policy initiatives or legislative proposals in the economic, environmental and social fields and to ensure the production of better and more coherent policies" (Commission, 2004a: 14-15). In particular, impact assessment guidelines emphasise the attention given to development issues. Under economic impacts, impact assessment evaluates i.a. the impact on third countries and international relations (Commission, 2011k). For instance: "does [the initiative] affect EU foreign policy and EU/EC development policy? What are the impacts on third countries with which the EU has preferential trade arrangements? Does it affect developing countries at different stages of development in a different manner? Does the option impose adjustment costs on developing countries?" (Commission, 2009b:34). Impact assessments constrain the drafting for two reasons. First, the IA report - submitted at the end of the process - must meet a number of requirements, not only formal (the IA report has to follow a specific structure; Commission, 2009b:9) but also substantial. A body specifically set up for that purpose, the Impact Assessment board, controls the quality of the assessment 
(Commission 2011k). This board is composed of high-level officials from the Commission departments most directly linked with the three pillars of the impact assessment - economic, social and environmental impacts. The opinion of the IA board is integrated into the impact assessment by the lead DG. Second, each assessment is steered by an Impact Assessment Steering Group. Overall, an impact assessment steering group serves the same purpose as an inter-service group. It constitutes a forum in which well before the inter-service consultation, issues concerning the range of core policy areas impacted by the envisaged proposal can be raised and horizontal view on the topic can be developed (Commission, 2011k; Hartlapp, Metz \& Rauh, 2012:5; interview 42). It provides a platform for intense contacts between the different DGs concerned (interview 41), the "DGs whose policies are likely to be affected by or contribute to the objectives of (an) initiative, and the relevant policy coordination unit of the Secretariat General" (Commission, 2009b:8). This raises awareness on cross-policy effects of proposals and encourages to take these effects into consideration when drafting a proposal.

Once a proposal has reached a sufficiently advanced stage within the lead department, the case officer closes the informal administrative phase and produces the first formal draft of the proposal. If the proposal is a new policy initiative or a politically sensitive policy initiative, the case officer must seek and receive approval from the DG and the lead cabinet before launching the ISC (Commission, 2010j:17).

The second phase of administrative coordination is both formal and written (Miglioli, 2009:31). This is what is formally referred to as inter-service consultation (ISC). It gives the lead DG the opportunity to get the formal opinion in written form of all other services with a legitimate interest in the proposal. CIS-net, an electronic platform, serves to circulate the proposal to all the services. ${ }^{38}$ The platform has been modified to allow EEAS' contributions. Once the draft has been circulated, services have ten working days (fifteen working days when the text of the proposal is longer than twenty pages) to upload their comments on CIS-net. ${ }^{39}$ Meetings may in theory be organised during this phase to allow services to express their positions or to ask questions; bilateral meetings may happen as well to discuss a specific issue. Overall, bottom-up efforts towards a coordinated proposal are facilitated by the existence of an administrative network within the Commission. This network ensures that qualitative conditions are met for substantial coordination to take place. Each DG and the EEAS have an ISC correspondent, who has a special responsibility with regard to coordination. Correspondents receive the consultations sent by other DGs and allocate them to the relevant units of their DGs. They also ensure that their DGs submit the required documents on time and guarantee the formal quality of submissions and their conformity with the rules

\footnotetext{
${ }^{38}$ The use of this electronic instrument is obligatory for all Commission departments and for all consultations (with a few exceptions such as consultations regarding State aid; Commission no date a).

${ }^{39}$ For the specifics of the ISC procedure, see for instance Commission, 2010a:4 \& 9.
} 
(interview 5; Commission, n.d. a). The ISC-correspondents' network ensures a levelplaying field for policy coordination (interview 5; interview 32; see section 5.3.2).

Inter-service consultations have three possible outcomes. DGs may agree on the proposal, give a favourable opinion subject to comments being taken into account (the most common type of opinion) or issue a negative opinion (Commission, 2010a:9). This last option has the potential to cause problems depending on the procedure by which the proposal is to be adopted. If the proposal is to be adopted by oral procedure, a negative opinion is not an issue, as the proposal will be discussed at cabinet level. In theory, when a negative opinion is issued, the proposal is directly passed on to the College and discussed by Commissioners. In practice, the controversial proposal is discussed at cabinet-level first, with a view to resolving the issues raised at service-level. The Commissioner responsible for the DG that has issued the negative opinion has to defend the negative opinion at the College meeting. If the Commissioner is not available to attend it, the negative opinion falls (interview 43). It is a mechanism that makes Commissioners politically accountable for the opinions given by their DGs at the inter-service level (interview 43). In the event of a written procedure however, any negative opinion has to be cleared up before the ISC is closed. After it closes the ISC, the lead DG drafts the formal proposal to incorporate the comments and results of the ISC.40 The registry office of the Commission, or greffe, forwards the proposal to the cabinets once the proposal has been finalised and approved by the lead cabinet.

During any ISC, the consultation of certain horizontal services is obligatory. The Secretariat General and the Legal Service must be included in any ISC. Their role is outlined in the Commission communication on the functioning and internal coordination. They "screen proposals to ensure that the principles of subsidiarity, proportionality and good legislative practice, as well as linguistic requirements, are respected, as well as to ensure the formal quality and form of initiatives" (Commission, 2004a:11). The Legal Service ensures "conformity with the Treaties, coherence with existing legislation and with agreed procedures in other areas of Community business" (Spence, 2006:148). DG Admin, DG Budg, DG Comm, DG Estat and OLAF must be consulted on certain proposals as well (Commission, 2010a:6).

Overall, at service-level, coordination in the process just discussed above is also facilitated by the existence of specific instruments. Intra-DG instruments, as well as inter-service groups and inter-service meetings are an illustration.

First, coordination is facilitated by the creation of horizontal instruments within certain DGs. These instruments address a medium- to long-term need for coordination and consistency. Thus, DGs develop a cross-policy approach to certain issues. In turn, this spills over beyond the boundaries of these DGs with the

\footnotetext{
${ }^{40}$ It is after all the objective of the CIS to collect comments and opinions from the different DGs, ultimately to ensure that the proposal will be acceptable to everyone: "The department responsible shall endeavour to frame a proposal that has the agreement of the departments consulted." (article 23.7 Commission, 2010i-b).
} 
emergence within the Commission of networks of officials working, directly or indirectly, on related topics and sharing a certain methodology. DG Devco and DG Trade constitute interesting examples. DG Devco first has created a "Policy Coherence for Development (PDC) team" to offer expertise on development-related issues to the Commission as a whole. The team identifies policy proposals in the Commission's Work Programme - i.e. at the planning stage - that are likely to have consequences for development policy and flags them as particularly interesting for DG Devco (interview 21). In turn, Devco officials pay greater attention to the development of the relevant proposals. For instance, the Trade Technical Unit within Devco is responsible for following trade-related proposals, taking into account the recommendations of the PCD team and its own technical expertise on trade issues (interview 45). The identification of 12 priority sectors for development is a second illustration of the horizontal tools developed by DG Devco: in trade, environment and climate change, security, agriculture, bilateral fisheries agreements, social policies, migration, research/innovation, information technologies, and transport and energy. In addition, particular attention is paid to the consequence of any action on development (Commission, DG Development and Cooperation - EuropeAid, n.d. c). The PCD Work Programme outlines how the priority sectors contribute to development objectives by identifying targets and indicators (Commission, 2010d). Concretely, for each sector, DG Devco has identified at least one contact person who focuses on policy consistency and ensures that development concerns are taken into consideration. The network was realised institutionally in 2006 with the creation of an inter-service group on PCD within the Commission (Commission, 2011b:13).

DG Trade offers an additional illustration. It has set-up two units that are of interest with regard to coordination. First, the Coordination Unit within the DG focuses on administrative coordination and on inter-institutional relations (Commission, DG Trade, n.d. g; interview 13). This unit was created when David O'Sullivan was Director General for Trade (2005-2010). His sensitivity for horizontal coordination as one of the former Secretaries General of the Commission (between 2000 and 2005) led him to create this horizontal unit (interview 13). However, this unit is not responsible for substantial policy coordination: it is a support unit to policy coordination. A second example is the creation of the Strategy Unit (1 January 2012), which bridges a gap in the definition of trade policy within DG Trade itself. Its added value is to provide a horizontal and strategic input, the "bigger picture" on trade policy in the post-Lisbon era. It aims to enhance the consistency and coherence of bilateral and multilateral negotiations, between various trade policy instruments, between trade policy and other policies, and of foreign policy in general (interviews 34 and 35).

Inter-service groups (ISG) constitute a second type of instrument that is crucial in facilitating coordination, including in the first, informal, steps of decision-making (Hartlapp, Metz \& Rauh, 2012:5 \& 2010:10; Spence, 2006:148; Nugent, 2001:243). 
They address long-term coordination needs in a particular policy area. ${ }^{41} \mathrm{An}$ ISG is a "group or a network of Commission services, set up formally and characterised by its internal composition, the continuity of coordination and the definition of a clear remit which is unchanged throughout the life of the group" (Commission, n.d. a \& n.d. c). There are more than 250 ISGs, most of which present an external dimension: in that case, DGs with external portfolios are involved. For instance, under the leadership of DG Trade, the group on Economic Partnership Agreements is composed of the following DGs: Aidco, Devco, Taxud, Mare, Estat, Agriculture, Enterprise, Competition, EcFin, Environment, Budget, Legal service, Relex, Secretariat General, EAC, Employment, OLAF, Energy, Move (Commission, n.d. d). Since the entry into force of the Lisbon Treaty, the EEAS has replaced DG Relex in ISGs, either chairing some ISGs (e.g.: Group on non-proliferation and disarmament) or participating in other groups (e.g. the Group on UNCTAD XIII Conference) (ibidem; Commission, Secretariat General, 2011:13).

Interdepartmental meetings are a more flexible instrument than ISGs, which address a punctual coordination need in the drafting phase of a particular policy proposal. They constitute a tool at the disposal of the lead DG, which plans one or several such meetings whenever a specific difficulty arises or simply to discuss the drafting (Commission, n.d. a). The different DGs with an interest in the proposal under discussion may participate in such meetings. The EEAS, as any Commission DG, may participate in or chair the meetings when it is the lead service.

\subsubsection{Coordination at the political level, finalizing the proposal}

After coordination at the service-level, the proposal has to go through cabinet-level coordination procedures. Cabinets focus on the remaining substantial issues (Cini, 1996:154). The involvement of cabinets may also prove to be a double-edged instrument for a proposal as cabinets may raise new issues, from a more national point of view for instance (interview 41). The coordination steps at the political level depend on the type of procedure for the adoption of a particular Commission proposal. Typically, important political or sensitive questions will be decided on by oral procedure while initiatives of regular or routine nature will be adopted using a written procedure. The written procedure can only be used if the proposal is not controversial (as demonstrated by the ISC and informal consultation of the cabinets), with the agreement of the DGs concerned and after the lead DG has given its approval. Under both procedures, equal attention is paid to coordination (Commission, 2004a:7).

\footnotetext{
${ }^{41}$ In officials' words, ISGs cannot always be understood in the formal meaning of the expression (interview 4). Often, a reference to an ISG meeting means that an inter-service meeting (outside of any particular group, only gathering together officials concerned by a proposal) was convened. This research makes the distinction between both expressions.
} 
In the event of a written procedure (article 12 Commission, 2010j), the consultation between cabinets mirrors the ISC process at DG level: the proposal is circulated to all cabinets. If no objections are raised within five working days, the text is deemed adopted. If one or several cabinets object to it, they may call for a suspension of the procedure. It might be possible to solve the issue by a dialogue between the lead cabinet and the members of cabinets responsible for the proposal. If the disagreement persists, the text will not be adopted by written but rather by oral procedure.

In the event of an oral procedure, the proposal is discussed in three settings (section 1 Commission, 2010j). Coordination between Commissioners' cabinets takes place within a tight timeframe (Spence, 2006:67). The proposal goes first through the special chefs meetings to the hebdo (the meeting of heads of cabinet) before proceeding up to the College level. Special chefs meetings discuss substantive sectoral policy proposals (Spence, 2006:66). Chaired by a member of the President's cabinet, they are attended by members of all cabinets with responsibility within their cabinet for the issue under discussion (Spence, 2006:151). The positions of those DGs that have been consulted are circulated to all cabinets at least 48 hours in advance. This gives an overview of the remaining issues. Cabinets that have not been involved or informed by their DGs so far are made aware of the proposal (Spence, 2006:67). A cabinet may disavow the objections of its DG. The Monday chefs de cabinet meeting, also called hebdo, builds on the conclusions of the special chefs and follows the same agenda as the College meeting scheduled two days later. The hebdo is chaired by the SG of the Commission. Input from DGs remains important but other parameters are at play: the outcome of the special chefs meeting, and the influence of the President's chef de cabinet and of the SG on the agenda. When unanimous agreement is reached on a point, it is considered an 'A' point on the Commission agenda (to be adopted without discussion). If consensus cannot be reached on an item, it is transmitted as a 'B' point to the College. The hebdo may also send proposals back to the rapporteurs. If there are controversies, the SG may call in the contending parties and conciliate. However, although it has strong formal and informal powers, the SG cannot arbitrate - the final decision rests with the College. These are the last steps in the decision-making process to ensure that each item has been well prepared (Commission, 2004a:6). The College meetings take place on Wednesday. Ideally, most items are agreed on at lower levels so that the College only discusses the most controversial points (Commission, 2010j:3).

Similar to the services, political actors - Commissioners' cabinets on particular proposals and the President of the Commission for the Commission as a whole also have a coordination responsibility. They fulfil this role by giving the necessary political impetus at different stages of policy-making. Cabinets are key players in this respect. They aim at preserving collegiality "by acting as the Commissioners' eyes and ears in other parts of the organisation" (Coombes, 1970:256). Cabinets interact with each other on a permanent basis - as services do - with a view to 
solve any difference on a policy issue. Cabinets are also the interface between DGs and Commissioners (Christiansen, 1997:81). As such, they monitor coordination at DG-level and discuss with their DGs potential difficulties. Their involvement and the guidelines they may give to their DGs vary, depending on the approach defined by the respective Commissioner and on the importance of the proposal discussed. Cabinet specify the working arrangements with their DGs in general and may also issue specific political guidelines with regard to particular proposals (Commission, n.d. a). For instance, a cabinet may request that particular attention be given to coordination in the drafting of a politically important proposal in order for the proposal to be stronger (for instance interview 43). Overall, the role of cabinets in coordination - with their respective DGs, between DGs and between Commissioners - is generally emphasised (Spence, 2006a:68-71; Nugent, 2001:160-161; Christiansen, 1997:81; Cini, 1996:157).

Next to the cabinets and as provided for in articles 17.6 TEU and 248 TFEU, it is the responsibility of the President of the Commission to ensure collegiality within the Commission (article 17.6 TEU; article 248 TFEU; article 3.2 Commission, 2010j; Commission, 2004a:4). The Commission has to work under the political guidance of the President who is "the guardian of the collegiate interest". Institutionally, the President defines and allocates Commission portfolios according to this goal (art. 248 TFEU and Commission, 2004a:2]. Substantially, the President is supported in his tasks by his service, the Secretariat General (see sub-section 5.2.2) and groups of Commissioners (see sub-section 5.2.3). In addition, the Commission President may also use a specific instrument, Commissioners groups. "[Commissioners] groups work within particular families of Commissioners or in particular policy areas and their purpose is to ensure that the Commission's action is better prepared and coordinated" (Commission, n.d. a). There are currently eight Commissioners groups (Commission, n.d. a; President of the Commission, 2010c). Particularly interesting for our policy focus is the Group of Relex Commissioners. It counts the Commissioners for External Relations, Development, International cooperation, Humanitarian aid and crisis response, Enlargement, Trade, Economic and monetary affairs and the Foreign Policy Instruments service (President of the Commission, 2010c). ${ }^{42}$ The Relex group aims to

ensure the coherence of the Commission's external policies with the Union's external action and to bring the necessary external dimension to the internal policies of the Commission. (...) It should be used as a forum in which to coordinate positions, [...to] prepare debates in the College on strategic "aspects" of external relations and their implications for internal policies. (President of the Commission, 2010b; see also Commission, Secretariat General, 2011:14)

\footnotetext{
${ }^{42}$ Compared to its composition under Barroso I (it then included Development, Enlargement and Humanitarian aid and crisis response), the Relex group has been expanded under the Barroso II Commission (Erkelens \& Blockmans, 2012:7).
} 
When he appointed the new Commission in 2009, President Barroso specifically called on coordination in external policies. The mission letters to Commissioners Füle (enlargement), Piebalgs (development) and Georgieva (humanitarian aid) request them to "exercise their functions in close cooperation with the HRVP" (President of the Commission, 2009a). Besides, despite the fact that groups of Commissioners are normally an instrument of the Commission's President (Commission, n.d. a; President of the Commission, 2010c, Commission, 2004a:1011), President Barroso formally tasked the HRVP - building on her consistency and coordination mandate within the Commission - to chair the meetings - but he has retained the initiative to convene it and has actually chaired the group whenever it was meeting (European Parliament, 2013:52-53; Blockmans, 2011:11; President of the Commission, 2010c). Groups of Commissioners could constitute a powerful tool by preparing for discussion or decision-making by the College. For instance, the Relex group illustrates the strong policy linkages that exist between external policies and the potential for crosscutting approaches (Secretariat General, 2011:11). It could be a key instrument in setting horizontal policy or geographical priorities for instance (European Parliament, DG for external policies, 2013:52). However, these groups do not have any discretionary power and remain within the limits of the mandate defined by the President of the Commission (Erkelens \& Blockmans, 2012:7). In particular, interviewees insisted on not over-estimating the importance of the Relex group, which has met once or twice a year since 2010 and is "not good at follow-up" (European Parliament, DG for external policies, 2013:53; interviews 4, 5, 6, 7 and 46). Realising the full potential of the Relex group of Commissioners remains an often-cited recommendation to enhance the consistency of the Commission's action (CEPS High-Level Group, 2014 \& EEAS, 2013).

\subsubsection{Conclusion}

Within the Commission, the responsibility for coordination is decentralised. It is both the responsibility of the services or DGs, and of the political actors, Commissioners and their cabinets. Policy coordination efforts start very early when a proposal is envisaged. They rely on transparency within the Commission and the accessibility of information, in particular facilitated by the existence of IT-platforms such as the 'agenda planning' or CIS-net. The former gives information on any initiative foreseen, the lead DG and the officer in charge, how it is to be adopted, the timing of the proposal, the impact assessment prepared (interviews 5, 8 and 10) while the later gives information on inter-service consultations. These efforts do not necessarily solve all issues but they can highlight differences or particular difficulties to think about in the drafting process (Cini, 1996:152). It is as if the Commission is being shadowed by a mirror institution on any proposal (interview 28). For each dossier there is a lead officer and a lead cabinet, who are being shadowed by other officials in other DGs and other cabinets (interview 28). It reflects the existence of networks of officials in different DGs and cabinets working 
on related topics or on the same topic, thus substantially contributing to policymaking from across the range of policy areas, with the objective of developing consistent policy proposals. Internal efforts towards coordination and consistency within the Commission are all the more important since the Commission must cooperate with the Council to ensure the consistency of EU external action as explicitly specified in the Lisbon Treaty (article 21.3 TEU). Despite the significant discretion left to services and political actors on the extent of coordination, there exists one central service that supervises coordination within the Commission, the Secretariat General of the Commission, to which the next section turns.

\subsection{The Secretariat General of the Commission, the guardian angel of coordination}

Because it has the 'overall picture' of Commission action that DGs and cabinets lack, the Secretariat General of the Commission (SG) plays "a crucial coordinating role in a fragmented institutional environment" (Kassim, 2006:75). This sub-section does not intend to give an overview of the history of the Secretariat General and of the Secretaries General (see Bossuat, 2010; Kassim, 2006:75-102; Kassim, 2004b), but rather focuses on the functions performed by the SG with regard to consistency and the supervision of coordination within the Commission. ${ }^{43}$

"(G)uardian of the collegial nature of the Commission" (Coombes, 1970:249), the SG "offers a channel for two-way communication between Commissioners and the services, and oversees inter-departmental coordination" (Kassim, 2006:75; interview 5). The Secretariat supports the College in general and the Commission President in particular in ensuring substantial and procedural consistency (article 20.2 Commission, 2010j; Commission, 2004a:2; Nugent, 2001:146-153; Cini, 1996:151-154; Davignon, 1995). Article 20.2 of the rules of procedure of the Commission provides that

The Secretary-General shall help to ensure political consistency by organising the necessary coordination between departments at the start of the preparatory stage.

Coordination efforts by the SG can be observed at several levels. First, at the service level, the Secretariat General controls the quality of coordination between DGs to overcome the fragmented policy-making. It ensures that the conditions for substantial coordination are met: circulation of documents, respect of deadlines and power to suggest additional DGs to be included in the process. Second, at the political level, it has a rather limited role but ensures a level playing field for coordination. Its role depends on the procedure by which a decision is to be taken: it is more important if the proposal is to be adopted by oral procedure as the SG

43 The SG counts 464 staff, i.e. 2\% of the total Commission staff (Commission, 2013). 
chairs the chefs de cabinet meetings (for more details on oral procedures, see above section 5.2.3). The Secretariat may also have a direct policy responsibility when the President asks it to take the lead on a particular proposal. Third, the SG "act[s] as the interface between the political and the administrative levels of the Commission" (Committee of Independent Experts, 1999:127). It makes sure that during strategic planning and policy-making, information is available to services and cabinets, that consultations are properly conducted, and that procedures are respected. For instance, if the SG considers that the absence of a particular DG in an inter-service group meeting is prejudicial to the discussion of a proposal, it may either advise the lead DG to include the missing DG in the discussion or directly signal to a DG that it ought to be participating in the discussion (interviews 5 \& 8; Nugent, 2001:243). This power of suggestion of the SG also holds for inter-service meetings to ensure the effet utile of ex ante coordination, namely to make sure to realize the potential of coordination undertaken even before a draft proposal is circulated (Hartlapp, Metz \& Rauh, 2012:8). As it is informed of any proposal considered, the SG may also decide to attend preparatory meetings. The role of the SG thus seems to reflect a focus on service-level coordination (rather than on cabinet-level coordination). However, ultimately, service-level coordination is goal-oriented and aims at facilitating political coordination and the adoption of a collegial decision.

Among these various coordination tasks, the most important coordination function of the SG is upstream coordination at the level of the services. This function refers to "early steering and screening of internal processes to prevent conflicts appearing at later stages of decision making" (Hartlapp, Metz \& Rauh, 2010:13; interviews 5, 8 and 10). This function is implemented by the position of policy coordinators within the SG. They monitor what DGs are planning to do, what they are actually doing and the consistency of proposals across policies. They ensure that this control happens systematically, as a process (interviews 5, 8 and 41). From a procedural point of view, they check that the policy documents are in the right form with the right references. From a substantial point of view, the documents should make sense, be consistent with proposals on similar or related topics, with any instructions given by the President, and with what a coordinator knows about the respective topic. It is not necessary to "know everything", but rather "to know enough" to be able to put a proposal into context and to address an issue horizontally, to "use [one's] wider institutional perspective to act as an 'honest broker'” (Commission, 2004a:9; interviews 5 and 41).

The structure of the SG reflects the political importance attached to consistency and to coordination in general (interviews 5 and 10). The focus on coordination has been progressively introduced by Commission communications on crosscutting issues. The first coordination unit was created in 1978 with the aim of planning Commission action (Kassim, 2006:78). Between 2001 and 2012, one or more directorates of the SG dealt with coordination (Kassim, 2006:90 \& 2004b:64). In 2005 , programming and administrative coordination on one side, and policy coordination on the other side were allocated to two different directorates 
(Directorates C and D). Since then, policy coordination was organised around core themes in Directorate D (Commission, Secretariat General, n.d.). What is particularly interesting in the light of this research is the growing importance given to the coordination of external policies, and the concurrent changes in the structure of the SG (EEAS, 2011:para.13). Between 2005 and July 2010, coordinating external policies was the responsibility of one of the units dealing with policy coordination (unit D3). In July 2010, a new unit - unit F3 "External institutional relations"- was specifically created to take over this task. It was not a creation ex nihilo but the responsibilities for this new unit were taken away from unit D3 (interview 5). The new unit was not placed under Directorate D, although it was in charge of policy coordination, but under Directorate F "Relations with the European Council/Council, International Relations and G8/G20 coordination". Unit F3 coordinates DEVCO, enlargement, trade, ECHO, the FPI service and the EEAS. It counts seven policy officers (April 2012), two of whom contribute to and supervise the coordination of external policies (Commission, Secretariat General, n.d.; interviews $5 \& 41$ ). The creation of this new unit responded to the specificity of external policies and their transformation after Lisbon. First, the disappearance of DG Relex within the Commission created a void regarding the coordination of the Commission's position on external policies. ${ }^{44}$ Second, the enhanced status of external policies in a more complex institutional environment characterised by new actors, such as the double-hatted HRVP and the EEAS, created new coordination needs.

Several factors influenced the development of the Secretariat General into its present role. First, the responsibilities of the Secretariat expanded as the scope of Community competences grew. The Community became involved in new policy areas, most notably foreign affairs. This process created new and different coordination demands. For instance, a specific EPC (European Political Cooperation) Unit was created within the Secretariat. It assumed this responsibility, when the EPC was launched in the 1970s and continued in this role until the early 1990s when a specific foreign policy DG was created. Second, the Commission became a larger organisation, if only with respect to the growing number of Commissioners and portfolios. A more fragmented institution, at both service and political levels, requires enhanced coordination throughout the process of decision-making. Third, changing inter-institutional dynamics (for instance the increasing role of the European Parliament in the co-decision procedure) have also imposed new coordination requirements. Consequently, the coordination functions of the SG assumed greater importance (Kassim, 2004b:56).

Overall however, the Secretariat continues to face many challenges as a coordinator. The "silo mentality" of the DGs is a strong structural and cultural obstacle to its operation, further complicated by the changing institutional

\footnotetext{
${ }^{44}$ Before the Lisbon Treaty, the Commission had contracted to DG Relex its external representation and thus the coordination of Commission positions, notably in Council working groups.
} 
environment in which the Commission acts (Kassim, 2006:91; Kassim \& Menon, 2004:28). Former Secretary General Williamson (1987-1997) described the Commission as "a structure of mini-Ministries called DGs" whose desire for independence - all the more since officials stay while Commissioners change leads to recurrent coordination problems. ${ }^{45}$ Despite the strengthening of upstream coordination (with the creation of positions of policy coordinator) under the leadership of Catherine Day (Secretary General since 2005), the SG has limited resources (Hartlapp, Metz \& Rauh, 2012:8). Moreover, although the Secretary General is the most senior official in the Commission, (s)he does not have authority over the other DGs. The SG does supervise their work with the objective to ensure coordination, but not to the same extent as national coordination bodies do. In particular, the SG neither chairs inter-service meetings nor has formal arbitration powers (Spence, 2006b:129). The changing institutional environment of the Commission also further complicates internal coordination.

In conclusion, the Secretariat General has become a more complex organisation in a more complex institutional environment. It grew in size and changed its structure to reflect new coordination demands and its new responsibilities. The strengthening of the service dedicated to the coordination of external policies in particular illustrates the importance of this concern. Even if the influence of the SG should not be over-estimated as it does not have unlimited resources (human resources, time and political capital), it is in this changing context that the Secretariat's contribution to coordination and consistency has grown (Kassim, 2004b:52). The supervision by the SG is not only a control ex post of the quality of coordination but may also act as a factor constraining ex ante the decision taken by the lead DG.

\subsection{The consistency and coordination mandate of the HRVP}

The double-hatted position of High Representative/Vice President of the Commission is an innovation introduced by the Lisbon Treaty in the field of external policies. The Treaty provisions relating to the position refer both to consistency and coordination. Indeed, to put into effect the HRVP's responsibility for the consistency of EU external policies, the position has a central coordinating function within the Commission (EEAS, 2011:paras 9, 13-15).

When the Amsterdam Treaty (1999) created the position of High Representative, Javier Solana as the first HR was not responsible for the consistency of EU external action in general. He had no mandate within the Commission and had to collaborate with the Commissioner for external relations and the other Relex portfolios of the Commission. The Lisbon Treaty merged the

\footnotetext{
${ }^{45}$ Williamson draws the comparison between the structure of the Commission, the DGs, and the national ministries; Spence, 2006b:129-135.
} 
positions of HR and of Commissioner for external relations: Catherine Ashton, the first HRVP, is both the High Representative for foreign affairs and security policy and the Vice-President of the Commission in charge of external relations. Together with the Council and the Commission, the HRVP is co-responsible for the consistency of EU external action (article 21.3 TEU). In that respect, (s)he is supported by the newly created EEAS (see next sub-section). ${ }^{46}$ In addition, beyond the Commission, the consistency responsibility is also materialised in the fact that the HRVP was made the permanent chairperson of a new Council formation, the Foreign Affairs Council (FAC). The creation of a specialised formation of the Council that deals with CFSP, trade and development policies aims at bridging the policy divide. The TEU stipulates that the FAC "shall elaborate the Union's external action on the basis of strategic guidelines laid down by the European Council and ensure that the Union's action is consistent" (art. 18.3 and 16.6 TEU). However, the HRVP does not chair the FAC meetings when commercial policy is discussed (see figure 5.1). This actually reintroduces a distinction between external policies.

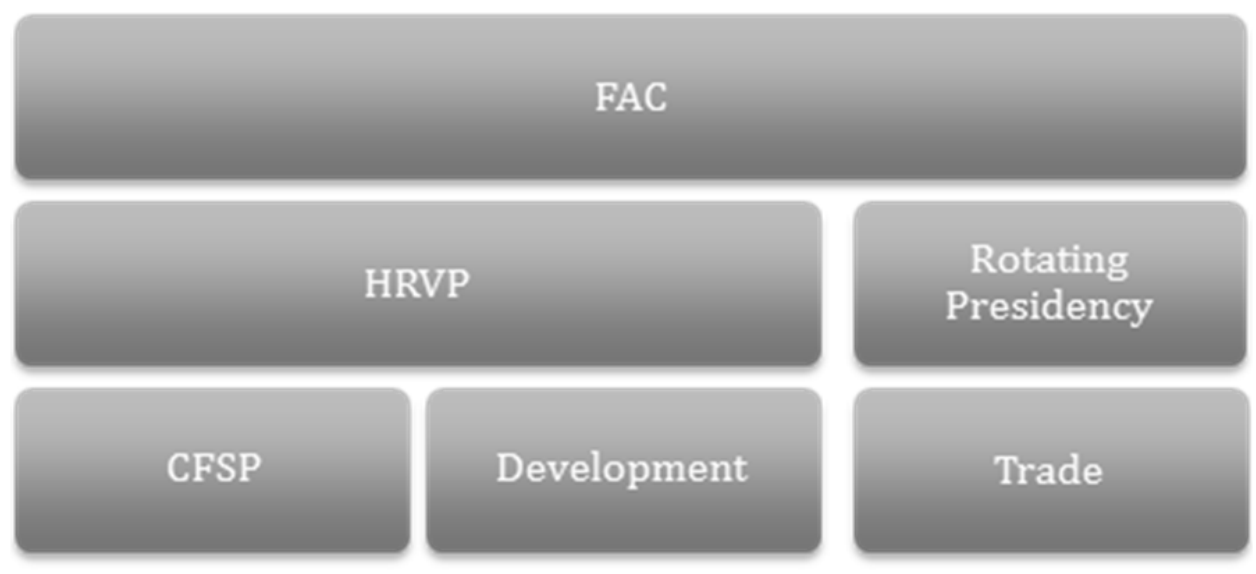

Figure 5.1: The chairmanship of the FAC

According to the Treaty, the HRVP is responsible for external relations. She ensures the consistency of CFSP, which is her specific policy domain (Art. 18.2 and 26.2 TEU; Rüger, 2011:213). For instance, she coordinates the civilian and military aspects of the Petersberg tasks in the Common Security and Defence Policy (Art. 43.2 TEU). She also coordinates all external aspects of policies within the Commission (Art. 18.4 TEU). The HRVP, alone or together with the Commission, has the power to submit proposals. These proposals may constitute a powerful tool for consistent strategies or to identify areas where consistency is missing

${ }^{46}$ For a discussion of the contribution of the HRVP position to all four dimensions of consistency, see Marangoni, 2012. See also Rüger, 2011 on inter-institutional consistency and Balfour, 2012 on vertical consistency for instance. 
(Vanhoonacker \& Pomorska, 2013; Blockmans, 2011:14). The HRVP has at her disposal thematic and geographic external assistance instruments (article 9.2 of the Council decision 2010/427/EU). Their programming and implementation however require coordination between the HRVP and the EEAS on one side, and the Commission on the other side.

Overall, the position suffers from several limitations with respect to coordination. While the double hat anchors the HRVP in the Commission, the HRVP is not a full-timer in this institution. At best regarded as a part-timer ${ }^{47}$, at worst as a Trojan horse, the lack of trust weakens her capacity to coordinate the Union's external action and in turn to enhance consistency (interview 9). The fact that the HRVP is not a full-time position within the Commission is resented as if the position left open the possibility to choose the role as HR over the role of VP (European Parliament, 2013:32; interviews 3, 4, 6, 7 and 9). The design of the position, its only partial anchoring within the Commission and the extent of the HRVP mandate in general also have consequences in terms of opportunities for coordination between the Commission and the EEAS (see section 5.2.4). For instance, if the HRVP cannot attend College meetings because of the CFSP-related attributions, the HRVP misses out on opportunities for coordination within the Commission (European Parliament, DG for external policies, 2013:53). Contacts and exchanges at the political level between cabinets could palliate the absence of the HRVP but interviewees outlined that there was no specific coordination between Ashton's cabinet and other cabinets or specific follow-up with services (interview 4, 5, 6, 9 and 13). In addition, the HRVP has neither any authority over the other Commissioners nor specific powers (such as arbitration power) to coordinate. The mission letters of Relex Commissioners and their declarations on their own portfolios confirm the political importance attached to coordination between these portfolios in order to achieve consistency but also the challenge it represents and the suspicion with which it is sometimes regarded. There are underlying tensions in the relation between the Commission and the HRVP. Ashton is said to have established good relationships with the Commissioner for Development - what is indeed of key importance since Piebalgs represents the Commission at the Foreign Affairs Council (interview 9) - and with the Commissioner for enlargement and ENP, Stefan Füle in particular (European Parliament, 2013:53). As working guidelines have not been specified either, working habits have developed on an $\mathrm{ad}$ hoc basis and depend on several factors. In particular, they depend on the background (Commission background or not i.a.), on the mindset, on the interpretation of the Treaty provisions (more or less favourable to the Community method) and on the political impetus given by the HRVP. The background of the HRVP as Trade Commissioner might be relevant in that respect but findings are not conclusive (interview 49). Finally, as illustrated by the series of dramatic

\footnotetext{
${ }^{47}$ Lady Ashton did not attend around 40\% of the Commission's meetings from January, $6^{\text {th }} 2010$ to January, $4^{\text {th }} 2011$ (Waterfield, 2011).
} 
international events in 2010-2011, the extent of the HRVP's mandate makes it hardly possible to work on coordination.

In conclusion, the shortcomings noted on intra-institutional consistency have a negative impact on horizontal consistency. The position of HRVP is theoretically far-reaching with respect to coordination in order to enhance the consistency of external policies - what is particularly important since it supports the Council and the Commission in their consistency mandate (art. 21.3 TEU). However, the job is challenging given the tensions created and the questions left open. In theory, the role of the HRVP in the different dimensions of consistency has been specified, but it remains to be seen how the HRVP may actually coordinate external policies within the Commission (Gebhard, 2011:122). The extent of the HRVP's mandate makes it even more challenging and the HRVP might have been put in a "situation of dependency within the Commission" (Erkelens \& Blockmans, 2012:14). In particular, the Commission's President has developed a pro-active approach to coordination, building on his responsibility for the collegiality principle (art. 17.6(b) TEU). To enhance coordination, he also built on several instruments such as his arbitration powers or the regular informal contacts between his cabinet and the other cabinets (Gaspers, 2008:24; interviews 3, 4, 5, 6 and 9). In addition, the Commission's President also capitalise on the contribution made by the Secretariat General, which is the service of the President.

\subsection{The EEAS' contribution to consistency and coordination}

The foreign policy service of the HRVP, the European External Action Service, also has a consistency mandate (article 27.3 TEU; article 2.1 Council 2010c). In particular, the recitals of the Council decision of July 2010, establishing the organisation and the functioning of the diplomatic service, specify the support it provides to the HRVP:

The EEAS will support the High Representative, who is also a Vice-President of the Commission (...), in fulfilling his/her mandate (...) to ensure the consistency of the Union's external action (...). The EEAS will also support the High Representative in his/her capacity as Vice-President of the Commission, in respect of his/her responsibilities within the Commission for responsibilities incumbent on it in external relations, and in coordinating other aspects of the Union's external action, without prejudice to the normal tasks of the Commission services (Council, 2010c: (3)).

Without being supported at service level, the political commitment to consistency would remain declaratory (Spierenburg report, 1979:para.33). The decision to create the EEAS acknowledges this fact (Balfour, 2012:1). It raises high expectations (European Parliament, DG for external policies, 2013:12) and creates a new challenge at the same time. The EEAS enhances consistency through its participation to Commission strategic planning and decision-making in external 
policies, as well as, in particular, to the programming of financial instruments (Erkelens \& Blockmans, 2012:22; art. 9 Council, 2010c).

The EEAS shall support, and work in cooperation with, (...) the services of the Commission, in order to ensure consistency between the different areas of the Union's external action and between those areas and its other policies. (art. 3.1 Council 2010c)

To achieve the consistency objective, coordination is considered a vital step (Balfour, 2012:1; Blockmans \& Hillion, 2013:31). In particular,

The EEAS and the services of the Commission shall consult each other on all matters relating to the external action of the Union in the exercise of their respective functions, except on matters covered by the CSDP. The EEAS shall take part in the preparatory work and procedures relating to acts to be prepared by the Commission in this area. (art. 3.2 Council 2010c)

The Council decision refers to the integration of the EEAS into Commission decision-making and the service's "truly participative rights in policy shaping" from the preparatory work to the actual drafting (Blockmans \& Hillion, 2013:36). The EEAS may prepare proposals for adoption by the College or jointly by the College and the HRVP, when the HRVP's responsibilities within the Commission are considered (Commission, Secretariat General, 2011:7-8). In such a case, the EEAS is considered to be a Commission DG (European Parliament, DG for external policies, 2013:20) and Commission procedures apply (article 18.4 TEU). As the lead service, the EEAS must launch an inter-service consultation and consult the interested Commission's services. Equally, when Commission services are drafting a proposal on issues relevant to the work of the EEAS, the EEAS must be consulted. For instance, the Global Issues Unit (previously Coordination and Analysis Unit in DG Relex) makes a significant contribution in that respect (European Parliament, DG for external policies, 2013:23). It follows internal policies with a (strong) external dimension and external policies. Its policy scope ranges from trade, financial issues, transport, regional policy, employment and social affairs, global health, energyrelated issues, climate change, environment to home affairs and immigration (EEAS, n.d.; interviews $20 \& 40$ ). The unit coordinates different policies and ensures that the external dimension of any policy is duly taken into consideration in order to enhance consistency. ${ }^{48}$ The Global Issues Unit works closely together with the Development Cooperation Unit created in the same directorate to follow specifically EU development policy and to enhance its consistency (interview 20). ${ }^{49}$

\footnotetext{
${ }^{48}$ It is the unit that answers the most ISCs every year (between 800 and 850 a year i.e. $70 \%$ of legislative acts produced every year; interview 20).

${ }^{49}$ The responsibilities of these units and of the F3 unit of the SG of the Commission (see section 5.2.5) do not overlap but complement each other, helped by a long-lasting working relationship between the heads of unit (interview 20).
} 
Despite its expected contribution given its mandate and internal organisation, the EEAS has at first challenged rather than facilitated coordination within the Commission by disrupting coordination patterns and creating new coordination needs (interview 19). Indeed, the EEAS' participation in regular decision-making requires coordination between the EEAS and the Commission (European Parliament, DG for external policies, 2013:50). It takes time to develop precise operational coordination and new working relationships between Commission services and the EEAS (interviews 5 and 28). Coordination between the Commission and the EEAS was not a natural reflex as the setting up of the EEAS created an insider-outsider divide. The diplomatic service is perceived as an outsider, both formally (the EEAS is an "autonomous" body) and physically, as it is located in a separate building. 50

Overall, actors need to learn again how to work together and to coordinate their activities (interviews 3, 5 and 7). Documents specifying working procedures were adopted only in 2011 and early 2012. They include the Working arrangements between Commission services and the European External Action Service (EEAS) in relation to external relations issues (Commission, Secretariat General, 2012) and a Vademecum on Working Relations with the EEAS (Commission, Secretariat General, 2011), as well as a service level agreement between DEVCO and the EEAS on Commission staff in Delegations (Commission, Secretariat General, 2010). However, the transition is facilitated by the presence of former Commission officials transferred to the EEAS, who were already working by the Commission's rules of procedure.51 New working arrangements also rely on the adaptation of the ITsystem used for coordination within the Commission. For the EEAS to be totally included in the ISC process of the Commission, it is now an entity in CIS-net (Commission, Secretariat General, 2011:9), e-greffe 52 and in all other IT applications related to decision-making (ibidem). In the event of a difficulty in working relationships with the Commission, the 'policy board'53 constitutes a

\footnotetext{
${ }^{50}$ The situation was even more complicated before February 2012, when all EEAS staff finally moved in the same building. They were previously scattered in several locations in Brussels, with people being transferred to the EEAS from the Commission remaining in the Commission's offices between the creation of the EEAS and the inauguration of the EEAS building (Rettman 2012a).

${ }^{51} \mathrm{On}$ the contrary, at the highest political level, one interviewee noted that the lack of Commission background in Ashton's cabinet might have at first jeopardised coordination. The balance within the cabinet is now more favourable (interview 46).

52 E-greffe is an application that supports the Commission's decision-making. The system electronically manages all Commission documents and makes them available to the relevant actors in EU institutions.

53 The Policy Board includes the Executive Secretary-General (or a member of the Corporate Board), all Managing Directors (who must be replaced by their deputies if they are unable to attend) but also the chair of the Political and Security Committee, one member from policy coordination, one member of the cabinet, one member from the spokesperson office and one member of the unit responsible for the relations with the Parliament in an effort to discuss any burning issues horizontally (interview 46). The Policy Board meets every morning and a written report is circulated shortly after each meeting, tasking individual departments to follow up (ibidem).
} 
bridge at senior level with the relevant DGs via the Deputy Secretary-General in charge of the relations with the Commission (Duke, 2012:57).

Overall, while initial reactions were really enthusiastic about the creation and the potential of the EEAS, feelings today are more mixed and it is realised that the EEAS maybe does not constitute an "antidote to inconsistency" (European Parliament, DG for external policies, 2013:30; Duke, 2012). If the report by the HRVP on the EEAS welcomes improved levels of coordination and consistency reached thanks to the new service (EEAS, 2011:para.13), adapting to a new institutional landscape in a sensitive policy domain is not an easy enterprise. It has been argued that there is a need for a

new deal between the EEAS and the Commission, implying a far greater coordination reflex on both sides, i.e. a mutual understanding that the only way to arrive at coherent and effective EU external action is through a permanent structured relationship at all levels and a close cooperation for all areas of EU external action (...). (European Parliament, DG for external policies, 2013:57)

The creation of the EEAS has not solved all the questions. It has even raised new coordination challenges: not only between the Commission and the EEAS but also within the Commission. The disappearance of DG Relex created a coordination void within the Commission, as this DG used to perform an important internal coordination function. The EEAS cannot fill in this void as it is an autonomous body, outside of the Commission (European Parliament, DG for external policies, 2013:50; interviews 2, 3, 4, 5 \& 6), with a risk of putting into question the raison d'etre of the new service (Balfour, 2012:7). Most interviewees deplored the necessity to focus on administrative - formalistic - coordination - as opposed to strategic and substantial coordination and the lack of resources. Even now that the organization chart of the EEAS is public, there remain many questions about how consistency will be promoted in operational terms, when it comes to the responsibilities and exact portfolios of everyone (Duke, 2011a:30; interviews 4 \& 5). Lastly, the effectiveness of the EEAS in contributing to consistency and coordination will also depend on the socialisation process among EEAS officials. Indeed, coming from different backgrounds, the EEAS staff does not have a unified working method yet, in particular sometimes lacking the coordination reflex said to characterise the Commission (Spence 2012).

\subsection{Conclusion: coordination, a renewed challenge}

Already in 1979, focusing on internal functioning and decision-making, the Spierenburg report pointed to the lack of cohesion within the College and poor inter-departmental coordination as clear failures that were challenging the consistency of Commission action. The multiplicity of Commissioners and 
departments, the fragmentation of areas of responsibility, the tendency to autonomy of departments, the lack of strategic overview and overlapping competences constituted weaknesses of the Commission's organisation (Commission, Inspectorate General, 1999:28). Although it is an organizing theme of the Commission's internal decision-making process and the genuine focus of its institutional "narrative" (interview 10), coordination remains a multifaceted challenge for the institution (Committee of Independent Experts, 1999; Commission, Inspectorate General, 1999:57). External policies are no exception to this concern: coordination is challenging despite the particular political attention attached to this policy domain and the innovations introduced by the Lisbon Treaty.

Overall, this chapter has explored how the Commission put into effect the consistency requirement established by the Treaties. Investigating internal decision-making, it has shown that the Commission aims at consistency through coordination. With a highly decentralised coordination responsibility, the system involved both services and political actors. Specific instruments have been set up to facilitate coordination. There also exists a central authority, the Secretariat General, whose task it is both to ensure that the conditions for coordination are met and to supervise the coordination process as such. The Lisbon Treaty has introduced a number of innovations relevant for the decision-making of external policies. With the creation of the double-hatted HRVP position and the setting-up of the EEAS, the new Treaty has added new actors to the decision-making process. The EEAS in particular renews the coordination challenge. Although it is an outsider, this actor fully participates in the Commission's regular decision-making process and follows Commission rules of procedure. Consequently, coordination of Commission decision-making is not a purely intra-institutional exercise; it presents now an inter-institutional dimension as well. This new institutional deal has disrupted previous coordination patterns and created new coordination needs (European Parliament, 2013:13).

This chapter has discussed how a particular institution, the Commission, gives shape to the consistency requirement. This focus on internal decision-making is an original contribution to the literature. The case studies chapters will apply this framework in specific policy fields to discuss how the Commission's proposals were prepared and which choices were made in the episodes under scrutiny. Moreover, the consistency of these proposals will be assessed before identifying which factors influence the success of coordination or lack thereof. 



\section{CHAPTER 6.}

\section{THE CONSISTENCY OF APPROPRIATE MEASURES AGAINST ZIMBABWE IN 2002 AND IN 2012}

\subsection{Introduction}

After the introduction of the Treaty framework and Commission decision-making as two important levels of analysis, this chapter now turns to the first case study. It deals with a particular type of sanctions adopted by the EU against Zimbabwe, the so-called "appropriate measures" adopted under article 96 of the Cotonou agreement. Appropriate measures are at the crossroads between foreign policy, development and trade and aim at ensuring the respect for what the Cotonou agreement considers as "essential elements", i.e. human rights, democratic principles and the rule of law (article 9 Cotonou agreement), which constitute "flagship objectives" of the EU (Portela, 2014:2). ${ }^{54}$ The chapter focuses on the 2002 Commission proposal to adopt appropriate measures under article 96 against Zimbabwe (Commission, 2002c) and its 2012 proposal to renew these appropriate measures (Commission, 2012d). The chapter aims to answer the following question: to what extent are the Commission's proposals consistent and what are the factors explaining successful coordination in the drafting of the proposal?

Zimbabwe gained independence in 1980 and signed the Lomé Convention with the EU in 1982 (Delegation of the EU to Zimbabwe, n.d. b). The following two decades, under the leadership of Robert Mugabe, were characterised by statesponsored violence against large parts of the population of Zimbabwe, violations of human rights and fundamental freedoms, economic quagmire and humanitarian crisis. In response to the situation, the EU adopted appropriate measures under article 96 against Zimbabwe in February 2002, measures that have been renewed every year until 2012.55 This case illustrates the prevalence of particular concerns

\footnotetext{
54 This chapter will not discuss specifically humanitarian assistance provided by the EU to Zimbabwe as it falls beyond the scope of the decision to adopt appropriate measures against the country.

55 In July 2012, the Council decided to lift appropriate measures against Zimbabwe (Council, 2012a).
} 
at certain times and the challenge to ensure the overall consistency of the action. ${ }^{56}$ The consistency question was raised at several steps of the decision-making process under article 96 but the research focus is put here on the consistency challenge in the design of appropriate measures against Zimbabwe.

The chapter is organised as follows. To assess the consistency of the Commission's proposals, it will take up the levels identified in chapter 3. Building on the Treaty framework for the consistency of EU external action discussed under chapter 4, this chapter discusses the policy framework and the decision-making process of the 2002 and 2012 proposals. The comparison between the pre- and post-Lisbon context is a structuring element of the case study because significant changes to the decision-making process were introduced as a consequence of the revised Treaty. The second section presents the dramatic situation in Zimbabwe at the end of the 1990s and sets the scene and the circumstances under which the Commission prepared its proposals. It is against this background that the EU decided to take action against Mugabe's regime. The third section discusses the policy framework, which is the second level at which the consistency requirement is expressed, as introduced in the conceptual framework of the research (chapter 3). The fourth section explores the third level of analysis, the decision-making process of the two Commission's proposals in this specific case. Emphasising the differences in the process resulting from the Lisbon Treaty, this section is subdivided into two, discussing first the 2002 proposal and then the 2012 proposal. The fifth section assesses the consistency of both proposals. Lastly, the chapter aims to identify, deductively, the conditions under which coordination was successful in the drafting of the proposals.

\subsection{A regime that cannot be left unpunished}

The escalation of violence in Zimbabwe in the late 1990s-early 2000s triggered a series of reactions from the international community. Progressively strengthening his grip on the country, Robert Mugabe turned state violence against the population of the country, denying political freedoms, violating human rights while plundering Zimbabwe's resources. International partners, including the EU, could not leave the regime unpunished. This section does not aim to provide an exhaustive account of

\footnotetext{
${ }^{56}$ The focus on foreign policy in Zimbabwe includes two other types of action. First, appropriate measures were combined with the adoption of CFSP sanctions (Council, 2002c). This sanctions package aimed at increasing the EU's leverage on Mugabe's regime with a view to restoring essential elements in Zimbabwe. CFSP sanctions are not covered by this study, which focuses on article 96 measures only. Second, because of human rights abuse and the plundering of the country's natural resources, Zimbabwe was also included in the Kimberley process, an international process certification scheme for rough diamonds (WTO, 2011:38; n.a. n.d. b). However, the Kimberley process is not covered either in this chapter. The only foreign policy elements hereunder considered are the foreign policy elements of the Cotonou agreement.
} 
the history of Zimbabwe's independence but to outline the main elements that led to the ruin of the "jewel of Africa" 57 and to the EU's reaction.

Zimbabwe's independence sowed the seeds of a tense relationship between the EU and the former British colony. Established on the basis of a concession for mining rights granted to the British South Africa Company, Rhodesia was renamed Zimbabwe only in 1980 when the black majority took power. In 1965, the unilateral declaration of independence triggered a civil war against the white minority rule. At the initiative of the British government, the Lancaster House agreements were finally signed in December 1979, ending the civil war, and giving the power to the black majority (Power, 2003:1; Laakso et al., 2007:68). Shortly after, Zimbabwe signed the Lomé convention that constituted the framework for its partnership with the EU.

The civil war in Zimbabwe saw the rise of ZANU (Zimbabwe African National Union) and its leader, Robert Mugabe, who became Prime Minister in 1980 and was elected President in 1987. Mugabe has remained in power since then. Although first an example of national reconciliation and sound politics, Zimbabwe quickly succumbed to violence (Forsythe, 2009, vol.5:400). Political developments in Zimbabwe responded to Mugabe's insatiable quest for power (Meredith, 2003:233; Meredith, 2002:13-15, 228 and interview 17). The land question durably poisoned the relations between the white minority and Mugabe's regime, leading to the use of violence against the former (Grebe, 2010:4, 7; Weiland, 2004:141; Meredith, 2003:8; Meredith, 2002:45; Taylor \& Williams, 2002:549-550). The 2000 referendum (on a new constitution) lost by Mugabe opened the Pandora box (Windrich, 2010:1186; Meredith, 2002:228; interview 26). Mugabe launched a violent campaign of intimidation of the opposition (Martin, 2006:249-250; Taylor \& Williams, 2002:549-550). It forced ZAPU (Zimbabwe African People's Union) and its leader Joshua Nkomo to accept the unity accord of 1987 and to join ZANU, which became ZANU-PF (Zimbabwe African National Union - Patriotic Front) thus creating a de facto one-party state (Grebe, 2010:4). However intimidation and violence did not stop the opposition: in a context of growing discontent at the regime, Morgan Tsvangirai, a union leader, established an opposition party, the Movement for Democratic Change (MDC), which entered the parliament in 2000, winning 57 out of 120 seats (Lafargue, 2010:98; Grebe, 2010:7). At the same time, the economic situation quickly deteriorated and in the mid-2000s, Zimbabwe was the world's fastest shrinking economy (WTO, 2011:3; Dowden, 2006:284; Power, 2003:2-3). In addition, the decade was characterised by an unprecedented HIV pandemic, the systematic plunder of Zimbabwe's resources while the humanitarian situation was catastrophic (see for instance Power, 2003). Zimbabwe's viability was doubtful without any external aid. The economic situation was further destabilised by the decisions of the International Monetary Fund to suspend its loans in 1999

\footnotetext{
${ }^{57}$ After the word of then President Machel of Mozambique and President Nyerere of Tanzania to Mugabe; Lessing, 2003.
} 
and of the World Bank to block payments to Zimbabwe in 2000 (Weiland, 2004:133).

The EU expressed concerns at two levels. The rapidly deteriorating economic situation and the humanitarian crisis were calling for a quick action. Zimbabwe's political situation was even more worrying. In 2000, the EU was already involved on the ground through an election observation mission. The latter could do little but take note of continued intimidation and violence. Despite international criticism and the concerns expressed by the EU inter alia, violence continued ahead of the 2002 presidential elections. In 2001, Mugabe had declared 'total war' against the opposition in his campaign for re-election (Weiland, 2004:134). The EU demanded that Zimbabwe invite EU election observers to supervise the electoral process without which it warned the regime against the adoption of sanctions (Council, 2002g). Past the deadline he had been given, Mugabe invited an EU observation mission provided that it did not include any observer from the UK, Germany, the Netherlands, Sweden, Finland and Denmark (Weiland, 2004:135; Allen \& Smith, 2002:108). The conditions were rejected by the EU, which nevertheless dispatched observers. The head of the mission, Pierre Schori, entered Zimbabwe on a tourist visa (interview 17). The mission could do little but to witness Mugabe's victory, a "coup by ballot-box" (Taylor \& Williams, 2002:548). Awareness of violations of democratic principles, human rights and the rule of law as much as of the dramatic economic and humanitarian situation was rising in the EU. ${ }^{58}$ While political dialogue was considered a failure, pressure increased to take a decision.

Certain Member States pushed the EU to eventually sanction Mugabe's regime (Taylor \& Williams, 2002:553). The EU had actually put itself in a position where it would have to act: already in July 2000, it had tied development aid to the restoration of law and order (Weiland, 2004:134-135). On 29 October 2001, the Council requested the Commission to open article 96 consultations, consultations that were held in January 2002. They were quickly declared inconclusive and the EU adopted a "sanction package" on 18 February 2002 (interviews 17, 19, 25, 26). By its decision 2002/148/EC, the Council adopted article 96 appropriate measures and by its decision 2002/145/CFSP it adopted CFSP sanctions. The sanctions and measures targeting the government did not reach their political objective, the situation even further deteriorated. The 2000 and 2005 parliamentary elections, and the 2002 presidential elections were characterised by intimidation, violence and abduction of opposition party members and even the use of food as a political weapon (Weiland, 2004:134-135). A new electoral crisis occurred between March and June 2008, opposing Mugabe and Tsvangirai, the leader of the opposition. In the 2008 presidential elections, Tsvangirai protested against political violence by withdrawing his candidature: Mugabe declared victory while the election never actually took place (Grebe, 2010:8). Later on, the negotiation of the Global Political

\footnotetext{
${ }^{58}$ See for instance Written parliamentary questions to the Commission and to the Council, 2001-2011.
} 
Agreement (GPA, September 2008) and the formation of a Government of National Unity (GNU, February 2009) led the EU to start reengaging with Zimbabwe: regular political dialogue under article 8 of the Cotonou agreement was reopened in June $2009 .{ }^{59}$ Further signs of reengagement from the EU's side appeared with high-level meetings in Brussels and Harare in 2011 (interview 19). Between 2002 and 2012, the "sanction package" was renewed every year. Article 96 measures were renewed for the last time in February 2012. In the light of the progress towards essential elements, measures were suspended in July 2012 (Council, 2012a).

Overall, the Commission's proposals illustrate the potential tensions between the different dimensions of EU action in Zimbabwe. In the wake of violence committed against large parts of the population, the EU could not remain passive. Yet, the coordination of a strong position focused on foreign policy objectives with the needs of the population in the field proved challenging. The chapter now turns to the policy framework and the drafting of the Commission's proposals that, building on the general requirement provided for in the Treaty framework, aim at consistency.

\subsection{The policy framework}

To answer the main question raised in the introduction - to what extent are the Commission's proposals consistent? - this section explores the policy framework of EU action. As introduced in chapter 3, it is the second level of relevance for understanding the parameters within which actors operate to put into effect the consistency requirement. The policy framework further specifies the general Treaty framework for consistency (discussed in chapter 4) in one particular area and therefore contributes to the framing of EU action against Mugabe's regime on the basis of article 96 in 2002 and in 2012. It consists of three elements: first, the general orientations of the Cotonou agreement, second, the specificities of article 96 mechanism and third, the concept of "targeted sanctions".

\subsubsection{Cotonou, a 3-pillar agreement}

A long-lasting arrangement ${ }^{60}$ between the EU and ACP countries (African, Caribbean and Pacific), the Cotonou agreement is multifaceted and provides a general framework for the EU-ACP partnership, partly shaped by the former colonial ties that existed between the ACP countries and some of EU Member States. The Yaoundé (Yaoundé I and II from 1963 to 1975) and Lomé conventions (Lomé I,

\footnotetext{
${ }^{59}$ An inclusive delegation from Zimbabwe, led by Tsvangirai, visited Brussels to discuss the country short-term strategy and its roadmap while the EU offered to lift appropriate and restrictive measures and to sign the $10^{\text {th }} \mathrm{EDF}$, would significant progress be achieved in the political situation. An EU delegation led by Commissioner for Development De Gucht visited Harare (interview 19).

60 Upon its signature in 2000, the Cotonou agreement replaced the Lomé Conventions (1975-2000).
} 
II, III and IV from 1975 onwards) successively defined the association of ACP countries with the Community until the signature of the Cotonou agreement in 2000. Cotonou encompasses three dimensions - development cooperation, trade and foreign policy - the interconnectedness of which has been emphasised by successive reforms. The Cotonou agreement was then revised in 2005 and in $2010^{61}$ (Commission, DG Development and Cooperation - EuropeAid, 2011; Babarinde \& Faber, 2004:27-47). This sub-section does not aim at recalling the negotiations of the agreement or the historical developments that led to the Cotonou agreement, but emphasises the general policy framework for consistency that Cotonou provides while introducing the specificities of EU-Zimbabwe relationship in the three dimensions.

Development cooperation is often the first element that comes to mind. Poverty reduction, sustainable development and integration into the world economy are the central objectives of the Cotonou agreement. These goals are pursued through integrated strategies with economic, social, cultural, environmental and institutional elements. The European Development Fund (EDF) is the main financial instrument in that respect; specific budgetary instruments and EC/EU budget lines - such as the Development Cooperation Instrument, the Instrument for Stability or the European Instrument for Democracy and Human Rights - complement it. Development cooperation takes place on the basis of two programming documents - Country Strategy Papers (CSP) and National Indicative Programmes (NIP). These documents are agreed by the EU and individual ACP partners. Addressing particular development needs or mirroring a partner's development strategy, they set out development objectives and specify envisaged actions. Between February 2002 and July 2012, the existence of article 96 measures against Zimbabwe constrained development cooperation. Measures had an impact on the type of funding available, the amounts available and the conditions under which development cooperation could take place (see section 6.5).

Trade is the second dimension of the Cotonou agreement. Today, the trade regime is rather complex due to the coexistence of a variety of instruments. To a large extent, trade is understood as a tool to promote economic development and the integration of ACP into the world economy, thus significantly contributing to development objectives. For Zimbabwe, trade with the EU is an important component of the bilateral relation, amounting to €463 million in 2010 (WTO, 2011:16). The trade relationship consists of several instruments. Before the revision of the trade dimension of Cotonou, Zimbabwe was benefiting from nonreciprocal trade preferences (interviews 14 and 30; European Commission, DG Fiscalité et Union Douanière, 2012a, 2012b \& 2007). To a lesser extent, it also benefited from import preferences under the general arrangement of the

\footnotetext{
61 The EU and ACP countries initialled the text of the second revision of the Cotonou agreement in March 2010. The Commission (Commission 2011e) proposed to the Council to adopt a decision concluding the agreement in July 2011 while EP voted on the new text in June 2013.
} 
Generalised System of Preferences (Commission, DG Trade, n.d. d; interview 30). Following complaints before the WTO against the non-reciprocal and discriminatory nature of the Lomé trade regime, the EU had to revise its preferences architecture.62 Preferences under Lomé expired in 2007 and were replaced by a system of reciprocal preferences under the Economic Partnership Agreements (EPAs). ${ }^{63}$ Since May 2012, trade between the EU and Zimbabwe falls under the Interim EPA with Eastern and Southern Africa (ESA) (interview 14; Commission, DG Trade, 2011d; Commission, DG Devco - EuropeAid, 2010). The EPA introduces a duty-free-quota-free access ${ }^{64}$ for all imports from ESA.

The final dimension of the Cotonou agreement, the foreign policy dimension, has developed and acquired a more prominent status over time. It was only in 1995 that "essential elements" - and with them political conditionality - were formally introduced. 65 The subsequent reviews of the convention confirmed the focus on the various components of good governance, thus strengthening political conditionality (Weiland, 2004:128).66 Essential elements consist of respect for human rights, democratic principles and the rule of law (article 9.2 Cotonou agreement). The wording of article 9 also emphasises the mutually reinforcing nature of "democratisation, development and the protection of fundamental freedoms and human rights" (article 9.2) and the centrality of these elements in development strategies to which the EU contributes (article 9.4). The special status of these elements is further supported by the objectives of political dialogue under article 8 - the regular interaction between the EU and any ACP partner under normal circumstances. The special legal status of the political (essential) elements opens an additional option for the EU to intervene. Under Article 96, when the EU considers that there is a breach of essential elements, it may open special consultations with

\footnotetext{
62 The perspective of the revision was introduced in the Cotonou agreement in 2000 already and a waiver from the WTO negotiated for the period between 2000 and 2007, when unilateral trade preferences were to expire.

${ }^{63}$ As the EPA negotiations took longer than expected, the EU adopted a temporary bridging instrument, the market access regulation, to define market access for ACP countries between the lapsing of preferences in 2007 and the entry into force of the EPAs.

64 The EPA encompasses a market-access deal (with Zimbabwe i.a.); duty-free-quota-free access for all imports from ESA as of $1^{\text {st }}$ January 2008 with transition periods for rice and sugar (see EU sugar protocol; interview 20; Commission, DG Devco, 2012g). ESA will liberalise its market - with some exclusions such as cereals, or textiles and clothing for instance - to EU imports in line with individual schedules depending on the sectors (European Commission, DG Trade, 2012e \& 2011d). The agreement also provides for synergies with Cotonou institutions (for instance, the Joint Ministerial Trade Committee will focus on the common trade interest of ACP states, discuss any trade-related issues of concern to all ACP states, monitor the negotiation and implementation of EPAs....) to ensure coordination, coherence and complementarity (Delegation of the EU to Zimbabwe, no date c).

${ }^{65}$ Before the introduction of essential elements in 1995, the granting of EU development aid to ACP countries took the shape of an entitlement: "the EU was obliged to support an ACP country even if it was implementing policies that were contrary to development, human rights, rule of law, etc (...)"; Babarinde and Faber, 2004:37.

${ }^{66}$ Despite the lack of legal basis, political conditionality had already led to aid cut-offs before that date; Portela, 2007:40.
} 
that partner and take additional action with a view to restoring essential elements and thereby to influence the political situation in this partner country. The next sub-section discusses the specificities of article 96 mechanism.

\subsubsection{Article 96 mechanism}

"Essential elements" are protected under the Cotonou agreement by a unilateral safeguard mechanism, article 96. This article is the most controversial article of the Cotonou agreement (Mackie \& Zinke, 2005:1). When there is a breach of the essential elements of the Cotonou agreement, the EU may withdraw benefits (development aid and trade preferences) that would otherwise be available (Portela, 2007:40) and use them to pressure the ACP partner into normalising the situation. It could be a serious blow for fragile economies because aid is typically allocated on a 5-year basis (interview 10). Benefits are restored if and only if essential elements are restored.67 ACP countries perceive article 96 as a unilateral sanction mechanism (Mackie \& Zinke, 2005:5). This perception increases the pressure on the EU when it considers using article 96.

According to the EU, article 96 is a dispute resolution mechanism of last resort when regular political dialogue under article 8 fails to prevent the breach of or to restore essential elements. ${ }^{68}$ In principle, the EU's reaction should always be the same in the event of a breach of essential elements (Hazelzet, 2005:9-10). However, interviewees emphasised that article 96 very much depended on political interests. Decision-makers have much discretion over the decision to activate article 96 - and take into consideration factors such as country circumstances, public opinion, the timing of the decision for the EU - what is perceived to lead to inconsistency in the use of this instrument (interviews 11, 17 \& 19). Nevertheless, the 2007 evaluation report on article 96 outlines that overall there was no general pattern of double standards in the EU's utilization of article 96 (Laakso et al., 2007:48-51). When article 96 consultations are concluded and the EU and the ACP country agree a checklist and timetable for restoring essential elements, no further measures are taken. In the absence of such agreement, the EU may adopt appropriate measures

\footnotetext{
${ }^{67}$ For instance, the Commission proposal COM(2012)26 final recognises that "the overall situation has improved" but regrets that "the implementation of political reforms remains slow, and certain essential elements of the ACP-EU Partnership Agreement, to which the GNU has committed in the Global Political Agreement, still need to be implemented" (Commission 2012d). As a consequence, it proposes to renew article 96 measures.

${ }^{68}$ Article 96 Essential elements: consultation procedure and appropriate measures as regards human rights, democratic principles and the rule of law:

2. (a) If, despite the political dialogue on the essential elements as provided for under article 8 and paragraph 1a of this article, a Party considers that the other Party fails to fulfil an obligation stemming from respect for human rights, democratic principles and the rule of law referred to in article $9(2)$, it shall (...) invite the other Party to hold consultations that focus on the measures taken by the Party concerned to remedy the situation.
} 
(article 96.2(c)) to force the ACP country into respecting its commitment to the essential elements. ${ }^{69}$

In practice, article 96 is a sensitive policy instrument. The decision to open article 96 consultations and that of adopting appropriate measures raise consistency questions. The existence of a rule and the clear justification of any exception to this rule are key elements of consistency (Lerch \& Schwellnus, 2006:307). Both are lacking in the case of article 96, which leaves discretion to the decision-makers. For instance, the fact that the mechanism can be activated either on the Commission's proposal or upon request by the Council illustrates well the political considerations behind the actual use of this article. These shortcomings of article 96 procedure actually constrain the EU's action. At any step of the process in activating article 96, in conducting consultations and in designing appropriate measures - the EU has to carefully justify its choice and balance its interests and objectives, what in turn constitutes an additional pressure for consistency.

\subsubsection{Targeted sanctions, accounting for different objectives}

This sub-section does not discuss the concept of sanctions in general ${ }^{70}$ but clarifies $^{-}$ the concept of 'targeted sanctions', which is the third component of the policy framework. Although appropriate measures are formally not called sanctions ${ }^{71}$, they have the same objective and modus operandi as sanctions (Portela, 2007:39$40,42-43)$. Consequently, it is interesting to discuss the influence of the concept of targeted sanctions in the design of appropriate measures. Instead of imposing general economic sanctions that would have an indiscriminate effect - thus possibly harming the population - targeted sanctions are designed to affect only and directly the leadership responsible for the objectionable behaviour (Portela, 2014:7 \& 2007:39). Appropriate measures shall target the leadership responsible for the objectionable behaviour only. It is also a strategic choice of the sender of smart sanctions to legitimize the measures and to limit the possibility of the targeted leadership to instrumentalise article 96 policy (European Parliament, 1982). In Zimbabwe, this concept played an important role in the design of appropriate measures. It has had consequences on the definition of the development and trade dimensions of the measures in an effort to avoid contradictions between foreign policy objectives on the one side and development and trade interests on the other side.

In conclusion, the policy framework constitutes a relevant level for understanding the parameters of Commission action. It further specifies the general consistency requirement in the drafting of particular proposals. In that case, it

\footnotetext{
${ }^{69}$ Additional measures can be imposed by the EU unilaterally such as CFSP measures, what further sharpens the consistency challenge.

${ }^{70}$ For a discussion on the different categories of sanctions, see for instance Portela, 2007:19-34

71 The EU insists on using the terms "appropriate measures" in the Cotonou context while sanctions are only adopted under CFSP.
} 
provides substantial guidelines for the action of the Commission on the basis of article 96 of the Cotonou agreement. The policy framework provides benchmarks against which to assess the consistency of the Commission's proposals, as will be discussed in more detail under section 6.5.

\subsection{The Commission's internal decision-making process}

The chapter now turns to the third and last level of the conceptual framework introduced in chapter 3 . The decision-making level puts into effect the consistency requirement as provided for in the Treaty framework (chapter 4) and in the policy framework (section 6.3). The focus will be successively on Commission decisionmaking in 2002 (pre-Lisbon; section 6.4.1) and in 2012 (post-Lisbon; section 6.4.2).

\subsubsection{The adoption of appropriate measures against Zimbabwe in 2002}

Article 96 measures against Zimbabwe were adopted for the first time in February 2002 on the basis of the Commission's proposal COM(2002)73 final. This first section discusses the different steps taken in the drafting of the 2002 Commission's proposal, after an introduction to the specificities of article 96 procedure before the Lisbon Treaty.

A preliminary remark on the type of procedure used to adopt the proposals studied is necessary. The Council's decisions on appropriate measures are adopted following a non-legislative procedure as per article 297 TFEU, on the basis of a Commission proposal. In this case, Commission proposals are taken by written procedure in accordance with articles 4(b) and 12 of Commission rules of procedure (Commission, 2010j). The 2002 proposal to adopt appropriate measures was adopted by written procedure under the responsibility of the Commissioner for Development. Detailed internal decision-making is discussed below.

\section{The pre-Lisbon Article 96 procedure}

Technical details of the article 96 procedure are useful to understand how and when different actors weigh in, to outline risks for consistency and to identify instruments to address those (article 96 of the Cotonou agreement; Laakso et al., 2007:25-27; Hazelzet, 2005:6-7).

As the lead institution, the Commission plays a key role in the process. It is in charge of preparing the proposal to open consultations, the information note to conclude consultations, an information note on development cooperation for the ACP working group of the Council and the proposal to adopt appropriate measures (Hazelzet, 2005:6-7). At its own initiative or upon request from the Council, the Commission drafts a proposal to open article 96 consultations. The possibility for the Council to request the opening of the consultations introduces a strong element 
of political appreciation on the situation of a particular ACP country (interviews 11, $17,19)$. Overall, although the Commission is formally in the lead, it is particularly sensitive to Member States' positions. Consequently, it is reluctant to go against Member States and will follow the prevailing opinion - as illustrated in particular by the Zimbabwe case (interview 17).

Once the proposal (to open consultations, to conclude consultations and to adopt appropriate measures) is adopted by the Commission, two Council working groups intervene in the decision-making process (Hazelzet, 2005:6). The Commission's proposal is discussed by the COAFR, the Council geographical working group on Africa: on the basis of a political assessment of the situation, COAFR takes the political decision on article 96. The ACP working group then discusses the situation from a more technical point of view, as the decision on article 96 is likely to have implications for development cooperation with the country targeted - on the basis of an information note from the Commission on the state of play of development cooperation with the ACP partner concerned. Once agreed at working level, the proposal is adopted by the Coreper and the Council.

The EU informs the other party and invites it to hold consultations (article 96.3 of the Cotonou agreement). The ACP country may accept or refuse this invitation for consultations. If it refuses, the EU can move directly to the adoption of appropriate measures. If it accepts, consultations shall begin no later than 30 days after the invitation and shall not last longer than 120 days (increased from 60 days in the 2005 mid-term review; ibidem). Consultations start with a meeting in Brussels between the troika (Council presidency, SG/HR, Relex Commissioner) and the ACP country ${ }^{72}$; during the initial phase of article 96 mechanism, the ACP country may be accompanied by a number of ACP countries of its choice and representatives from regional organisations (Laakso et al., 2007:27; Hazelzet, 2005:6; Mackie \& Zinke, 2005:6)..$^{73}$ Associating ACP countries to the process is an additional safeguard against the perceived unilateralism of the process and the double-standard criticism. However, it occurs only when the measures are adopted for the first time, not when the renewal of measures is discussed (interview 17). Consultations aim at finding an agreement between the EU and the ACP country on measures to be taken within a precise schedule towards the restoration of "essential elements" (Hazelzet, 2005:6). This evaluation process is followed through by DG Development, what shall ensure a systematic evaluation process and a consistent use of article 96 mechanism whatever the country concerned (interview 17). During the consultations, the EU and the responsible government adopt a list of commitments to restore essential elements. If the EU deems the

\footnotetext{
72 Post-Lisbon, the consultation meeting is chaired by the HRVP. The Commissioner for development participates in the meeting, as well as the Commission and the EEAS (EEAS/Commission, 2012).

${ }^{73}$ For instance, during article 96 consultations, Zimbabwe's delegation was accompanied by a 'group of friends', including Nigeria, Namibia, Angola, Malawi but also other ACP countries participating as observers (Kenya, Zambia, South Africa, Jamaica, Botswana, Cameroon, Mozambique). However, the exact list of participants is not available to the public (Council 2002h).
} 
outcome of the consultations inconclusive, the Commission proposes to close consultations and transmits to the Council an information note (article 96.3 of the Cotonou agreement). The two same Council working groups are involved: the COAFR prepares the political decision to adopt appropriate measures and the ACP working group deals with the implications of this decision for development cooperation. The decision is adopted by unanimity if development aid is totally suspended or by qualified majority if the suspension is partial (Laakso et al., 2007:27). Decisions against Zimbabwe automatically expire after one year (between 2002 and 2012) but in February 2012 measures were renewed for 6 months only. It takes another Council decision on the basis of a Commission proposal to renew the measures.

Two procedural instruments - typical in the case of the Commission's regular decision-making process (see chapter 5) - are not found in the article 96 pre- and post-Lisbon procedure as the proposal responds to a crisis situation. Neither was an impact assessment required, nor did the Commission conduct a public consultation in preparation of the texts. To some extent, public opinion indirectly influenced the decision-making process on the importance of foreign policy concerns - for instance, the British public opinion would have considered it unacceptable not to sanction Zimbabwe. Public opinion also continuously supported the continuation of EU development and humanitarian aid in Zimbabwe (interview 17).

Overall, article 96 procedure aims at ensuring the consistency of the EU's action on this basis. Procedural safeguards, both internal - how the decision is prepared by the Commission - and external - the association of outsiders to the preparation process - constrain the Commission and in particular DG Development in the drafting of the proposal and the coordination of different interests and objectives (see section 6.6).

\section{The leadership of DG Development}

An instrument of the Cotonou agreement, article 96 falls under the mandate of DG Development, which is thus the chef de file to draft the Commission's proposal. ${ }^{74}$ In 2002, the formal dynamics at play throughout the drafting of the proposal were internal - the process involved different services of the Commission, both Brusselsbased and in Harare, under the leadership of DG Development - contrary to the situation in 2012 (see section 6.4.2).

As the lead DG, DG Development was in charge of following and monitoring EU relations with any ACP partner in general and for preparing decisions relating to article 96. As per definition, while drafting the proposal to adopt appropriate

\footnotetext{
${ }^{74}$ The leadership of DG Development also reflected the specificity of the EU-ACP relationship - ACP countries fell under the portfolio of this DG contrary to other EU partners that were under the portfolio of DG Relex before the Lisbon Treaty.
} 
measures against Zimbabwe, DG Development was responsible for including the DGs concerned in the process and taking into consideration their views. In addition to its internal coordination responsibility, DG Development had also an external coordination responsibility, liaising with Council working groups for further steps of decision-making ${ }^{75}$ and representing the Commission at these meetings.

Supporting the lead DG, the EC delegation in Harare proved a coordination instrument in the field. Feeding intelligence on the situation to Brussels helped in the drafting of the proposal as it gave an actual picture of political developments while also drawing attention to the difficulties of the population and the risks that article 96 measures might bear. The delegation was also an important instrument for the follow-up of the decisions as it was constantly monitoring the situation. For instance, the delegation reported on the humanitarian crisis enabling the EU to activate specific financial instruments to provide relief to the population. However, the approach of the delegation always depended on the background of the head of delegation, focusing either on human rights or on development, with the risk that it would be perceived as taking a subjective position on the situation in Zimbabwe (Laakso et al., 2007:33). ${ }^{76}$

Overall, in the pre-Lisbon era, DG Development was formally the lead DG but the highly political nature of article 96 mechanism and national sensitivities over the situation in Zimbabwe polarized the decision-making process. Different objectives were expressed by actors within and outside of the Commission, as revealed by the discussion of the preparation of the proposal to which we now turn.

\section{Drafting the proposal}

Under the leadership of DG Development, the drafting of the proposal to adopt article 96 measures must follow a number of procedural steps as introduced in chapter 5 . They aim at ensuring the coordination of different concerns to produce a consistent policy proposal. This sub-section discusses both informal and formal coordination. Informal coordination refers to any efforts undertaken before the inter-service consultation on the draft proposal is actually launched. Inter-service consultation and the finalisation of the proposal constitute the formal steps taken towards coordination.

All interviewees outlined the initial, informal, phase of coordination as the first and most important phase in terms of coordination. Phone calls, emails and meetings are instruments used on a continuous basis to assess the situation, discuss the policy options and evaluate the positions of the different services and DGs. A collaboration habit develops between the actors of a dossier, which is

\footnotetext{
75 See for instance Putnam's 2-level game theory in Buchet de Neuilly, 2003:96

${ }^{76}$ The delegation also coordinated with Member States' embassies in Harare and with non-EU states in an effort to bring the different initiatives against Mugabe's regime closer together (Laakso et al., 2007: 69-71).
} 
perceived as very strong (interviews $11,17,19)$. These informal steps are key for the chef de file to identify the common ground for the proposal and, by way of contrast, what is likely to remain an issue in the short-, medium- and long-term.

The initial decision was the result of tight coordination between the desk Zimbabwe of DG Development, the lead DG, and the two cabinets of the Commissioners for External Relations and for Development (interviews 11, 17). This core group of officials ensured coordination "at days and at nights (...), discussing the latest developments and the options available" (interview 17). The composition of this group illustrated the dual nature of article 96 measures, both political and technical, and thus the necessary articulation between the political actors and the technical experts in the drafting of the proposal (interview 19). The composition of the group also reflected the efforts to ease the tensions by continuous contacts on the dossier between the two main DGs involved and their different approaches in the case of Zimbabwe. Relex officials focused on the human rights situation and pushed for the adoption of sanctions and appropriate measures, while development officials favoured a more constructive approach. Lastly, the involvement of the two cabinets very early in the process was the consequence of the extreme political sensitivity of the situation in Zimbabwe, as signalled by the strong position taken by certain Member States (Commission, $2001 \mathrm{~b}$ ), and an additional sign of the potential tensions between different approaches to the situation.

Informal coordination in Brussels was helped by joint missions in the field. Decided on an ad hoc basis, joint missions were meant to monitor the situation and to test policy options: they highlighted the concrete challenges to address in Zimbabwe but also the different positions of actors (interviews 17, 19). Efforts in the field were twofold. First, a mission of the EU visited Zimbabwe to better assess the situation: it was composed of the desk Zimbabwe of DG Development and the head of the geographical unit, electoral observers and country experts (interview 17). At the same time, in the region, another delegation of the EU (composed of the deputy director of DG Development, the desk Zimbabwe of DG Development and the Spanish Presidency of the EU) was active in the CFSP framework and met with Zimbabwe's neighbours, South Africa, Mozambique and Malawi (ibidem). If these informal efforts usually take place before the actual drafting of the Commission proposal to define what is the preferred policy option, this was not exactly the case here as there was little doubt as to the outcome because of certain Member States' positions (ibidem; Commission, 2001b). The adoption of article 96 measures was the preferred option and DG Development had already started drafting the proposal in that direction (ibidem).

The second, formal, phase of coordination took place on the basis of the first draft circulated by DG Development.

The inter-service consultation (ISC) involved different actors. DG Development launched the ISC and consulted the following DGs and services of the Commission: Relex, EuropeAid, ECHO, Trade, the legal service, DG budget and the Secretariat 
General (Commission, 2001c; interview 31). As in any ISC, the Secretariat General, DG budget and the legal service were systematically consulted. Coordination with EuropeAid did not exclusively focus on the proposal but also on the consequences that the adoption of appropriate measures would have on development cooperation: the rationale behind this consultation was to anticipate the new parameters of development cooperation in Zimbabwe and the conditions that development aid would have to meet as long as article 96 would remain activated (Commission, 2001c; interview 17). Coordination with ECHO did not directly serve the preparation of the decision either but reflected EU humanitarian responsibility and its political commitment not to abandon the population (Commission, 2001c; interview 33). Lastly, coordination with trade was more at the level of information sharing as restrictive measures in trade had been excluded from appropriate measures (Commission, 2001c; interview 14).

Overall, substantially, Development and Relex were the two pivotal actors of the inter-service consultation. As already mentioned, they constituted the core group in the drafting of the 2002 proposal. They worked closely together, each in charge of one aspect of article 96. While Development provided the technical expertise on article 96 and the potential consequences thereof on development cooperation, Relex was more concerned by political developments in the country, not least because of it being in charge of electoral observation. Relex was also closer to the interests expressed by certain Member States (interview 17). Typically, exchanges between Development and Relex - both at DG level and at the political level - illustrated the different approaches to the situation in Zimbabwe (see section 6.6.3). Relex was eager to adopt a strong stance against Mugabe's regime and to prepare a sanction package including article 96 measures to exert pressure on the government. Development officials were likewise concerned about the climate of political violence in Zimbabwe. But they were equally concerned about the adverse effects that article 96 measures could have on the population and the strain it would put on the EU-Zimbabwe relationship, with a risk to further alienate Mugabe's government and to see Mugabe instrumentalise sanctions (interviews 11, 17). The move towards adopting appropriate measures may be interpreted as a victory of the former over the latter, as will be discussed in section 6.5.

In summary, opening up the black box of the decision-making process of the 2002 proposal reveals that the drafting results from the coordination between two opposite positions. Development, formally in the lead, and Relex shaped the Commission's proposal to a large extent. Other DGs of the Commission were also involved in the drafting process, but to different degrees depending on their portfolios and on the direct or indirect impact that article 96 measures would have thereon. 


\subsubsection{The renewal of appropriate measures against Zimbabwe in 2012}

If before the Lisbon Treaty only Commission services formally prepared the proposal, the entry into force of the new Treaty changed the situation. The Commission's decision-making process now presents an inter-institutional dimension. The 2012 proposal to renew article 96 measures against Zimbabwe (COM(2012)26 final) was still adopted by written procedure as a Commission proposal but under the responsibility of the HRVP and in collaboration with the Commissioner for Development. As such, the proposal was prepared by an actor external to the Commission, the newly created EEAS, in association with DG Devco. It was the first proposal fully prepared under the new rules (interviews 11, 19). ${ }^{77}$ After a preliminary remark on the post-Lisbon procedure, this sub-chapter discusses the steps taken to draft the proposal.

\section{The post-Lisbon article 96 procedure}

The entry into force of the Lisbon Treaty introduces minor changes to article 96 procedure, as described in an internal document on article 96 procedure (EEAS/Commission, 2012a). This document was issued in March 2012 only, i.e. after the adoption of the 2012 proposal to renew appropriate measures against Zimbabwe. Little has actually changed but the name of the lead service (interview 31). The newly created EEAS has become the lead service in article 96 proceedings, in association with DG Devco (EEAS/Commission, 2012a). This association materialises the dual nature of article 96 , on the one side the political decision and on the other side the consequences of the decision on development instruments. To prepare any proposal relating to article 96, the EEAS drafts the document and launches the ISC as if it was a Commission DG. Although an external body, the foreign policy service has to follow Commission rules of procedures to prepare the act, which is to be adopted as a Commission proposal: first, it informally consults Commission DGs to test the ground for the proposal and then formally requests their contributions to the draft. The HRVP in her capacity as Vice-President and the Commissioner for Development jointly submit the proposal to the College of Commissioners for adoption by written procedure (ibidem). Although prepared by an outsider, the proposal remains a Commission proposal. Successively, the same steps as before the Lisbon Treaty are taken in the Council. The discussion on the impact of appropriate measures on development cooperation takes place on the basis of background documents drafted by DG Devco. The HRVP chairs the Council meeting, in which the EEAS and the Commission participate - the Commissioner for Development representing the Commission (EEAS/Commission, 2012a).

\footnotetext{
77 The change in article 96 procedure happened in January 2011. However, the Commission's proposal to renew appropriate measures adopted in February 2011 had been prepared under the pre-Lisbon rules.
} 


\section{The leadership of the EEAS in association with DG Devco}

Since Lisbon, the EEAS, is now chef de file on article 96 in association with the Commission DG in charge of development cooperation. Since January 2011, the EEAS desk Zimbabwe is the key policy officer working on the proposal. The change of chef de file necessitated a one-year transition period during which the "business as usual" rule applied, as the consequences of the Lisbon changes for article 96 decision-making had not been specified at first. The post-Lisbon era, although synonymous with a new institutional architecture and a new division of task, is actually characterised by continuity. The change of the chef de file is perceived as more formal than substantial: little has changed but the hat that actors put on (interviews 11, 19). The desk Zimbabwe official was wearing the "DG Development hat" until 31 December 2010 and had to change for the "EEAS hat" on 1 January 2011 (ibidem). Although affiliated to a different service, the policy officer drafting the Commission's proposal was the same before and after Lisbon. Besides, the proposal is now not drafted by the EEAS only but in association with DG Devco. This might be considered a legitimising element of decision-making given Devco's expertise on article 96 in general and its application in Zimbabwe in particular. The same duality is present at the political level, as the HRVP and the Commissioner for development jointly present the proposal to the College. A priori, this new institutional deal complicates coordination, as the EEAS is not formally a DG of the Commission but an outsider: the coordination between different institutions proves more challenging and sensitive than intra-institutional coordination.

The situation of the chef de file is unique as it is now also the permanent chair of the COAFR at the Council, involved in article 96 procedure. DG Devco represents the Commission in this working group. In contrast, the ACP working group is still chaired by the rotating Presidency but DG Devco represents the Commission in the group as well. The change in the chairmanship of COAFR led to a change in the behaviour of the chef de file: with the EEAS in lead, it is a diplomatic actor that drafts the proposal. This coordination - between a diplomatic actor, the EEAS, and a more technical actor characterised by its expertise in development cooperation, the Commission - might be a source of tensions due to the different competencies and responsibilities of the actors involved. These potential difficulties of coordination recalled the difficulties that arose between DG Relex and DG Development, as well as between the Commission's development interests and Member States' objectives, in the drafting of the 2002 proposal to adopt appropriate measures. The relations between the EEAS and the Commission, sometimes difficult, also reflect the proximity between the EEAS and Member States as the foreign policy service chairs and fully participates in the COAFR discussion. It appears that the EEAS has actually managed to play down this opposition as part of its strategy to reach an agreement on the proposal (interview 19).

In 2012, the EU delegation enjoyed enhanced capacities in the field. The new title and the new competences of EU delegations - previously Commission 
delegations - reflect the formal abolition of the pillar structure in the Lisbon Treaty and an enhanced integration of different external policies and instruments. The delegation has competence across the full range of the EU's external policies. It is still in charge of monitoring concrete developments and of providing feedback to Brussels, should a particular situation arise that needs to be addressed. However, as was previously the case, the delegation may also weaken the EU's action if the EU is perceived as applying a double standard, depending for instance on the personality or background of the head of delegation (interviews 17, 19). A head of delegation too close to DG Devco position will be criticised by some Member States. At the opposite end of the spectrum, too strong a focus on human rights issues was perceived by Zimbabwe as a confrontational and biased position (interview 17).

The Lisbon Treaty replaced the Relex-Development tandem by the association between the EEAS and DG Devco. This change materialises the dual nature of appropriate measures. It fully played for the first time in 2012. Thereby, the new Treaty introduced an additional, inter-institutional, dimension to the coordination and consistency challenges in the drafting of the Commission proposal.

\section{Drafting the proposal}

To prepare the 2012 renewal, despite the change in the institutional set-up, the procedural instruments remained the same (EEAS/Commission, 2012a). Commission rules of procedure still applied as for the 2002 proposal. Informal and formal steps taken in the drafting of the proposal are discussed below.

In 2012, much importance was still attached to informal instruments as coordination is not a one-time effort but a continuous process. If the 2002 proposal was adopted in reaction to the crisis in Zimbabwe, in 2012, after 10 years of renewal, there was no tabula rasa in the preparation of the proposal and the actors' positions were well established. The longer officials work on the same dossier, the more important informal contacts are between them - as was the case with the EEAS desk Zimbabwe who, in 2012, had been working on Zimbabwe for three years. Daily contacts, very close working relationships and joint missions served the same purpose as in 2002, forming a consensus and drafting a proposal that would reflect each actor's input. Both the EEAS and DG Devco participated in joint missions in Zimbabwe: the last one before the 2012 decision took place in November 2011 (interview 19). In addition, before formally launching the ISC, the EEAS was also in contact with sectoral DGs other than Devco, in particular ECHO, Trade and the service of foreign policy instruments (interview 19). Overall, the same network as in 2002 prepared the proposal.

Formally, the ISC followed the same steps as in 2002. The EEAS was responsible for creating the conditions for coordination among services to take place, for launching the ISC and for consulting all DGs concerned. In particular, it relied on DG Devco with regard to consequences of article 96 measures on development cooperation. DG Devco (associated to the lead DG) and DG Trade, ECHO, DG Budget, 
the legal service and the Secretariat General were consulted in the ISC (EEAS/Commission, 2011). However, the service of foreign policy instruments was not formally included in the ISC (ibidem). The contribution of DG Devco focused on the development aid channelled by the EU to Zimbabwe: Devco raised consistency concerns as to the amounts of aid still available to Zimbabwe despite the regime of article 96 measures by comparison to other ACP countries targeted by appropriate measures but also by comparison to developing countries in general (see section 6.5). Although no trade measures had been adopted against Zimbabwe, DG Trade was included in the ISC, as in 2002, for strategic reasons. ${ }^{78}$ As DG Trade was negotiating an Economic Partnership Agreement (EPA) with Zimbabwe ${ }^{79}$, the renewal of appropriate measures could jeopardise the EU's position in the negotiations and possibly the new framework for EU-ACP trade (see section 6.5.3).

In conclusion, rules have been adapted to the existence of a new actor and the leading role it has assumed. Article 96 decision-making is now characterised by an inter-institutional dimension. Overall, the key importance of informal efforts remained and coordination in 2012 built on the same network of DGs as in 2002. From the outset of decision-making, the different stakeholders exchanged views on the situation and on the options to address it. This exchange helped to identify the different positions, shared and divergent concerns and different horizons for the drafting to take into consideration. In 2012, the drafting of the proposal to renew article 96 measures had also become a repetitive exercise, in which positions were clearly established. However, contrary to 2002, the political inter-institutional dimension was more openly recognised in the coordination efforts in 2012 given the double-hat of the lead service as lead service on article 96 and permanent chair of the COAFR working group: the aim of the ISC was not only to draft a collegial proposal but also to make a strategic choice on a proposal that would be acceptable to Member States.

\subsection{Consistency challenges}

Chapter 6 has so far introduced the context of the Commission's proposal, explored its policy framework and discussed the steps taken in its drafting. Coordinating the foreign policy, trade and development dimensions in the pursuit of a single objective is challenging, a point to which this section now turns. It raises questions with regard to the content of appropriate measures. ${ }^{80}$ As defined in chapter 3 , the assessment of consistency will be done as follows. The case study evaluates

\footnotetext{
${ }^{78}$ Interviewees did not list DG Trade when first asked the question on the different DGs involved, but added it to the list of DGs included once asked specifically about DG Trade (interview 19).

${ }^{79}$ EPA with Eastern and Southern Africa.

${ }^{80}$ Consistency also constitutes a challenge ex ante when the EU decides to activate article 96 mechanism and to end article 96 consultations as inconclusive. These two elements will not be discussed in this section as they go beyond the scope of this study.
} 
consistency on the basis of the existence or absence of contradictions with the respective primary objectives of the proposals and determines the degree of consistency reached in the proposals on the basis of the scale presented earlier (see p.56). The case study discusses how the balance achieved in theory in the Treaty and policy frameworks is put into practice in the drafting of particular proposals. With the specific objective to restore essential elements in Zimbabwe through appropriate measures, the Commission's proposals may introduce contradictions with the other dimensions of Cotonou. In order to systematically review this issue, the consistency of the individual dimensions of foreign policy, development and trade with the primary objective of the appropriate measures will be discussed separately, before the findings are brought together in the conclusion.

\subsubsection{Consistency between appropriate measures and foreign policy}

The article 96 mechanism is clearly geared towards the realisation of foreign policy objectives such as the respect for human rights and the rule of law. Indeed, as defined by the "essential elements", the foreign policy dimension of Cotonou enjoys a protected legal status. Whenever an ACP partner is considered in breach of democratic principles, the rule of law or human rights, the EU may pressure it into normalising the situation by adopting appropriate measures in the other two dimensions of the Cotonou agreement, development cooperation and trade. The discussion below turns to the question of how the primacy of foreign policy played out in the 2002 proposal ( $1^{\text {st }}$ sub-section) and in the 2012 proposal (2 ${ }^{\text {nd }}$ subsection).

\section{The 2002 Commission's proposal, adopting appropriate measures}

The primary objective of appropriate measures was a foreign policy objective, the restoration of essential elements in Zimbabwe. The 2002 proposal to adopt appropriate measures was drafted and adopted in a short time span. If the move to adopt appropriate measures was very much criticised, the content of the measures did not reflect the focus on foreign policy objectives only but also the Commission's efforts to account for other objectives at the same time.

Procedurally, article 96 consultations provide the EU and the ACP partner with an opportunity to discuss their substantial disagreement. In 2002, these consultations were almost immediately considered inconclusive: steps announced by Zimbabwe in response to EU requests were deemed insufficient (Council, 2002f). The EU's decision to conclude article 96 consultations was also a reaction to intimidation attempts at members of the EU's electoral observation mission (Stübig, 2007:2; Weiland, 2004:127). The outcome of the consultations and the move to appropriate measures did not come as a surprise as it had been clear for almost two years already that no other policy decision would be acceptable to the Council (Council, 2000c). As one interviewee put it, "the only clash had been 
political on the decision to activate article 96 or not"; once article 96 activated, there was little doubt as to the outcome of the process (interview 17). As summarized in a Council document (Council, 2002f), although formally different, all policy options either implicitly or explicitly refer to the adoption of appropriate measures against Zimbabwe, as if the EU had already decided to take measures (Weiland, 2004:135).

Substantially, appropriate measures were justified in principled terms by the violations of essential elements. The adoption of appropriate measures responded to the deterioration of human rights record, the non-respect for democratic principles (freedom of expression, violence and intimidation), attacks against the rule of law, the erosion of the quality of governance, the authoritarianism of the ruling party, illegal occupation of farmland and regional destabilisation (Giumelli, 2013:32; Council, 2002b). ${ }^{81}$

A 'sanction package' was adopted on 18 February 2002 - the Council adopted appropriate measures as well as CFSP sanctions (Council, 2002c). The following article 96 appropriate measures were adopted: suspension of the budgetary support under EDF7 and EDF8, suspension of financial support for all projects except those in direct support of the population, re-orientation of financial support to assist the population, suspension of the signature of EDF9 (Bradley, 2005:12-13; Commission, 2002c: annex; Council, 2002b). While these measures "target[ed] President Mugabe's immediate circle with the intention of internationally isolating Zimbabwe's leadership and bringing about a change in government policies" (Weiland, 2004:127), they were also designed not to completely disregard objectives other than foreign policy objectives. Consequently, the decision was taken not to totally suspend development cooperation (only direct budgetary support was suspended, see above) and to exclude trade measures from appropriate measures. Deciding otherwise would have harmed the population, put at risk Zimbabwean development and above all introduced an additional risk of instrumentalisation of article 96 measures that would have run counter to foreign policy objectives (see sections below).

\section{The 2012 proposal, renewing appropriate measures}

In a timespan of ten years, the situation in the field in Zimbabwe had changed. Despite the fact that it considered that essential elements were still not restored in 2012, the EU acknowledged the progress made and consequently reconsidered its strategy.

First, article 96 measures have to be understood as part of the larger EU sanction package adopted against Zimbabwe. The EU combined the use of article 96 measures and CFSP sanctions to have lever over Mugabe and eventually to restore

\footnotetext{
81 These were also the same reasons that had led to the activation of article 96 (Commission, 2001a; Council, 2002h :15-17 \& 2002g).
} 
essential elements. Indeed, appropriate measures and CFSP sanctions were adopted for the first time on the same day in February 2002 and the package was renewed every year for a period of ten years. In February 2012, the EU recognised that some progress had finally been made (Commission, 2012d: (3) and (4)). Nevertheless, it renewed the measures because "the implementation of political reforms [had] remain[ed] slow and certain essential elements of the ACP-EU partnership agreement, to which the GNU [Government of National Unity] had committed in the Global Political Agreement [GPA], still need[ed] to be implemented" (Commission, 2012d: (4)). This remark concerned the constitutional process, and the organisation of peaceful and credible elections (Commission, 2012d: article 1 and annex). The measures were however renewed for six months only, a shorter period than the previous one-year renewals, a fact that further illustrated the EU's reengagement and its more dynamic approach to Zimbabwe (Commission, 2012d: article 1). Shortly afterwards, on the basis of the progress made in implementing the GPA, the constructive dialogue with all parties in the GNU and the steps taken "to improve the freedom and prosperity of the Zimbabwean people", the EU agreed to suspend the appropriate measures (Council, 2012a).

Second, if foreign policy objectives initially led to the imposition of a very strict framework on the cooperation between the EU and Zimbabwe (article 96 framework), this framework has been progressively relaxed over time. The first decisions on appropriate measures were particularly constraining for development cooperation, but the conditions have been relaxed over time. For instance, the Commission introduced the possibility to provide for "transitional assistance (...) [in] the implementation of the GPA in support of the GNU and its reforms programmes" in its 2012 proposal (Commission, 2012d: annex). The relaxation of the framework for development cooperation illustrates the adoption of a positive action to support civil society and political organisations. Initially seeking to constrain the activities of the government, the EU later on began to adjust sanctions to create incentives to encourage political change in Zimbabwe (Giumelli, 2012:3233). Conditions on development cooperation reached out to the institutional and political fundamentals of a country. In addition to working towards the long-term political change in the country, which include the full restoration of essential elements and their consolidation, these elements were also considered to be key in development strategies in general, a point that will be made in the next section (interviews 11, 19, 25, 26, 27). Overall, the relaxation of conditions in 2012 enhanced the consistency of the proposal.

\section{Conclusion}

In conclusion, in absolute terms, appropriate measures were justified on the basis of violations of essential elements and have remained so between 2002 and 2012, as the political situation in Zimbabwe had still not fully normalised (Commission, 
2012d: (4)). All the steps taken under article 96 illustrated the primacy of foreign policy objectives. ${ }^{82}$ Development and trade concerns appeared to be secondary elements in the initial analysis given the urgency of the political situation. Overall, the existence of a hierarchy of objectives does not mean that a decision is inconsistent (Laakso et al., 2007:35). On the contrary, the hierarchy of objectives clearly states what is the main objective of the EU - the foreign policy objective to restore essential elements - to which any other dimension of the action is supposed to contribute.

If both proposals were found to be consistent, they were so to different degrees. In 2002, by sanctioning the government and subjecting development cooperation to restrictive conditions, the EU aimed to pressure Mugabe's regime into normalising the situation. However, if the introduction of this restrictive framework did not contradict the primary objective, it did not reinforce it either, leading the EU to be strongly criticised by ACP countries and leaving Mugabe in a position to instrumentalise the EU's action. For this reason, on this dimension, the proposal reaches a medium degree of consistency.

In 2012, the primary objective of the restoration of essential elements remained the same as in 2002 for the EU assessed that the progress made did not suffice. The proposal renewed appropriate measures but for a shorter period of time than the previous renewals and under relaxed conditions: it did not contradict the Commission's primary objective and even actively supported its realisation for several reasons. It gave the image of a pro-active Union, acknowledging the progress made in Zimbabwe notably on the basis of the implementation of the GPA. The renewal materialised the re-engagement strategy of the EU as relaxed conditions allowed a direct political intervention of the Union, which could thereby contribute to the realisation of the objective in the areas it had identified as lacking progress. The Union also appeared willing to directly support regional mediation efforts towards the normalisation of the situation in Zimbabwe. Therefore, it qualifies for a high degree of consistency.

\subsubsection{Consistency of appropriate measures with development objectives}

The coordination of foreign policy and development objectives proved more difficult between 2002 and 2012. It seemed contradictory that a government sanctioned by the EU was still receiving development aid from the EU. One may argue that foreign policy and development objectives are two faces of the same coin to the extent that development is also concerned with a country's political fundamentals - such as the absence of state-sponsored political violence, the organisation of free and fair elections, the respect of human rights, the rule of law or press freedom. But often under article 96, the focus is perceived as an "either-or"

\footnotetext{
82 The idea of the primacy of foreign policy objectives is also supported by the adoption of CFSP sanctions against Zimbabwe and the inclusion of Zimbabwe in the Kimberley process.
} 
choice. So, the question arises whether the focus placed on foreign policy is at the expense of development or whether the continuation of development cooperation contradicts foreign policy objectives? The primacy of foreign policy objectives is enshrined in the article 96 mechanism as essential elements are given a special legal protection. However, development objectives are not put aside up-front: they are instead adapted to the article 96 regime, as we will see in the case of Zimbabwe.

\section{Risk of contradiction and actual contradiction}

Article 96 measures introduce a risk of contradictions with development objectives because they impose a constraining framework for development cooperation.

When appropriate measures are adopted, only specific EDF funds are available and projects funded by development aid have to fulfil specific conditions. With regard to the availability of funds, article 96 measures prevent the "A-envelope" (for a country, l'enveloppe pays) for general budget support from being used (interviews 4, 5, 6, 13; Commission, DG Devco-EuropeAid, 2012f). This is an important limitation in terms of the funding available, which constrains the government targeted. However, it does not mean that EDF cannot be used at all. To avoid systematically undermining development objectives, funds may come from the EDF "B-envelope", the reserves for unforeseen needs (Article 3.2 of the annex IV of the Cotonou agreement; interview 13). Suspension is meant for projects that are not yet in place - on-going programs are left unaffected. Besides, the restriction does not apply to other budget lines and financial instruments. Second, it means that, for EDF and other budget lines and financial instruments to be used, certain conditions must be met.

Regarding the question of conditions attached to the spending of funds from the EDF and other budget lines and financial instruments, appropriate measures in practice only partially suspended development cooperation in Zimbabwe. Under certain conditions, the use of development funds continued when appropriate measures were in place. Thus,

[t]he financing of all projects and budgetary support (...) is suspended except those in direct support of the population (...). Financing shall be reoriented in direct support of the population, in particular in the social sectors, democratisation, respect for human rights and the rule of law. (Commission, 2002c: annex I)

The same conditions remained in the 2012 renewal (Commission, 2012d: annex). It meant that aid did not use official, government channels. Aid was channelled through international organisations and non-governmental organisations. The 2012 renewal reaffirmed the relaxed conditions introduced in 2010 to allow "support to institutions and processes related to the implementation of the Global Political Agreement" (Council, 2010d; interviews 3, 4) and the support that the EU "continue[d] to provide to the economic recovery, social sectors and the 
implementation of the GPA" (Commission, 2012d: annex). ${ }^{83}$ Provided that these conditions were met, development cooperation with Zimbabwe continued. The EDF still represented $30 \%$ of the total aid in Zimbabwe (Delegation of the EU to Zimbabwe, n.d. e). Besides the EDF, depending on the priority areas and the nature of projects, specific budget lines and instruments were used - provided that the conditions specified in the appropriate measures were met. ${ }^{84}$ Development cooperation also included the support provided to government priorities under the GPA, the so-called "transitional aid" (interviews 11, 19 and 23; Commission, 2012d: annex; Ministry of Finance of Zimbabwe, 2012). The continuation of development cooperation was consistent with development objectives, especially given the dramatic economic situation in which the country was sinking when appropriate measures were first adopted.

Overall, although it would have been possible, development cooperation was never totally suspended in Zimbabwe. A total suspension would have had dramatic consequences on the humanitarian situation (Giumelli, 2013:32). It could also have been instrumentalised by Mugabe's regime. In general, however, the impact of article 96 on development cooperation is not clear-cut. Firstly, in theory, article 96 reduces the amount of financial resources available for development cooperation with a country. If measures are implemented over a long period of time, as it was the case with Zimbabwe, reserves diminish. Zimbabwe however proved a deviant case in this respect, as development aid remained very important in terms of the amounts available. Secondly, article 96 severely constrains the use of development aid. For development cooperation to be effective, the privileged option is direct budget support and the use of official government channels; this however is precisely what is prohibited under article 96 (interviews 11,19). Preventing direct budget support decreases the effectiveness of development cooperation and

\footnotetext{
${ }^{83}$ The reorientation of EU strategy is also visible in the ad hoc programming documents used in Zimbabwe. These documents are development in agreement with the priorities of the Government of Zimbabwe to accompany the political reform process (interviews 5, 6, 13; Delegation of the EU to Zimbabwe, n.d. b; Delegation of the EU to Zimbabwe, 2010).

84 These include under Title 19 "External Relations" and Title 21 "Development and Relations with ACP States": the European Instrument for Democracy and Human Rights (which covers action supporting civil society, promoting human rights and electoral observation inter alia), food security, non-state actors in development (support to civil society), human and social development (covering action in health, education, gender equality and decentralised cooperation for instance) and geographical cooperation with ACP states (2012 Budget of the European Union, vol. II, section III Commission, 2012). In Zimbabwe, EU development aid focuses on three priority sectors: social sectors (health and education), food security/agriculture and governance (democratisation, human rights and rule of law) in which the added value for the population is well established as per the conditions established since the 2002 proposal and subsequently revised (see for instance Ministry of finance of Zimbabwe, 2012). Each of the three priority sectors also illustrates the intermeddled nature of foreign policy, development and trade objectives. For instance, the action in food security and agriculture contributes to development at the micro- and macro-level (small scale farmers, land reform programme and sugar adaptation strategy to support the recovery of the commodity sector for instance) and to trade (Delegation of the EU to Zimbabwe, no date a).
} 
weakens the government structures as they are under-used (interviews 11, 19). Obviously, this conflicts with institution building as a development objective (interviews 11, 19, 25). Lastly, article 96 also constitutes a particularly heavy machinery as there is "no stop-and-go" with this type of measures: it is a constraint on development cooperation in the medium- to long-term (interviews 25, 27). In conclusion, article 96 entails a risk of inconsistency with development objectives in theory. The actual bearing on the consistency of article 96 measures depends on the exact provisions of the decision to adopt appropriate measures and the conditions imposed upon development cooperation, as discussed above.

\section{The mutually reinforcing nature of development and foreign policy objectives?}

The Commission outlines the potential contribution that development cooperation can make to foreign policy objectives. The EU strategy for Zimbabwe 2012-2013 was self-explanatory in that respect and detailed how foreign policy and development objectives were closely intertwined:

\footnotetext{
The overall objective of EU support is to contribute to a democratic, peaceful and prospering Zimbabwe. The emphasis of the Medium Term Strategy for 2012-2013 is on contributing to an environment conducive for credible elections, by supporting the continued economic recovery and the restoration of basic social services, as well as supporting the effective implementation of governance reforms in the GPA and promoting human rights and the rule of law (“EU strategy for Zimbabwe 2012-2013" in EEAS/Commission, 2012b).
}

When measures were first adopted in 2002, the partial suspension of development cooperation was an instrument to put pressure on Zimbabwe's government in an attempt to make it comply with the EU's political demands in the short term. The instrumentalisation of EDF development aid explicitly started in 2006 (Commission, 2006a). Appropriate measures were adjusted in 2010 and 2011, allowing support for the political stabilisation process and the reform programme of the Government of National Unity (Commission, 2010k; Commission, DG Devco, 2012f; interview 11, 19, 31). In 2012, the relaxation of conditions on development cooperation made even clearer the contribution of development cooperation to foreign policy objectives in the medium- to long-term:

[T] he EU will continue to provide transitional assistance to the economic recovery, social sectors and the implementation of the GPA. 85

The EU supports the GNU in its entirety which presently constitutes the only political framework for restoring democracy. The GPA sets out a series of reforms which address EU concerns on human rights, rule of law and democratic principles such as the elaboration of a new constitution, a land audit, a national healing process, independence of the media etc. Its

\footnotetext{
85 The new condition was introduced in Commission 2010k. In the 2012 renewal, the same condition is recalled; Commission, 2012d: annex; Darracq, 2010:10 and 17-22; interviews 4, 7, 8, 10.
} 
implementation is essential for the conduct of credible elections (Commission, 2012d: Exploratory Memorandum para.6).

For instance, the EU supported the Zimbabwe's electoral commission although its chairwoman was on the list of individuals targeted by CFSP sanctions. Often used as a carrot in the reengagement strategy, the suspension of measures was decided in July 2012 and the EU welcomed the possibility, finally, "to work directly with the GNU to develop new assistance programmes for the benefit of the people of Zimbabwe that would come on stream under the next European Development Fund" (Council, 2012a).

Despite the existence of a sanction package targeting the regime, the EU wanted the Zimbabwean population to perceive it as a development actor committed to providing significant support (interviews 19, 25, 26). Overall, the biggest share of the development aid Zimbabwe received between 2002 and 2012 still came from the EU and Member States despite article 96 measures - article 96 restrictions do not affect bilateral cooperation. By so doing, the EU tried to raise the awareness among the population of the benefits of development aid, in an attempt to shape the outcome of the electoral period opened in Zimbabwe until the 2013 elections (interview 19). ${ }^{86}$ In conclusion, for EU action in Zimbabwe to be consistent with development objectives, it was impossible to simply suspend development cooperation. While constraining development cooperation to a certain extent, the adopted measures left possibilities for development cooperation to take place. The continuation of development cooperation might have seemed odd in the light of the EU's condemnation of Mugabe's regime. However, this decision was to be understood in a long-term perspective. Development cooperation in Zimbabwe under article 96 measures aimed to building the conditions for the restoration of essential elements in the long-term. ${ }^{87}$ The two Commission's proposals thus were consistent with the objective to pressure Mugabe into restoring essential elements.

\footnotetext{
${ }^{86}$ After the 2012 renewal of appropriate measures, the decision on an ad hoc $€ 60$ million allocation for Zimbabwe was but another illustration of EU continued engagement despite the sanctions and of the intersection between development cooperation and foreign policy objectives (EEAS/Commission, 2012 b).

${ }^{87}$ The amounts of development aid available to Zimbabwe raise an additional consistency question, which falls outside of the scope of this research, the consistency of the situation with EU development policy at large. Since 2009 only, the EU has provided $c a$. €1 billion to the African country (Commission, DG Devco, 2012f). The 2009-2010 period even marked an important increase in aid, which is part of the EU's reengagement strategy and its willingness to accompany the GPA process with overall €110 million per year on average (Delegation of the EU to Zimbabwe, n.d. e \& 2010; Ministry of Finance of Zimbabwe, 2012; see also WTO, 2011:16-17; interview 23). Compared to other DCs and to other countries targeted by article 96 , Zimbabwe seemed to be in a favourable position (interview 31 ).
} 


\section{Conclusion}

In conclusion, there was no contradiction with the primary objective in both the 2002 and the 2012 proposals. Restrictions on development cooperation resulted from the choice to put pressure on Mugabe's government. However, the degrees of consistency of both proposals differed. By introducing a constraining framework for development cooperation, article 96 measures constituted an impediment to the realisation of development objectives, which were secondary in the case of Zimbabwe. Appropriate measures restricted the type of funding available and the nature of development projects that could be funded, thereby limiting the impact of EU development cooperation in Zimbabwe. Consequently, on this dimension, the 2002 proposal reached only a low degree of consistency. In 2012, the situation had evolved and the constraints on development cooperation had been relaxed by the Commission's proposal. The new framework of appropriate measures allowed for a more direct action of the Union in Zimbabwe in the field of development, thereby supporting the primary objective of restoring essential elements. It qualifies for a high degree of consistency.

\subsubsection{Consistency of appropriate measures with trade}

\section{The risks associated with trade measures}

Appropriate measures did not include a trade dimension for three reasons (Commission, 2002c). ${ }^{88}$ First, trade measures would have jeopardised foreign policy objectives not only in Zimbabwe but could also have had far-reaching consequences for EU external relations more broadly. Adopting trade measures would have meant withdrawing trade preferences, which would in turn have put strain on the EU-ACP relation in general. Indeed, in 2002, ACP states participated in the initial article 96 consultations between the EU and Zimbabwe and expressed their concerns that, should the EU withdraw trade preferences, this would create a precedent. It would have been the first time that trade preferences were withdrawn under the Cotonou agreement (interview 14). The EU could not take the risk to create a hostile coalition of ACP states, which in turn would have reinforced Zimbabwe's position and correspondingly weakened the EU (interviews 11, 14, 17, 19). Secondly, adopting trade restrictions would also have run counter to development objectives (Portela, 2014:7). ${ }^{89}$ Indeed, trade is an important instrument for economic development. Trade measures were threatening to penalise mostly farmers, the engine of the economy, thus further weakening

\footnotetext{
${ }^{88}$ The only trade element of the sanction package was the arms embargo adopted under the CFSP sanctions.

${ }^{89}$ The absence of trade measures did not prevent EU-Zimbabwe trade to decrease significantly because of the severity of the economic crisis and the loss of productive capital, reaching its lowest in 2004-2005 before a revival from 2010 onwards (Commission, DG Trade, 2012d).
} 
Zimbabwe's economic development. Thirdly, the Zimbabwe government might also have instrumentalised trade measures as targeting an innocent population, contrary to the concept of targeted sanctions (see section 6.3.3).

\section{Conclusion}

Overall, the decision not to adopt trade restrictions in 2002 and not to introduce trade measures in 2012 did not contradict the primary foreign policy objective but it did not actively support this primary objective either. In addition it was also consistent with the EU's secondary development objectives in Zimbabwe. This qualifies for a medium degree of consistency in 2002 and in 2012.

Interestingly, in 2012, the existence of appropriate measures against Mugabe created problems regarding the larger context of EU trade policy with ACP partners and the negotiations of Economic Partnership Agreements (EPA; see section 6.6.4). Although this EPA was the first EPA with an African region that has entered into force (interview 30; Commission, 2012b), the uncertainty created by the situation illustrates the importance of the trade dimension in the handling of the EUZimbabwe relations.

\subsubsection{Assessing consistency}

In conclusion, assessing the consistency of the Commission's proposals is a complex exercise not only because the different dimensions of the Cotonou agreement are particularly interlinked, but also because the impact of appropriate measures on these dimensions is not straightforward. In 2002 and in 2012, article 96 measures responded to violations of essential elements and put pressure on Zimbabwe for the restoration of essential elements. Discussing the different dimensions of EU action against Mugabe's regime one by one, the assessment above showed that the two Commission proposals were consistent but to different degrees. Consistency was defined as the absence of contradiction between the primary objective of a proposal and the rest of the provisions of this proposal. In the case study on Zimbabwe, the individual dimensions of the EU's action supported the primary objective of the Union, the restoration of essential elements. This section discussed the potential for contradiction between such a primary objective and the total suspension of development cooperation as well as the adoption of trade restrictions. The decision of the EU to partially suspend development aid and to exclude trade measures was an informed decision taken not to jeopardise the foreign policy primary objective and in an attempt to capitalise on the different dimensions of the Cotonou agreement to work towards the restoration of essential elements in Zimbabwe.

Although both proposals were found to be consistent, they were so to different degrees. On the basis of the intermediate conclusions drawn above, it appears that the 2002 proposal reached a low to medium degree of consistency (medium, low, 
medium) while the 2012 proposal reached a medium to high degree of consistency (high, high, medium). Between 2002 and 2012, as also revealed by the initial expectations of the interviewees, the Commission enhanced the consistency of its proposals on appropriate measures. Indeed, while development cooperation remained constrained by article 96, the Commission relaxed the conditions imposed on development cooperation in order to directly contribute to the political changes taking place in the field.

Assessing the consistency of the Commission's proposals only constitutes one dimension of this research. On the basis of the findings on the degree of consistency of both proposals, this section can conclude that coordination was limitedly to moderately in 2002 and moderately fully successful in 2012. In turn, this conclusion leads to ask how such an outcome was possible, in particular despite conflicts within the Commission and the tough stance adopted by some Member States. On the basis of the empirical material, the next analytical step is to identify the factors that explain the extent of the success of coordination.

\subsection{The factors explaining successful coordination}

This research posits that the three-level framework is key in achieving consistency and that coordination in particular is of crucial importance. Typically, the drafting of a Commission proposal is subject to contradictory pressures that may impact upon this process. This section aims to answer the questions that were just raised in the conclusion above. Several elements were pondered when the Commission was preparing its proposals in 2002 and in 2012, elements that are deducted from our empirical research and that will now be discussed. Both external and internal to the Commission, four kinds of factors are identified. These include the international reaction to the situation in Zimbabwe; the salience of Member States' interests; the nature of the proposals; and bureaucratic politics.

\subsubsection{The international factor}

Generally speaking, the international environment influences EU decisions. This international factor is the first factor to consider in the case study on Zimbabwe. It has evolved between 2002 and 2012.

In 2002, this factor pulled in two opposite directions. Between 1980 and the early 2000s, few international initiatives were taken against Mugabe's regime, and pressure from the international public opinion increased in the wake of violence against the population and the unprecedented economic crisis. Media and NGOs were drawing the attention of international actors to a rapidly deteriorating situation. The first measures against Mugabe's regime were taken by international financial institutions. The IMF and the World Bank suspended their cooperation with Zimbabwe in 1999 and 2000 but no direct action was taken by the United 
Nations. Shy responses by individual countries or regional organisations followed suit. In 2001, the US passed the "Zimbabwe Democracy and Economy Recovery Act", which led to the adoption of a freezing of financial assets of and a visa ban on the persons responsible for political violence (which entered into force in 2003 only). It instructed US directors on the boards of the World Bank and the IMF to vote against any lending to Zimbabwe except on humanitarian grounds (Forsythe, 2009, vol.5:262, 403). The Commonwealth decided to suspend Zimbabwe in 2002. However, the condemnation of the government's abuses in Zimbabwe was not universal. The SADC (Southern African Development Community), neighbours and regional actors in Africa were supporting Zimbabwe because of Mugabe's prestige as a hero of the independence war. Zimbabwe exploited these differences: it engaged in a war of images, playing on international divisions and instrumentalising sanctions that were not endorsed by the United Nations. Under those conditions, the right balance was particularly difficult to find for the EU. It felt pressure from different sides and in different directions, fully aware of the complications that would result from its action. These divisions were also evident internally. The situation represented a consistency challenge as on the one side the violations of human rights could hardly be left unpunished while on the other side the dramatic economic situation in the country prevented any external actor from simply suspending developing cooperation. Besides, international actors were also aware of the risk that an action against Mugabe would constitute for the relationship with Africa and with ACP countries (interviews 17, 19). EU-Africa and EU-ACP relations were already tense. An EU-SADC meeting was relocated from Copenhagen to Maputo because of the travel ban targeting members of Mugabe's government; the $4^{\text {th }}$ session of the ACP-EU joint parliamentary assembly in 2002 was cancelled at the last minute because the European Parliament did not allow two Zimbabwean Ministers to access the building. This type of pressure could have led the EU to adopt a very careful approach to Zimbabwe, possibly putting the adoption of a sanction package on hold, to avoid sharp criticisms, including criticisms about the inconsistency of its action. Eventually, the combination of international condemnations and of a rapidly deteriorating situation in the country, violence escalation but also intimidation attempts at the members of the EU's electoral observation mission led the EU to decide on action.

In 2012, another type of international strategic calculations factored in the decision. After ten years of marginally effective attempts to influence the political situation in Zimbabwe and to work towards a regime change, actors aimed at a more dynamic strategy (interviews 11, 19, 25). The EU was also aware of the limitations of the previous strategy: article 96 had not allowed it to play a dynamic role in the attempt to reach its foreign policy objectives in Zimbabwe. In addition, the EU's strategic change also responded to changed regional dynamics. The request to better accompany the political process came from Zimbabwe's neighbours involved in the mediation process. The Southern African Development Community (SADC) summit held in Livingstone in March 2011 marked a change in 
South Africa's approach to Zimbabwe (SADC, 2011). The more critical stance adopted by South Africa vis-à-vis Mugabe reassured the EU. The Union conceded a softening of article 96 regime to accompany mediation efforts by South Africa's President to normalise the situation in Zimbabwe (Commission, 2012d: (5), (11), (12) and annex)..$^{90}$ Besides, the EU also wanted to signal its support to South Africa, which was considered a strategic partner (interviews 11, 19, 25, 26, 27). ${ }^{91}$

The international factor pulled in different directions in 2002 and in 2012. International pressures did not formally bind the EU. The intensity of international criticism vis-à-vis Mugabe's regime in 2002 however certainly contributed to the EU's willingness to send a strong signal when it first adopted the sanction package including appropriate measures. Thus, international events strengthened the voice of hardliners in Brussels, contributing to the decision to adopt appropriate measures in the first place. At the same time, the international factor also constrained the EU's action for the EU did not want its action to raise too loud criticisms of inconsistency. Because of the risk that appropriate measures in general and in particular against Mugabe would create for the EU-ACP relationship, the Commission favoured a balanced approach, through which it only partially suspended development cooperation and did not adopt trade restrictions. Ten years later, the insufficient progress achieved by these earlier measures and a changing regional context led the EU to rethink its strategy and to design a more comprehensive approach towards Zimbabwe. The lack of progress and the necessity to move to a comprehensive approach led the Commission to relax the conditions imposed on development cooperation, to better support political developments in Zimbabwe and to accompany regional mediation. In both cases, international dynamics - combined with the influence of hardliners in Brussels (see next section) - set the tone for what would be the acceptable decision with respect to the violations of essential elements in Zimbabwe.

\subsubsection{The Member States factor}

The nature of the Cotonou agreement as a mixed agreement implies an important role of the Council both in 2002 and in 2012. This situation put pressure on the lead service on article 96, which was DG Development in 2002, and the EEAS in collaboration with DG Devco in 2012. This sub-section explores the influence of Member States on the Commission's internal process. It introduces the major lines of divergence between Member States, the consequences of which are further developed with respect to Council-Commission (for the 2002 proposal) and EEASCommission-Council (for the 2012 proposal) dynamics.

\footnotetext{
${ }^{90}$ Later, it would also be in the light of the progress made on the SADC roadmap that the EU decided to suspend article 96 measures (Council, 2012a).

${ }^{91}$ The EU and South Africa have signed a strategic partnership agreement in 2007. Zimbabwe has been a shared concern in this relationship (see for instance SADC, 2011:5).
} 
The Commission usually prefers presenting a proposal that is acceptable to the Council, a circumstance that in turn constrains the options available to the Commission (Laakso et al., 2007:17). In 2002, the Commission was aware of the salience and the polarization of national interests (Laakso et al., 2007:69). The United Kingdom was the only EU Member State for which Zimbabwe was both an internal and a foreign policy issue (Cameron, 2010:9-10; Hazelzet, 2005:9-10). With a strong pull from its public opinion ${ }^{92}$, it was the leader of the hardliners, having itself adopted sanctions already in 2000 (Grebe, 2010:12; Stübig, 2007:2; interviews 17, 19, 26). For the UK, a quick and forceful answer to the situation was the only option in 2002 (Grebe, 2010:13), a position supported by Nordic countries, as well as by the Netherlands and Germany. Sweden in particular, holding the rotating presidency during the first semester of 2001, played a critical role. On the other side of the spectrum, Belgium, Spain and France adopted a more moderate position, opting to leave open the political dialogue.

These diverging positions, but also the fact that article 96 had been activated upon the request of the Council that would decide on the Commission's proposal constrained the options available to the Commission in 2002. Bilateral consultations between the Commission and Member States - notably the United Kingdom, Sweden and France - tested policy options (Council, 2002f; interview 17) although there was little doubt as to the outcome of these consultations (Weiland, 2004:134-135). Strong and polarised national interests left the adoption of appropriate measures as the only possible option to send a strong signal against an illegitimate regime (Commission, 2001b; Giumelli, 2013:32; Grebe, 2010:13).

In 2012, the Member States factor had evolved. The proposal to renew appropriate measures was prepared by the EEAS in collaboration with the Commission. In the preparation of the proposal to renew appropriate measures, a full normalisation of EU-Zimbabwe relation and the suspension of article 96 measures were still not acceptable to a few Member States (interviews 24, 25, 27). The dossier had remained very sensitive for the UK, even if the position of Nordic countries had evolved towards a more dynamic approach to Zimbabwe (interview 26). The continued sensitivity explains how the renewal was agreed upon while elements of a reengagement strategy were included in the package (Commission, 2012d: explanatory memorandum (5), (6), (7), (9)).

A characteristic of the EEAS hierarchy is particularly interesting to note with regard to the drafting of the 2012 proposal. Looking at the nationalities of the EEAS Director for Africa and of the chairperson of COAFR, it is easy to point at an AngloSaxon connection, all the more since the Director for Africa is said to have a privileged relationship with the HRVP: the chairperson of COAFR, Mrs Lunny, is Irish, and the Director for Africa at the EEAS, Mr Wescott, is a British diplomat. However, only one interviewee emphasized this connection (interview 26). The

\footnotetext{
${ }^{92}$ The land question and the violence used against white farmers in particular triggered a violent reaction of the British public opinion (see section 6.2).
} 
presence of DG Devco, representing the Commission, in COAFR meetings appears to be a safeguard and aims at a balanced articulation between development and foreign policy objectives in the handling of article 96.

Because of the nature of EU competence, Member States' interests were a significant determinant of the drafting of both proposals. They constrained the Commission's choice even before coordination took place during the drafting of the proposal. The Member States factor determined the acceptable policy options. Despite the existence of two opposing blocs of Member States, the Commission was not in a position to play one against the other and the harder line prevailed. The hardliners' influence strengthened the position of the Relex cabinet and DG Relex, which was crucial in the decision to adopt appropriate measures. In 2012, the positions were not as extremely opposed as in 2002 anymore but some Member States still could not accept the suspension of appropriate measures against Zimbabwe. It led to the compromise between the renewal of article 96 measures and the relaxation of conditions imposed on development cooperation.

\subsubsection{The nature of the decision}

The nature of decision-making is an important factor to consider, all the more in this case study since it evolved substantially between 2002 and 2012. It is defined by several elements.

The distinction between crisis and routine decision-making is the first determinant. It does not only define the decision-making instruments used but also the choices made in the drafting of the proposal. By definition, the 2002 Commission's proposal addressed a crisis situation in Zimbabwe. Crisis decisionmaking requires a quick action. Evidently in that case, there is no strategic planning phase before the decision is taken. Besides, the preparatory phase of the decision is also simplified, as for instance no impact assessment is required. In addition to the absence of certain coordination instruments, crisis decision-making also allows less time for coordination. The nature of the decision in 2002 played in favour of the hardliners: the perceived necessity to act quickly and to provide a forceful response to the violations of human rights in Zimbabwe strengthened the influence of hardliners in the drafting process. It left the other camp, led by DG Devco in a position in which it could only mitigate the potential negative consequences of the adoption of appropriate measures. The result was the only partial suspension of development cooperation and the exclusion of trade restrictions in order to not further destabilise the country but also not to run counter to the EU's own foreign policy objectives in Zimbabwe. In contrast, the 2012 proposal cannot be qualified as crisis decision-making anymore. The ties between the officials who had been working for ten years on Zimbabwe were consolidated by then. They created a common ground to prepare the yearly renewal of appropriate measures. The permanent contacts between officials and shared understanding of the situation palliated the absence of certain decision-making instruments and facilitated 
coordination over time by smoothing working relationships between the different DGs. A consensus had emerged over time on the necessity to adapt the EU's strategy in Zimbabwe, thus paving the way for the relaxation of appropriate measures.

The political importance of the proposal that the Commission is preparing is the second determinant to take into consideration. The 2002 and 2012 proposals were not considered important pieces of legislation as such. However, the Member States were looking to send a strong signal. As shown above, this introduced a bias in decision-making for a particular policy option and strengthened the position of hardliners.

Lastly, the legal nature of the competence is also important. In the Zimbabwe case, the situation was complicated by the fact that foreign policy remains a competence of the Member States, while development cooperation is a mixed competence, and trade policy an exclusive competence. The three dimensions of EU appropriate measures against Zimbabwe were responding to different dynamics and different institutional contexts, and also had consequences beyond appropriate measures for EU action in Zimbabwe in general. It resulted from the nature of the competence that Member States were particularly influential in the decisionmaking process, even in the Commission's internal decision-making. This factor contributed to the strength of hardliners in the drafting, steering the Commission towards the adoption and the renewal of appropriate measures.

\subsubsection{Bureaucratic politics}

Lastly, opening the black box of internal processes within the Commission revealed inter-service dynamics in the drafting of the proposals. Within the Commission in 2002 and between the EEAS and the Commission in 2012, several actors were involved in the preparation of the proposals. Exploring the drafting of both proposals brings to the fore the conflicting positions taken by these different actors and the extent to which they were coordinated. We concentrated on the contributions made by DG Trade and DG Relex on the draft circulated by DG Development in 2002 and by DG Trade and DG Devco on the draft circulated by the EEAS in 2012 as we were looking at the coordination between trade and development on the one side and foreign policy on the other side.

Already in 2002, the preparation of the Commission's proposal was marked by tensions between DGs. This section focuses on the contributions by DG Trade and DG Relex. ${ }^{93}$ The tensions did not oppose DG Trade and Development, but DG Relex and DG Development (interviews 11,17).

DG Development and DG Trade are usually said to have different mindsets and different objectives but, in that case, officials from both DGs were working along the same lines (interviews 14,15 ). One important factor in this was that the unit in DG

\footnotetext{
${ }^{93} \mathrm{ECHO}$, another external DG, also contributed to the ISC. It was however not involved to the same extent in the drafting as humanitarian aid was not to be affected by article 96 measures (interview 33).
} 
Trade dealing with trade with ACP countries had belonged to DG Development until it was transferred to the newly created DG Trade in 1999. This unit's officials thus had an approach to the topic that was compatible to the one of DG Development (ibidem). It was only in 2010 that a head of unit was appointed for this unit who had not been at DG Development before (interview 15). In addition to the absence of up-front opposition in the approach of DG Development and DG Trade, DG Trade also occupied a back seat position in the consultations on the proposal, as appropriate measures did not include restrictive trade measures.

The main internal gap occurred between DG Development and DG Relex, as also illustrated at the political level by the divergent positions adopted by the cabinets of Commissioners Patten (external relations) and Nielson (development). This tension was due to different foci of action of the two sides. On the one hand, Relex was involved in electoral observation and thus was focusing on violations of the essential elements of the Cotonou agreement. DG Relex was also the first point of contact of Member States within the Commission, in particular of the hardliners, and thus was sensitive to the balance within the Council. Overall, the Relex position echoed the condemnations expressed by the EU already before the drafting of the 2002 proposal. This had put the EU in a position where it would have to adopt sanctions against Mugabe's regime (see for instance Council, 2000c). On the other hand, Development was more concerned about the possible adverse effects of article 96 measures (interview 17). First, it was concerned that the interruption of the regular political dialogue between the EU and Zimbabwe (under article 8 of Cotonou) would break any communication line with Zimbabwe and thus incapacitate the EU in its attempt to exert any influence on the ZANU-PF and the actual situation in the country (ibidem) - notably to engage with ZANU-PF on land reform, a key point of Mugabe's electoral campaign, as illegal occupation of farmland was one of the major contentious issues. ${ }^{94}$ Secondly, DG Development warned against the risk that Mugabe would instrumentalise appropriate measures. It argued that Mugabe was in a position to turn Zimbabwe's population against the EU by misrepresenting the appropriate measures. Article 96 measures did indeed serve the regime propaganda (interviews 17, 19, 25, 26). DG Development also warned against the risk of strengthening the anti-white sentiment: in turn, this would further deteriorate the situation in the field by antagonising parts of the population (interview 17). In the communication on the opening of article 96 consultations with Zimbabwe, the Commission referred to the issue of neocolonialism and anti-white sentiment (Commission, 2001a: para.5). Thirdly, DG Development tried to prevent the setting-up of too constraining a framework for development cooperation (interview 17). With the adoption of article 96 measures, budget support was excluded: it implied that the EU needed to find other partners in Zimbabwe to implement development projects. Besides, article 96 measures also

\footnotetext{
${ }_{94}$ Tensions between Zimbabwe and the United Kingdom over the modalities of the land reform had further sharpened the issue; Vircoulon, 2010:255; and interview 17.
} 
imposed specific conditions for development aid that would still be channelled to the country despite the measures. The exclusion of direct budget support and the existence of strict conditions upon the use development funds were considered as jeopardising the effectiveness of development cooperation in Zimbabwe - these restrictions on the use of development aid justified the inclusion of DG Aidco in the ISC as it was the DG responsible for development cooperation in the field. The risk of creating a coalition of ACP countries against the EU was also raised (interview 17). The controversy surrounding the activation of article 96 and the adoption of appropriate measures was lengthily discussed. Lastly, DG Development was very much concerned that adopting article 96 measures would create a blockage difficult to remove as there was "no stop and go" with this policy (interviews 17, 25, 27). Overall, DG Development, arguing on the negative impact that a redirection of development cooperation would have on Zimbabwe, its population and development objectives, was in favour of a more open approach to the crisis in Zimbabwe (interviews 17, 19).

Overall, the comparison of the different DGs' positions illustrates the influence of bureaucratic politics at two levels in the drafting process. First, it very much shaped the policy option chosen by the Commission. The move towards the adoption of appropriate measures reflected the DG Relex position. According to one interviewee, DG Development resisted this move for two years but had to give up eventually (interview 17). As there was no objective definition of what qualified as a violation of essential elements that should trigger an EU response, much was left to the political appreciation of the situation - also determined by national sensitivities as already discussed above. The influence of bureaucratic politics on the choice of policy option was also strengthened by the type of decision. The perception by EU actors of the necessity to address a crisis situation gave an advantage to the hardliners. Second, bureaucratic politics also influenced the design of appropriate measures. In an effort not to contradict foreign policy objectives, the proposal did not provide for extreme appropriate measures that a total suspension of development cooperation and the withdrawal of trade preferences would have constituted. Instead, trade measures were excluded and development cooperation was only partially suspended. The outcome thus was a consistent proposal.

In 2012, the situation had changed. DG Relex had disappeared and its lead role had been taken over by the EEAS in association with DG Devco. As any Commission DG in the drafting of the proposal, the EEAS consulted other DGs. The focus will be put below on the contributions by DG Trade and DG Devco. ${ }^{95}$

Although appropriate measures still did not include a trade dimension, DG Trade informally contributed to the drafting process. Zimbabwe participated in the

\footnotetext{
${ }^{95}$ ECHO was also formally included in the ISC on the 2012 proposal but it did not substantially contribute thereto. Indeed, humanitarian assistance was being progressively phased out of the country (interviews 11, 31).
} 
negotiation of the EU-ESA (Eastern and Southern Africa) Economic Partnership Agreement (EPA). When preferences expired on 31 December 2007, the EU-ACP trade relationship fell under the framework of EPAs signed at regional level (interview 14; Commission, Development and Cooperation - EuropeAid, 2010). The text of the EPA with ESA was initialled at the end of 2007 by six (out of eleven) ESA countries (Comoros, Madagascar, Mauritius, Seychelles, Zambia and Zimbabwe) but signed by only four countries in August 2009 - Comoros and Zambia did not sign it (Commission, DG Trade, 2012e \& 2011d). With Comoros and Zambia dropping out, ratification by Zimbabwe was a sine qua non, as the ratification of four ESA countries was needed for the EPA to be applicable. Although the reaction to the Zimbabwean crisis did not constitute a major contentious issue during the negotiation of the agreement (interview 30), the EU's handling of the political situation in Zimbabwe could have had a major impact on the implementation of the agreement. DG trade informally expressed its concern that the 2012 decision to renew appropriate measures (and CFSP sanctions) could further delay the ratification process and create a legally challenging situation for the EU as the entry into force of the EPA was called for by the WTO, but did so only informally (it did not formally raise any obstacles during the inter-service consultation (EEAS/Commission, 2011; interview 30). To a certain extent, Zimbabwe could therefore exert pressure on the EU and the other ESA countries and create a serious political and legal risk for the EU. In March 2012, signals were given that the internal ratification process in these four countries was completed so that the EPA could enter into force. However, the EU only received Zimbabwe's ratification instrument in May 2012 (interview 30). Although the EPA with ESA is the first EPA with an African region that has entered into force (interview 30; Commission, $2012 \mathrm{~b}$ ), the uncertainty created by the situation illustrates the importance of the trade dimension in the handling of the EU-Zimbabwe relations.

To a certain extent, the position of DG Devco was more ambiguous in 2012 than in 2002 as it was open on a certain dimension and strict on another one. On the one side, openness was demonstrated by Devco's advocacy for reengagement with Zimbabwe. Highlighting the importance of continuous support of political developments taking place in Zimbabwe, Devco supported the lifting of conditions to allow the EU to significantly support the Global Political Agreement and Government of National Unity (interviews 11,19). It also promoted the reference to the steps taken towards the normalisation of EU-Zimbabwe relations and the readiness of the EU to reconsider its action in the country at any time should Zimbabwe take new political steps (Commission, 2012d; EEAS/Commission, 2011). Strategically, this new dynamic approach aimed at accompanying Zimbabwe more closely ahead of an important electoral year, and at inducing political change by building on the image of the EU as a development actor and showing the benefits of EU-Zimbabwe cooperation to the population (Commission, 2012d: explanatory memorandum (10); interview 19). This more dynamic strategy was also deemed necessary, as the previous static approach to the situation had not proved 
successful so far (interviews 19, 25, 27). The relaxation of the conditions on development cooperation reflected a more comprehensive approach to restoring essential elements and aimed at strengthening the contribution of development cooperation to foreign policy objectives.

On the other side, DG Devco proved stricter on a second dimension, the possibility to specify EU development aid commitments to Zimbabwe as supported by the EEAS. This question created tensions during the inter-service consultation on the draft circulated by the EEAS but also within the Council, as already outlined above (see section 6.5.2; EEAS/Commission, 2011; Commission, DG DevcoEuropeAid, 2012f; interview 31). The drafting of the proposal on the renewal of appropriate measures took place in the middle of a review exercise conducted by DG Devco on the consistency of EU development aid in general. Devco raised several concerns in that respect. Above all, it was concerned about the large amounts of aid still channelled to Zimbabwe despite the existence of article 96 measures. These amounts were large not only when compared to the amounts available to other countries that were targeted by appropriate measures, but also in comparison to countries not targeted by this mechanism. This raised serious consistency issues with development policy at large (interview 31). For this reason, during the inter-service consultation, the Commission refused to include a commitment to additional funds for Zimbabwe (EEAS/Commission, 2011; Commission, DG Devco-EuropeAid, 2012f; interview 31). This position was also explained by the ad hoc character of the programming documents defining development cooperation with Zimbabwe (the existence of appropriate measures had prevented the signing of CSP and NIP, the traditional programming documents). Some tensions re-emerged when the proposal was discussed at the COAFR. Chairing the Council working group, the EEAS supported amendments presented by Member States to reintroduce in the proposal provisions specifying amounts of aid that would be available (interview 31). Eventually, the decision did not lead to the commitment of EU funds. In sum, there was no contradiction between Devco's position on that point and the primary objective of appropriate measures. Committing EU funding in the text of the proposal would have contradicted the logics of the restrictive framework of article 96 and consequently weakened the Union's leverage on Zimbabwe.

Overall, tensions within the Commission as well as between the Commission and the EEAS illustrated the politicisation of the discussion on Zimbabwe and the salience of diverse interests. The positions expressed by different DGs, in particular by DG Devco, had a decisive impact on the drafting of the 2012 proposal. Compared to the EEAS' attempt, the removal of references to specific amounts of development money in the proposal strengthened the consistency of the proposal. At the same time, the relaxation of the conditions for development cooperation with Zimbabwe introduced a contradiction in the medium-term with the primary foreign policy objective while aiming at strengthening the mutually reinforcing nature of the development and foreign policy dimensions in the long-term. The expression of 
different positions during the drafting of the proposal is not an indicator of inconsistency of the policy output, it is the way that these different opinions are coordinated in the proposal that matters. Interestingly, the context of the drafting of the proposal had also evolved in 2012 compared to 2002 - and that reinforced the trend in coordination between the different DGs (see section 6.6.3). Internal coordination went smoother in 2012 than in 2002. The change from a crisis response to what can be considered a repetitive decision-making had created a common ground on which to prepare the proposal. The positions of different actors had moved closer together as actors had been working for ten years on the dossier. The DGs contributing to the drafting shared a positive assessment of the evolution of the situation in Zimbabwe, noted the progress still to be made by the regime while agreeing that rethinking EU strategy towards Zimbabwe was a necessity (Commission, 2012d: explanatory memorandum, (3), (4), (5), article 1 \& annex; EEAS/Commission, 2011). If bureaucratic politics tends to jeopardise coordination efforts, the progressive socialisation process among the officials working on the dossier and the resulting (informal) network toned down the negative impact of bureaucratic politics on coordination by bringing the different positions closer together. As shown above, in 2012, there was a consensus on the need for a more dynamic approach to Zimbabwe and on the policy choice to implement it.

In conclusion, different factors had an influence on coordination attempts during the drafting of both proposals. As discussed above, these factors pulled the Commission in different directions. In 2002, the international context of the decision as well as Member States' influence steered the proposal towards foreign policy objectives, which introduced contradictions in the proposal with the other dimensions of EU action in Zimbabwe. These first two factors were reinforced by a third element, the nature of the decision and the nature of the competence. Indeed, in this decision-making process, the Member States' voice - in particular that of the hardliners - was brought to the fore because of the urgency of the situation and via the role of the Council in the adoption of the decision. Under such circumstances, the Commission aims to produce a proposal that is acceptable to the national capitals. Bureaucratic politics was the fourth factor considered. Usually, the existence of conflicting positions and objectives within the institution jeopardises coordination. However, the Zimbabwe case has shown that the existence of different voices within the Commission paved the way to a certain degree of success of the coordination between the primary foreign policy objective on the one side and development cooperation and trade on the other.

\subsection{Conclusion}

This chapter has discussed the Commission's proposal to adopt appropriate measures against Zimbabwe in 2002 and to renew these measures in 2012, followed by an assessment of their consistency. In a second step, this chapter also 
identified the factors that influenced coordination during the drafting of the Commission's proposals and thus the consistency of the policy output.

By definition, because this action took place under the Cotonou agreement, the two proposals illustrate the necessary coordination between foreign policy, development cooperation and trade. As a first step, the research has discussed the relevant legal (Treaty), substantial (policy framework) and procedural (internal decision-making) guidelines framing the Commission's action. The first level of the Treaty framework, which has been extensively discussed in chapter 4, outlines the mutually reinforcing nature of the foreign policy, development and trade dimensions, which are central in the Cotonou agreement. At the second level of the policy framework, mechanisms and policy concepts have been developed to avoid contradictions between the different elements in the design of appropriate measures. The legally protected and thus elevated status of the "essential elements" - the foreign policy dimension - constitutes a challenge for the other two dimensions. But a mechanism such as the B-envelope of the EDF for unforeseen needs ensures, under specific conditions, that development cooperation continues despite the existence of article 96 measures. In this way, this instrument can reconcile foreign policy and development objectives. The partial suspension of development cooperation in Zimbabwe and the decision not to adopt trade measures - following from the concept of targeted sanctions - show that the EU is actually using the entire spectrum of reactions, and that foreign policy, trade and development concerns have been balanced in different ways over the years. Complementing these two first levels, internal decision-making consists of rules of procedure that aim at coordinating different objectives. It defines how the Commission prepares the proposal with the aim to put into effect the consistency requirement.

Overall, the primary objective of both the 2002 and 2012 Commission's proposals was the restoration of essential elements in Zimbabwe. The research concluded that the proposals were consistent since their provisions did not contradict the primary objective of restoring essential elements. Interestingly, the findings on the 2002 proposal thus differ from the initial expectations formulated on the basis of the exploratory interviews conducted. This difference results from a difference in the benchmark used: this research discussed the existence or absence of contradiction in the proposals against the Union's primary objective in Zimbabwe. By contrast, after the interviewees themselves, initial expectations were based on the general perceptions of EU action, the communication by Zimbabwe and ACP countries on appropriate measures and the criticisms formulated by these same stakeholders against the EU's action. Nevertheless, the degree of consistency of the 2012 proposal remained higher than in the case of the 2002 proposal. Indeed, what might prima facie seem to be a contradiction - the juxtaposition of the foreign policy objective to restore essential elements, the resulting renewal of appropriate measures and the relaxation of conditions for development cooperation - actually provided for a more consistent strategy towards the 
restoration of essential elements. On the basis of these findings on the consistency of the proposals, the research concluded that coordination was limitedly to moderately successful in 2002 and moderately to fully successful in 2012. In the next step, the chapter aimed to explain why this was the case.

Exploring in more detail the drafting of the proposals, a number of factors appear to determine the degree of success of coordination. Deducted empirically, these factors range from international pressure, the influence exercised by Member States and the type of decision prepared to the potentially conflicting objectives of the different DGs concerned involved in decision-making. It is difficult to assess the individual influence of each factor: factors shall rather be understood as a set of elements, external and internal to the Commission, the combined effects of which determine the directions taken by the Commission. Overall, although the factors identified had a diverse influence on coordination, they actually offset each other paving the way for a consistent output. In 2002, international reactions to political violence in Zimbabwe strengthened the voice of those Member States that advocated sending a strong signal to Zimbabwe, thereby putting to the fore the primary focus on foreign policy objectives. In turn, this constrained the Commission and put DG Relex in 2002 in a relatively strong position compared to DG Development, although DG Development was the lead DG. DG Relex favoured a strong position on Zimbabwe, pushing for the adoption of a sanction package. DG Development did not want at first to activate article 96 mechanism in order not to introduce a restrictive framework for development cooperation and not to further alienate Mugabe's regime, which would have in turn run counter to the Union's primary objective in Zimbabwe. Eventually, the risk of inconsistency was circumscribed as the Commission proposed a partial instead of a total suspension of development aid, accounting for the costs that a total suspension would have in terms of foreign policy objectives. The situation in 2012 was different because the different positions of actors involved in the drafting process had moved closer together. Positions were less extreme: the international context of the decision and Member States' positions had evolved towards a more comprehensive strategy visà-vis Mugabe's regime, emphasizing the importance of increased coordination between the different dimensions of the EU's action. This trend also reinforced factors internal to the Commission, the then routinized drafting process of the proposal and the existence of an integrated network of officials working on Zimbabwe who had grown more tightly interconnected and who shared common objectives in Zimbabwe. Consequently, the combination of these factors in 2012 led to a higher degree of success of coordination in the drafting of a proposal that was found to be more consistent than the 2002 proposal. 


\title{
CHAPTER 7.
}

\section{THE CONSISTENCY OF THE 2011 COMMISSION'S PROPOSAL TO REVISE THE GSP}

\begin{abstract}
The Generalised System of Preferences helps developing countries, particularly Least Developed Countries, reduce poverty by generating or increasing their revenues from international trade. It does so by providing import preferences. On top of this central goal, the scheme has taken up an additional role. This is to provide incentives, in the form of additional import preferences, to those countries committed to promote sustainable development and good governance (Commission, 2011h, vol.I:1).
\end{abstract}

\subsection{Introduction}

The preferential import scheme for developing countries (DCs) is often presented as a flagship instrument of EU external action, its trade policy and its commitment to the realization of development objectives. First introduced in 1971, the Generalised System of Preferences (GSP) has remained a major element of the EU'S relationship with DCs ever since. The Commission considers import preferences as an effective trade instrument tailored to the needs of DCs, promoting the diversification of their economies and the expansion of their trade (Commission, 2011h, vol.I:3). The second case study of this thesis focuses on the Commission's legislative proposal (COM(2011)241 final) revising the GSP. ${ }^{96}$ As in the previous case study, this chapter aims to answer the question whether and to what extent this Commission's proposal is consistent and to identify the factors explaining successful coordination or the lack thereof in the drafting of the proposal.

The adoption of the new GSP regulation (regulation (EU) 978/2012) marks the end of an important revision process initiated by the Commission. The EU's revised Generalised System of Preferences was published on 31 October 2012. ${ }^{97}$ It entered into force in November 2012 but preferences have been applied as of 1 January 2014 only. The objectives of the revision are first to target preferences on DCs most in need, secondly to better match the trade, economic and financial needs of DCs and thirdly to adapt to changing global trade patterns (Commission, 2011m).

\footnotetext{
${ }^{96}$ Up to the 2012 revision, the GSP relied on 10-year cycles and 3-year implementation regulations, ensuring that the scheme was regularly revised to account for the evolution of the needs of the targets. The new GSP will be revised every 10 years with 5-yearly reports (recitals 6 and 34 of regulation (EU)978/2012).

${ }_{97}$ The revision does not cover Everything But Arms (EBA, which is not subject to periodic reviews) or rules of origin (for which new legislation came into force in 2011, see for instance Inama 2011).
} 
Indeed, since the previous revision of the scheme in 2009, the position of DCs in global trade has evolved significantly, requiring a refocused approach and refocused instruments. ${ }^{98}$

As a first step, it is important to set the scene. Introducing the logic behind the granting of trade preferences, the next section (7.2) presents the importance of trade into the EU for developing countries. Section 7.3 deals with the policy framework, the policy-specific level relevant for understanding the parameters within which actors operate to put into effect consistency, characterised by the centrality of the concept of policy coherence for development and a long-lasting international commitment to provide a comprehensive approach towards development. Section 7.4 focuses on the Commission's internal decision-making in trade as an area of exclusive competence. This level puts into effect the general and policy-specific commitment to consistency in the drafting of the Commission's proposal. It successively discusses the consistency and coordination mandate of particular actors and the concrete steps taken in the drafting of the proposal. Section 7.5 evaluates the degree of consistency reached in the policy output. Section 7.6 finally identifies conditions that have led to the success or failure of the coordination instruments. ${ }^{99}$

\subsection{Background}

The GSP addresses the asymmetry that exists between the economic situation of the EU and that of the exporting developing countries (DCs). This section first introduces the context of EU-DC trade. It then presents the main characteristics of the 2008 GSP regulation (Regulation (EC) 732/2008), which is revised by the new regulation. Building on EU-DC trading patterns, this background outlines the significance of the GSP but also the inconsistencies of the scheme that the revision aimed to address.

\footnotetext{
${ }^{98}$ Incidentally, the revision of the GSP also aimed at reflecting the new institutional balance that emerged after the Lisbon Treaty. In particular, decision-making involved the EP, after it gained significant power in trade policy. However, the 2011 revision of the GSP was not the first revision that was adopted under the Lisbon Treaty. In 2010, the EU adopted a regulation extending the validity of the previous GSP regulation until 31 December 2013 to ensure the continuity of the preferential scheme while the revision was being prepared. Although an interesting dimension of the process, this chapter will not explore the inter-institutional dynamics between the Commission and the European Parliament, and between the Commission and the Council. The inter-institutional dimension might be alluded to indirectly though when it is of relevance to explain a position taken by the Commission.

${ }^{99}$ Throughout the chapter, the object of the case study is the Commission's proposal (Commission, 2011f). Once adopted by the Commission, the proposal became an European Parliament/Council regulation (European Parliament/Council, 2012). Whenever the regulation was adopted without modification to the original Commission's proposal, references are made only to the proposal articles. When the provisions of the regulation differ from the provisions of the proposal, specific references to both texts will be made.
} 


\subsubsection{EU-DC trade}

Overall, EU trade with the rest of the world has significantly increased since the 1980s. The EU has remained the first destination for exports from developing countries, with $c a$. one third of total ACP exports and about half of exports from Africa entering the EU (Commission, 2005b:8-9). After a sharp decline in 2009, EU imports from DCs amounted to €1,000 billion in 2011 (Commission, DG Trade (2012f).

The relative importance of specific groups of DCs in trade with the EU has changed over the last decade. First, the benefits of preferences are concentrated on a limited number of DCs, mostly emerging economies from South East Asia, Brazil and South Africa (Commission, 2005b:20). Second, despite the overall expansion of imports into the EU from DCs, imports from the poorer countries have largely stagnated and are concentrated on a limited number of products, notably agricultural goods (Commission, 2012e:4). Although the EU constitutes the first destination for LDCs' exports (they amounted to $€ 30$ billion in 2011; Commission, DG Trade, 2012f), LDCs are under increasing competitive pressure from higherincome DCs within the GSP (Commission, 2005b:8). Lastly, competitive pressure exists even amongst the group of LDCs: the share of imports into the EU from nonACP LDCs ${ }^{100}$ is much more dynamic that the share of ACP LDCs (Commission, 2005b: 20).

With the exception of a few East Asian economies, imports from DCs were limited to a small range of products derived mainly from the exploitation of natural resources or products with low added value (Commission, 2002a:9). For instance, in 2003 , over $50 \%$ of EU imports from each ACP country (excluding South Africa) came on average from 1.9 products, a situation which contrasts with more dynamic economies such as Thailand and India (Commission, 2005b:10). Illustrating the competition between DCs and the vulnerability of the poorer DCs to changes in preferences on specific products, these statistics also highlight the potential for the GSP to contribute to the diversification of these economies.

The GSP is only one regime under which DCs exports enter the EU. They can also enter under MFN (most favoured nation) treatment, bilateral free trade agreements (FTAs) or other preferences under regional arrangements for instance. Between 2002 and 2012, despite minor evolutions, the importance of GSP (3 regimes) in total EU imports remained rather low (CARIS, 2010:22). In 2008, GSP, GSP+ and EBA accounted only for $4.18 \%, 0.46 \%$ and $0.46 \%$ of total EU imports respectively (ibidem).

Nevertheless, the EU's GSP is the most important GSP worldwide (CARIS, 2010:16) and provides a significant support to DCs. ${ }^{101}$ Conceived as an instrument matching DCs' specific needs, the GSP remains a relevant instrument. Over the last

\footnotetext{
100 Afghanistan, Bangladesh, Bhutan, Cambodia, Laos, Maldives, Nepal and Yemen

101 The amount of unpaid import duties per annum, €2.1 billion in 2009, gives an approximation of the benefit for exporters (Commission, 2011h, vol.I:5).
} 
decade, DCs have benefited from trade to different extent and the differentiated evolution of EU-DC trade patterns outlines the major consistency challenge of the GSP, consistency between trade and development objectives. ${ }^{102}$ Refocusing the GSP on those countries most in need has become the major aim of the revision, in the view of enhancing the consistency of the scheme as an instrument for development matching the specific trade, development and financial needs of DCs as requested by WTO law (Commission, 2011i:1).

\subsubsection{The EU GSP, factsheet}

Before discussing the changes introduced by the revision, this section presents the characteristics of the scheme under the previous regulation. The research uses the evaluation exercise carried out by an external consultant, CARIS (Centre for the Analysis of Regional Integration at Sussex) in 2010 and the impact assessment conducted by DG Trade in the run-up to the revision as data sources. Before the revision, the GSP was granting preferential access to EU markets on a nondiscriminatory basis to 176 eligible countries. It was articulated in three arrangements: the general arrangement, the GSP+ and the Everything But Arms (EBA) initiative. Each was characterised by its country- and product-coverage, and the level of preferences it granted. Despite the differences, all three programs were generally considered as attractive, as illustrated by the relatively high level of utilisation of the preferences: 53\% for GSP countries, 69\% for EBA and $85 \%$ for GSP+(Commission, 2011h, vol.I:5).103

The general arrangement was the largest programme before the revision. Overall, 111 countries were benefiting from the general arrangement, provided that they were neither high-income countries nor FTA partners (Commission, 2011h, vol.II:1). This arrangement had extensive product coverage: 6,200 tariff lines ${ }^{104}$ of the 7,100 dutiable were covered. ${ }^{105}$ Preferences granted varied according to the distinction between sensitive and non-sensitive products. The sensitivity of a product depended on whether it was produced in the EU and on how competitive European producers were (CARIS, 2010:17). Non-sensitive products (2,400 lines) included most manufactured goods. They enjoyed duty-free access. Sensitive products (3,800 lines) typically included some labour-intensive goods, such as

\footnotetext{
102 Preferences are only one of the trade instruments used by the EU to support trade from DCs. The EU also facilitates trade by making the rules and requirements transparent and accessible, provides financial support to improving trade, negotiates comprehensive trade agreements and supports valuebased trade (European Commission, DG Trade, no date e).

103 The scheme was simplified in 2004 when the number of arrangements was reduced from 5 to 3 with the creation of the GSP+ in replacement of the social and environmental incentives.

104 Tariff lines are products defined at a highly detailed level for the purpose of setting import duties.

105 Dutiable lines are tariff lines on which import duties exist. 2,300 tariff lines of EU common customs tariffs are not covered as they have already a MFN duty rate of zero. Consequently, tariff preferences are not relevant for these. The GSP also excludes arms and ammunition (chapter 93 of the nomenclature); CARIS, 2010:17.
} 
textiles, clothing and footwear, and agricultural products. They entered the EU at a rate reduced by half (or 3.5 percentage points) reduction from the MFN ad valorem tariffs. This reduction did not apply to the textile and clothing sectors, where the reduction was $20 \%$ of the applicable MFN tariff rate (CARIS, 2010:17). In 2009, out of the $€ 60$ billion imports that received preferences, €48 billion were imported under the general arrangement (Commission, 2011h, vol.II:1).

The GSP+ arrangement is the special arrangement for sustainable development and good governance. While the general arrangement and GSP+ have essentially the same product coverage (GSP+ was covering 70 more lines than the general arrangement; CARIS, 2010:18), all products entered at zero-rate. GSP+ is covering 15 countries until 31 December 2013, with Sri Lanka being suspended since August 2010 (Commission, 2011h, vol.II:3; European Parliament/Council, 2011:para.6). GSP+ was set up in 2006, resulting from the merger of the drugs arrangement and the labour and environment arrangement (DS246, EC-Conditions for the Granting of Tariff Preferences to DCs). This new arrangement was offering additional preferences under three specific conditions (Commission, 2011h, vol.II:3; Bartels, 2007:871). First, DCs had to ratify and to effectively implement 27 specific international conventions in the fields of core human and labour rights, environment and good governance. Second, they had to give an undertaking to maintain the ratification and implementation of the conventions, and to accept regular monitoring and review of the implementation. Third, they had to be considered vulnerable. Entry was possible once every 18 months. In 2009, €5 billion imports were made under GSP+ (Commission, 2011h, vol.II:3).

With the Everything But Arms initiative (EBA), the EU provides non-reciprocal quota-free and duty-free access for all products except arms from LDCs, as classified by the UN (CARIS, 2010:19; Brenton, 2003). EBA is not subject to periodic reviews, its characteristics will remain the same after the revision. Under this arrangement, preferences are granted for an unlimited period. Compatibility with WTO law is not questioned as these additional preferences are granted to a specific sub-group of DCs, the LDCs. EBA covers over 7,000 tariff lines, all EU non-zero tariff lines with the exception of arms and armaments. The EBA is the most generous arrangement of the EU's GSP. In 2009, €6 billion imports were made under EBA (Commission, 2011h, vol.II:4).

\subsection{The policy framework}

To answer the main question raised in the introduction - to what extent is the Commission's proposal consistent? - this section explores the policy framework of EU action. As introduced in chapter 3, it is the second level of relevance for understanding the parameters within which actors operate to put into effect the consistency requirement. As discussed under chapter 4, development and the integration of developing countries into the world economy are amongst the 
general objectives of EU external action (article 21.2(d) \& (e) TEU). The policy framework further specifies the general Treaty framework for consistency in one particular area and therefore contributes to the framing of the Commission's proposal to revise the Generalised System of Preferences. This section focuses on the overarching development objective of import preferences and the consistencyrelated objectives of the revision of the GSP that constrain the Commission's action. In this case study, the proposal was framed first by the concept of "policy coherence for development" (PCD) and second by trade-development strategic documents. PCD and the strategic documents outline the defining elements of the GSP and point at the necessity to avoid contradictions between trade, development and foreign policy.

\subsubsection{Policy Coherence for Development}

In order to achieve the complex objective of development (see for instance Winter, 2006), the international community has been promoting a comprehensive approach since the 1990s and renewed its commitment thereto in the 2000s with a view to achieve the Millennium Development Goals (MDGs; 2000 UN Millennium Summit, 2001 Doha Development Agenda; 2002 Johannesburg World Summit on Sustainable Development; 2002 Monterrey conference on Financing for Development). The concept of "Policy Coherence for Development" (PCD) advocates the streamlining of development across the range of policies and policy instruments, to avoid contradictions and create synergies to reach development objectives. Trade is one policy area, the contribution of which to development objectives is recognised. Discussion on the role played by trade in development strategies has actually been on going since the 1960s (see for instance UNCTAD, 1968). The inclusion in world trade was understood as one element of development strategies and poverty reduction (Commission, 2011h, vol.I:5). At the same time however, potentially, the liberalisation of trade can expose DCs, already in a vulnerable situation, to further external competitive pressure. In order to facilitate their integration into world trade and to ensure that they would benefit to the largest possible extent from trade, the general view was that DCs required a special focus to be given more time and better terms (dos Santos, Farias \& Cunha, 2005:638; Bartels, 2003:510-511), a logic on which the GSP is based (UNCTAD, 1968). Action on the political fundamentals of developing countries is also expected to contribute to development strategies, hence the promotion of the components of good governance for instance.

The concept of Policy coherence for development (PCD) thus frames EU action in order to accelerate progress towards attaining the Millennium Development Goals (MDGs; Commission, 2005d). The EU political framework for PCD consists of the Commission Communication on PCD of April 2005 (Commission, 2005d), the subsequent Council conclusion of May 2005 and the European Consensus on Development adopted in December 2005 (European Parliament/ Council/ 
Commission, 2005). The "EU shall take account of the objectives of development cooperation in all policies that it implements which are likely to affect developing countries, and [shall ensure] that these policies support development objectives" (op.cit., p.2). As a process, PCD is goal-oriented (see for instance Commission, DG Devco-EuropeAid, 2012b \& 2012c). In this case study, the GSP contributes more particularly to the realization of MDG8 "Develop a global partnership for development", subdivided into target 8A: "Develop further an open, rule-based, predictable, non-discriminatory trading and financial system" and target 8B: "Address the special needs of least developed countries" (UN, n.d).

Since 2005, the EU translates the general commitment of the Consensus on Development into a 'Policy Coherence for Development Work Programme'. Initially focused on 11 priority policy areas (Commission 2005d), the programme was made more operational with a sharpened focus on five core areas following up on the PCD Council conclusions of November 2009 (Commission, 2010d:4). In addition, since 2007, to monitor implementation and encourage continual progress, the European Commission publishes a report every two years on PCD.

Since 2005, trade is a priority area in the efforts towards development objectives and import preferences constitute a development-oriented instrument. Import preferences are designed to increase DCs export earnings, to promote their industrialization and to accelerate their rate of economic growth, i.e. to help them benefit from trade to the largest extent possible (Commission, 2012e:8 \& 2010l:10; Commission, DG Trade, n.d. f). Beyond development objectives, preferences are also an instrument of the "value-based trade agenda" (Commission, 2012e:13) to promote foreign policy objectives (Commission, 2010b: 15).

\subsubsection{Trade-development strategic documents}

Taking PCD as a guiding principle, the Commission and DG Trade implement the concept in strategic documents. At Commission level, the Communication on "Trade and development - assisting developing countries to benefit from trade" (Commission, 2002a) illustrates the necessary coordination between trade and development. This communication commits "the EU (...) to make trade a central part of development strategies" outlining the necessity to find the most appropriate instruments for DCs "to better reap the benefits of trade" (Commission, 2002a:5). Evidently, the GSP is an important instrument in that respect (Commission, 2010b:8). The revision of the GSP "aims to focus the benefits on those countries most in need (to better meet development objectives) and on those which effectively implement international labour standards and principles of human rights, environment protection and good governance" to better meet foreign policy objectives (Commission, 2010b: 8; see also Commission, 2012e:2,4,9-10). Development objectives are central in the GSP general objectives, hence in the revised GSP as well (Commission, 2011h:18). The Communication from the Commission on the function of the Community's GSP - which constitutes the 10- 
year strategic framework of the GSP - specifies the general objectives for the 20062015 period. In particular, the Communication draws the attention to these specific objectives, thus further specifying the substantial framework for the revision:

- Maintain generous tariff preferences that continue to provide real incentives for DCs to expand their exports in a sustainable manner;

- Target the preferences on countries most in need, in particular by terminating preferential access for countries that no longer need it, and by ensuring that GSP preferential rates are withdrawn from competitive products;

- Make graduation more transparent and targeted;

- Further encourage sustainable development and good governance;

- Provide withdrawal mechanisms and safeguard instruments in order to ensure that the sustainable development and good governance aspects of the GSP as well as the EU's financial and economic interests are protected (Commission, 2004b:7-12).

The agenda of DG Trade is also turned toward development objectives (Commission, DG Trade, n.d. a:4). Following up on these substantial guidelines, the impact assessment prepared for the revision translates the general objectives of the GSP into specific and operational objectives for the revised GSP that aims to enhance its overall consistency with development, trade and foreign policy objectives:

- Better focus the preferences on the countries most in need;

- Remove disincentives for diversification for countries most in need

- Enhance consistency with overall trade objectives

- Improve the efficiency of safeguard mechanisms ensuring that the EU's financial and economic interests are protected

- Strengthen support for sustainable development and good governance (Commission, 2011h, vol.I:18-19).

In conclusion, the policy framework complements and specifies the consistency requirement of the Treaty framework. It sets substantial policy goals (the MDGs) and a process-oriented principle (PCD) that in turn define the frame in which the specific instrument of GSP is adopted and revised. The overarching development objective of import preferences and the particular consistency-related objectives of the revision of the preferential scheme highlighted in this section provide a benchmark against which the consistency of the Commission's proposal will be assessed. The proposal for a revised GSP is prepared with a view to meet these objectives, but the different actors participating in the decision-making process still have different views on the specifics of import preferences, a point to which the following section now turns. 


\subsection{The Commission's internal decision-making process}

The third level to ensure consistency discussed below is the decision-making process of the Commission. It puts into effect the general (Treaty framework) and policy-specific (policy framework) commitment to consistency. In our case study, these are the steps taken to draft the Commission's proposal to revise the GSP under the leadership of DG Trade. Exploring the Commission's internal decisionmaking process contributes to a better understanding of the substance of the proposal, explaining how different positions expressed within the Commission were coordinated and how choices were made on the revision of the GSP.

\subsubsection{The leadership of Trade}

The GSP is an instrument of EU trade policy and as such falls under the exclusive competence of the Union. Consequently, the Commission in general, DG Trade in particular, has a very strong role in the revision.

DG Trade was the only lead DG for the revision of the preferential scheme: it steered the process and was responsible for the coordination throughout decisionmaking. More specifically, the then "Trade and Development" unit of DG Trade was responsible for the revision (17 staff) ${ }^{106}$. As lead DG on a major policy proposal, DG Trade was in particular responsible for coordinating the public consultation on the revision, to prepare the impact assessment, to draft the Commission's proposal in collaboration with the Trade cabinet and to coordinate with the DGs concerned. Despite the obvious implications of the GSP for developing countries, DG Devco was not co-responsible for the drafting of the revision. ${ }^{107}$ Neither was the EEAS despite the foreign policy implications of trade preferences. The reason for the exclusive leadership role of DG Trade was that this specific proposal was not about the general political direction of the commercial policy (in which case the EEAS would have been more involved) but about the technicalities of a specific trade instrument (interview 40). ${ }^{108}$

The lead cabinet, the cabinet of Commissioner De Gucht (2010-2014), closely monitored the policy developments from very early on, as the Commission considered the GSP a very important trade instrument. The member of the cabinet

\footnotetext{
106 As of January 2012, the unit was renamed 'Trade and Sustainable Development, Generalized System of Preferences' unit (interview 37).

${ }^{107}$ However, defining EU strategic orientations on trade and development, DG Trade and DG Devco were co-responsible for the preparation of the communication on Trade and Development (interview 45).

${ }^{108}$ Formally, at the time of the interviews, there is only one official within the EEAS who specifically works on the coordination between trade and the EEAS; he works in the Global Issues unit (interview 40). However, other EEAS officials work on GSP-related issues and were as such involved in the revision as well, for instance, the human rights unit that is responsible for human rights monitoring (interview 48). Consequently, the External Action Service contributed to the drafting process as any other Commission DG concerned did. Its contribution was coordinated by the Global Issues unit with i.a. inputs from the human rights unit.
} 
assigned to the dossier adopted a very proactive stance in the decision-making process, and the head of cabinet was also carefully following the process (interview 41). The role of the Trade cabinet was not limited to political steering and coordination amongst cabinets. Because the GSP team in DG Trade was very small and due to time constraints, the Trade cabinet was also involved from very early onwards in the substantial preparation of the proposal, for instance re-reading drafts, giving comments on texts, checking the economic data and communicating on the revision along the key objectives of GSP (interview 43). It had also specifically instructed DG Trade to be kept informed of any difficulty that would arise at service level to anticipate the discussion between cabinets (ibidem).

\subsubsection{Drafting the proposal}

Identifying and assessing the steps taken to draft the proposal is necessary to understand how and when different actors may weigh in and how the different dimensions of the scheme are articulated. Importantly, the revision did not only consist of a technical adaptation of the scheme but also implied political choices on defining features of the preferential scheme, so that political conflicts emerged in the course of the drafting process. To analyse the drafting of the proposal, this section first discusses the strategic planning of the revision, illustrating the early start of coordination. The section then turns to the preparatory steps taken in the drafting of the Commission's proposal (mid-term review, public consultation and impact assessment) before turning to the inter-service consultation.

A preliminary remark concerns the type of procedure. The Generalised System of Preferences is a typical example of long-term planning and integrated decisionmaking based on 10-year cycles and 3-year implementation regulations (interview 42). The proposal was included in the Commission's work programme for 2010/2011 (Commission, 2010m). Consequently, the drafting of the Commission's proposal (COM(2011)241 final) requires to consider both strategic planning and concrete steps taken to draft the proposal. The new GSP regulation was adopted by the ordinary legislative procedure (co-decision) as foreseen in article 207 TFEU for measures defining the framework for implementing the Common Commercial Policy. In addition, as with any important political question, the Commission's proposal was adopted by oral procedure (section 1 of the Commission rules of procedure).

\subsubsection{Strategic planning}

The long-term approach adopted in internal strategic planning illustrates the commitment to address development concerns across the range of Commission instruments, in particular thanks to specific trade instruments such as the GSP. In turn, the fact that the revision is framed in a long-term perspective reinforces coordination. Exploring the policy framework (section 7.3) and exploring the 
strategic planning of decision-making are not the same. The policy framework provides the substantial guidelines in a particular policy field or for a particular policy instrument while strategic planning refers to the programming of work within the Commission, signalling which proposals should be adopted within a particular period of time.

The President's political guidelines, the first step of the strategic planning and programming exercise of the Commission, outline the necessary efforts to pursue in parallel on trade, development and a more normative dimension of external action for the EU to embrace a global role (President of the Commission, 2009c:33). President Barroso specifically refers to EU engagement with Africa and outlines the EU's leading role towards the achievement of the MDGs (President of the Commission, 2009c:35).

Constituting a milestone of the EU's global agenda, the revision of the preferential scheme was included in the Commission's work program for 2011 in the following terms:

In its comprehensive approach, [the EU] will also address how [its] trade policy can best serve developing countries in their integration into the global economy. The Commission will make a legislative proposal for a new Regulation on the Generalised System of Preferences aimed at maximizing its positive impact on sustainable development and the countries most in need (Commission, 2011d:8).

This extract does not only announce a major legislative initiative but also the direction to be taken and the reasons why such a revision should be prepared. The development perspective and the need to refocus the GSP on "the countries most in need" are central in the work program: they require trade to be better coordinated with development in order to reach overall objectives. The Commission's work program 2012 does not refer to the finalisation of the revision process but reaffirms the contribution of an integrated development-trade agenda, emphasising the instrumental nature of trade (Commission, 2011d:9-10).

Overall, the SPP process clearly reinforces coordination among the different actors within the Commission. The fact that the revision is framed in a long-term perspective ensures that coordination does not only take place when it is time to draft the Commission's proposal but starts very much ex ante. Putting a proposal on the Commission's work programme already sends a signal to the other DGs, allowing them to plan how to contribute to the proposal and to ensure consistency with their own policy objectives (interview 42).

\subsubsection{2. $\quad$ Preparatory steps}

This section discusses the steps taken to prepare the Commission's proposal and emphasises their role in building a common ground for the inter-service consultation (section 7.4.2.3). Three steps were taken to prepare the mid-term 
review of the GSP, namely the commissioning of an independent expert report (the CARIS report), a public consultation exercise and an extended impact assessment.

\section{The CARIS report}

As mentioned before, DG Trade first commissioned an independent study. It was conducted by the Centre for Analysis of Regional Integration at Sussex (CARIS). The final report was submitted on 26 May 2010. Procedurally, the report was an instrument to support and inform the discussion that would take place within the impact assessment steering group (see below). The report - a draft version and then the finalised version - was circulated to the DGs involved in decision-making with the aim to inform the discussion within the steering group (interview 47), notably by outlining the potential inconsistency of the existing GSP (also see section 7.2).

\section{Public consultation}

DG Trade also coordinated a large public consultation exercise, aimed at "all parties with an interest in the operation of the EU GSP scheme" including EU stakeholders (such as importers or producers of like and competitive products to those imported under the scheme, but also consultative actors such as NGOs and academic) and non-EU stakeholders (such as investors in beneficiary countries exporting goods to the EU under the scheme; Commission, 2010h:4). Launched in March 2010 (Commission, 2010f:4 \& 2010l), the consultation was available online from 27 March 2010 to 4 June $2010 .{ }^{109}$ The questions (36 in total) were organised around clusters discussing the defining characteristics of the GSP (Commission, 2010g \& 2010f). Answers recognised the value of trade preferences as an instrument for development (Commission, DG Devco-EuropeAid, 2012e). Points that were frequently raised during the stakeholder consultations related to the consistency of the GSP with development objectives and highlighted the opportunity to take development objectives more into account in a revised preferential scheme. Although not a legal requirement, the consultation informed the drafting of the proposal and the discussion within the impact assessment steering group (interview 47).

\section{Impact assessment}

As required for all major policy proposals, the lead DG also prepared an impact assessment (IA) for the revision of the GSP. Such an exercise aims at analysing the

\footnotetext{
109 The Commission received 143 exploitable answers from beneficiary and non-beneficiary countries, business associations, trade unions, research centres, NGOs, private companies and individuals, half from the EU, half from outside of the EU (Commission, 2010f:6).
} 
problem, presenting the policy options and assessing these options against a baseline. ${ }^{110}$ The impact assessment for the revision of the GSP (prepared in late summer/autumn 2010) was the first major such exercise for the DG after the 2009 revision of the IA guidelines (interviews 41,42). From a procedural and substantial perspective, the impact assessment was important for DG Trade because of the visibility of the topic. To deflect any criticism that the revision would reflect onesided interests, DG Trade and the Trade cabinet paid careful attention to any step of decision-making and emphasised in their communication on the revision the inclusiveness of the process and its focus on coordination (interviews $42 \& 43$ ).

Procedurally, the impact assessment constitutes the first opportunity for coordination between DGs (interviews 41, 42, 43, 44). ${ }^{111}$ Besides DG Trade, the other DGs that were involved in the preparation of the impact assessment were: DG Agriculture and Rural Development, DG Budget, DG Economic and Financial Affairs, DG Employment, Social Affairs and Equal Opportunities, DG Enterprise and Industry, DG Environment, DG Maritime Affairs and Fisheries, DG Development, EEAS, European Anti-Fraud Office, Eurostat and the Secretariat-General (Commission, 2011h:2). The impact assessment steering group was set up in 2010 and led by DG Trade. It constituted a forum in which major issues were raised (well before the inter-service consultation) between the different DGs concerned (Commission, 2009b:8; interviews $41 \& 42$ ). The steering group was in charge of first defining the issue, second developing and testing policy options, and third formulating recommendations for the revision. After the submission of the first IA report in November 2010, the impact assessment board invited the steering group to re-submit the report in order to better follow the impact assessment guidelines (Commission, IA board, 2011:3).112 Most significantly, the board recommended to strengthen the evaluation by including a breaking down of the different types of impacts of the revision and the effect on different groups of beneficiaries, and to compare options against a baseline scenario on the basis of the required efficiency, effectiveness and consistency criteria (Commission, 2011h, vol.I: 2-4 and Commission, IA board, 2011:1). The second report was submitted on 2 March 2011 and accepted by the board (Commission, IA board, 2011:1).

Substantially, the IA was a delicate exercise, as it required the DGs concerned to agree on the identification of the problems and on the assessment of the policy

\footnotetext{
110 The IA report has to follow a specific structure (Commission, 2009b:9): 1. Procedural issues and results from consultation of interested parties; 2. Policy context, problem definition and subsidiarity; 3. Objectives; 4. Policy options; 5.Analysis of impacts; 6.Comparing the options; 7.Monitoring and evaluation.

111 The public consultation and collection of expertise were part of the impact assessment process as well (see above; interview 42). On paper, the impact assessment is similar to an inter-service consultation but it involves external stakeholders such as civil society, industry, beneficiary countries, the European Parliament and WTO members.

112 The IA steering group takes the lead of the IA exercise. It constitutes a group that discusses the impact of a proposal on the range of core policy areas. The IA board controls the quality of the IA report, ensuring that it meets formal and substantial criteria; see section 5.2.2.
} 
options. The IA exercise built on the strengths and weaknesses identified by CARIS, and gave the participating DGs the opportunity to express their opinions on the revision (Commission, 2011h, vol.I: 19). The IA report was prepared by a series of meetings, informed by the CARIS report and by the results of the public consultation i.a., which provided the opportunity to exchange views between DGs and to bring together the necessary expertise from the different DGs (interviews $42,47)$. The impact assessment provided a general assessment of economic, social and environmental effects of the revision for developing countries on one side, with a focus on the countries most in need, and for the EU on the other side (Commission, 2011g:10-13 \& 2011h vol.I: 35-42). The IA report adopted the findings of the CARIS report regarding the extent to which existing preferences were meeting the objectives of the scheme (see section 7.2; Commission, 2011g: 8-9 \& 2011h, vol.I: 19-25). Consequently, four options were discussed amongst the DGs participating in the impact assessment: discontinuation, baseline, partial redesign and full redesign of the preferential scheme (see annex I). Under the discontinuation scenario, preferences would have been abandoned for GSP and GSP+ beneficiaries, while only the EBA arrangement would remain. The baseline option would have meant a continuation of the existing scheme. The partial redesign was to refocus preferences, adjust the graduation threshold and the GSP+ vulnerability criteria while the full redesign would have gone beyond these changes with a extension of the product coverage. The second step of the assessment was the comparison between these four policy options, based on the three criteria of effectiveness, efficiency and consistency. Effectiveness was defined by the degree to which an option achieves the general policy objectives of GSP (Commission, 2011h, vol.I: 42). Efficiency was defined by the use of resources necessary to meet the objectives of the preferential scheme and consistency was the consistency of the instrument with overall EU objectives (Commission, 2011g:14-15 \& 2011h, vol.I:42-46). On the basis of the assessment along these three criteria, a consensus formed within the steering group on partial redesign of the scheme as the preferred option (Commission, 2011h, vol.I:46; interview 47).

In conclusion, the impact assessment provided the first opportunity for coordination among DGs, even before the coordination on a concrete piece of legislation, and was key in shaping decision-making (interviews 41, 42, 43, 44). In theory, the lead DG was not bound by the content of the IA report. In practice, it followed it as the report had been discussed by the DGs concerned and reflected a consensus on a partial redesign of the scheme (interview 47). The IA report thus provided the basis on which the lead DG developed the actual legislation. However, the absence of public records of the steering group meetings and the impossibility to discuss the meetings with interviewees prevent from elaborating on the conditions under which this consensus emerged and constitute a limiting factor for the research. 


\subsubsection{Inter-Service Consultation}

The inter-service consultation (ISC) on the draft proposal was the last step, launched by DG Trade, to finalise the Commission's proposal before its adoption by the College. The sections above have shown that coordination started well before the ISC was formally launched. The revision of the GSP is a clear example of integrated decision-making within the Commission, a necessity when the dossier is characterised by its technical, all-encompassing and political nature (interview 42).

The inter-service consultation on the revision of the GSP was a broad consultation. As already mentioned, DG Trade was the only lead DG on the proposal. It launched the ISC in March 2011 and formally consulted 22 services. The consultation of DG Budget, the Secretariat General (SG) and the Legal Service was mandatory, as in any ISC. ${ }^{113}$ The other DGs that contributed to the ISC were Agriculture, Climate, Devco, DGT-Edit, EcFin, Echo, Employment, Energy, Enlargement, Enterprise, Environment, Estat, Home, Justice, Mare, Markt, Olaf, Taxud as well as the EEAS (Commission, 2011i). As in any ISC, the inclusiveness of consultations was left to the discretion of the lead DG. In addition to the interservice exchanges of views on the general elements of the GSP, DG Trade also held bilateral meetings with certain DGs to discuss specific issues and/or to better understand the different positions expressed (interviews 41, 43). Services had two weeks until mid-April 2011 to contribute to the consultation. Overall, the majority of opinions issued were favourable provided that certain comments would be included. Five DGs issued a negative opinion on the proposal (interview 43). In particular, DG Devco issued a negative opinion while the Secretariat General and the EEAS issued a favourable opinion provided that certain comments were considered. Due to the sensitivity of the revision and to protect the Commission's interest, access to the full content of the ISC was not granted for the research: only the general elements of the ISC were accessible, but not for instance the individual contributions by DGs. Nevertheless, more details could be inferred from the interviews conducted.

During the ISC, two major lines of conflict emerged, both relating to GSP+ (as will be elaborated in section 7.5). The first issue was an attempt to specify conditionality requirements by extending the list of conventions that countries benefiting from GSP+ had to adopt, thus aligning the GSP with foreign policy objectives. Some DGs (for instance DG Mare or DG Environment) were supporting the extension of the list of conventions to include international agreements in their policy domains (e.g.: Multilateral Environmental Agreements and the UN Framework Convention on Climate Change; interviews 42, 43, 44 \& 47). The second

\footnotetext{
${ }^{113}$ As outlined in section 5.2.2, the SG's contribution is both procedural and substantial. The SG ensures that coordination steps are respected, in particular at service level. It also made a substantial contribution to the drafting. For instance, it had to take a position on comitology and delegated acts, vulnerability thresholds or the list of international conventions for the GSP+ arrangement (interview 41).
} 
issue concerned protectionist interests against the inclusion of certain countries that would threaten sensitive sectors - thus trying to align the GSP with trade objectives. This proposal raised concerns as to the realisation of development objectives. The principal issue here became how to re-focus the scheme on those countries most in need, for instance through a redefinition of the vulnerability threshold, while at the same time taking care that such a redefinition would not lead to a surge of imports into the EU in sensitive sectors.

Coordination between cabinets on the revision of the GSP was a key element in overcoming the divisions reviewed above. It succeeded in solving the issues that could not be solved at DG level thanks to the constructive attitude of the member of the Trade cabinet in charge (interview 41). While the ISC was still taking place at service-level, the Trade cabinet was actually already holding bilateral meetings with other cabinets (interview 43). Coordination amongst cabinets was also anticipated by the instructions the Trade cabinet had given to DG Trade to keep it informed of any difficulty raised at service level (ibidem).

Cabinets had in general been kept informed of the development of the legislation and the different issues raised at service-level by their DGs (interview 44). Bringing the different positions expressed (see section 7.6.4) required three special meetings of the cabinets: an "information chefs" (réunion d'information des cabinets) took place in April 2011 followed by two special chefs meetings ( 3 and 5 May 2011). Lastly, the chefs de cabinet ("hebdo") met on 6 May 2011 (interviews $41,43)$. By the time the proposal reached the College, the discussion focused on the safeguard mechanism and the vulnerability threshold for GSP+, two interrelated features of the scheme (interview 43). As the proposal was of major political importance and contained technical provisions, the College meeting had been carefully prepared at cabinet level - i.e. between the members of the different cabinets following the revision (interview 43).

Three elements in particular were key in finalising the decision-making process. First, President Barroso supported the revision. At the College meeting on 10 May 2011, the position of the President became clearer: in particular, he did not play the national card against some elements of the revised GSP although the Portuguese textile sector would for instance potentially be negatively affected by the relaxation of entry conditions into GSP+ (interview 43). This de facto alliance between DG Trade and the President of the Commission helped to mitigate opposition to the revision by other DGs (interview 41). Second, the High Representative-Vice President was unambiguously supportive at the College meeting (interview 43). Her support had been demonstrated at hebdo level already, when the representative of Ashton's cabinet decisively expressed support to the Trade proposal (interview 43). Third, the dissenting voice of development eventually disappeared. As shown above, DG Devco had issued a negative opinion during the ISC. The Development cabinet restated the criticism according to which the immediate consequences of a refocusing of preferences under the revised scheme would destabilise developing countries. But the negative opinion fell at 
College level because Development Commissioner Piebalgs did not attend the meeting (interview 43). A priori, the rule according to which a negative opinion simply falls if the Commissioner responsible for it does not attend the College meeting might seem surprising. In the case of the revision, it was not possible to find out whether the absence of Commissioner Piebalgs at the College meeting reflected a change of opinion with respect to the proposal.

Overall, the inter-service consultation was a relatively "easy exercise" not because the choices between the different options were necessarily easy to make, but because the consultation had been well prepared (interview 47) so that the proposal was adopted by the College on 10 May 2011. Ex post, the DG Trade activity report for 2011 and its management plan for 2012 welcomed the finalisation of the revision process of the GSP by emphasising that only a coordinated approach to a problem could actually address this problem (Commission, DG Trade, n.d. a:3, 8, 28 \& n.d.b).

\subsection{Consistency challenges}

After having discussed the policy framework (section 7.3) and the modalities of the drafting of the proposal (section 7.4), the chapter now aims at assessing the consistency of the Commission's proposal to revise the GSP. As defined earlier, this will be done qualitatively by looking at the content of the proposal and by assessing the existence or absence of contradictions against the benchmark of the primary objective of the proposal. The conclusion will be drawn on the basis of the scale presented in chapter 3.

A starting point for the discussion of the consistency challenges and the way they were addressed is the impact assessment discussed above. The IA report had elaborated on the manifold challenges to consistency under the previous GSP:

1. Consistency between trade and development, as illustrated by the criticism of a suboptimal support to development through the expansion of exports of the countries most in need under the previous GSP;

2. Consistency between trade and foreign policy, as illustrated by the criticism of a suboptimal promotion of sustainable development and good governance under the previous GSP;

3. Consistency between different trade objectives, as illustrated by the criticism about the possibility for certain beneficiaries to choose preferences (Commission, 2011h:10).

The impact assessment also outlined that the revision of the preferential scheme aimed to enhance the overall consistency of the scheme by enhancing each of these dimensions (ibidem). Consistency was mentioned only once directly in the contributions to the inter-service consultation but it was indirectly mentioned several times by sectoral DGs. First, the consistency concern was directly raised regarding the effects the revision of the GSP would have on on-going EU bilateral 
trade negotiations (Commission, 2011i). For instance, the potential inclusion of a country in any GSP arrangements that would be more favourable than the proposed agreement under negotiations could jeopardise the outcome of the negotiations (Commission, 2011i). Some sectoral DGs (such as the EEAS and DG Environment) indirectly raised the consistency concern between trade and foreign policy, as they suggested a more comprehensive approach to political conditionality (Commission, 2011i; interviews 42, 43, 47 \& 48). For instance, the inclusion of conditionality on child labour or on environmental principles were discussed (Commission, 2011i).

In order to systematically review this issue, the consistency of the revised scheme with the objectives pursued in the individual policy dimensions of development, foreign policy and trade will be discussed separately, before the findings are brought together in the conclusion.

\subsubsection{Consistency between the GSP and development}

The raison d'être of the GSP, a trade instrument, is to serve development purposes. Despite the continuous erosion of preferences resulting from multilateral negotiations, the scheme is considered to be an effective instrument in achieving development objectives (Commission, 2011h, vol.I:4-5; Commission, 2011i:1; Commission, 2010l: 8-12; CARIS, 2010: 7, 15; interview 45). However, when reviewing the previous GSP, the EU and stakeholders noted the existence of competitive pressures between the beneficiaries of the GSP due to a lack of focus of preferences (Commission, DG Trade, 2012a:8; Commission, 2011h, vol.I: 3, 10-11; CARIS, 2010:12). The availability of identical import preferences to developing countries in very different economic situations was jeopardising the realisation of development objectives as the more advanced countries were benefiting from a support that they did not need any longer to participate in global trade. Consequently, the consistency of import preferences with development objectives under the previous GSP regulations was questionable. This led to the necessity to refocus import preferences to improve the "consistency [of the scheme] at country level", which constituted the primary objective of the revision (Commission, 2011i:1; Commission, 2010c:8; Commission, 2010l:10; CARIS, 2010:12;). The consistency challenge, both direct and indirect, to the objective of refocused preferences resulted from four factors, which were addressed by the revision, and to which this section now turns.

The first factor directly challenging the objective was the criteria defining the beneficiaries of import preferences under the previous GSP regulation (Commission, 2011h, vol.I:11-14; CARIS, 2010:12; Commission, 2010f: answer to question 1). Under the previous GSP, the targeting of beneficiaries was suboptimal as high-income countries (HICs) as well as Upper Middle Income Countries (UMIs) continued to be beneficiaries if their economies were not sufficiently diversified (income and diversification are cumulative eligibility criteria; Council 2008: article 3.1). However, these countries had the necessary resources to attain higher 
diversification without the help of EU preferences, introducing competitive pressure for the countries most in need under the preferential scheme (Commission, 2011h, vol.I: 11). In addition, the income levels of these countries were sometimes the same as that of some EU member states. Did it for instance make sense for Bulgaria to grant unilateral preferences to Qatar (interview 39)? Granting these countries preferences to export to the EU was not a politically sustainable decision (Commission, 2011h, vol.I: 12), although excluding countries from the benefit of preferences ran a risk of being criticised as an arbitrary decision. As the more advanced economies were undermining the support to the development of the countries most in need, the new GSP regulation introduced income-based criteria, excluding countries that were classified as HICs and UMIs during three consecutive years before the update of the list of beneficiaries (Commission, 2011f:article 4.1(a)). The revised GSP now uses income criteria based on the World Bank's definition to limit the margin for political discretion on the granting of preferences to some countries.

These provisions do not contradict the primary objective of the revision. First, evidently, they directly refocused preferences: combined with the exclusion of countries benefiting from another market preferential agreement (reaffirmed in the proposal, see section 7.5.3), the number of beneficiaries dropped from 176 to 89 as listed in annex II of the proposal (Commission, DG Trade, 2012b:6). Refocused preferences in the general arrangement translated into less competitive pressures on the LDCs. Second, these new criteria also take into consideration the risk to contradict secondary objectives of the scheme, the development objectives. The proposal avoided disruptive effects for countries excluded from the benefits of preferences. Removing countries from the list of beneficiaries might have proved disruptive. However, Overseas Countries and Territories (OCTs) and beneficiaries from other preferential arrangements had alternative market access arrangements with the EU. Consequently, their exclusion was not expected to have a negative impact on their trade with the EU. Besides, for the countries excluded on the basis of article 4.1(a) and (b), transition periods of respectively one and two years were foreseen in the regulation under article 5.2(a) and (b) of the new GSP. In addition, under the new regulation, the countries remain eligible to GSP and as such are in a position to benefit again from GSP in the future should they meet again the criteria. 
The second factor of challenge to the focus of preferences was the suboptimal graduation mechanism. ${ }^{114}$ The previous graduation formula was considered to be problematic as it was based on sections of the EU customs tariff that were too large and covered heterogeneous products. Potentially, large and emerging countries could still be beneficiaries at the expense of the exports of the least developed countries. Moreover, under the previous GSP regulation, graduation did not apply to EBA countries but did apply to GSP+ countries. This was introducing another distortion and competitive pressure among DCs, as EBA and GSP+ countries were often in the same economic situation (Commission, 2011h, vol.I:13). In practice, the mechanism had hardly been used before 2011: out of 2,400 country-sections, 20 only had been graduated, 13 of which were Chinese (ibidem). This provided a mechanism not responsive and not effective enough in protecting the interest of beneficiary countries - but also the interest of EU industry.

The GSP revision adapted the basis for graduation. The revised GSP introduced more homogeneous categories of products, either sections or subsections (Commission, 2011f: recitals 21 \& European Parliament/Council 2012: recitals 22) and expanded the number of sections used for graduation from 21 to 32 (Commission, 2011m:3). The thresholds were increased: the new regulation set them at $17,5 \%$ in general and $14,5 \%$ for textiles in particular, while they were set at 15 and $12,5 \%$ respectively under the previous regulation. Graduation is now expected to happen sooner with these new thresholds as the number of beneficiaries dropped (Commission, 2011f: article 8 and annex VI). The revision also evened out the treatment of EBA and GSP+ countries, excluding the application of graduation to GSP+ and EBA beneficiaries (Commission, 2011f: recitals 21 \& European Parliament/Council 2012: recitals 22).

Third, in the specific case of GSP+, the consistency of the focus of preferences was challenged by the suboptimal entry mechanism to GSP+. The GSP+ arrangement was initially designed to meet the specific needs of vulnerable

\footnotetext{
114 Graduation is a mechanism by which a section (category of products) of the Common Customs Tariff does not benefit from preferences anymore. The logic behind the graduation mechanism is that a certain category of products does not need preferences to penetrate the market once it has become competitive at the global level so that, at the macro-level in aggregated terms, the "scheme benefits only those countries it is intended to benefit" (Commission, 2011f: recitals 20 \& European Parliament/Council 2012: recitals 22). The Commission considers that global competitiveness is a consequence of successful development strategies: some DCs have export-oriented categories of products, which are in a relatively strong position on world markets as they exploit advantages such as low labour costs and economies of scale (Commission, 2011h, vol.I: 12). If a sector that has become competitive still benefits from preferences, it puts competitive pressure on the same sector of countries at a lesser development stage thereby creating concerns over the lack of focus of GSP preferences. At the same time, the graduation mechanism also responds to concerns to protect the EU's industry against products that have too strong a comparative advantage when entering the European market (Commission 2011h, vol.I: 13). The relative strength of a category of products is defined by a threshold: before the revision, graduation was applying when the average imports of a section from a country accounted for more than $15 \%$ of all Community imports of the same products from all beneficiaries during three years. The threshold was lower (12,5\%) for textiles, overall considered more sensitive (Council, 2008:article 13.1).
} 
economies. However, eligibility and entry criteria (such as the prerequisite for countries to be defined as vulnerable economies and to effectively implement the 27 international conventions, Commission, 2011f: article 9.1) were considered to be restrictive. With the 2012 revision, the vulnerability criterion was relaxed, as was the entry window. The explanatory factors of the choice made in the draft will be discussed under section 7.6.2.

The last challenge concerns a sub-dimension of the focus of preferences, the product coverage. An insufficient product coverage compared to the needs of the beneficiaries was a factor of inconsistency of the previous scheme (Commission, 2011h, vol.I:14). Under the previous regulation, GSP and GSP+ countries benefited from preferences on $66 \%$ of the EU's 9,443 tariff lines, and EBA countries on $75 \%$ of the lines (ibidem). Besides, the coverage was also limited by the distinction between sensitive and non-sensitive products: in principal, non-sensitive products enjoy duty-free access while sensitive products enjoy a tariff reduction (before the revision, $61 \%$ of the lines were sensitive for GSP beneficiaries, accounting for $63 \%$ of covered imports; Commission 2011h, vol.I:14). However, the room for improving the coverage was limited as only $9 \%$ of dutiable tariff lines were outside of the GSP. The new GSP expanded the product coverage and preference margins to a limited extent: 15 new duty-free tariff lines were added to GSP as non-sensitive; 4 tariff lines under GSP were turned from sensitive into non-sensitive; and 4 new duty-free lines were added to GSP+ (Commission, DG Trade, 2012a:7). The Commission justified its limited changes to the product coverage by the necessity not to put further pressure on LDCs: "increasing the products or preferences which enjoy[ed] GSP [would] then make LDC exports relatively less attractive" (Commission, DG Trade, 2012a:8).

In conclusion, the challenge to consistency with the primary objective of refocused preferences, with the risk of preference diversion and the resulting competitive pressure put on the countries most in need, resulted from several factors that this section has discussed. This section showed that the Commission's proposal addressed each of them satisfactorily. The revised provisions do not contradict the primary objective of the revision and the steps taken on each dimension of the problem actually actively support the primary objective. Overall, this qualifies for a high degree of consistency.

\subsubsection{Consistency between the GSP and foreign policy}

The section now turns to the consistency between the revised preferential scheme and foreign policy. The foreign policy dimension of GSP is present in several mechanisms. First, it is the foundation of the special incentive arrangement for sustainable development and good governance (GSP+), which makes the granting of additional preferences to vulnerable economies conditional upon the ratification and implementation of a number of international conventions. Second, the EU's attempt to influence political developments in partner countries is also visible in 
the reasons listed for the temporary withdrawal of preferences. Enhancing the consistency of the scheme with foreign policy objectives led to rethinking both aspects, while aiming at avoiding any contradictions with the primary objective of the revision.

The special incentive (GSP+) constitutes an attempt by the EU to steer and shape political developments in DCs in favour of sustainable development and good governance as defined by a list of international conventions (Commission, 2011f: annex VIII; Council, 2008: annex VIII under the previous scheme). If it seemed that $\mathrm{GSP}+$ had had a positive effect on the ratification of the conventions listed in the regulation, the impact was less clear-cut as to the actual implementation of these conventions (Commission, 2011h, vol.I: 5; CARIS, 2010:151-188). Nevertheless, GSP+ remains a meaningful instrument, as illustrated by the withdrawal of preferences for Sri Lanka in 2010 for instance (CARIS, 2010:155). Beyond this uncertainty, three weaknesses were identified in the impact assessment.

First, the entry to GSP+ was suboptimal because of a combination of restrictive criteria (Commission, 2011h, vol.I: 16). In principle, to be eligible to GSP+, DCs need to qualify as vulnerable economies. Under the previous GSP regulation, a vulnerable country was defined in terms of its income, diversification of exports and share in GSP imports (Council, 2008: article 8.2). ${ }^{115}$ CARIS and the public consultation noted that the vulnerability criterion left some vulnerable countries out (CARIS, 2010:174; see also Commission, 2010f:22-23). The different options to revise the criterion are elaborated on under section 7.6.4, illustrating internal debates between Commission DGs. In order to strengthen GSP+ and to support states that were serious about implementing annex VIII conventions (interview 43), the decision was taken to relax the vulnerability threshold. The 2011 Commission's proposal redefined this threshold in article 9 and annex VII: the threshold of the share in GSP imports was relaxed from 1 to $2 \%$. At the same time, the relaxation was the result of a compromise that aimed to leave the possibility to protect certain EU industrial interests, a concern in terms of consistency within trade policy (interview 42). Consequently, the relaxation of the threshold must be read together with the strengthening of the safeguard mechanism to protect certain EU interests (interview 43). ${ }^{116}$

In addition, the impact assessment noted that the double-condition of ratification and effective implementation was unnecessarily limiting the access to

\footnotetext{
${ }^{115}$ Article 8.2 of the 2008 Regulation reads: "[A] vulnerable country means a country: (a) which is not classified by the World Bank as a high-income country during three consecutive years, and of which the five largest sections of its GSP-covered imports into the Community represent more than $75 \%$ in value of its total GSP-covered imports; and (b) of which the GSP-covered imports into the Community represent less than $1 \%$ in value of the total GSP-covered imports into the Community."

116 The relaxation of the vulnerability criterion was coupled with the clarification of the safeguard clause. Enhancing the legal certainty of the safeguard clause also contributes to enhancing the consistency of the mechanism as it limits for possibility for a discretionary appreciation of the situation.
} 
GSP+ (Commission, 2011h, vol.I:16). ${ }^{117}$ Yet the double-condition of both the ratification and "a binding undertaking to maintain ratification of the relevant conventions and to ensure effective implementation thereof" was kept in the revised GSP (Commission, 2011f: article 9.1(b) \& (c)). The country should also accept without reservation the reporting requirement and should give a binding commitment to accept regular monitoring and review of its implementation record (Commission, 2011f: article 9.1(d) \& European Parliament/Council, 2012: article 9.1 (e)). The EEAS was also concerned about the credibility of GSP+ with respect to this double condition. In its contribution to the ISC, it wanted to limit the possibility for applicant countries to introduce reservations to conventions (interview 48). This was an answer to a country-specific concern: indeed Pakistan had ratified the ICCPR (International Covenant on Civil and Political Rights), but introduced a reservation that it would not report to the monitoring body of the convention. Concerned that such a move would have deprived the convention of its effect, services discussed the opportunity to introduce a provision on reservations in the proposal. Compared to the original Commission's proposal, the regulation also requires the absence of any reservation that is "prohibited by any of the relevant conventions" or "which is for the purposes of this Article considered to be incompatible with the object and purpose of that convention" (European Parliament/Council, 2012: article 9.1(c)).

Besides, under the previous regulation, DCs could only apply to GSP+ every 18 months (Council, 2008:article 9.1(a)) and not as soon as they fulfilled entry requirements (Commission, 2011h, vol.I:16). The revision introduced the possibility to apply to GSP+ at any time, thereby better reflecting the actual situation of potential beneficiaries (Commission, 2011f: article 10).

Second, the debate also evolved around the exact list of conventions that would have to be ratified by GSP+ beneficiaries. Numerous new additions to the list were put forward by different DGs and their international agendas (for instance multilateral environmental agreement or the UN framework convention on climate change, or the additional protocols I and II to the Geneva convention; interview 43). A list of 50 conventions would have been unrealistic in terms of operationalisation and of the monitoring of the arrangement. The lead DG and cabinet identified specific criteria to ensure that the additions suggested to the list of conventions would not hide protectionist interests aiming at actually restricting the access to import preferences (see section 7.6.4).

Third, the monitoring mechanism for the implementation of the GSP+ conventions under the previous GSP regulation was suboptimal. How to define what constitutes "effective implementation"? How to monitor the effective implementation of the conventions? There were also concerns about the potential

\footnotetext{
117 The point on ratification and implementation also relates to the list of conventions that should be ratified and implemented. Different DGs of the Commission had different suggestions to add to the list of conventions, a discussion to which we turn later (SEC(2011)536 final:17 and ISC).
} 
demand from the European Parliament to get more involved in human rights monitoring. This explained why the new regulation enhanced the conditions of the two-yearly reporting exercise by the Commission before the Council and the European Parliament (Commission, 2011f: articles 14.3 and 14.4). The report should include conclusions of the monitoring bodies of the GSP+ conventions, the Commission's conclusions on whether each GSP+ beneficiary country respected its undertakings and the Commission's assessment of the conclusions of the monitoring bodies, and any other relevant information. The clarification of the monitoring mechanism was a necessary step to give the EU the possibility to act on its words and to ensure the actual implementation of GSP+ conventions by beneficiary countries.

Fourth, the temporary withdrawal mechanism was another illustration of the importance of the foreign policy objectives under the preferential scheme. ${ }^{118}$ For instance, preferences were withdrawn in Burma/Myanmar and Belarus because of their internal political situations. ${ }^{119}$ During the ISC, some DGs suggested to introduce additional reasons on the basis of which preferences could be withdrawn, such as child labour, the violation of Multilateral Environmental Agreements or the conventions listed in Part B of annex VIII (interview 44; ISC). Compared to the previous GSP regulation and instead of introducing references to new international conventions, the proposal for a revised GSP only added a reference to unfair trading practices in the supply of raw materials to the list of reasons to withdraw preferences - a reason different in nature to the provisions under the previous scheme (Commission, 2011f: article 19.1). It was the clarification of the modalities of this mechanism by the revised GSP that enhanced the consistency of GSP with the values and principles listed by the EU by giving to the Union the power to take concrete actions.

In conclusion, this section shows that the changes introduced on the foreign policy dimension do not contradict the primary objective of the revision. Steps were taken to contribute to the targeting of those countries most in need with the refocusing of the GSP+ arrangement. At the same time, the more specifically foreign policy-related revisions ensured that the foreign policy dimension of the GSP would not be emptied of its substance - as illustrated by the decision to keep the condition on ratification and effective implementation upon entry into the GSP+. The long discussion on the vulnerability threshold and on the list of GSP+ conventions in

\footnotetext{
118 The temporary withdrawal mechanism can be activated under the preferential scheme in general and not under the GSP+ arrangement only. The reasons for temporary withdrawal are not linked to the respect of the GSP+ list of international conventions but are listed in a separate article of the GSP regulation.

${ }^{119}$ Following the revision, Belarus is not a beneficiary country. GSP preferences were reinstated for Burma/Myanmar in July 2013.
} 
particular illustrated the inconsistency risk between the GSP and foreign policy. ${ }^{120}$ In principle, the logic behind import preferences is to facilitate the integration of DCs into global trade. At the same time, the promotion of good governance is one of the objectives of the preferential scheme. The difficulty was to find the right balance between the granting of preferences for development purposes on the one hand and their withdrawal out of general foreign policy reasons but the revision satisfactorily addressed the weaknesses of the previous scheme. The criteria of conditionality (the vulnerability threshold, the condition of ratification and implementation of international conventions, and the grounds for temporary withdrawal) were central here. If too constraining or too rigid, there would have been a risk that conditionality limited the access of DCs to preferences. The strict framing of conditionality ensured consistency between the GSP and foreign policy objectives, limiting the potential for a discretionary use of conditionality. It also ensured that GSP+ preferences were targeted without creating perverse effects for the countries most in need. Overall, this qualifies for a high degree of consistency.

\subsubsection{Consistency between the GSP and trade policy}

During the revision, concerns of inconsistency between the GSP and overall trade objectives were raised. As the GSP is a trade instrument, the inconsistency risk with trade might be counterintuitive. Yet, the specificity of the GSP as a trade instrument raised several questions at the time of the revision. In principle, trade instruments with a development purpose address specific objectives of EU trade policy. The insufficient focus on countries most in need, as discussed above (section 7.5.1), was a first sign of inconsistency with trade objectives because the GSP was a trade instrument aimed at developing countries with specific needs only. Three other weaknesses are discussed below with regard to consistency with trade policy at large: first, the articulation between the GSP and other import preferential arrangements; second, the implications of the scheme for domestic producers; and third, the relationship between import preferences on the one side, and bilateral and multilateral trade negotiations on the other side.

First, the revision aimed to clarify the articulation between different arrangements of import preferences (interview 45). The previous regulation was already excluding the possibility for a country benefiting "from a preferential trade

\footnotetext{
120 Beyond the exact wording of the provisions, the foreign policy-trade consistency also raises the question of the foreign policy use made of the GSP. The granting of preferences to Pakistan in 2011 did not only respond to a dramatic economic situation after massive flooding (preferences were activated six months after the flooding not as an emergency aid) but also to strategic considerations for the position of Pakistan in the fight against terrorism; it was perceived as such by Pakistani authorities (interview 40). Considerations for the consequences of the revision on production and employment in certain neighbours after the Arab spring offer a second illustration. The EU had an obvious interest in promoting stabilisation in the North African rim, for which social conditions were central (Commission, 2011i). This goes however beyond our research focus.
} 
agreement with the Community which covers all the preferences provided for by the present scheme" to benefit from the GSP at the same time (Council, 2008: article 3.2). Yet, this prohibition was hardly enforced because of legal uncertainty. Indeed, it was particularly difficult to determine that all preferences were covered when rules of origin differ in the GSP and in the preferential agreement (Commission, 2011h, vol.I:12). It followed that certain partners of the EU could opt in or out of the GSP depending on the generosity of the preferences, thereby distorting EU objectives (Commission, 2011h, vol.I:12; Commission, 2010e: question 6). The revised GSP reiterated the exclusion of countries benefiting from a preferential market access arrangement (Commission, 2011f: recitals 9 and article 4.1(b)). The new GSP also excluded Overseas Countries and Territories, which had an alternative market access arrangement for the EU market (Commission, 2011f: recitals 10). In theory, this contributes to ensuring that preferences under the GSP benefit only the countries whose specific needs are targeted by the preferential scheme.

Second, assessing the consistency of the scheme with trade objectives also referred to the intersection between internal and external objectives. The revision of the GSP needed to take into consideration the effect that the revised scheme would have on European industry. Under the scheme, European interests are protected by the safeguard mechanism. The previous regulation provided that the safeguard mechanism could be activated (and thus preferences temporarily withdrawn) as soon as imports from one beneficiary country exceeded $15 \%$ of the value of Community imports of products from all countries and territories over three consecutive years (Council, 2008: article 13). To better safeguard EU interests and to enhance the legal certainty of the mechanism - secondary objectives of the revision - the Commission's proposal clarified the modalities of the safeguard mechanism. The revision expanded special safeguards (previously only for agriculture and fisheries sectors) to cover textiles and ethanol, two sectors that, during the ISC, had been signalled as politically sensitive. For sensitive sectors, the revision also specified stricter thresholds than under the previous GSP regulation (Commission, 2011f: article 29.1(a) on the special safeguard; Commission, 2011f: article 29.1(b) and annex VI for the sensitive sectors).121 Under the general safeguard provisions, preferences might now be temporarily withdrawn when the average value of Union imports from a section originating in a GSP beneficiary country over three consecutive years exceeds $17,5 \%$ of the value of Union imports of the same products from all GSP beneficiary countries (Commission, 2011f: article 8 and annex VI).

\footnotetext{
${ }^{121}$ For the special safeguard (but textile products), the threshold is stricter in the new GSP regulation than in the Commission's proposal: a surge of 13,5\% in quantity as compared to the previous calendar year (European Parliament/Council 2012: article 29.1(a)) against a surge of 15\% as initially proposed (Commission, 2011f: article 29.1(a)). In the textile sector, the threshold is set at $14,5 \%$ of the value of Union imports of the same products during any period of 12 months (Commission, 2011f \& European Parliament/Council 2012: article 29.1(b) and annex VI).
} 
Lastly, the consistency of the revision of the GSP with trade policy at large may be questioned at two levels. First, the revision might have an impact on the ongoing bilateral negotiations and the design of trade relationships with some partners - such as Brazil that will no longer be a beneficiary. In addition, some partners could have a disincentive to conclude bilateral negotiations with the EU given the already low level of EU tariff duties and the granting of additional preferences resulting from the GSP revision - for instance following the relaxation of the vulnerability threshold (Commission, 2011h, vol.I:15; Commission, 2011i). However, this risk also had to be put in perspective as the EU successfully concluded FTAs with partners despite them being withdrawn from the preferential scheme as a consequence of the revision (Commission, 2011h, vol.I:15). Second, the example of Non-Agricultural Market Access (NAMA) negotiations in the framework of the WTO was specifically discussed in the context of the revision (interview 39). For the first time in these negotiations, emerging economies were asked to contribute to tariff reduction. The existence of preferences (such as those under the GSP) deprived the EU of bargaining chips in the negotiations. If emerging economies could benefit from GSP preferences, why would they agree on tariff reduction? The revision of the GSP had to take into consideration the risk it constituted and not to further jeopardise EU position in the negotiations (interview 39).

In conclusion, the risk of inconsistency of the new GSP with EU trade policy objectives, secondary in the revision, existed at several levels. Balancing between the external impact of the revision and its internal consequences, the proposal was consistent with the trade objectives. The changes introduced did not contradict the primary objective of refocused preferences and even supported it by ensuring the continued benefit of preferences to those countries that actually needed them. This qualifies for a high degree of consistency.

\subsubsection{Assessing consistency}

In conclusion, assessing the consistency of the Commission's proposal constitutes a particularly relevant exercise in the case of the revision of the GSP as enhancing the consistency of the preferential scheme was an objective at the heart of the revision. The coordination of trade, development and foreign policy has been a major concern for the Commission throughout the drafting of the proposal. This chapter has assessed the consistency of the revised GSP with the individual dimension of development, foreign policy and trade. The assessment was done against the benchmark provided by the primary objective of the revision - refocusing preferences on those countries most in need - and was based on the discussion of the inconsistencies in the previous scheme and on how the revision addressed them.

The main objective of the revision - refocusing the GSP on those countries most in need - illustrated the centrality of the consistency concern. Empirical research 
showed that the changes introduced by the revision contributed to enhancing the consistency of the scheme in this respect by not contradicting and supporting the realisation of the primary objective - even with respect to the risk of disruptive effects of the refocusing of preferences as transition periods were introduced in the phasing out of preferences.

The revisions introduced to meet secondary trade and foreign policy objectives could have challenged the consistency of the proposal by contradicting its primary objective. However, the choices made ensured both that the primary objective could be met while not emptying the trade and foreign policy objectives of their substance. For instance, the negotiation of the vulnerability threshold defining the beneficiaries of the GSP+ arrangement raised questions. From a foreign policy perspective, a rather loose definition of this criterion might have been sensible, as it would allow the EU to offer a more generous trade package to these developing countries in exchange for their compliance with international conventions. From a trade and development perspective though, a stricter definition would have been sensible so that the revised GSP would be opened only to DCs with specific trade, development and financial needs. A strict definition of vulnerability would also satisfy the specific trade objective of protecting Member States' interests under the scheme, while the relaxation of this threshold could create a competitive risk for EU industries. Eventually, relaxation was agreed in exchange of a strengthening of the safeguard mechanism to prevent any destabilising surge of imports into the EU. The safeguard mechanism was also thought of as a mechanism to keep the focus of import preferences on those countries most in need to avoid competition between beneficiaries of the scheme. Another illustration of the potential challenge to the consistency of the scheme would be the battle over the exact list of international conventions, in an attempt to beef up the conditionality of the GSP+ arrangement of the scheme and its foreign policy objectives. The Trade cabinet and DG Trade took a firm position to avoid that the broadening of political conditionality under GSP+ hide protectionist intents. They identified clear-cut criteria to ensure that the conventions included would meet a specific need of developing countries, thereby supporting the realisation of the primary objective of the revision, while at the same time maintaining the credibility of the conditionality under the scheme.

Overall, this section concludes that the 2011 Commission's proposal to revise the GSP reaches a high degree of consistency. The steps taken in the three dimensions (development, foreign policy and trade) do not contradict and actually support the realisation of the primary objective of the revision of the GSP, the refocusing of preferences on those countries most in need. This conclusion is however only the first step of this case study. As introduced in chapter 3, the consistency of the policy output is explained by the success of coordination in the decision-making process. In this case study, given the degree of consistency reached, the research can conclude that coordination was fully successful. It raises the question of how to explain such a success, despite the existence of different objectives within the Commission. The next section aims to address this question 
by identifying the factors that explain why and how development, foreign policy and trade objectives were successfully coordinated in the revision of the GSP.

\subsection{The factors explaining successful coordination}

In this research, the three-level framework introduced in chapter 3 answers the question of how the Commission ensures consistency. The third level, Commission decision-making and its focus on coordination, is a central factor as it is at this stage that the consistency requirement is practically implemented. The revision of the GSP illustrated the contradictory pressures that impacted the drafting of the Commission's proposal either by narrowing down policy options or by giving some actors more strength. Deducted from the empirical research, these types of pressure, both external and internal to the Commission, explain why coordination was fully successful within the Commission. Four kinds of factors have been identified. These include the constraint exercised on the proposal by international trade law; the nature of decision-making; the nature of the proposal; and bureaucratic politics.

\subsubsection{Abiding by WTO law}

Unilaterally granting import preferences to DCs departs from the MFN principle under the General Agreements on Tariffs and Trade (GATT). A ten-year waiver to Article 1 of the GATT was adopted in 1971 to authorize the adoption of schemes of import preferences, recognizing that "a principal aim of the contracting parties [was the] promotion of the trade and export earnings of developing countries for the furtherance of their economic development" (WTO 1971). In 1979, the "Enabling Clause" (or decision on "Differential and more favourable treatment, reciprocity and fuller participation of DCs") gave a permanent basis to set up the GSP (WTO 1979). ${ }^{122}$ The promotion of trade from DCs was reaffirmed, together with the need to design specific trade instruments matching their specific economic difficulties and development, financial and trade needs (ibidem).

WTO law constrains the design of preferential schemes. It aims at ensuring that import preferences target the countries that need to be helped to fully benefit from global trade. Setting up the GSP was possible under WTO law provided that the treatment was "generalised, non-reciprocal and non-discriminatory" (ibidem). This meant that the scheme would have to cover substantially most of the trade between the EU and DCs, would need to be non-reciprocal in the sense of the EU unilaterally granting preferences, and it would have to be non-discriminatory: preferences shall

\footnotetext{
122 The literature explores the legal value of the different decisions on which GSP-like schemes were based since 1971, a question that is not developed in this research (see for instance Bartels, 2003; McQueen, 2007:212; Turksen, 2009:930-932).
} 
be the same for DCs that are in the same economic situation as defined by objective criteria. ${ }^{123}$ As noted above, refocusing preferences on the countries most in need, the primary objective of the revision, met these conditions on paper. The revision built on different provisions to limit the competition between beneficiaries and excluded DCs that did not need the help of preferences anymore. The definition of strict criteria by the Trade cabinet and DG Trade to arbitrate on the list of conventions under the GSP+ arrangement (section 7.6.3) illustrated the strong position of the Trade actors within the Commission. In practice, the existence of a constraining WTO framework helped the Trade cabinet and DG Trade to further enhance their power in the drafting process, giving them the possibility to have the last say against the resistance of other players. Overall, the existence of a legally binding international framework for preferential schemes influenced coordination by both narrowing down policy options and consequently strengthening the position of the lead actor within the Commission.

\subsubsection{Inter-institutional dynamics}

Inter-institutional dynamics also played a role, as the Commission was not the only institution to decide on the revision. As the proposal had then to go through codecision, both the Member States in the Council and the European Parliament had an influence on the proposal. This factor relates to the relative strengths of different actors during the drafting process.

First, during the interviews conducted for this research, Member States' interests were mentioned several times as the reason why specific provisions found their way into the revised GSP. An interviewee even mentioned that a few Member States (without listing which though) came to see Trade officials during the preparation of the College meeting in an attempt to influence the decision (interview 43). Member States concerns focused on the vulnerability threshold for GSP+ and the safeguard mechanism. Significantly, these two points were still under discussion by the time the proposal reached the College, while the other issues had already been solved at lower levels (interview 43). Member States feared that too low a vulnerability threshold - determining which countries are eligible to GSP+ preferences and thus which type(s) of imports would enter the EU under preferences - risked harming their industries. In principle, the GSP safeguard mechanism protects EU financial and economic interests whenever imports are likely to disrupt the balance on the European market between imports and

\footnotetext{
${ }^{123}$ For instance, the case EC-GSP brought before the WTO dispute settlement mechanism recalls the importance of the non-discriminatory nature of preferences. The dispute related to the granting of additional tariff preferences by the EC to countries involved in combating drug production and trafficking. First targeted at South and Central America, the arrangement was extended specifically by the EU to Pakistan in 2001, a decision that India challenged as violating the Enabling Clause. The panel decided in India's favour, what led the EU to redefine the arrangement, setting up the GSP+ arrangement instead (Bartels, n.d.:4-5).
} 
European products. Member States' interests upset the drafting process as they reflected protectionist concerns, inconsistent with the proposal being discussed. Eventually, given the existence of a legally binding framework that constrained the options for the revision (the conditions imposed by the WTO on the design of preferential schemes), the Commission was in a position to solve these tensions, by striking a balance between the relaxation of the vulnerability threshold and the strengthening of the safeguard mechanism of the revised GSP. Nevertheless, the strengthening of the safeguard mechanism reflected the influence that Member States exerted early in decision-making, as the Commission aimed at presenting a proposal that was largely acceptable to the other institutions (interview 43).

Second, the European Parliament also wanted its voice to be heard as a result of the new powers it had gained under the Lisbon Treaty. In general, the Parliament is involved very early in the Commission's strategic planning cycle, since its plenary discusses the Commission's work programme (interview 43); in practice, the Parliament did not take this opportunity to get closely involved in the revision process. Following the entry into force of the Lisbon Treaty, the EP has become a co-legislator in trade policy. As the revision of the GSP had to be adopted by codecision, the Parliament in principle had a voice in the process. The structured dialogue with the responsible EP committee, INTA (International Trade), led DG Trade to anticipate some of the details of the final proposal (interview 43). ${ }^{124}$ It agreed to give the EP delegated acts for the purpose of amending annexes for instance (interview 43). ${ }^{125}$ In the co-decision phase, the more salient issues in the INTA report were the exclusion of some countries and the vulnerability threshold of GSP+ (European Parliament, Committee on Development, 2012; European Parliament, Committee on International Trade, 2012a, 2012b, 2012c, 2011a, 2011b, 2011c). Besides, the EP also expressed its interest in the human right monitoring, but it did not constitute a major problem. Overall, the influence of the European Parliament had been circumscribed in the drafting of the proposal. Having taken care of not alienating the Parliament in a previous, and partial, revision exercise, the Commission compromised on the extension of the transition period between the entry into force of the regulation and the implementation of preferences for countries being left out was found (interview 43).

\subsubsection{The nature of the decision}

Evidently, the nature of decision-making is an important factor to consider. It is defined by several elements.

First, as argued above, there is a distinction between crisis and routine decision-making. Depending on this distinction, the procedures to adopt a Commission proposal and the opportunities and resources for coordination vary.

\footnotetext{
124 The Development committee was also asked for an opinion.

125 On the powers of the EP on delegated acts, see for instance Christiansen \& Dobbels (2012).
} 
Regular decision-making potentially offers the full range of coordination instruments, gives time for coordination ex ante and is characterised by the existence of several safeguard mechanisms to ensure that coordination steps are respected. In this case study, the drafting of the proposal had been included in the Commission work programme thereby already signalling that a consultation would take place on the exact terms of the revision of the scheme. This increased the visibility of the revision, not only for actors within the Commission but also for outsiders in turn constituting a constraining factor for the lead DG. For DG Trade did not want to submit a proposal that could be easily criticised as inconsistent, it knew it had to follow the decision-making steps carefully and ensure the success of coordination. In addition, the revision of the GSP is actually a repetitive exercise, what contributes to the consolidation of a network of officials within the Commission working on the topic and to the smoothing of working relationships on the proposal.

The importance of the proposal to be prepared by the Commission is the second determinant to take into consideration. The relative importance of the proposal plays at two levels by giving more or less leeway to actors in the drafting. Procedurally, when a proposal is particularly important, certain steps have to be taken in the drafting. In particular, an impact assessment has to be prepared, an exercise that proved to be decisive in the eventual shaping of the Commission's proposal as revealed in this chapter. The IA exercise provides an additional opportunity to coordinate the actors concerned within the Commission and the EEAS very early in the drafting phase of the proposal. Because an IA requires the lead DG to already include the DGs concerned, its discretion over the decision is limited. Besides, the mandate of the IA board to check the quality of the assessment constitutes an additional guarantee for the quality of coordination. The existence of specific procedural steps to be followed for the drafting of an important proposal as well as their inclusive character contribute to the smoothing of coordination and eventually to the success of coordination. Substantially, the importance of a proposal has also implications. In the case of the revision of the GSP, the political salience of the proposal made the lead DG and cabinet eager to have a balanced wording in order not to create a controversy either within the Commission or at a later stage of the process with the other EU institutions and with the beneficiaries of the scheme. The political salience of the proposal also meant that the revision of the GSP constituted a visible decision-making exercise. This in turn introduced a reputational risk for the institution, thus keen not to present a proposal that could be criticised for instance as inconsistent.

Lastly, the nature of the competence also influences the extent of coordination (see section 7.6.3). GSP is a trade instrument and as such, the revision discussed in this chapter happened in a policy field of exclusive competence. An exclusive competence means that the lead DG - here DG Trade - is in theory in a relatively strong position (interviews 40 \& 43). Trade is not only the preserve of DG Trade, it is also a clear-cut example of a competence left completely outside of the EEAS' 
portfolio: the lead DG on this policy has not changed with the Lisbon Treaty and the coordination patterns in the decision-making process have not been disrupted by the new Treaty (interview 45). It is interesting to consider the impact of the nature of the competence combined with the "international factor" on the position of DG Trade in the revision of the GSP. Indeed, as already outlined, the existence of a legally binding international framework for the design of the preferential scheme actually further strengthened the position of the lead DG - already in a relative strong position given the exclusive nature of the trade competence - vis-à-vis other DGs and the amendments to the proposal they suggested. However, DG Trade did not take the opportunity to impose its decision. Instead, given the high salience of the proposal in a field of exclusive competence, it did not want to run the risk of presenting an inconsistent proposal. Consequently, it provided objective criteria to make a decision on the draft and used the full range of coordination instruments available to consult other DGs, in turn mitigating conflicts.

\subsubsection{Bureaucratic politics}

Bureaucratic politics also shed light on the coordination process during the revision of the GSP. Within the Commission, different interests were expressed trying to pull the new regulation in one direction or another. The situation was very specific because trade competence is an exclusive competence of the Union. For DG Trade, "this [was] a luxury" as it was in a relatively strong position vis-à-vis other DGs (interview 43). However, it does not mean that no other positions than that of DG Trade and the cabinet of Commissioner De Gucht were expressed. In that respect, it is interesting to note here three fronts that were open between DGs.

The first front related to the first objective of the revision of the GSP, the focus of preferences on the countries most in need (Commission, 2011f: recitals 9). Overall, the revision of the GSP had to be understood not only in the context of the agenda of DG Trade only but in the broader context of other DGs' international agendas and the EU's efforts to be perceived as a first-rank development actor (interview 42). As an application of the PCD principle, development is in theory streamlined across the range of EU policies and in particular, during any impact assessment, the impact of particular policies or instruments on development objectives is systematically assessed. Hence, the process was as inclusive as possible because it aimed to identify the contribution by any DG to overall development goals. Yet, if DG Devco welcomed the objective to refocus the benefits of the scheme on the countries most in need, it expressed its concerns during the ISC regarding the economic effects of the refocusing on the excluded countries (interview 43). The new criteria could also have raised concerns regarding the adaptation of the countries that would lose the benefits of preferences under the new regulation. This was avoided with the introduction of transition periods for the new preferences to enter into force (Commission, 2011f: article 5.2); besides, the countries that lost the benefits of preferences actually remained eligible to the GSP. 
Overall the combination of criteria to define the eligibility of DCs (Commission, 2011f: recital 4) was found WTO-compatible and relevant in identifying the countries most in need (Commission, 2011f: recital 4 \& Commission 2011i).

Second, one of the objectives of the revision, the better safeguard of EU interests, could work against the promotion of DCs interests in global trade and led to conflicting positions within the Commission. ${ }^{126}$ First, the safeguard of EU interests raised the question of the product coverage of the GSP. Defining the product coverage was a delicate exercise, because it also related to the development objectives of import preferences and the interests DCs had in the suppression of tariffs on certain imports to the EU. There was little room for improving the product coverage given the already large coverage of the GSP. Removing the distinction between sensitive and non-sensitive products to move towards tariff suspension - instead of maintaining tariff reductions for sensitive products - was not an option in order to protect particular sectors (fisheries or textiles for instance) in the EU (Commission, 2011f: recitals 17 and 18) as pointed out during the ISC (Commission, 2011i). Second, the objective to better safeguard EU interests also required the GSP safeguard mechanism to be strengthened. Barely used in the past, the mechanism had to be clarified to effectively protect certain sectors. Significantly, the changes introduced to this mechanism have to be read as part of the trade-off DG Trade agreed on in exchange for the relaxation of the vulnerability criterion, a point to which this section now turns (interviews 42, 43).

Third, GSP+ raised a 2-dimension battle on its own. On the one hand, the objective to enhance the realisation of foreign policy objectives was interpreted by certain DGs (Commission 2011i) as requiring the addition of other international conventions to the list already existing. By doing so, it would have in their view strengthened the conditionality of GSP+ and created a more comprehensive set of conventions for the application of import preferences, including for instance the UN Framework Convention on Climate Change or additional protocols on human rights (interview 48). Overall, the suggestions would have added 40 conventions to the list. The lead DG and cabinet were constrained by international trade law on this issue. The Enabling Clause imposed specific conditions as to the details of the GSP scheme. The GSP could not become a human rights instrument with a trade outcome: the conventions of GSP+ had to meet the conditions of the Enabling Clause and to respond to DCs' specific trade, development and financial needs. This is why for instance the genocide convention did not fit in (interview 43). Concerned that "do good intentions" were hiding protectionist interests (interview 43) and to avoid the "Christmas tree effect" (interview 42) whereby if a request was satisfied, any request would have to be satisfied, the Trade cabinet identified strict criteria to

\footnotetext{
${ }^{126}$ Indirectly, EU interests are safeguarded by the refocusing of preferences as, after the revision, imports under the GSP will amount to $€ 37.7$ million, a reduced amount compared to the situation under the previous regulation (Commission, 20111:2).
} 
determine which convention could be added and which request would be turned down (interview 43). The criteria were the following (interview 43):

1. What is the effect on the current GSP+ beneficiaries?

2. Have all EU Member States ratified this convention and are they effectively implementing it?

3. Do these conventions respond to specific trade, development and financial needs (as requested by the WTO)?

On the basis of these criteria, one convention was added - UNFCCC - while the reference to the convention on apartheid was dropped as it was no longer relevant (Commission, 2011f: annex VIII). ${ }^{127}$ The total number of conventions for GSP+ was kept to 27, as the position adopted by DG Trade and the Trade cabinet on the criteria was firm (interview 42). The effectiveness of political conditionality raised questions as to the impact of GSP+ on the ratification and implementation of the relevant conventions. These questions were of particular interest for the EEAS. More specific provisions on the monitoring of the implementation of the relevant conventions were introduced in the proposal. Overall, the division line ran between the EEAS and DG Trade because of a difference of mindsets. While the EEAS considered that trade constituted a powerful incentive to enhance the effectiveness of the foreign policy dimension of the scheme, DG Trade was more careful about the potentially disruptive effect of political conditionality on trade. Nevertheless, and significantly, the EEAS welcomed the revision. Unilaterally granting trade preferences was important for the (self)-perception of the EU as a major development actor at the international level and the revision strengthened a major instrument of EU external action.

On the other hand, the vulnerability threshold was also a particular bone of contention. A defining criterion of GSP+, this threshold materialises the potential tensions between different sectors of activity (for instance textiles, fisheries...) and thus between different DGs within the Commission. The relaxation of the threshold, as suggested by DG Trade, raised concerns for several (internal) DGs. It was likely to jeopardise the balance between EU industry and importers' interests in particular sectors (for instance textiles and clothing, fisheries, and ethanol), as competitive developing economies would meet the new threshold (Commission 2011i; interviews 41, 42 \& 43). The risk of a surge of imports from emerging economies that would become beneficiaries of GSP+ would threaten the balance on EU market between EU industry and imports, a risk against which some DGs took a firm stance (ibidem). Besides, the presence of advanced developing economies under a relaxed threshold would also create unfair competition with the weakest economies under GSP+ that would as such contradict the objective of the revision to refocus on countries most in need (ibidem). Interestingly, Member States strengthened the salience of this internal battlefront - although their

\footnotetext{
127 This addition only concerns the GSP+ arrangement, the UNFCCC was not included under the general temporary withdrawal mechanism.
} 
argumentation was based on protectionist concerns. Eventually, agreement on a limited relaxation of the vulnerability threshold was possible in exchange for a strengthening of the safeguard mechanism.

In conclusion, the different factors had a mutually reinforcing effect on the success of coordination both by narrowing down the policy options and by influencing actors' positions in the decision-making process. The existence of legally binding international trade regime constrained the Commission's initiative. Providing a framework for any preferential schemes, this first factor limited the options available for the revision, thereby limiting the expression of particular interests in the proposal while insisting on the necessary coordination between the different dimensions of the GSP. The exclusive nature of the trade competence reinforced the effect of the international legal framework on the position of the Trade cabinet and DG Trade: they would have had to pay reputational costs for an inconsistent revision of the GSP given the visibility of this particular instrument. Combined, these two factors gave much authority to DG Trade and the Trade cabinet in the drafting process, in turn playing down the divergences that appeared between services within the Commission. Internal divergences were also less likely given the routine nature of the revision of the GSP and the long time frame in which the drafting was embedded, as well as the Commission's willingness to present a consistent proposal in a highly visible policy area. The authority of DG Trade also extended to actors outside of the Commission. The DG was in a position to circumscribe some Member States' attempt to introduce protectionist provisions in the revision given the existence of the WTO legal framework binding the policy options available for the GSP. The leadership of the Trade cabinet and of DG Trade ensured that attention was kept on the primary objective to refocus the scheme on those countries most in need and that the proposal was free of contradiction.

\subsection{Conclusion}

This chapter discussed the 2011 Commission's proposal to revise the Generalised Scheme of Preferences and assessed its consistency. As outlined above, the GSP combines trade, development and foreign policy objectives. Choices made in one dimension have evident consequences on the other dimensions and thus raise a consistency question. This chapter also elaborated on the factors that influenced the success of coordination during the drafting of the Commission's proposal.

By definition, because import preferences are a trade instrument for development, the GSP illustrates the necessary coordination between trade and development policies. In addition, the general safeguard mechanism of the scheme and one of its particular arrangements (GSP+) introduce political conditionality in the granting and continued benefit of import preferences, so that coordination with foreign policy objectives is also required. 
The consistency of the proposal was ensured at different levels: the Treaty framework, the policy framework and the Commission's internal decision-making process. First, as defined in the Treaty framework, trade, development and foreign policy objectives should be mutually supportive and contribute to EU action in favour of developing countries (article 3.2(d) TEU, see section 4.3). Second, the GSP is framed in concepts, strategies and policy documents that elaborate on the necessity for trade and foreign policy to support development objectives and on how to mainstream development objectives in EU instruments targeting developing countries (policy framework). These first two levels influence the content of the policy options that may be considered. Third, exploring the internal decisionmaking process for the preparation of this proposal has both highlighted the risk of inconsistency - on the basis of the evaluation of the previous scheme - and the efforts to address such problems to meet the objective of refocusing preferences and to ensure the consistency of the revised preferential scheme. Evidently, DG Trade was in charge of developing the proposal, within the substantial limits just mentioned. Enjoying a comparative advantage in the process given the exclusive nature of the trade competence, the lead DG used its own expertise as well as external expertise to steer the drafting. Despite the limited staff number of the unit in charge within DG Trade, the proposal was carefully prepared as a result of an inclusive inter-service consultation.

The different internal and external factors, which this chapter highlighted, influenced the extent of the success of coordination process both by narrowing down the policy options that could be considered and by determining the relative strength of the different actors involved in decision-making. These factors explained how coordination succeeded on the one hand in refocusing preferences and excluding the countries the least in need from the preferential scheme. On the other hand, they also explained how the Commission further contributed to this objective by balancing foreign policy objectives while resisting to the protectionist temptation, as well as resolving tensions between the GSP and broader trade objectives. The potential inconsistencies of the scheme, as revealed in the impact assessment, made coordination a requirement from the outset of decision making to bring actors together and to articulate their different positions. The WTO framework substantially constrained the content of the proposal, as the GSP had to meet certain criteria. In turn, the WTO constraint strengthened DG Trade - giving it the legal basis to exclude protectionist concerns in particular - but the DG was wise enough not to play a unilateral game in the drafting process. The importance of the GSP in EU external action and the salience of the proposal, even more so in a field of exclusive competence, further strengthened the position of the Trade cabinet and of DG Trade in the process. These factors gave them the instruments to arbitrate between the different positions. The same factors also required a carefully planned and executed decision-making process, while creating a risk for the reputation of the Commission because of the visibility of the GSP. The revision of the GSP thus constituted an example of integrated decision-making, framed in a long-term 
strategy. The drafting process was supported by the use of the full range of coordination instruments, and the coordination between trade, development and foreign policy was a central objective throughout the decision-making process. A highly consistent proposal was agreed on. 


\section{CHAPTER 8. CONCLUSION}

Since the emergence of European Political Cooperation in the 1970s, the consistency of its external action has remained a key concern for the EU. The accumulation and strengthening of external policies and instruments over time have led to the fragmentation of EU external action. This, in turn, has jeopardised the EU's international actorness. The way in which the EU seeks to ensure consistency between development, trade and foreign policy has been the research focus of this $\mathrm{PhD}$. The consistency requirement is expressed at several levels, more or less specific. The centrality of this concern has been reaffirmed in political and legal documents alike and culminated with the introduction of several new provisions for the enhanced consistency of EU external action in the Lisbon Treaty. These provisions have had far-reaching institutional consequences in the internal organisation of EU institutions as well as in the rules of intra-institutional functioning and inter-institutional cooperation.

The main research question addressed in this thesis was to what extent EU external policies are consistent and how we can explain this. The research focus was narrowed down to one institution, the European Commission. This choice was justified by the Commission's role in the definition of the trade and development policies, its expertise in these key external policy areas and its significant contribution to EU external action in general. It was also justified by the institution's long-time responsibility to ensure the consistency of EU action. The research question was addressed on the basis of two case studies - the adoption and renewal of appropriate measures against Zimbabwe, and the revision of the GSP. To organise the discussion, three sub-questions were asked:

- How and at which levels is consistency aimed for?

- To what extent is the policy output consistent?

- Under which circumstances is coordination successful?

These three sub-questions are addressed successively below.

\subsection{A three-level framework for consistency}

As a first step, the research contributes to the literature by developing a comprehensive framework to assess the consistency of Commission proposals. It identifies the three different levels at which the consistency requirement is expressed and put into effect: the general Treaty framework, the specific policy framework, and the Commission's internal decision-making process.

The first level, the Treaty framework, constitutes the legal or constitutional framework for the consistency of EU external action i.e. the most general level at 
which the consistency requirement is expressed. It applies to EU external action largo sensu and was thus common to the different case studies. As discussed in chapter 4, Treaty provisions have been progressively strengthened - because of the growing concern that inconsistency jeopardises the effectiveness of EU international action. At the same time, they have been elaborated and specified ranging from the general consistency requirement to the consistency mandate of certain institutions and positions such as the mandate of the High Representation/Vice President for instance.

The policy framework constitutes the second level at which the consistency requirement is expressed. By definition, it specifies the general consistency requirement as provided for in the Treaty in a particular policy area. Each case study is embedded in such a policy framework, which addresses interdependencies between trade, development and foreign policy and in this sense defines the contribution of individual policies to an overarching objective. The adoption of appropriate measures against Zimbabwe was framed by the Cotonou agreement, its article 96 in particular and the concept of targeted sanctions; the revision of the GSP was guided by documents implementing the concept of Policy Coherence for Development, in particular looking for a contradiction-free coordination between trade and development objectives (sections 6.2 and 7.2).

The third level concerns the way in which the consistency requirement for external policies - as defined in the Treaty and in the policy frameworks - is put into effect within the Commission. The Commission's internal decision-making process focuses on coordination from the onset of the drafting of any proposal. While the general characteristics of Commission decision-making in external policies were discussed in chapter 5 , the case study chapters explored how the various coordination instruments within the Commission were practically operating in the drafting of particular proposals (chapters 6 and 7). Discussing internal decision-making in concrete case studies helped to better understand how contradictions between the primary objective of a proposal and the different dimensions of this proposal were resolved in practice.

Overall, consistency is an organizing theme of the Lisbon Treaty and the research focused on how this imperative was concretely put into effect. The threelevel framework defines the legal, substantial and procedural guidelines that constrain the Commission in the field of external policies. In contrast to most of the literature, this research focused on the Commission's internal decision-making process, instead of focusing on implementation. By using particular case studies, the combination of these three levels shows that the consistency objective of the EU is not only a rhetoric objective, but also that it is actively pursued by the Commission. Further research, possibly applying the same three-level framework, could generalise the findings to other policy domains or to other EU institutions and bodies. 


\subsection{Assessing consistency}

The first case selected consisted of the Commission's proposal to adopt (in 2002) and the proposal to renew (in 2012) appropriate measures under article 96 of the Cotonou agreement against Zimbabwe. The 2011 Commission's proposal to revise the Generalised System of Preferences was the second case study. Discussing the existence or absence of contradictions within the proposals with their respective primary objectives, the thesis aimed at qualitatively assessing the degree of consistency reached in each case.

In the first case study on Zimbabwe, the primary objective was the same in 2002 and in 2012: the Commission proposal principally aimed at restoring essential elements. The assessment first discussed the different dimensions of the Commission's proposals before concluding on the general level of consistency. First, on the foreign policy dimension, in order to restore the respect for human rights, democratic principles and the rule of law in the country, the EU activated the "sanction mechanism" of the Cotonou agreement, article 96. The rationale was to pressure Mugabe's regime into normalising the political situation. In 2002, the details of appropriate measures indeed did not contradict the Union's primary objective, but also did not significantly add to their achievement. In 2012, the situation was different. Not only did the appropriate measures not contradict the primary objective of restoring essential elements, but they also significantly contributed to its realisation by allowing the Union to directly intervene in the political sphere. This is why the 2002 proposal reached only a medium degree of consistency, while the 2012 proposal was classified as highly consistent. Second, with respect to the consistency between the appropriate measures and development cooperation, the continuation of development cooperation had appeared prima facie as running counter to the proposal's primary objective. However, the case study showed that this was actually not the case: the continuation of development cooperation resulted from a careful assessment of the benefits and risks of a total suspension of development cooperation. Although theoretically possible under article 96, a total suspension was not adopted in the case of Zimbabwe in order not to jeopardise the objective of the restoration of essential elements in the ACP country. Development cooperation could continue, however under specific and restraining conditions. In 2002, the conditions were extremely restrictive though, raising a serious risk for the realisation of development objectives in Zimbabwe. This qualifies for a low degree of consistency as far as the coordination between appropriate measures and development cooperation is concerned. On the contrary, in 2012, the relaxation of the restrictive framework that was agreed allowed to use development cooperation in direct support of the primary objective of restoring essential elements in Zimbabwe, thereby qualifying for a high degree of consistency. Lastly, on the trade dimension, the initial decision in 2002 not to adopt trade restrictions was taken not to jeopardise the foreign policy objective and was confirmed in 2012. It qualifies for a 
medium degree of consistency in both cases. In conclusion, the 2002 proposal reached a low to medium degree of consistency (medium, low, medium) while the 2012 proposal reached a medium to high degree of consistency (high, high, medium). In turn, on the basis of the findings on the degree of consistency, the research also concluded that coordination was limitedly to moderately successful in 2002 and was moderately to fully successful in 2012.

In the second case study, the Commission's primary objective was the refocusing of preferences on those countries most in need. The consistency of the proposal to revise the GSP was assessed against this objective. First, to meet the primary objective of refocused preferences, the proposal addressed the different sources of competitive pressure on the countries most in need. Thereby it actually supported the realisation of the primary objective, what qualified for a high degree of consistency. Second, the changes introduced to the foreign policy dimension of the scheme also contributed to the primary objective of the revision while ensuring that conditionality under the scheme was not emptied of its substance. On this dimension, the proposal reached a high degree of consistency. Lastly, the changes proposed ensured the continued benefit of preferences to those countries most in need. It also qualified for a high degree of consistency. Overall, the research concluded that the proposal was highly consistent as its provisions on the different dimensions and mechanisms of the scheme did not contradict and actively contributed to the realisation of the primary objective of the revision - the refocusing of import preferences on those countries most in need (thereby also addressing the inconsistency criticism formulated against the previous GSP). It is not to say that no risk of contradiction existed. Potential tensions between the different components of the preferential scheme certainly existed and were carefully discussed on the basis of the criticisms formulated against the previous scheme; chapter 7 showed how the drafting process of the proposal addressed them. On the basis of this discussion, coordination during the decision-making process was found to be fully successful, a point to which the next section now turns.

\subsection{The factors explaining successful coordination}

This research posits that coordination is a main instrument in putting into effect the consistency requirement. However, the presence of coordination instruments is not a sufficient condition to ensure that the policy output is consistent. The drafting of any proposal, and hence internal coordination taking place within the Commission, up to the adoption of the proposal by the College of Commissioners, is subject to potentially contradictory pressures. The Commission's internal decisionmaking process is influenced by different factors, which either impede coordination or contribute to making it successful, thus explaining the drafting of a consistent proposal. On the basis of the case studies, the research inductively isolated and 
discussed these factors. Several types of factors were identified, both external and internal to the Commission.

With regard to external factors - i.e. factors external to the Commission - the research discussed two aspects: first, the influence of the international context, and second the influence of inter-institutional dynamics on the success of coordination within the Commission.

As regards the first aspect, the international context, in which the Commission prepares a proposal, may exercise a subtle influence through public mobilization or through initiatives taken by other actors. Although these actions do not legally bind the EU, they may influence it. The Zimbabwe case is telling in that respect. Although the Commission was not bound by the public mobilisation against Mugabe's regime and the sanctions adopted outside of the EU against the country between 2000 and 2002, these elements influenced the drafting of the Commission. It strengthened the position of hardliners in Brussels, contributed to limit the number of policy options that would be acceptable and thereby steered the Commission's proposal into a certain direction. The international context may also exert a direct and forceful influence when it consists of, typically, an international consensus or legally binding provisions that constrain action in a particular policy domain. The proposal for a revision of the GSP illustrated well the effects of this factor. In particular, international trade law limited the acceptable options for political conditionality under the preferential scheme. This external constraint was an important determinant of the drafting process, limiting the options that the Commission could consider and thereby putting ex ante pressure on DG Trade on the choices that it would make. At the same time, it gave DG Trade more leverage in the negotiations with other DGs and provided it with a compelling argument to put aside certain policy options. Overall, the case studies showed that the international context narrowed down the options that were available to the Commission, which in turn empowered certain actors and disempowered others who pursued preferences that were not in line with political or legal demands articulated at the international level, and thereby facilitated coordination.

Although this research focused on the European Commission, case studies also probed into inter-institutional dynamics. The starting point for this discussion is that the Commission does not take decisions on behalf of the Union on its own: it adopts a proposal that will be examined by the Council or by the Council and the European Parliament depending on the topic. Because the Commission aims at submitting a proposal that is unlikely to meet strong resistance in the subsequent stages of decision-making, the preferences of other actors at the European level are factored in during the Commission's coordination and internal decision-making processes. Concerns voiced by other actors are therefore echoed in the Commission's proposal - for instance the willingness to take a strong position vis-àvis Mugabe's regime or the fear of import surges in sensitive sectors in the case of the revision of the GSP. Such pressures can steer Commission proposals in a certain direction with a risk of, sometimes, introducing contradictions with the objective(s) 
initially defined by the Commission. The extent of the influence of this factor on the Commission's drafting depends on several elements. First, it depends on the nature of the competence. Because it determines the power of the Commission, the nature of the competence also determines how much other institutions can weigh in. Contrasting the Zimbabwe case and the GSP case shows that, in the former, the Council was much more influential than it was in the revision of the GSP. This has to do with the preeminent role of the Council in the Union's decision-making process on sanctions, as opposed to the GSP case where the Commission enjoys a much stronger position. Second, the influence of this factor depends on the polarisation of the positions within the Council. For instance in the Zimbabwe case in 2002, one could have thought that internal divisions within the Council on the position to take vis-à-vis Zimbabwe would have lessened the Council's influence on the Commission. Actually, hardliners were so outspoken that, although the Council was formally divided, in a policy area closely related to foreign policy and given EU decision-making in that matter, there was no doubt as to the only acceptable option. The Commission could not play Member States against each other, what left the Council in a position to significantly influence the content of the proposal. It follows that the existence of divisions within the Council does not systematically empower the Commission. This Commission's capacity depends on the nature of the decision-making process. Third, the extent to which inter-institutional dynamics may play also depends on the Commission's own strategic behaviour, as illustrated by the GSP case. A co-legislator, the European Parliament was in theory in a relatively strong position vis-à-vis the Commission. The Parliament could have questioned some of the substantial features of the preferential scheme in an attempt to get more powers on certain elements in return for its agreement. Yet, anticipating the Parliament's demands on procedural aspects of the GSP and meeting these in its early drafts, the Commission prevented the Parliament from playing this game. The Commission thereby limited the Parliament's impact on the substance of the revision.

Overall it is clear from the above examples that the Commission's decisionmaking is informally open to other institutions' influence because it is eager to submit proposals that are acceptable. This has an impact on the definition of the primary objective and the options considered, in turn constraining coordination and the choices made throughout its internal drafting process. The extent of this influence depends on the nature of the competence - which determines the Commission's position in EU decision-making - and it can be mitigated. The influence of inter-institutional dynamics is not different pre- and post-Lisbon but on one point. The Lisbon Treaty has also formally introduced an inter-institutional dimension to the core of the Commission's decision-making process. With the setting up of the EEAS, an outsider contributes to the drafting of Commission proposals and may even be the lead service in this process. Although the inclusion of the diplomatic service has, at first, challenged coordination, the case study on Zimbabwe in particular shows that the transition has been facilitated by the 
adjustment of coordination mechanisms, as well as by individual efforts - the new EEAS desk Zimbabwe being the former Devco desk Zimbabwe in charge of the dossier. This also shows the potential disruption of this new inter-institutional dynamics as the success of coordination in that case very much depended on the Commission background of the official in question, the familiarity with Commission procedures and the existing network within the Commission working on Zimbabwe.

In addition to external factors, the case studies have revealed the importance of internal factors, which can be of three types: they may first relate to the type of decision and second to the nature of the competence. Third, they may also reflect intra-institutional dynamics, being linked to bureaucratic politics and to the question of leadership within the Commission.

The first factor relates to the type of decision the Commission is preparing. The Commission's proposal is either one included in the work programme or on the contrary one that is addressing a crisis. Depending on this distinction, the steps of internal decision-making are more or less comprehensive. Drafting a policy proposal that is included in the work programme builds on substantial and procedural checks and balances. Efforts are even more important if the proposal is also considered to be a major piece of legislation either by a Commissioner, a DG or the Commission as a whole. In contrast, addressing a crisis situation introduces a dimension of time pressure into the process, which may prevent the use of certain procedural instruments. This difference existed between the 2002 proposal to adopt appropriate measures against Zimbabwe (a crisis decision) and the 2011 proposal to revise the GSP (routine decision). The 2012 proposal to renew appropriate measures against Zimbabwe illustrates a more subtle nuance: although conceived of as a response to a crisis, appropriate measures had actually been implemented against the regime for ten years when the Commission was preparing the 2012 renewal, thus turning decision-making from a crisis decision into a more routine decision. Overall, if a proposal is included in the Commission's work programme, the coordination requirement within the Commission will be more constraining. The constraint is even more important if the proposal is considered a major piece of legislation that has an impact on the visibility and the reputation of the institution. Contrasting the Zimbabwe case with the GSP case for instance, the research showed that the Commission in general, DG Trade in particular, was particularly eager to present a consistent proposal to revise the GSP in order to avoid paying the costs of inconsistency of a major policy proposal that would jeopardise the institution's reputation. The more visible a proposal is for the Commission, the more constrained the Commission's decision-making process is. Indeed, as the Commission wants to project the image of a consistent actor, it will pay particular attention to the success of the coordination and consistency, all the more so in the event of a highly visible proposal, in order not to be exposed to criticisms. 
The type of decision the Commission prepares also depends on the nature of the competence involved, which has not only an impact on inter-institutional dynamics as discussed above, but also on the distribution of power within the Commission. If the competence is exclusive, the lead DG and cabinet will be in a more powerful position vis-à-vis other DGs and cabinets within the Commission during the drafting process, as it was the case with the revision of the GSP. The legitimacy of an established competence and the expertise of policy-makers usually result in a less contested drafting phase. Disagreements may still exist, but they are likely to be more easily resolved by the authority of the lead service or thanks to a political intervention at cabinet or Commissioner level. Such a difference could be easily observed when discussing the Zimbabwe and GSP cases. In the GSP case, DG Trade, the lead DG on a proposal relating to an exclusive competence, was in a relatively strong position to steer the drafting process, define conditions to include or disregard contributions made by other DGs, and eventually to propose a draft. In the Zimbabwe case, the situation can be further differentiated between 2002 and 2012. Although the lead DG in 2002, DG Development had to develop a policy option it did not believe in. Comparatively, the drafting in 2012 was easier for the lead service. The EEAS had become the lead player on the dossier but its staff had actually been transferred from DG Development. Thereby it could build on a 10year experience of the DG - also still formally associated to the lead service - and was in a position to propose an evolution in the Union's action. If the nature of the competence can give more or less resources to the lead service in the coordination process, it can also introduce constraints for the lead actor. The risk of paying reputational costs in a field of exclusive competence for an inconsistent proposal typically prevented DG Trade from acting unilaterally and encouraged it to work towards the success of coordination in the drafting process of the proposal to revise the GSP. Overall, the nature of the competence is a key element to consider because it influences the authority of the lead actor in the coordination process and the resources it has access to throughout decision-making. However, this factor may either encourage the lead actor to play the coordination card to its fullest or instead give it the opportunity and the resources to shortcut coordination efforts.

The third internal factor reflects intra-institutional dynamics, determined by both bureaucratic politics and the leadership question.

Evidently, bureaucratic politics is the first element that comes to mind when one considers the Commission's internal decision-making. Dividing lines run through the organisation as different services and cabinets have different objectives and different approaches. For instance, the first case study on Zimbabwe illustrated oppositions between Development and Relex in 2002, and between Development and the EEAS in 2012, as well as to a lesser extent between the EEAS and Trade. Overall, the literature has already lengthily discussed the role of bureaucratic politics (Allison \& Halperin, 1972:43; Allison, 1971), in particular in the EU (see Egeberg, 2003:116; Smith, 2003:139; Christiansen, 1997:78; Simon, 1997:112). The extent to which this factor plays out though depends on the service 
officials belong to, their mandates and their objectives. They are also very much determined by officials' backgrounds, their sensibility to other policy areas and their readiness to develop cross-policy approaches to issues. For instance, interviewees mentioned the existence of a common culture between Development and Trade on trade with ACP countries as an important factor. In DG Trade, the awareness of development challenges for ACP countries results from the institutional origins of the unit dealing with trade with ACP countries in DG Trade. Initially part of DG Development, this unit was relocated to DG Trade but staffed with officials with a development background and/or transferred from DG Development. Divergences of opinions may also be accentuated by the relative weight of the actors involved in decision-making. Weight is determined i.a. by actors' resources, their expertise or the nature of the competence. For instance, during the drafting of the 2002 proposal to adopt appropriate measures against Zimbabwe, the weight of Relex in the choices made was partly due to its proximity to the Council and the influence exercised by certain Member States. At the same time, some elements may also counter-balance the a priori negative influence of bureaucratic politics on coordination in decision-making. The case on Zimbabwe, more particularly the 2012 proposal, shows that the socialisation process among officials working on a dossier and the constitution of a network of officials working closely together tone down potential differences of objectives. Therefore, the existence of bureaucratic politics does not per se mean that coordination fails in the decision-making process and produces an inconsistent policy output.

The second element to consider under intra-institutional dynamics is the question of leadership within the Commission with respect to consistency and coordination. Two issues are of interest here. First, to what extent is the Relex group of Commissioners (composed of the HRVP, the Commissioners for Development, International cooperation, Humanitarian aid and crisis response, Enlargement, Trade, Economic and monetary affairs and the Foreign Policy Instruments service) leading on consistency and coordination? Realising the potential of this group remains an often-suggested recommendation to enhance the consistency of Commission action (CEPS High-Level Group, 2014; EEAS, 2013). Potentially, the Relex group could improve coordination and consistency on issues related to external action - bringing together for instance the three Commissioners involved in the case studies. However, the role of this group is actually limited, as shown in the empirical case studies. Post-Lisbon, its leadership in the Commission's external strategy and action could have been enhanced with the decision of President Barroso to task the HRVP to chair it - however, the HRVP has not actually been chairing the group meetings. This leads to a second issue. According to the Treaty, the HRVP should aim to enhance the consistency of EU external policies and facilitate the coordination of external policies within the Commission. However, in practice, this role has been very limited. The reasons are, first, the shortcomings of the position - for instance, the HRVP is not perceived as a Commissioner - and second, the HRVP's very extensive mandate, which makes it hardly possible to do 
everything at the same time, despite the support provided by the EEAS. Chapters 6 and 7 have revealed the very limited presence of the HRVP in the particular cases selected. Without rethinking the position with a clearer focus on the coordination of external policies within the Commission, the situation is unlikely to evolve much. In addition, in the current situation, the personal criticisms against the first incumbent have weakened the position.

In conclusion, quite expectably, different DGs of the Commission might have different viewpoints but, depending on the circumstances (type of proposal, nature of the competence and relative strength of DGs and Commissioners), these differences have a more or less important influence on coordination and ultimately on consistency. The Lisbon Treaty has added an insider-outsider dimension to these tensions linked to bureaucratic politics observed within the Commission. Although thought of as a service aiming at coordination and consistency, the EEAS actually renewed at first the coordination challenge, requiring to adapt procedures and to create a new coordination reflex among actors. Within the Commission, challenges may also be explained by the insufficiencies of the political leadership on the issue. Despite the existence of several instruments aiming at coordination and consistency in theory - the HRVP position and the Relex group of Commissioners for instance - the potential has not materialised, leaving room for strategic positioning by different actors that thereby weaken the system.

Overall, the case studies chapters have thus brought to the fore the different factors that influence the coordination process, and in turn the consistency of the policy output. The international context, inter-institutional dynamics, the type of decision being prepared, the nature of the competence, intra-institutional rivalries and the question of leadership were successively elaborated on above. However, empirical evidence was not conclusive as to the relative strength of the different factors. A unique combination of these factors characterises each proposal drafted by the Commission. The case studies made it clear that factors may have a mutually reinforcing effect on the success of coordination or negatively affect coordination efforts. For instance, in the case on Zimbabwe, the crisis nature of the decisionmaking process reinforced inter-institutional challenges to coordination with hardliner Member States trying to steer the drafting in a particular direction. However, bureaucratic politics played a moderating role in that context by allowing a dissenting voice to be expressed that re-balanced the content of the proposal. In the second case, the revision of the GSP, one will note that the international factor, the type of decision and the nature of the competence had a mutually reinforcing effect on the drafting process, emphasising the importance of coordination and constraining the substantial choices that the lead actor, DG Trade, could make. 


\subsection{Consistency after the Lisbon Treaty}

The Arab spring that arose immediately after the entry into force of the Lisbon Treaty and the multifaceted action it required from international actors - foreign policy including security issues, development, trade and social policy i.a. - illustrate the relevance of the consistency issue for the EU to deploy an action across the range of policies available. At the same time, it provided a dramatic test case for the EU's ability to actually put into effect the consistency requirement.

At the time of the writing, the approach to the consistency challenge is evolving. Consistency has long been addressed by a focus on the legal and institutional framework - the specification of the consistency requirement in the Treaty and institutional arrangements to implement this requirement (respectively levels 1 and 3 in this research). However, the answers brought to the consistency issue have not always been satisfactory and the EU still needs to capitalise on the potential of the changes introduced by the Lisbon Treaty. At the same time, attention is shifting to a new approach that aims to strengthen the policy framework for consistency (level 2 in this research). The development of the concept of "comprehensive approach" - as implemented for instance in the Horn of Africa, the Sahel and the Great Lakes even before the adoption of the joint communication on the concept (Commission/High Representative, 2013) - could be a new direction taken by the EU to address the consistency challenge. With this concept, the EU aims to enhance the horizontality of decision-making and to address crosscutting issues.

Overall, the centrality of the consistency of EU external action in the Lisbon Treaty reflects the EU's efforts to live up to expectations - although consistency is only one of the difficulties faced by the EU. To respond to demands for more international presence and to address multidimensional and global challenges, the EU seeks to promote the consistency of its external policies and the associated characteristics of effectiveness, credibility and legitimacy. However, the Union still needs to capitalise on the potential of some of the newest instruments set up to coordinate external policies. If the EU succeeds in enhancing the consistency of its external action, the outcome will in turn be an enhanced international status. 



\section{Annex I:}

\section{Policy options for the revision of the GSP}

(after Commission, 2011h, vol.I:19-25)

\begin{tabular}{|c|c|}
\hline Policy options & Main elements \\
\hline Discontinuation A & $\begin{array}{l}\text { Preferences are abandoned for GSP and GSP+ beneficiaries, } \\
\text { EBA would remain }\end{array}$ \\
\hline \multirow[t]{3}{*}{ Baseline B } & $\begin{array}{l}\text { Current policy continues without change. } \\
2 \text { baseline scenarios }\end{array}$ \\
\hline & $\begin{array}{l}\text { B1 (short run): continuation of the scheme taking into } \\
\text { account the current status of multilateral and bilateral } \\
\text { agreements }\end{array}$ \\
\hline & $\begin{array}{l}\text { B2 (long run): continuation of the scheme based on the } \\
\text { assumption that all on-going but unfinished multilateral and } \\
\text { bilateral negotiations have been concluded successfully }\end{array}$ \\
\hline
\end{tabular}

Partial redesign C

\section{2 scenarios}

Common elements

- Preferences deferred for certain eligible countries: Overseas Countries and Territories, High Income Countries, Upper-Middle Income countries, countries with a preferential trade agreement covering substantially all preferences

- Graduation principles are revised: product sections are redefined, graduation does not apply to GSP+

- GSP+ entry mechanism is simplified and made more flexible: countries must ratify, not fully implement, conventions while providing binding commitments to guarantee their implementation, countries can apply for GSP+ at any time

- GSP+ monitoring mechanism is redesigned to enhance implementation of the conventions

- More transparent and efficient procedures for temporary withdrawal of preferences are introduced

- The administrative procedures of safeguard mechanisms are improved 
C1

- Graduation threshold remains unchanged

- GSP+ vulnerability criteria: import-share threshold is relaxed (increased from $1 \%$ to $2 \%$ )

- List of GSP+ conventions unchanged

$\mathrm{C} 2$

- Graduation threshold reduced to 7,5\% and 50\% safety net is eliminated

- Vulnerability criteria is eliminated

- List of GSP+ conventions is expanded

Full redesign D D builds upon the features of $\mathrm{C}$ but product coverage in particular is redesigned:

D1: all beneficiary countries receive full product coverage and all products are deemed non-sensitive. No graduation takes place

D2: a number of industrial and agricultural products move from the sensitive to the non-sensitive list

D3: the list of products covered by the scheme is expanded to include a number of industrial and agricultural products 


\section{Annex II: \\ Countries no longer beneficiaries of the new GSP}

(after Commission, DG Trade, 2012b:10-12)

\begin{tabular}{|c|c|}
\hline $\begin{array}{l}\text { Categories of } \\
\text { countries excluded }\end{array}$ & Countries no longer beneficiaries \\
\hline OCTs & $\begin{array}{l}\text { Anguilla, Netherlands Antilles, Antarctica, American Samoa, } \\
\text { Aruba, Bermuda, Bouvet Island, Cocos Islands, Christmas } \\
\text { Islands, Falkland Islands, Gibraltar, Greenland, South Georgia } \\
\text { and South Sandwich Islands, Guam, Heard Island and } \\
\text { McDonald Islands, British Indian Ocean Territory, Cayman } \\
\text { Islands, Northern Mariana Islands, Montserrat, New } \\
\text { Caledonia, Norfolk Island, French Polynesia, St Pierre and } \\
\text { Miquelon, Pitcairn, Saint Helena, Turks and Caicos Islands, } \\
\text { French Southern Territories, Tokelau, United States Minor } \\
\text { Outlying Islands, Virgin Islands - British, Virgin Islands- US, } \\
\text { Wallis and Futuna, Mayotte }\end{array}$ \\
\hline
\end{tabular}

Other preferential arrangements
- Euromed (6): Algeria, Egypt, Jordan, Lebanon, Morocco, Tunisia.

- Cariforum (14): Belize, St. Kitts and Nevis, Bahamas, Dominican Republic, Antigua and Barbuda, Dominica, Jamaica, Saint Lucia, Saint-Vincent and the Grenadines, Barbados, Trinidad and Tobago, Grenada, Guyana, Surinam.

- Market Access Regulation (12): Côte d'Ivoire, Ghana, Cameroon, Kenya, Seychelles, Mauritius, Zimbabwe, Namibia, Botswana, Swaziland, Papua New Guinea, Fiji.

- Other (2): Mexico, South Africa

HICs

Saudi Arabia, Kuwait, Bahrain, Qatar, United Arab Emirates, Oman, Brunei Darussalam, Macao

UMIs

Argentina, Brazil, Cuba, Uruguay, Venezuela; Belarus, Russia, Kazakhstan; Gabon, Libya, Malaysia, Palaos 


\title{
Annex III: \\ List of interviews
}

\section{Exploratory interviews}

\author{
Exploratory interview $1 \quad$ Brussels, 5 November 2010 \\ Exploratory interview 2 exchange of emails, October 2010 \\ Exploratory interview 3 exchange of emails, October 2010 \\ Exploratory interview 4 Commission, Brussels, 16 November 2010 \\ Exploratory interview 5 General Secretariat of the Council, Brussels, 1 December 2010 \\ Exploratory interview 6 Commission, Brussels, 15 December 2010 \\ Exploratory interview 7 Maastricht, 16 December 2010 \\ Exploratory interview 8 Maastricht, 16 December 2010 \\ Exploratory interview 9 Brussels, 24 January 2011
}

\section{Interviews}

Interview 1 General Secretariat of the Council, Brussels, 10 December 2010

Interview 2 Commission, Brussels, 8 April 2011

Interview 3 EEAS, Brussels, 12 April 2011

Interview 4 Commission, Brussels, 20 April 2011

Interview 5 Commission, Brussels, 27 April 2011, follow-up emails 16 \& 24 June 2011

Interview 6 Commission, Brussels, 19 May 2011

Interview 7 Commission, Brussels, 20 May 2011

Interview 8 Commission, Brussels, 26 May 2011

Interview 9 Permanent Representation of Denmark to the EU, Brussels, 26 May 2011

Interview 10 Commission, Brussels, 31 May 2011

Interview 11 EEAS, Brussels, 6 June 2011

Interview 12 Commission, exchange of emails, 16 June 2011

Interview 13 Commission, Brussels, 30 June 2011

Interview 14 Commission, phone interview, 6 January 2012

Interview 15 Commission, exchange of emails, 6 \& 9 January 2012

Interview 16 Commission, exchange of emails, 9 January 2012 
Interview 17

Interview 18

Interview 19

Interview 20

Interview 21

Interview 22

Interview 23

Interview 24

Interview 25

Interview 26

Interview 27

Interview 28

Interview 29

Interview 30

Interview 31

Interview 32

Interview 33

Interview 34

Interview 35

Interview 36

Interview 37

Interview 38

Interview 39

Interview 40

Interview 41

Interview 42

Interview 43

Interview 44

Interview 45

Interview 46

Interview 47

Interview 48

Interview 49
EEAS, Brussels, 11 January 2012

Commission, exchange of emails, 12 January 2012

EEAS, Brussels, 13 January 2012

EEAS, Brussels, 27 January 2012

Commission, Brussels, 27 January 2012

EU delegation to Zimbabwe, exchange of emails, 25 January and 6 February 2012

EU delegation to Zimbabwe, exchange of emails, 8 February 2012

Permanent Representation of the United Kingdom to the EU, exchange of emails, 9 February 2012

Permanent Representation of Sweden to the EU, Brussels, 9 February 2012

Permanent Representation of Belgium to the EU, Brussels, 13 February 2012

Permanent Representation of France to the EU, Brussels, 23 February 2012

Commission, Brussels, 7 March 2012

Commission, exchange of emails, 10 April 2012

Commission, Brussels, 13 April 2012

Commission, Brussels, 27 April 2012

Commission, Brussels, 27 April 2012

Commission, phone interview, 4 May 2012

Commission, Brussels, 8 May 2012

Commission, Brussels, 5 June 2012

Commission, Brussels, 12 July 2012

Commission, Brussels, 26 July 2012

Commission, Brussels, 26 July 2012

Commission, Brussels, 10 September 2012

EEAS, Brussels, 13 November 2012

Commission, Brussels, 10 December 2012

Commission, Brussels, 18 December 2012

Commission, Brussels, 20 December 2012

Commission, phone interview, 8 January 2013

Commission, Brussels, 11 January 2013

EEAS, Brussels, 12 February 2013

Commission, Brussels, 21 February 2013

EEAS, Brussels, 26 February 2013

Commission, Brussels, 26 February 2013 


\section{References}

n.a. (n.d. a), Kimberley Process, online resource, http://www.kimberleyprocess.com/web/kimberleyprocess/kp-basics (accessed 30.06.2013)

n.a. (n.d. b) Kimberley Process, Zimbabwe, online resource, http://www.kimberleyprocess.com/web/kimberley-process/participant/zimbabwe (accessed 03.04.2012)

Alexander, E. R. (1993), "Interorganizational Coordination: Theory and Practice", Journal of Planning Literature, 7(4): 328-343

Alexander, E. R. (1995), How Organizations Act Together - Interorganizational coordination in theory and practice, Amsterdam: Gordon and Breach Science Publishers

Algieri, F. (1999), "The Coherence Dilemma of EU External Relations: The European Asia Policy”, Journal of the Asia Pacific Economy, 4(1): 81-99

Allen, D. (1996), "Conclusions: the European rescue of national foreign policy?" in Hill, C. (ed.), The Actors in Europe's Foreign Policy, London and New York: Routledge, pp. 288-304

Allen, D. (2002), “Who speaks for Europe?': the search for an effective and coherent external policy" in Peterson, J. and H. Sjursen (eds.), A Common Foreign Policy for Europe? Competing visions of the CFSP, London: Routledge, pp.41-58

Allen, D. and M. Smith (1994), "External Policy Developments”, Journal of Common Market Studies, 32(2): 67-86

Allen, D. and M. Smith (2002), "External Policy Developments", Journal of Common Market Studies, 40(s1):97-115

Allison, G. T. (1971), Essence of Decision: Explaining the Cuban Missile Crisis, Boston: Little, Brown and Company

Allison, G. T. and M. H. Halperin (1972), "Bureaucratic Politics: A Paradigm and Some Policy Implications", World Politics, 24: 40-79

Avery, G., Howorth, J., Dijks, D., Duke, S., Adebahr, C., Lieb, J., Missiroli, A., Le Gloannec, A.-M., Whitman, R., Keukeleire, S., Grevi, G. and A. Maurer (2007), "The EU Foreign Service: how to build a more effective common policy", EPC Working Paper, 28

Bacconnier, E. (2003), Les modes de coordination administratifs au sein de la Commission européenne: réconcilier sectorisation et cohérence politique - L'exemple de la politique de développement durable, Bruges: College of Europe

Balfour, R. with Bailes, A. and M. Kenna (2012), "The European External Action Service at work - How to improve EU foreign policy", EPC Issue Paper, 67

Babarinde, O. and G. Faber (2004), "From Lomé to Cotonou: Business as Usual?", European Foreign Affairs Review, 9(1): 27-47

Bartels, L. (n.d.), The appellate body report in European Communities - Conditions for the granting of tariff preferences to developing countries, WT/DS246/AB/R and its implications for conditionality in GSP programs, available at www.worldtradelaw.net/articles/bartelsgsp.pdf (accessed 11 June 2012)

Bartels, L. (2003), "The WTO enabling clause and positive conditionality in the European Community's GSP program", Journal of International Economic Law, 6(2): 507-532

Best, E. (1994), "The Maastricht Treaty: What Does It Actually Say and Do" in Laursen, F. and S. Vanhoonacker (eds.), The Ratification of the Maastricht Treaty: Issues, Debates and Future Implications, Maastricht: EIPA

Bindi, F. (2012), "European Union Foreign Policy: A Historical Overview" in Bindi F. and I. Angelescu (eds.), The Foreign Policy of the European Union, Washington, DC: Brookings, pp. 11-39

Biscop, S. (2012) "EU Grand Strategy: Optimism is Mandatory", Egmont Security Policy Brief, 16

Blockmans, S. (2007), "Coherence and Consistency" in Blockmans S. (ed.), The European Union and Crisis Management - Policy and Legal Aspects, The Hague: T.M.C. Asser Press, pp.145-214

Blockmans, S. (2011), "Beyond Conferral: The Role of the European External Action Service in DecisionShaping" in Larik, J. and M. Moraru (eds.), "Ever-closer in Brussels - Ever-closer in the world? EU external action after the Lisbon Treaty", EUI Working Paper LAW, 10: 5-17 
Blockmans, S. and C. Hillion (eds) (2013), EEAS 2.0 - A legal commentary on Council decision 2010/427/EU establishing the organisation and functioning of the European External Action Service, SIEPS, 1

Blockmans, S. and M. Spernbauer (2013), "Legal Obstacles to Comprehensive EU External Security Action", European Foreign Affairs Review, 18(4): 7-24

Blockmans, S. and R. A. Wessels (2012), "Introduction: Principles and Practices of EU External Representation, CLEER Working Papers, 5: 7-10

Bonavita, V. (2008), The principle of consistency of EU external relations as the litmus paper of the unity of the European legal order and the role of the Court of Justice, Bruges: College of Europe

Bosse-Platière, I. (2009), L'article 3 du traité UE: Recherche sur une exigence de cohérence de l'action extérieure de l'Union européenne, Brussels: Bruyland

Box, L. and A. Koulaïmah-Gabriel (1996), "Towards Coherence? Development Cooperation Policy and the Development of Policy Cooperation", ECDPM Working Papers, 21

Bradley, A. (2005), "An ACP Perspective and Overview of Article 96 Cases", Discussion Paper No. 64D, Maastricht: ECDPM

Bretherton, C. and J. Vogler (2006), The European Union as a Global Actor, Oxon: Routledge

Bretherton, C. and J. Vogler (2008), "The European Union as a Sustainable Development Actor: The Case of External Fisheries Policy", Journal of European Integration, 30(3): 401-417

Bretherton, C. and J. Vogler (2009), "Past its Peak? The European Union as a Global Actor 10 Years After" in Laursen, F. (ed.), The EU as a Foreign and Security Policy Actor, Dordrecht: Republic of Letters, pp. 23-44

Brie, M. and E. Stölting (2012), "Formal Institutions and informal institutional arrangements" in Christiansen, T. and C. Neuhold (eds), The International Handbook of Informal Governance, Cheltenham: Edward Elgar, pp.19-39

Buchet de Neuilly, Y. (2003), "European external relations fields: The multi-pillar issue of economic sanctions against Serbia", in Knodt, M. and S. Princen (eds), Understanding the European Union's External Relations, London \& New York: Routledge, pp. 92-106

Cameron, H. (2010), "Sanctioning Zimbabwe: Comparing the European Union and Canadian Approaches", Paper submitted to the CPSA conference

Carbone, M. (2008), "Mission Impossible: the European Union and Policy Coherence for Development", Journal of European Integration, 30(3): 323-342

Carbone, M. (2010), "The EU in Africa: Increasing Coherence, Decreasing Partnership" in Bindi, F. (ed.), The Foreign Policy of the European Union - Assessing Europe's Role in the World, Washington: Brookings Institution Press, pp. 239-253

Carbone, M. (2012), "Preserving Policy Autonomy: EU Development Cooperation from Maastricht to Lisbon" in Laursen, F. (ed.), The EU'S Lisbon Treaty: Institutional Choices and Implementation, Farnham: Ashgate, pp. 229-242

Centre for the Analysis of Regional Integration at Sussex (CARIS) (2010), Mid-term evaluation of the EU's Generalised System of Preferences, Sussex

CEPS High-Level Group (2014), Shifting EU Institutional Reform into High Gear - Report of the CEPS HighLevel Group, Brussels

Christiansen, T. (1997), "Tensions of European governance: politicized bureaucracy and multiple accountability in the European Commission", Journal of European Public Policy, 4(1): 73-90

Christiansen, T. (2001), "Intra-Institutional Politics and Inter-Institutional Relations in the EU: Towards Coherent Governance?”, Journal of European Public Policy, 8(5): 747-769

Christiansen, T. and M. Dobbels (2012): "Comitology and delegated acts after Lisbon: How the European Parliament lost the implementation game", European Integration online Papers (EIoP), 16, Art. 13, http://eiop.or.at/eiop/texte/2012-013a.htm

Christiansen, T. and C. Neuhold (2012), "Introduction" in Christiansen, T. and C. Neuhold (eds), The International Handbook of Informal Governance, Cheltenham: Edward Elgar, pp.1-18

Christiansen, T., Follesdal, A. and S. Piattoni (2003), "Informal governance in the European Union: an introduction" in Christiansen, T. and S. Piattoni (eds), Informal Governance in the European Union, Cheltenham and Northampton: Edward Elgar, pp. 1-21 
Cini, M. (1996), The European Commission: leadership, organisation and culture in the EU administration, Manchester: Manchester University Press

Collier, D. (2011), “Understanding Process Tracing”, Political Science and Politics, 44(4): 823-830

Commission (n.d. a), How the work of the Commission is organised, internal document not publicly available

Commission (n.d. b), The European Commission at work, online resource, http://ec.europa.eu/atwork/index_en.htm (accessed 12 January 2010)

Commission (n.d. c), Inter-service coordination groups, internal document not publicly available

Commission (n.d. d), GIS list, internal document not publicly available

Commission (n.d. e), Impact Assessment Board, online resource, http://ec.europa.eu/governance/impact/iab/iab_en.htm (accessed 19 April 2012)

Commission (n.d. f), Rules of procedure of the Impact Assessment Board, available at http://ec.europa.eu/governance/impact/iab/docs/iab_rules_of_procedure_final_en.pdf (accessed 19 April 2012)

Commission (2001a), Communication on the opening of consultations with Zimbabwe pursuant to Article 96 of the Cotonou Agreement, COM(2001)623 final, Brussels

Commission (2001b), Opening of Article 96 consultations, inter-service consultation, not publicly available, Brussels

Commission (2001c), Inter-service consultation on the opening of article 96 consultations with Zimbabwe, inter-service consultation not publicly available, Brussels

Commission (2001d), European Governance - A White Paper, COM(2001)428 final, Brussels

Commission (2002a), Communication from the Commission to the Council and the European ParliamentTrade and Development, Assisting Developing Countries to Benefit from Trade, COM(2002)513 final, Brussels

Commission (2002b), Proposal for a Council regulation concerning certain restrictive measures in respect of certain members of the Government of Zimbabwe, COM(2002)88 final, Brussels

Commission (2002c), Proposal for a Council decision concluding consultations with Zimbabwe under article 96 of the Cotonou Agreement, COM(2002)73 final/2 (declassified part), Brussels

Commission (2004a), Communication to the Members of the Commission - Functioning of the Commission and internal coordination, SEC(2004)1617/4, Brussels

Commission (2004b), Communication de la Commission au Conseil, au Parlement Européen et au Comité Economique et Social Européen - Pays en développement, commerce international et développement soutenable: Le rôle du Système de Préférences Généralisées (SPG) de la Communauté pour la décennie 2006/2015, COM(2004)461 final, Brussels

Commission (2005a), Decision amending its rules of procedure, 2005/960/EC, Euratom

Commission (2005b), Commission White Paper on market access for developing countries: opening the door to development, Brussels

Commission (2005c), Strategic Objectives 2005-2009, COM(2005)12 final, Brussels

Commission (2005d), Communication from the Commission to the Council, the European Parliament and the European Economic and Social Committee: Policy Coherence for Development, Accelerating progress towards attaining the Millennium Development Goals, COM(2005)134 final, Brussels

Commission (2006a), Proposal for a Council decision extending the duration of decision 2002/148/EC concluding consultations with Zimbabwe under Article 96 of the ACP-EC Partnership Agreement, COM(2006)24 final, Brussels

Commission (2006b), "Europe in the World - Some Practical Proposals for Greater Coherence, Effectiveness and Visibility", Communication from the Commission to the European Council of June 2006, COM(2006)278 final, Brussels

Commission (2007a), "Rapport de l’UE sur la cohérence des politiques pour le développement", Working document of the Commission, SEC(2007)1202, Brussels

Commission (2007b), Proposal for a Council decision extending the duration of decision 2002/148/EC concluding consultations with Zimbabwe under Article 96 of the ACP-EC Partnership Agreement, COM(2007)21 final, Brussels 
Commission (2007c), Projet de décision de la Commission concernant les dotations indicatives pour les Programmes indicatifs nationaux au titres du cadre financier pluriannual pour la période 2008-2013 de l'accord de partenariat ACP-CE, C(2007)5233, Brussels

Commission (2008), Annual Policy Strategy for 2009, COM(2008)72 final, Brussels

Commission (2009a), Communication from the Commission to the European Parliament, the Council, the European Economic and Social Committee and the Committee of the Regions - Policy coherence for development: Establishing the policy framework for a whole-of-the-Union approach, COM(2009)458 final, Brussels

Commission (2009b), Impact Assessment Guidelines, SEC(2009)92, Brussels

Commission (2009c), Communication from the Commission to the Council, the European Parliament the European Economic and Social Committee and the Committee of the Regions: Policy coherence for development - Establishing the policy framework for a whole-of-the-Union approach, COM(2009)458 final, Brussels

Commission (2010a), Guide to Inter-Service Consultation, internal document not publicly available

Commission (2010b), Communication from the Commission to the European Parliament, the Council, the European Economic and Social Committee and the Committee of the Regions: Trade, Growth and World Affairs - Trade Policy as a core component of the EU's 2020 strategy, COM(2010)612 final, Brussels

Commission (2010c), Communication from the Commission to the European Parliament, the Council, the European Economic and Social Committee and the Committee of the Regions - Commission Work Programme 2011, COM(2010)623 final, Brussels

Commission (2010d), Commission staff working document - Policy Coherence for Development Work Programme 2010-2013 accompanying the Communication from the Commission to the European Parliament, the Council, the European Economic and Social Committee, and the Committee of the Regions - A twelve-point EU action plan in support of the Millennium Development Goals, SEC(2010)421 final, Brussels

Commission (2010e), Public consultation - listing of answers received [on a new trade and development communication], Brussels

Commission (2010f), Summaries of contributions to the Public Consultation on: 'The revision and updating of the European Union's scheme of Generalised System of Preferences', Brussels, available at http://trade.ec.europa.eu/doclib/docs/2010/september/tradoc_146464.pdf (accessed 15 May 2012)

Commission (2010g), Public consultation on the EU Generalised System of Preferences (GSP), available at http://trade.ec.europa.eu/doclib/docs/2010/july/tradoc_146362.pdf (accessed 15 May 2012)

Commission (2010h), Public consultation exercise on the revision and updating of the European Union's scheme of Generalised System of Preferences (the GSP scheme), available at http://trade.ec.europa.eu/doclib/docs/2010/march/tradoc_145972.pdf (accessed 15 May 2012)

Commission (2010i), Commission Decision amending its rules of procedure, 2010/138/EU, Brussels

Commission (2010j), Annex: Rules giving effect to the rules of procedure, C(2010)1200 final, Brussels

Commission (2010k), Proposal for a Council decision on adapting and extending the period of application of the measures in decision 2002/148/EC concluding consultations with Zimbabwe under Article 96 of the ACP-EC Partnership Agreement, COM(2010)19 final, 2010/0012 (NLE), Brussels

Commission (2010l), EU trade policy towards developing countries: challenges and opportunities for the next years [conference], Brussels

Commission (2010m), Communication from the Commission to the European Parliament, the Council, the European Economic and Social Committee and the Committee of the Regions - Commission Work Programme 2010: Time to act, COM(2010)135 final, Brussels

Commission (2011a), Actions adopted by the Commission: 01/01/2011 - 31/12/2011, available at http://ec.europa.eu/atwork/key-documents/index_en.htm\#adopted2011 (accessed 7.12.2012)

Commission (2011b), Commission Staff Working Paper - EU 2011 Report on Policy Coherence for Development, SEC(2011)1627 final, Brussels

Commission (2011c), Summary of contributions to the public consultation on a new trade and development communication, Brussels 
Commission (2011d), Communication from the Commission to the European Parliament, the Council, the European Economic and Social Committee and the Committee of the Regions - Commission Work Programme 2012, Delivering European renewal, COM(2011)777 final, Brussels, available at http://ec.europa.eu/atwork/key-documents/index_en.htm (accessed 7.12.2012)

Commission (2011e), Proposal for a Council decision concerning the conclusion of the agreement amending for the second time the Partnership Agreement between the members of the Africa, Caribbean and Pacific Group of States, of the one part, and the European Community and its Member States, of the other part, signed in Cotonou on 23 June 2000, as first amended in Luxembourg on 25 June 2005, $\operatorname{COM(2011)469~final,~Brussels~(details~on~the~procedure~are~available~at~}$ http://ec.europa.eu/prelex/detail_dossier_real.cfm?CL=en\&DosId=200724 and http://www.europarl.europa.eu/oeil/popups/ficheprocedure.do?type=PROC\&year=2011\&number $=0207-$ accessed 21 May 2012)

Commission (2011f), Proposal for a Regulation of the European Parliament and of the Council applying a scheme of generalised tariff preferences, COM(2011)241 Final, Brussels and Prelex file, available at http://ec.europa.eu/prelex/detail_dossier_real.cfm?CL=en\&DosId=200411 (accessed 5 July 2012)

Commission (2011g), Commission staff working paper - Executive summary of the impact assessment accompanying the document 'Proposal for a Regulation of the European Parliament and of the Council on applying a scheme of generalised tariff preferences', SEC(2011)537 final, Brussels

Commission (2011h), Commission staff working paper - Impact assessment Vol.I and Vol.II accompanying the document 'Proposal for a Regulation of the European Parliament and of the Council on applying a scheme of generalised tariff preferences', SEC(2011)536 final, Brussels

Commission (2011i), Revision of the GSP, inter-service consultation not publicly available, Brussels Commission (2011j), Proposal for a Council decision on adapting and extending the period of application of the measures in decision 2002/148/EC concluding consultations with Zimbabwe under Article 96 of the ACP-EC Partnership Agreement, COM(2011)30 final, 2011/0013 (NLE), Brussels

Commission (2011k), Impact Assessment (last update 24 January 2011), available at http://ec.europa.eu/governance/impact/index_en.htm (accessed 6 February 2012)

Commission (20111), Focusing on needs: the EU reshapes its import scheme for developing countries, IP/11/xxx, Brussels, available at http://trade.ec.europa.eu/doclib/docs/2011/may/tradoc_147894.pdf (accessed 14 May 2012)

Commission (2011m), More benefits from preferential trade tariffs for countries most in need: Reform of the EU Generalised System of Preferences, MEMO/11/284, Brussels, available at http://trade.ec.europa.eu/doclib/docs/2011/may/tradoc_147892.pdf (accessed 14 May 2012)

Commission (2012a), Impact Assessment Board members (last update 19 April 2012), available at http://ec.europa.eu/governance/impact/iab/members_en.htm (accessed 13 February 2013)

Commission (2012b), EU's first Economic Partnership Agreement with an African region goes live, IP/12/475, Brussels

Commission (2012c), Commission decision concerning a fifth allocation of special support to Zimbabwe from the tenth European Development Fund for an ad hoc short term response, inter-service consultation not publicly available, Brussels

Commission (2012d), Proposal for a Council decision on adapting and extending the period of application of the measures in decision 2002/148/EC concluding consultations with Zimbabwe under Article 96 of the ACP-EC Partnership Agreement, COM(2012)26 final, 2012/0012 (NLE), Brussels

Commission (2012e), Commission staff working document - Trade as a driver of development, accompanying the document 'Communication from the Commission to the European Parliament, the Council and the European Economic and Social Committee - Trade, growth and development, Tailoring trade and investment policy for those countries most in need, Brussels

Commission (2012e), Communication from the Commission to the European Parliament, the Council and the European Economic and Social Committee - Trade, growth and development, Tailoring trade and investment policy for those countries most in need, COM(2012)22 final, Brussels

Commission (2013), Statistical Bulleting - Off \& TA, available at http://ec.europa.eu/civil_service/about/figures/ (accessed 5 September 2013) 
Commission, DG Development and Cooperation - EuropeAid (n.d. a), Management Plan 2012, available at http://ec.europa.eu/atwork/synthesis/amp/index_en.htm (accessed 7 December 2012)

Commission, DG Development and Cooperation - EuropeAid (n.d. b), How we evaluate, http://ec.europa.eu/europeaid/how/evaluation/introduction/introduction_en.htm (accessed 7 February 2011)

Commission, DG Development and Cooperation - EuropeAid (n.d. c), Policy Coherence for Development, http://ec.europa.eu/europeaid/what/development-policies/policy-coherence/index_en.htm (accessed 2 February 2012)

Commission, DG Development (2006), Document de travail - Critères d'allocation pour l'aide européenne aux pays ACP dans le cadre de la coopération géographique 10e FED couvrant la période 2008-2013, DEV D(05)8935, Brussels

Commission, DG Development and Cooperation - EuropeAid (2010), Economic Partnership Agreements (last update 31 December 2010), available at http://ec.europa.eu/europeaid/what/developmentpolicies/intervention-areas/epas/index_en.htm (accessed 16 December 2011)

Commission, DG Development and Cooperation - EuropeAid (2011), The Cotonou Agreement (last update 9 September 2011), available at:http://ec.europa.eu/europeaid/where/acp/overview/cotonou-agreement/index_en.htm (accessed 16 December 2011)

Commission, DG Development and Cooperation - EuropeAid (2012a), EU and the MDGs (last update 9 October 2012), available at http://ec.europa.eu/europeaid/what/millenium-developmentgoals/index_en.htm (accessed 13 February 2013)

Commission, DG Development and Cooperation - EuropeAid (2012b), The European Consensus on Development (last update 17 September 2012), available at http://ec.europa.eu/europeaid/what/development-policies/european-consensus/index_en.htmlast (accessed 13 February 2013)

Commission, DG Development and Cooperation - EuropeAid (2012c), An EU Action Plan to achieve the MDGs (last update 24 July 2012), available at http://ec.europa.eu/europeaid/what/milleniumdevelopment-goals/action_plan_en.htm (accessed 13 February 2013)

Commission, DG Development and Cooperation - EuropeAid (2012d), Intervention areas (last update 21 March 2012), available at http://ec.europa.eu/europeaid/what/development-policies/interventionareas/index_en.htm (accessed 13 February 2013)

Commission, DG Development and Cooperation - EuropeAid (2012e), Trade and regional integration (last update 17 February 2012), available at http://ec.europa.eu/europeaid/what/developmentpolicies/intervention-areas/trade/index_en.htm (accessed 13 February 2013)

Commission, DG Development and Cooperation - EuropeAid (2012f), Zimbabwe - Information note on EU development cooperation in Zimbabwe in the context of appropriate measures, internal document not publicly available, Brussels

Commission, DG Development and Cooperation - EuropeAid (2012g), ACP sugar protocol programme (last update 17 February 2012), available at http://ec.europa.eu/europeaid/how/finance/sugar_protocol_en.htm (accessed 13 April 2012)

Commission, DG Development and Cooperation - EuropeAid (2013), Annual report on the European Union's development and external assistance policies and their implementation in 2012, Luxembourg, POUE

Commission, ECHO (n.d.), Presentation, online resource (last update 13 September 2012) available at http://ec.europa.eu/echo/about/presentation_fr.htm (accessed 10 July 2013)

Commission, ECHO (2011), Humanitarian Implementation Plan - Zimbabwe / Socio-economic breakdown for 2011 (last update 25 February 2011), available at http://ec.europa.eu/echo/files/funding/decisions/2011/HIPs/zimbabwe.pdf (accessed 4 June 2011)

Commission, DG Fiscalité et Union Douanière (2007), Système des préférences généralisées (last update 3 January 2007), available at http://ec.europa.eu/taxation_customs/customs/customs_duties/rules_origin/introduction/article_781_fr.htm (accessed 12 March 2012)

Commission, DG Fiscalité et Union Douanière (2012a), Liste de pays non-membres de l'UE et régimes préférentiels applicables (last update 12 March 2012), available at http://ec.europa.eu/taxation_customs/customs/customs_duties/rules_origin/introduction/article_403_fr.htm (accessed 12 March 2012) 
Commission, DG Fiscalité et Union Douanière (2012b), Les pays d'Afrique, des Caraïbes et du Pacifique (last update 12 March 2012), available at http://ec.europa.eu/taxation_customs/customs/customs_duties/rules_origin/introduction/article_785_fr.htm (accessed 12 March 2012)

Commission, Impact Assessment Board (2011), Opinion - DG Trade - Impact Assessment on: a Regulation applying a scheme of generalised preferences for the period from 1 January 2014, Brussels

Commission, Inspectorate General (1999), Designing Tomorrow's Commission, A Review of the Commission's Organisation and Operation, Brussels

Commission, Legal Service (2008), Summaries of important judgments: C-91/05 Commission v Council, http://ec.europa.eu/dgs/legal_service/arrets/05c091_en.pdf (accessed 1 December 2010)

Commission, Secretariat-General (n.d.), Organization chart (online resource), available at http://ec.europa.eu/dgs/secretariat_general/sg_org_chart_en.pdf (accessed 10 July 2013)

Commission, Secretariat General (2010), Service Level Agreement between Commission services with staff in EU Delegations and the European External Action Service, 2011/0114, internal document not publicly available, Brussels

Commission, Secretariat-General (2011), Vademecum on Working Relations with the European External Action Service (EEAS), SEC(2011)1636, Brussels

Commission, Secretariat-General (2012), Working arrangements between Commission services and the European External Action Service (EEAS) in relation to external relations issues, SEC(2012)48, Brussels

Commission, Service for Foreign Policy instruments (2013), Homepage (last update 11 March 2013), http://ec.europa.eu/dgs/fpi/index_en.htm (accessed 19 March 2013)

Commission, DG Trade (n.d. a), Management Plan 2012, Management Plan 2011, available at http://ec.europa.eu/atwork/synthesis/amp/index_en.htm (accessed 7 December 2012)

Commission, DG Trade (n.d. b), Annual Activity Report 2011, available at http://ec.europa.eu/atwork/synthesis/aar/index_en.htm (accessed 7.12.2012)

Commission, DG Trade (n.d. c), Fact sheet: EC's GSP 2009-2011, available at http://trade.ec.europa.eu/doclib/docs/2008/july/tradoc_139988.pdf (accessed 11 April 2012)

Commission, DG Trade (n.d. d), 2008 statistics by countries, 2010, available at http://trade.ec.europa.eu/doclib/docs/2010/march/tradoc_145945.pdf (accessed 15 May 2012)

Commission, DG Trade (n.d. e), The EU is the most open market in the world for developing country exports, available at http://trade.ec.europa.eu/doclib/docs/2012/january/tradoc_148990.pdf (accessed 14 May 2012)

Commission, DG Trade (n.d. f), 10 benefits of trade for developing countries, available at http://trade.ec.europa.eu/doclib/docs/2012/january/tradoc_148991.pdf (accessed 14 May 2012)

Commission, DG Trade (n.d. g), Organization chart of the Coordination Unit, internal document not publicly available

Commission, DG Trade (2010), GSP: 2008 Statistics by countries, available at:http://trade.ec.europa.eu/doclib/docs/2010/march/tradoc_145945.pdf (accessed 16 December 2011)

Commission, DG Trade (2011a), The Generalised System of Preferences - Frequently Asked Questions (last update 1 October 2011), internal document non publicly available

Commission, DG Trade (2011b), Generalised System of Preferences (last update 26 October 2011), available at http://ec.europa.eu/trade/wider-agenda/development/generalised-system-of-preferences/ (accessed 14 May 2012)

Commission, DG Trade (2011c), Working arrangements between DG Trade and the Cabinet of Commissioner Karel De Gucht, internal document not publicly available

Commission, DG Trade (2011d), "Eastern and Southern Africa" and "Interim agreement establishing a framework for an Economic Partnership Agreement between the Eastern and Southern Africa States, on the one part, and the European Community and its Member States, on the other part", Economic Partnerships - Negotiations and agreements (last update 9 September 2011), http://ec.europa.eu/trade/wider-agenda/development/economic-partnerships/negotiations-andagreements/\#esa (accessed 8 March 2012) 
Commission, DG Trade (2012a), The EU's new Generalised Scheme of Preferences, available at http://trade.ec.europa.eu/doclib/docs/2012/december/tradoc_150164.pdf (accessed 14 May 2012)

Commission, DG Trade (2012b), Highlights of the EU's new Generalised Scheme of Preferences, available at http://trade.ec.europa.eu/doclib/docs/2012/october/tradoc_150027.pdf (accessed 27 November 2012)

Commission, DG Trade (2012c), The EU'S new Generalised Scheme of Preferences (GSP), available at http://trade.ec.europa.eu/doclib/docs/2012/october/tradoc_150028.pdf (accessed 27 November 2012)

Commission, DG Trade (2012d), Zimbabwe - EU bilateral trade and trade with the World, available at http://trade.ec.europa.eu/doclib/docs/2011/january/tradoc_147429.pdf (accessed 12 April 2012)

Commission, DG Trade (2012e), Factsheet on the interim Economic Partnership Agreements, Eastern and Southern Africa, available at http://trade.ec.europa.eu/doclib/docs/2012/march/tradoc_149213.pdf (accessed 13 April 2012, 8 March 2012)

Commission, DG Trade (2012f), European Union in the World, available at http://trade.ec.europa.eu/doclib/html/122532.htm (accessed 14 May 2012)

Commission, DG Trade (2013), DG Trade Statistical Pocket Guide, Luxembourg, Publications office of the EU, available at http://trade.ec.europa.eu/doclib/docs/2013/may/tradoc_151348.pdf (accessed 26 October 2013)

Commission/High Representative of the Union for Foreign Affairs and Security Policy (2011), Joint Communication to the European Council, the European Parliament, the Council, the European Economic and Social Committee and the Committee of the Regions - A Partnership for Democracy and Shared Prosperity with the Southern Mediterranean, COM(2011)200 Final, Brussels, 8 March 2011

Commission/High Representative of the Union for Foreign Affairs and Security Policy (2013), Joint Communication to the European Parliament and the Council - The EU's comprehensive approach to external conflict and crises, JOIN(2013)30 final, Brussels

Committee of Independent Experts (1999), Second report on Reform of the Commission: Analysis of current practice and proposals for tackling mismanagement, irregularities and fraud, Brussels, available at http://www.europarl.europa.eu/experts/default_en.htm (accessed 1 April 2011)

Conference of the Representatives of the Governments of the Member States (1996), The European Union Today and Tomorrow - A general outline for a draft revision of the Treaties (Dublin), Brussels

Conzelmann, T. (2012), "Informal Governance in International Relations" in Christiansen, T. and C. Neuhold (eds), The International Handbook of Informal Governance, Cheltenham: Edward Elgar, pp.219-235

Coombes, D. (1970), Politics and Bureaucracy in the European Community, London: George Allen and Unwin Ltd

Council (2000a), Accord interne entre les représentants des gouvernements des Etats membres, réunis au sein du Conseil, relative aux mesures à prendre et aux procédures à suivre pour la mise en ouvre de l'accord de partenariat ACP-CE, 2000/771/EC, OJ L 317, pp.376-381

Council (2000b), Partnership agreement between the members of the African, Caribbean and Pacific Group of States of the one part, and the European Community and its member states, of the other part, signed in Cotonou on 23 June 2000, OJ L 317, pp.3-353

Council (2000c), Zimbabwe - Draft conclusions for the GAC, 10136/00, PESC 338, COAFR 43, Brussels

Council (2001a), "I" Item Note: Opening of consultations with Zimbabwe pursuant to article 96 of the Cotonou Agreement, 15435/01, ACP 188, Brussels

Council (2001b), "I/A" Item Note: Zimbabwe - opening of consultations under Article 96 of the Cotonou Agreement, 13519/01, Brussels

Council (2001c), Cover Note - Communication from the Commission on the opening of consultations with Zimbabwe pursuant to Article 96 of the Cotonou Agreement, 13401/01, ACP 131, Brussels

Council (2001d), Draft Council conclusions on Zimbabwe, 10160/01, COAFR 35, PESC 253, Brussels

Council (2002a), Note - Restructuring of the EDF portfolio, 10569/02, ACP 102, COAFR 58, Brussels

Council (2002b), Council decision concluding consultations with Zimbabwe under Article 96 of the ACP-EC Partnership Agreement, 2002/148/EC, Brussels 
Council (2002c), Council Common Position concerning restrictive measures against Zimbabwe, 2002/145/CFSP, Brussels

Council (2002d), Council decision concluding consultations with Zimbabwe under Article 96 of the ACP-EC Partnership Agreement, 6285/02, Brussels

Council (2002e), "I" item note: Zimbabwe - Letter to Mr Mudenge in reply to his letter of 1 February 2002, 6230/02, ACP 27, COAFR 14, PESC 57, Brussels

Council (2002f), Report - Zimbabwe: Consultations under article 96 of the Cotonou Agreement, 5533/02, ACP 12, Brussels

Council (2002g), Note: Opening of consultations with Zimbabwe pursuant to article 96 of the Cotonou Agreement, 5293/02, ACP 7, COAFR 4, PESC 10, Brussels

Council (2002h), Zimbabwe - Consultations pursuant to article 96 of the Cotonou Agreement, 5286/02, ACP 6, COAFR 3, PESC 9, Brussels

Council (2006), Council decision extending the period of application of the measures in Decision 2002/148/EC concluding consultations with Zimbabwe under Article 96 of the ACP-EC Partnership Agreement, 2006/114/EC, Brussels

Council (2007a), Interim agreement establishing a framework for an Economic Partnership Agreement between the Eastern and Southern Africa States, on the one part, and the European Community and its Member States, on the other part, available at http://ec.europa.eu/trade/wider-agenda/development/economic-partnerships/negotiations-and-agreements/\#esa (accessed 8 March 2012)

Council (2007b), Council decision extending the period of application of the measures in Decision 2002/148/EC concluding consultations with Zimbabwe under Article 96 of the ACP-EC Partnership Agreement, 2007/127/EC, Brussels

Council (2008), Council Regulation (EC) No 732/2008 applying a scheme of generalised tariff preferences for the period from 1 January 2009 to 31 December 2011 and amending Regulations (EC) No 552/97, (EC) No 1933/2006 and Commission Regulations (EC) No 1100/2006 and (EC) No 964/2007, OJEU L 211, pp.1-39

Council (2009a), Presidency report to the European Council on the EEAS, 14930/09

Council (2009b), South Africa-European Union Strategic Partnership, Joint Communiqué from the Ministerial Troika Meeting in Kleinmond, South Africa, 5462/09 (Presse 12), Brussels

Council (2010a), Procedures under article 96 of the Cotonou Agreement - Overview, situation in November 2010 (online resource), http://consilium.europa.eu/policies/eu-development-policy-(ec-wbesite)/main-themes/cotonou-partnership-agreement/consultations-under-articles-96-and-97-of-cotonouagreement/policy-archive?lang=en (accessed 8 March 2012)

Council (2010b), Second Revision of the Cotonou Agreement - Agreed Consolidated Text, 11 March 2010, Brussels, available at http://ec.europa.eu/europeaid/where/acp/overview/documents/devcocotonou-consol-europe-aid-2012_en.pdf (accessed 25 September 2012)

Council (2010c), Council decision establishing the organisation and functioning of the European External Action Service, 2010/427/EU, OJEU L201/30

Council (2010d), Council decision on adapting and extending the period of application of the measures in decision 2002/148/EC concluding consultations with Zimbabwe under Article 96 of the ACP-EC Partnership Agreement, 2010/97/CFSP, Brussels

Council (2011), Council decision on adapting and extending the period of application of the measures in decision 2002/148/EC concluding consultations with Zimbabwe under Article 96 of the ACP-EC Partnership Agreement, 2011/106/EU, Brussels

Council (2012a), Council conclusions on Zimbabwe - 3183' Foreign Affairs Council Meeting, Brussels

Council (2012b), Council decision on adapting and extending the period of application of the measures in decision 2002/148/EC concluding consultations with Zimbabwe under Article 96 of the ACP-EC Partnership Agreement, 2012/96/EU, Brussels

Council (2012c), Council decision amending Decision 2011/101/CFSP concerning restrictive measures against Zimbabwe, 2012/97/CFSP, Brussels 
Council (2012d), Proposal from the European Commission for a Council decision on adapting and extending the period of application of the appropriate measures first established by Decision 2002/148/EC concluding consultations with Zimbabwe under Article 96 of the ACP-EC Partnership Agreement, 2012/96/EU, 5820/12, ACP 13, COAFR 20, PESC 94, Brussels

Court of Justice of the European Communities (2009), The Treaty of Lisbon and the Court of Justice of the European Union, Press Release Nr 104/09, Luxembourg, available at http://curia.europa.eu/jcms/upload/docs/application/pdf/2009-12/cp090104en.pdf (accessed 3 June 2011)

Cram, L. (1994), "The European Commission as a multi-organization: Social policy and IT policy in the EU”, Journal of European Public Policy, 1(2): 195-217

Cremona, M. (2003), "The Draft Constitutional Treaty: External Relations and External Action", Common Market Law Review, 40(6): 1347-1366

Cremona, M. (2004), "The Union As A Global Actor: Roles, Models and Identity", Common Market Law Review, 41(2): 553-573

Cremona, M. (2008), “Coherence through Law: What difference will the Treaty of Lisbon make?", in Portela, C. and K. Raube (eds.), "Revisiting Coherence in EU Foreign Policy", Hamburg Review of Social Sciences, 3(1):11-36

Cremona, M. (2011), “Coherence in European Union foreign relations law" in Koutrakos, P. (ed.), European Foreign Policy, Legal and Political Perspectives, Cheltenham: Edward Elgar Publishing, pp55-92

Daase, C. (2009), "Die Informalisierung internationaler Politik: Beobachtungen zum Stand der internationalen Organisation" in Dingwerth, K., Kerwer, D. and A. Nölke (eds.), Die Organisierte Welt, Baden-Baden: Nomos, pp. 290-308

DAC (2007), "Review of the Development Cooperation Policies and Programmes of the European Community", DAC Peer Review, Paris: OECD

Darracq, V. (2010), “Quelle politique pour l'UE au Zimbabwe aujourd'hui ?”, ISS Occasional Paper, 87

Dashwood, A. (2008), "Article 47 TEU and the relationship between first and second pillar competences" in Dashwood, A. and M. Maresceau (eds.), Law and Practice of EU External Relations: Salient Features of a Changing Landscape, Cambridge: Cambridge University Press, pp.70-103

Davignon, P. (1995), "What Future for the European Commission?", Philipp Morris Institute Discussion Papers, 6

De Baere, G. (2008), Constitutional Principles of EU External Relations, Oxford: Oxford University Press

De Jong, S. and S. Schunz (2012), “Coherence in European Union External Policy before and after the Lisbon Treaty: The Cases of Energy Security and Climate Change", European Foreign Affairs Review, 17(2):165-188

Delegation of the EU to Zimbabwe (n.d. a), Food security, online resource, http://eeas.europa.eu/delegations/zimbabwe/eu_zimbabwe/tech_financial_cooperation/food_security/index_en.htm (accessed 7 February 2012)

Delegation of the EU to Zimbabwe (n.d. b), Political and Economic relations, online resource, http://eeas.europa.eu/delegations/zimbabwe/eu_zimbabwe/political_relations/index_en.htm (accessed 7 February 2012)

Delegation of the EU to Zimbabwe (n.d. c), Trade (online resource), ttp://eeas.europa.eu/delegations/zimbabwe/eu_zimbabwe/trade_relation/index_en.htm (accessed 7 February 2012)

Delegation of the EU to Zimbabwe (n.d. d), Zimbabwe and the EU, online resource, http://eeas.europa.eu/delegations/zimbabwe/eu_zimbabwe/index_en.htm (accessed 7 February 2012) and http://www.delzwe.ec.europa.eu/en/ (accessed 20 May and 4 June 2011)

Delegation of the EU to Zimbabwe (n.d. e), Overview of funding EC in Zimbabwe, internal document not publicly available

Delegation of the EU to Zimbabwe (2009), European Union assistance in Zimbabwe amounts to 120 million Euros in 2009, PRESS RELEASE, Harare

Delegation of the EU to Zimbabwe (2010), European Commission Short Term Strategy for Zimbabwe 2010, DD/ER/wh(2010)01322, Harare

Devuyst, Y. (2012), “The European Council and the CFSP after the Lisbon Treaty”, European Foreign Affairs Review, 17(3): 327-349 
Dimitrakopoulos, D. G. and A. G. Passas (2003), "International Organizations and Domestic Administrative Reform" in Peters, B. Guy and Jon Pierre (eds.), Handbook of Public Administration, London: Sage, pp. 440-500

Dos Santos, B. N., Farias, R. and R. Cunha (2005), "Generalised system of preferences in General Agreement on Tariffs and Trade/World Trade Organisation: history and current issues", Journal of World Trade, 39(4): 637-670

Dowden, R. (2006), “Engaging with Mugabe”, The Round Table, 95(384): 283-286

Duke, S. (1999), "Consistency as an Issue in EU External Activities", Working Paper, 99/W/06, Maastricht: EIPA

Duke, S. (2002), “The Common Foreign and Security Policy: Significant but Modest Changes” in Laursen, F. (ed.), The Amsterdam Treaty: National Preference Formation, Interstate Bargaining and Outcome, Odense: Odense University Press, pp. 473-508

Duke, S. (2006), “Areas of Grey: Tensions in EU External Relations Competences", Eipascope, 1

Duke, S. (2008), “The European Commission: Inside and Out - 'Administering EU Foreign Policy after Lisbon: The Case of the EEAS'”, Working Paper, 2008/W/01, Maastricht: EIPA

Duke, S. (2009), "Providing for European-Level Diplomacy after Lisbon: The Case of the European External Action Service", The Hague Journal of Diplomacy, 4(2):211-233

Duke, S. (2011a), "Consistency, coherence and European Union external action: the path to Lisbon and beyond" in Koutrakos, P. (ed.), European Foreign Policy, Legal and Political Perspectives, Cheltenham: Edward Elgar Publishing, pp.15-54

Duke, S. (2011b), "Under the Authority of the High Representative" in Müller-Brandeck-Bocquet, G. and C. Rüger (eds), The High Representative for the EU Foreign and Security Policy - Review and Prospects, Baden-Baden: Nomos, pp.35-65

Duke, S. (2012), "The European External Action Service: antidote against incoherence?", European Foreign Affairs Review, 17(1): 45-68

Duke, S. and S. Vanhoonacker (2006), "Administrative governance and CFSP" in Hofmann, Herwig C. H. and A. H. Türk (eds.), EU Administrative Governance, Cheltenham: Edward Elgar, pp.361-390

Duke, S. and S. Vanhoonacker (2006), "Administrative Governance in the CFSP: Development and Practice", European Foreign Affairs Review, 11(2): 163-182

Dür, A. (2008), "Measuring interest group influence in the EU: A note on methodology", European Union Politics, 9(4): 559-576

ECDPM, Informal Senior Officials Meeting (2009), The implications of the ratification of the Lisbon Treaty for EU development cooperation, Maastricht

ECDPM (2010), "The post-Lisbon landscape: development at a crossroads", ECDPM Briefing Note, Maastricht, 18

ECDPM/Particip GmbH/ICEI (2007), "Appendix X: Case study report: The role of the European Commission inter-service consultation mechanism in the promotion of PCD within the European Commission", Evaluation study on the EU institutions and member states' mechanisms for promoting policy coherence for development, Maastricht

Eckes, C. (2013), “EU Foreign Policy after Lisbon: Ambiguity as a Way to Consistency?”, Maastricht Centre for European Law research seminar

EEAS (n.d.), Organisation chart of Global Issues Unit, internal document not publicly available

EEAS (2011), Report by the High Representative to the European Parliament, the Council and the Commission, Brussels

EEAS (2012), Zimbabwe - Information note on appropriate measures, internal document not publicly available, Brussels

EEAS (2013), EEAS Review, Brussels: European Union

EEAS/Commission (2011), 2012 Review of Council decision 2002/148/EC concluding consultation with Zimbabwe (Article 96 of the Cotonou agreement), inter-service consultation, not publicly available, Brussels

EEAS/Commission (2012a), Article 96 procedures - information note, internal document not publicly available, Brussels 
EEAS/Commission (2012b), Commission decision concerning a fifth allocation of special support to Zimbabwe from the tenth European Development Fund for an ad hoc short term response, interservice consultation not publicly available, Brussels

Egeberg, M. (1999), “The Impact of Bureaucratic Structure on Policy-Making”, Public Administration, $77(1): 155-170$

Egeberg, M. (2003), "How bureaucratic structure matters: An organizational perspective" in Peters, B. G. and J. Pierre (eds.), Handbook of Public Administration, London: Sage, pp. 116-125

Egeberg, M. (2004), “Organizing institutional autonomy in a political context: Enduring tensions in the European Commission's development", Arena working paper series, WP 02/04

Egeberg, M. (2006), "Executive politics as usual: role behaviour and conflict dimensions in the College of European Commissioners", Journal of European Public Policy, 13(1): 1-15

Elgström, O. and J. Pilegaard (2008), "Imposed Coherence: Negotiating Economic Partnership Agreements", Journal of European Integration, 30(3): 363-380

Elsuwege, P. van (2010), "EU external action after the collapse of the pillar structure: in search of a new balance between delimitation and consistency", Common Market Law Review, 47(4): 987-1019

Eppink, D.-J. (2007), Life of a European Mandarin, Tielt: Lannoo Publishers

Erkelens, L. and S. Blockmans (2012), "Setting up the European External Action Service: An institutional act of balance", CLEER Working Papers, The Hague: TMC Asser Institute

Europe Group of Foreign Ministers (2012), Final report of the Future of Europe Group of the Foreign Ministers of Austria, Belgium, Denmark, France, Italy, Germany, Luxembourg, the Netherlands, Poland, Portugal and Spain, available at http://www.auswaertiges-amt.de/cae/servlet/contentblob/626322/publicationFile/171784/120918-Abschlussbericht-Zukunftsgruppe.pdf (accessed 19 September 2012)

European Convention (n.d.), Outcome of the European Convention, available at http://europa.eu/scadplus/european_convention/ (accessed 7 April 2011)

European Convention (2002a), Final Report of Working Group VII on External Action, CONV 459/02, Brussels

European Convention (2002b), Working Group on External Action, Agenda for the meeting on 8 October 2002, CONV 312/02, Brussels

European Convention (2002c), Mandate of Working Group VII on External Action, CONV 252/02, Brussels

European Convention (2002d), Groupes de travail: "deuxième vague”, CONV 206/02, Brussels

European Convention (2002e), Rapport de synthèse relatif à la session plénière, CONV 200/02, Brussels

European Convention (2002f), Note on the External Action of the EU, CONV 161/02, Brussels

European Convention (2003), Contribution by Mr Barnier and Mr Vitorino, members of the Convention: "Joint External Action Service", CONV 839/03, CONTRIB 375, Brussels

European Council (2001), Conclusions, EUCO SN 300/1/01

European Council (2007a), Conclusions, EUCO 16616/1/07

European Council (2007b), Conclusions, EUCO 11177/1/07 REV1

European Council (2008), A Secure Europe in a Better World: European Security Strategy, Brussels, 12 December 2003 and Report on the Implementation of the European Security Strategy - Providing Security in a Changing World, S407/08, Brussels

European Council (2010), Conclusions, EUCO 21/1/10 REV1

European Parliament (2001-2011), Written parliamentary questions to the Commission and to the Council, http://eur-lex.europa.eu/Result.do?idReq=5\&page=13 (accessed 30 May 2011)

European Parliament (1982), Resolution on the significance of economic sanctions, particularly trade embargoes and boycotts, and their consequences for the EEC's relations with third countries, OJEC C 292, Brussels, pp.13-15

European Parliament/Council/Commission (2005), Joint statement by the Council and the representatives of the governments of the Member States meeting within the Council, the European Parliament and the Commission on European Union Development Policy: "The European Consensus", 0J C46, pp.1-19 
European Parliament, Committee on Development (2012), Opinion of the Committee on Development for the Committee on International Trade on the proposal for a regulation of the European Parliament and of the Council applying a scheme of generalised tariff preferences, COM(2011)0241 - C7-0116/2011 2011/0117(COD), Brussels

European Parliament, Committee on International Trade (2011a), Minutes of the meeting of 20 December 2011, INTA_PV(2011)1220_1, Brussels

European Parliament, Committee on International Trade (2011b), Draft report on the Proposal for a Regulation of the European Parliament and of the Council applying a scheme of generalised tariff preferences, COM(2011)0241 - C7-0116/2011 - 2011/0117(COD), Brussels

European Parliament, Committee on International Trade (2011c), Working document on Proposal for a Regulation of the European Parliament and of the Council applying a scheme of generalised tariff preferences, PE472.115v01-00, Brussels

European Parliament, Committee on International Trade (2012a), Minutes of the meeting of 29 February - 1 March 2012, INTA_PV(2012)0229_1, Brussels

European Parliament, Committee on International Trade (2012b), Minutes of the meeting of 25-26 January 2012, INTA_PV(2012)0125_1, Brussels

European Parliament, Committee on International Trade (2012c), Amendment to the draft Fjellner Report, COM(2011)0241 - C7-0116/2011 - 2011/0117(COD), Brussels

European Parliament, DG for external policies (2011d), Study: Reform of the Generalised System of Preferences, PE 469.728v01-00, Brussels

European Parliament, DG for external policies (2013), Organisation and Functioning of the European External Action Service: Achievements, Challenges and Opportunities, Brussels: European Union

European Parliament/Council of the EU (2011), Regulation (EU) No 512/2011 of the European Parliament and of the Council of 11 May 2011 amending Council Regulation (EC) No 732/2008 applying a scheme of generalised tariff preferences for the period from 1 January 2009 to 31 December 2011, OJEU L 145, pp.28-29

European Parliament/Council of the EU (2012), Regulation (EU) No 978/2012 of the European Parliament and of the Council of 25 October 2012 applying a scheme of generalised tariff preferences and repealing Council Regulation (EC) No 732/2008, OJEU L 303, pp.1-79

European Think Tanks Group - DIE, ECDPM, FRIDE and ODI (2010), "Development-proofing the European External Action Service", Policy Brief

Faber, G. and J. Orbie (eds.) (2007), European Union trade politics and development: 'everything but arms' unravelled, London: Routledge

Fielding, N. (2003), Interviewing, London: Sage

Forsythe, D. P. (2009), Encyclopedia of Human Rights, Oxford: Oxford University Press

Gaspers, J. (2008), "The quest for European foreign policy consistency and the Treaty of Lisbon", Humanitas Journal of European Studies, 2(1): 19-53

Gauttier, P. (2004), "Horizontal Coherence and the External Competences of the European Union", European Law Journal, 10(1): 23-41

Gebhard, C. (2011), "Coherence" in Hill, C. and M. Smith (eds.), International Relations and the European Union, Oxford: Oxford University Press, pp. 101-127

George, A. L. and A. Bennett (2005), Case Studies and Theory Development in the Social Sciences, Cambridge: MIT Press

Giumelli, F. (2013), “How EU sanctions work: A new narrative”, Chaillot Paper $N^{\circ} 129$, Paris: ISS

Grebe, J. (2010), "And they are still targeting: assessing the effectiveness of targeted sanctions against Zimbabwe", Africa Spectrum, 45(1): 3-29

Grevi, G. and F. Cameron (2005), "Towards an EU Foreign Service”, EPC Issue paper, 29

Gual, J. (1995), "The Coherence of EC Policies on Trade, Competition and Industry", CEPR Discussion Paper Series, 1105

Hage, J., Aiken, M. and C. Bagley Marrett (1971), "Organization Structure and Communications", American Sociological Review, 36(5): 860-871

Hall, P. A. and R. C. R. Taylor (1996), "Political Science and the Three New Institutionalisms", MPIFG Discussion Paper, 96(6) 
Hammond, T. H. (1986), "Agenda Control, Organizational Structure, and Bureaucratic Politics", American Journal of Political Science, 379-420

Hartlapp, M., Metz, J. and C. Rauh (2010), “The agenda set by the EU Commission: the result of balanced or biased aggregation of positions?", LEQS Paper, 21

Hartlapp, M., Metz, J. and C. Rauh (2012), "Linking Agenda Setting to Coordination Structures: Bureaucratic Politics inside the European Commission", Journal of European Integration, iFirst Article:1-17

Hazelzet, H. (2005), "Suspension of Development Cooperation: An Instrument to Promote Human Rights and Democracy?", Discussion Paper No. 64B, Maastricht: ECDPM

Heads of Government of the Community (1974), Paris Summit Communiqué, Bulletin of the EC, 12:7-12

Helwig, N., Ivan, P. and H. Kostanyan (2013), "The new EU foreign policy architecture - Reviewing the first two years of the EEAS", CEPS Studies

High Representative for Foreign Affairs and Security Policy and Vice-President of the European Commission (n.d.), My team, http://www.eeas.europa.eu/ashton/team/index_en.htm (accessed 3 April 2011)

Hill, C. (1993), "The Capability-Expectations Gap, or Conceptualizing Europe's International Role", Journal of Common Market Studies, 31(3):305-328

Hillion, C. (2008), "Tous pour un, un pour tous! Coherence in the External Relations of the European Union" in Cremona, M. (ed.), Developments in EU External Relations Law, Oxford: Oxford University Press, pp.10-34

Hillion, C. and R. A. Wessel (2009), “Competence Distribution in EU External Relations after ECOWAS: Clarification or Continued Fuzziness?", Common Market Law Review, 46(2): 551-586

Hyde-Price, A. (2006), “Normative' power Europe: a realist critique”, Journal of European Public Policy, 13(2): 217-234

Inama, S. (2011), "The reform of the EC GSP rules of origin: per aspera ad astra?", Journal of World Trade, 45(3): 577-603

International Crisis Group (2006), "Zimbabwe's Continuing Self-Destruction”, Africa Briefing, 38

Jordan, A. and A. Schout (2005), "Coordinated European Governance: Self-Organizing or Centrally Steered?", Public Administration, 83(1): 201-220

Jordan, A. and A. Schout (2006), The Coordination of the European Union, Exploring the Capacities of Networked Governance, Oxford: Oxford University Press

Jupille, K. and J.A. Caporaso (1998), "States, Agency and Rules: The European Union in Global Environmental Politics" in Rhodes, C. (ed.), The European Union in the World Community, Boulder: Lynne Rienner

Kassim, H. (2004a), "A historic accomplishment? The Prodi Commission and administrative reform" in Dimitrakopoulos, D. G. (ed.), The changing European Commission, Manchester and New York: Manchester University Press, pp.33-62

Kassim, H. (2004b), "The Secretariat General of the European Commission, 1958-2003: A singular institution" in Smith, A. (ed.), Politics and the European Commission: actors, interdependence, legitimacy, London: Routledge, pp.47-66

Kassim, H. (2004c), "The Kinnock Reforms in Perspective: Why Reforming the Commission is an Heroic, But Thankless Task", Public Policy and Administration, 19(3): 25-41

Kassim, H. (2006), "The Secretariat General of the European Commission" in Spence, D. (ed.), The European Commission, London: John Harper Publishing, pp.75-102

Kassim, H. and A. Menon (2004), "European Integration since the 1990s: Member States and the EU Commission", ARENA Working Papers, 6/04

Kassim, H., Menon, A., Peters, B. G. and V. Wright (eds.) (2000), The National Coordination of EU Policy The Domestic Level, Oxford: Oxford University Press

Kassim, H., Menon, A., Peters, B. G. and V. Wright (eds.) (2001), The National Coordination of EU Policy The European Level, Oxford: Oxford University Press

Kinnock, N. (2004), "Reforming the European Commission: Organisational Challenges and Advances", Public Policy and Administration, 19(3): 7-12 
Knill, C. and J. Tosun (2009), "Hierarchy, networks, or markets: how does the EU shape environmental policy adoptions within and beyond its borders", Journal of European Public Policy, 16(6): 873-894

Koehler, K. (2010), "European Foreign Policy after Lisbon: Strengthening the EU as an International Actor", Caucasian Review of International Affairs, 4(1): 57-72

Koenig-Archibugi, M. (2002), "The Democratic Deficit of EU Foreign and Security Policy", The International Spectator, 37(4): pp. 61-73

Krenzler, H.-G. and H. C. Schneider (1997), "The Question of Consistency", in Regelsberger, E., de Schoutheete de Tervarent, P. and W. Wessels (eds.), Foreign Policy of the European Union - From EPC to CFSP and Beyond, Boulder and Covent Garden: Lynne Rienner, pp. 133-152

Laakso, L., Kivimäki, T. and M. Seppänen (2007), "Evaluation of Coordination and Coherence in the Application of Article 96 of the Cotonou Partnership Agreement", Studies in European Development Cooperation Evaluation, 6, Amsterdam: Aksant

Lafargue, F. (2010), "Faillite économique et decomposition politique: le Zimbabwe à l'agonie", Questions Internationales, 41: 95-102

Laursen, F. (2009), "Introduction: The EU as a Foreign Policy Actor" in Laursen, F. (ed.), The EU as a Foreign and Security Policy Actor, Dordrecht : Republic of Letters, pp. 1-22

Laursen, F. (2012), "The Lisbon Treaty: Overview of Institutional Choices and Beginning Implementation" in Laursen, F. (ed.), The EU's Lisbon Treaty: Institutional Choices and Implementation, Farnham: Ashgate, pp. 3-20

Laursen, F., Vanhoonacker, S. and R. Wester (1992), "Overview of the Negotiations" in Laursen, F. and S. Vanhoonacker (eds.), The Intergovernmental Conference on Political Union - Institutional Reforms, New Policies and International Identity of the European Community, EIPA: Maastricht, pp. 3-24

Lauth, H.-J. (2012), "Informal governance and democratic theory" in Christiansen, T. and C. Neuhold (eds), The International Handbook of Informal Governance, Cheltenham: Edward Elgar, pp.40-84

Legislative Observatory European Parliament (n.d. a), Ordinary legislative procedure 2011/0117(COD) [on Commission proposal COM(2011)241 final], available at http://www.europarl.europa.eu/oeil/popups/ficheprocedure.do?lang=en\&reference=2011/0117(COD (accessed 5 July 2012)

Legislative Observatory European Parliament (n.d. b), Ordinary legislative procedure 2010/0140(COD) [on Regulation (EU) No 512/2011], available at http://www.europarl.europa.eu/oeil/popups/ficheprocedure.do?lang=en\&reference=2010/0140(COD) (accessed 5 July 2012)

Legislative Observatory European Parliament (n.d. c), Consultation procedure 2007/0289(CNS)[on EC Regulation 732/2008], available at http://www.europarl.europa.eu/oeil/popups/ficheprocedure.do? reference $=2007 / 0289$ (CNS)\&l=en (accessed 5 July 2012)

Lerch, M. and G. Schwellnus (2006), "Normative by nature? The role of coherence in justifying the EU's external human rights policy", Journal of European Public Policy, 13(2): 304-321

Lessing, D. (2003), "The Jewel of Africa", The New York Review of Books 50, 6

Lewis, A. (2012), "EU diplomatic service cautious on tough global stage", BBC News, available at http://www.bbc.co.uk/news/world-europe-20522201 (accessed 5 September 2013)

Lieb, J. and A. Maurer (2007), "Making EU Foreign Policy more effective, consistent and democratic - The options and variables for the European External Action Service", Working Paper FG1, Stiftung Wissenschaft und Politik, 7

Mackie, J. and J. Zinke (2005), “When Agreement Breaks Down, What Next? The Cotonou Agreement's Article 96 Consultation Procedure", Discussion Paper No. 64A, Maastricht: ECDPM

Manners, I. (2008), “The Normative Ethics of the European Union”, International Affairs, 84(1):45-60

Marangoni, A.-C. (2012), "One hat too many for the High Representative - Vice President? The coherence of EU external policies after Lisbon", EU External Action Review, 2:4-17

Marangoni, A.-C. (2013a), “Coordination of external policies: Feudal fiefdoms to coordinate”, in Boening, A. B., Kremer, J.-F. and A. van Loon (eds.), The EU: a global power in the making? Europe's present and future role in a changing world, Berlin Heidelberg: Springer-Verlag, pp. 37-54

Marangoni, A.-C. (2013b), "The 2011 Commission proposal for a revision of the Generalised System of Preferences: Articulating trade, development and foreign policy objectives", ATINER's Conference Paper Series, POL2013-0538, Athens 
Marangoni, A.-C. and K. Raube (2014), "Virtue or Vice? The Coherence of the EU's External Policies", Journal of European Integration, 36(5): 473-489

March, J. G. and H. A. Simon (1958), Organizations, New York: John Wiley \& Sons

March, J. G. and J. P. Olsen (1984), "The New Institutionalism: Organisational Factors in Political Life", American Political Science Review, 78(3): 738-749

March, J. G. and J. P. Olsen (1989), Rediscovering Institutions, New York: Free Press

March, J. G. and J. P. Olsen (1996), "Institutional Perspectives on Political Institutions", Governance, 9(3): 247-264

March, J. G. and J. P. Olsen (1998), "The Institutional Dynamics of International Political Orders", International Organisations, 52(4): 943-969

Marks, G., Hooghe, L. and K. Blank (1996), "European Integration from the 1980s: State-Centric v. Multilevel Governance", Journal of Common Market Studies, 34(3): 341-378

Martin, R. (2006), "The rule of law in Zimbabwe", The Round Table, 95(384): 239-253

Matthews, A. (2008), “The European Union's Common Agricultural Policy and Developing Countries: the Struggle for Coherence", Journal of European Integration, 30(3): 381-399

Maurie, F. and G. Gya (2009), "The Setting Up of the European External Action Service (EEAS): Laying the Basis for a More Coherent EU Foreign Policy?", European Security Review, ISIS Europe, 47

Mayer, H. (2013), "The Challenge of Coherence and Consistency in EU Foreign Policy" in Telo, M. and F. Ponjaert (eds.), The EU's Foreign Policy: What Kind of Power and Diplomatic Action?, Farnham: Ashgate, pp. 105-117

Mc Lean Hilker, L. (2004), “A comparative analysis of institutional mechanisms to promote Policy Coherence for Development - Case study synthesis, the European Community, United States and Japan", Institutional approaches to Policy Coherence for Development-OECD policy workshop

McMahon, M. and A. Willis (16/05/2011), "Member states responsible for EU 'single voice', EUObserver.com, available at http://euobserver.com/foreign/32315 (accessed 16 May 2011)

McQueen, M. (2007), "Are EU non-reciprocal trade preferences passé?", Intereconomics, 42(4): 205-218

Mearsheimer, J. J. (1994), "The False Promise of International Institutions", International Security, 19(3): 5-49

Meunier, S. and K. Nicolaïdis (2006), “The European Union as a conflicted trade power", Journal of European Public Policy, 13(6):906-925

Meredith, M. (2002), Robert Mugabe - Power, Plunder and Tyranny in Zimbabwe, Johannesburg \& Cape Town: Jonathan Ball Publishers

Meredith, M. (2003), Our votes, our guns, New York: Public Affairs

Metcalfe, L. (1994), “International Policy Co-ordination and Public Management Reform”, International Review of Administrative Sciences, 60: 271-290

Metcalfe, L. (2004), "European Policy Management: Future Challenges and the Role of the Commission", Public Policy and Administration, 19(3): 77-93

Miglioli, C. (2009), From coordinated decision-taking to integrated policy-making: how sustainable development and impact assessment have broken down the European Commission's internal boundaries, Bruges: College of Europe

Ministry of Finance of Zimbabwe (2012), Consolidated financial reporting for 2011 and Program Report Form: Bilateral donors (Jan.-Dec. 2011), internal documents not publicly available

Mintzberg, H. (1998), The Structuring of Organizations - A synthesis of the research, New Jersey: Prentice Hall

Missiroli, A. (ed.) (2001), "Coherence for Security Policy: Debates, Cases, Assessments”, Occasional Papers, 27, Paris: Institute for Security Studies

Missiroli, A. (ed.) (2013), "Enabling the Future and - European Military Capabilities 2013-2025: Challenges and Avenues", ISS Report, 16

Morisse-Schilbach, M. (2005), "France" in Hocking, B. and D. Spence (eds.), Foreign Ministries in the European Union, Integrating Diplomats, Houndmills: Basingstoke, Palgrave Macmillan, pp.111-131

Niemann, A. (2012), “The Common Commercial Policy: From Nice to Lisbon” in Laursen, F. (ed.), The EU's Lisbon Treaty: Institutional Choices and Implementation, Farnham : Ashgate, pp. 205-228 
Noël, E. (1962), "How the European Economic Community's Institutions Work", Speech to the Conservative Political Centre, Oxford

Nugent, N. (2001), The European Commission, Houndmills: Palgrave

Nugent, N. and S. Saurugger (2002), "Organizational structuring: the case of the European Commission and its external policy responsibilities", Journal of European Public Policy, 9(3): 345-364

Nuttall, S. (1992), European Political Cooperation, Oxford: Oxford University Press

Nuttall, S. (2000), European Foreign Policy, Oxford: Oxford University Press

Nuttall, S. (2001), “'Consistency' and the CFSP: a categorization and its consequences”, EFPU working paper series, 3

Nuttall, S. (2004), “On Fuzzy Pillars: Criteria for the Continued Existence of Pillars in the Draft Constitution", CFSP Forum, 2(3): 4-7

Nuttall, S. (2005), “Coherence and Consistency”, in Hill C. and M. Smith (eds.), International Relations and the European Union, Oxford: Oxford University Press, pp.91-112

Nuttall, S. (2006), "The Commission and European Political Cooperation", in Spence, D. and G. Edwards (eds.), The European Commission, London: John Harper Publishing, pp. 341-355

OECD (1996), "Building Policy Coherence: Tools and Tensions", Public Management Occasional Papers, 12

Olsen, G. R. (2008), “Coherence, Consistency and Political Will in Foreign Policy: the European Union's Policy towards Africa", Perspectives on European Politics and Society, 9(2): 157-171

Olsen, J. P. (2005), "Maybe it is time to rediscover bureaucracy?", Working Paper nr.10, Centre for European Studies, University of Oslo

Parkes, R. (2011), "The EU has a vice: coherence", EUObserver.com, available at http://blogs.euobserver.com/parkes/2011/06/11/the-eu-has-a-vice-coherence/ (accessed 12 June 2011)

Peters, B. G (1998), "Managing horizontal government: the politics of coordination", Public Administration, 76(2): 295-311

Peters, B. G. (2000), Institutional Theory in Political Science: The New Institutionalism, London \& New York: Continuum

Peters, B. G. (2001), The Politics of Bureaucracy, London \& New York: Routledge

Peters, B. G. (2010), The Politics of Bureaucracy, London \& New York: Routledge

Peters, B. G. and V. Wright (2001), "The national coordination of European policy-making” in J. J. Richardson (ed.), European Union: power and policy-making, London: Routledge

Pierre, J. and B. G. Peters (2000), Governance, Politics and the State, New York: St Martin's Press

Pierson, P. (1998), "The Path to European Integration: A Historical-Institutionalist Analyst" in Sandholtz, W. and A. Stone Sweet (eds.), European Integration and Supranational Governance, Oxford: Oxford University Press, pp.27-58

Pollitt, C. (2003), “Joined-up Government: a Survey”, Political Studies Review, 1(1): 34-49

Portela, C. (2007), "Aid suspensions as coercive tools? The European Union's experience in the AfricanCaribbean-Pacific (ACP) context", Review of European and Russian Affairs, 3(2): 38-53

Portela, C. (2010), European Union sanctions and Foreign Policy, When and why do they work?, London and New York: Routledge

Portela, C. (2014), “The EU's Use of 'Targeted' Sanctions: Evaluating effectiveness", CEPS Working Document, 391

Portela, C. and K. Raube (2008), "Six Authors in Search of a Notion: (In)Coherence in EU Foreign Policy and its Causes" in Portela, C. and K. Raube (eds.), "Revisiting Coherence in EU Foreign Policy", Hamburg Review of Social Sciences, 3(1): 1-10

Portela, C. and K. Raube (2009), "(In-)Coherence in EU Foreign Policy: Exploring Sources and Remedies", Paper presented at the European Studies Association Bi-Annual Convention

Power, S. (2003), "How to kill a country", Atlantic Monthly 292, 5

President of the Commission (2000), 2000-2005: Shaping the New Europe, SPEECH/00/41, Strasbourg 
President of the Commission (2009a), Mission Letters to Baroness Catherine Ashton (High Representative designate), to Olli Rehn (Commissioner designate for Economic and Financial Affairs), to Andris Piebalgs (Commissioner designate for Development), to Karel de Gucht (Commissioner designate for Trade), to Stefan Füle (Commissioner designate for ENP), to Kristalina Georgieva (Commissioner designate for Humanitarian aid and crisis response), Brussels

President of the Commission (2009b), Barroso unveils his new team, IP/09/1837, Brussels

President of the European Commission (2009c), Political guidelines for the new Commission, Brussels, available at http://ec.europa.eu/commission_2010-2014/president/about/political/index_en.htm (accessed 7.12.2012)

President of the Commission (2010a), State of the Union 2010, SPEECH/10/411, Brussels

President of the European Commission (2010b), Note from José Manuel Barroso, President of the European Commission to Catherine Ashton, High Representative/Vice President of the European Commission, Olli Rehn, Member of the European Commission, Andris Piebalgs, Member of the European Commission, Karel de Gucht, Member of the European Commission, Kristalina Georgieva, Member of the European Commission, Stefan Füle, Member of the European Commission on Commissioner's group on External relations, D(2010)/1162, Brussels

President of the Commission (2010c), Information Note from the President - Commissioners Groups, SEC(2010)475 final, Brussels

President of the Commission (2010d), Communication from the President - The working methods of the Commission 2010-2014, C(2010)1100, Brussels

President of the Commission (2012), Discours sur l'état de l'Union 2012, SPEECH/12/596, Strasbourg

President of the Commission (2013), State of the Union address 2013, SPEECH/13/684, Strasbourg

Quinn, P. (2012), "The Lisbon Treaty: Answering the Call for Greater Consistency in EU External Relations?", in Mahncke, D. and S. Gstöhl (eds.), European Union Diplomacy - Changes and Challenges under the Lisbon Treaty, Brussels: PIE Lang, pp.45-62

Radin, B. A. (2003), "The Instruments of Intergovernmental Management" in Peters, B. G. and J. Pierre (eds.), Handbook of Public Administration, London: Sage, pp. 607-618

Raube, K. (2007), Die Verfassungsaussenpolitik der Europäischen Union: Die Gemeinsame Aussen-, Sicherheits- und Verteidigungspolitik im Konvent zur Zukunft Europas, Baden-Baden: Nomos

Reh, C. (2012), "Informal politics: the normative challenge" in Christiansen, T. and C. Neuhold (eds), The International Handbook of Informal Governance, Cheltenham: Edward Elgar, pp.65-84

Rettman, A. (2011a), “UK attacks Ashton over 'ludicrous' budget proposal”, EUObserver.com, available at http://euobserver.com/institutional/32384 (accessed 24 May 2011)

Rettman, A. (2011b), “UK champions own diplomacy over EU 'action service”, EUObserver.com, available at http://euobserver.com/foreign/32271 (accessed 5 May 2011)

Rettman, A. (2012a), "EU foreign service moves into new home", EUObserver.com, available at http://euobserver.com/institutional/115290 (accessed 17 February 2012)

Rettman, A. (2012b), “Commission still pulls the strings on EU foreign policy”, EUObserver.com, available at http://euobserver.com/18/115145 (accessed 6 February 2012)

Rüger, C. (2011), "A Position under Construction: Future Prospects of the High Representative after the Treaty of Lisbon" in Müller-Brandeck-Bocquet, G. and C. Rüger (eds), The High Representative for the EU Foreign and Security Policy - Review and Prospects, Baden-Baden: Nomos, pp.201-233

Rüger, C. (2012), "From an Assistant to a Manager - The High Representative for Foreign Affairs and Security Policy after the Treaty of Lisbon" in Laursen, F. (ed.), The EU's Lisbon Treaty: Institutional Choices and Implementation, Farnham : Ashgate, pp. 141-170

Rynning, S. (2006), "European Security and Defence Policy: Coming of Age?” in Laursen, F. (ed.), The Treaty of Nice: Actor Preferences, Bargaining and Institutional Choice, Leiden/Boston: Martinus Nijhoff Publishers, pp. 479-502

SADC (2011), Réunion du Sommet de la Troïka de l'organe de coopération en matière de politique, défense et sécurité de la SADC - Communiqué, Livingstone

Schmalz, U. (1997), "Kohärenz der EU-Aussenbeziehungen? Der Dualismus von Gemeinschaft und Gemeinsamer Aussen- und Sicherheitspolitik in der Praxis", Konrad Adenauer Stiftung Arbeitspapier 
Schmalz, U. (1998), “The Amsterdam Provisions on External Coherence: Bridging the Union's Foreign Policy Dualism?", European Foreign Affairs Review, 3(3): 421-442

Schmidt, V.A. (2013), 'Democracy and legitimacy in the European Union revisited: input, output and 'throughput', Political Studies, 61(1), 2-22

Schout, A. (1999), Internal Management of External Relations: The Europeanization of an Economic Affairs Ministry, Maastricht: EIPA

Schuman, R. (1950), Déclaration du 9 mai 1950, Paris

Sicurelli, D. (2008), "Framing security and development in the EU pillar structure. How the views of the European Commission affect EU Africa policy", Journal of European Integration, 30(2): 217-234

Simon, H. A. (1997), Administrative Behavior: A Study of Decision-Making Processes in Administrative Organizations, New York: The Free Press

Smith, A. (2003), "Why European Commissioners Matter", Journal of Common Market Studies, 41(1): 137155

Smith, M. (2006), "The Commission and External Relations" in Spence, D. (ed.), The European Commission, London: John Harper Publishing, pp.313-340

Smith, M. E. (2001), "The Quest for Coherence: Institutional Dilemmas of External Action from Maastricht to Amsterdam" in Stone Sweet, A. Sandholtz, W. and N. Fligstein (eds.), The Institutionalization of Europe, Oxford: Oxford University Press, pp.171-193

Smith, M. E. (2004), Europe's Foreign and Security Policy: The Institutionalization of Cooperation, Oxford: Oxford University Press

Smith, S. and M. Clarke (1985), "Foreign Policy Implementation and Foreign Policy Behaviour" in Smith, S. and M. Clarke (eds.), Foreign Policy Implementation, London: George Allen \& Unwin, pp.1-10

Spence, D. (2006a), "The President, the College and the Cabinets" in Spence, D. (ed.), The European Commission, London: John Harper Publishing, pp.25-74

Spence, D. (2006b), "The Directorates-General and the Services: Structures, Functions and Procedures" in Spence, D. (ed.), The European Commission, London: John Harper Publishing, pp.128-155

Spence, D. (2006c), "The Commission and the Common Foreign and Security Policy" in Spence, D. (ed.), The European Commission, London: John Harper Publishing, pp.356-395

Spence, D. (2012), "The Early Days of the European External Action Service: A Practitioner's View”, The Hague Journal of Diplomacy, 7(1): 115-134

Spierenburg, D. (1979), Proposals for Reform of the Commission of the European Communities and its Services [Spierenburg Report], Brussels

Stetter, S. (2004), “Cross-Pillar Politics: Functional Unity and Institutional Fragmentation of EU Foreign Policy”, Journal of European Public Policy, 11(4): 720-739

Stevens, A. and H. Stevens (2001), Brussels Bureaucrats?, Basingtoke and New York: Palgrave

Stoss, S. (2011), "The review of the European Neighbourhood Policy: Increasing the coherence and coordination of EU external action?", TEPSA Brief

Stübig, S. (2007), "Wirkungsloser Druck: "Pariastaat" Simbabwe zwischen westlichen Sanktionen und regionaler Solidarität", GIGA Focus Afrika, 5

Taylor, I. and P. Williams (2002), "The limits of engagement: British foreign policy and the crisis in Zimbabwe", International Affairs, 78(3): 547-565

Thoenig, J.-C. (2003), "Institutional Theories and Public Institutions: Traditions and Appropriateness" in Peters, B. G. and J. Pierre (eds.), Handbook of Public Administration, London: Sage, pp. 127-137

Tietje, C. (1997), "The Concept of Coherence in the Treaty on European Union and the Common Foreign and Security Policy", European Foreign Affairs Review, 2(2): 211-233

Timmermans, C.W.A. (1996), "The Uneasy Relationship between the Communities and the Second Union Pillar: Back to the 'Plan Fouchet"?, Legal Issues of European Integration, 23(1): 61-70

Thomas, D. C. (2012), "Still Punching below Its Weight? Coherence and Effectiveness in European Union Foreign Policy", Journal of Common Market Studies, 50(3):457-474

Trondal, J. (2007), "The public administration turn in integration research", Journal of European Public Policy, 14(6): 960-972

Turksen, U. (2009), "The WTO law and the EC's GSP+ arrangement", Journal of World Trade, 43(5): 927968 
United Nations (n.d.), Millenium Development Goal 8: Develop a global partnership for development, online resource, available at http://www.un.org/millenniumgoals/global.shtml (accessed 18 February 2013)

United Nations (2011), General Assembly Resolution GA/11079/Rev.1, New York

United Nations Conference on Trade and Development (n.d.), Generalized System of Preferences, http://www.unctad.org/en/Pages/DITC/GSP/Generalized-System-of-Preferences.aspx (accessed 21 May 2012)

United Nations Conference on Trade and Development (1968), Resolution 21 (II) - Preferential or free entry of exports of manufactures and semi-manufactures of developing countries to the developed countries, New Delhi

United Nations Conference on Trade and Development (2008), Generalized System of Preferences Handbook on the scheme of the European Community, New York and Geneva: United Nations

Vanhoonacker, S. (1992), "A Critical Issue: From European Political Cooperation to a Common Foreign and Security Policy" in Laursen, F. and S. Vanhoonacker (eds.), The Intergovernmental Conference on Political Union - Institutional Reforms, New Policies and International Identity of the European Community, EIPA: Maastricht, pp. 25-33

Vanhoonacker, S. (2005), "The Institutional Framework" in Hill, C. and M. Smith (eds.), International Relations and the European Union, Oxford: Oxford University Press, pp.67-90

Vanhoonacker, S. (2007), "The ESDP and Coherence Challenges in the Council”, in Blockmans, S. (ed.), The European Union and Crisis Management - Policy and Legal Aspects, The Hague: T.M.C. Asser Press, pp. 145-156

Vanhoonacker, S. (2011), “The Institutional Framework”, in Hill, C. and M. Smith (eds.), International Relations and the European Union, Oxford: Oxford University Press, pp.75-100

Vanhoonacker, S. and K. Pomorska (2013), "The European External Action Service and agenda-setting in European foreign policy", Journal of European Public Policy, 20(9): 1316-1331

Vanhoonacker, S. and N. Reslow (2010), "The European External Action Service: Living Forwards by Understanding Backwards", European Foreign Affairs Review, 15(1):1-18

Van De Ven, A. H., Delbecq, A. L. and R. Koenig Jr (1976), "Determinants of Coordination Modes within Organizations", American Sociological Review, 41(2): 322-338

Van Ooik R. (2008), "Cross-Pillar Litigation Before the ECJ: Demarcation of Community and Union Competences", European Constitutional Law Review, 4(3): 399-420

Venzke, I. (2008), "International Bureaucracies from a Political Science Perspective - Agency, Authority and International Institutional Law", German Law Journal, 9(11): 1401-1428

Verola, N. (2012), "The New EU Foreign Policy under the Treaty of Lisbon" in Bindi, F. and I. Angelescu (eds.), The Foreign Policy of the European Union, Washington, DC: Brookings, pp. 40-50

Vircoulon, T. (2010), "Zimbabwe", in de Montbrial, T. and P. Moreau Defarges (eds.), Crise mondiale et gouvernance globale, Paris: IFRI

Warin, C. (1997), La politique extérieure de l'Union européenne: quelle coordination au sein de la Commission?, Bruges: College of Europe

Waterfield, B. (2011), “Is absent Ashton a part-timer?", EUObserver.com, 10 January 2011, http://blogs.euobserver.com/waterfield/2011/01/10/absent-ashton-a-part-time-eu-foreignminister/ (accessed 01 July 2011)

Weiland, H. (2004), "EU Sanctions Against Zimbabwe: A Predictable Own Goal?" in Holland, M. (ed.), Common Foreign and Security Policy, The first ten years, London: Continuum, pp.127-143

Wessel, R. A. (2000), "The Inside Looking Out: Consistency and Delimitation in EU External Relations", Common Market Law Review, 37(5): 1135-1171

Wildavsky, A. (1996), Speaking Truth to Power - The Art and Craft of Policy Analysis, New Brunswick and London: Transaction Publishers

Willis, A. (2011), "Belgian minister publicly attacks EU foreign relations chief", EUObserver.com, available at http://euobserver.com/9/32269 (accessed 25 May 2011)

Windrich, E. (2010), “Then and now: Reflections on how Mugabe rules Zimbabwe”, Third World Quarterly, 23(6): 1181-1188 
Winn, N. and C. Lord (2001), EU Foreign Policy beyond the Nation-State, Houndmills: Basingstoke, Palgrave

Winters, A. L. (2006), "International trade and poverty: cause or cure?", The Australian Economic Review, $39(4): 347-358$

Wollmann, H. (2003), "Coordination in the Intergovernmental Setting" in Peters, B. Guy and Jon Pierre (eds.), Handbook of Public Administration, London: Sage, pp.594-606

World Trade Organization (1971), Waiver Generalized System of Preferences, Decision of 25 June 1971, BISD 18S/24

World Trade Organization (1979), "Decision of 28 November 1979 (L/4903)", Legal Texts: Differential and more favourable treatment reciprocity and fuller participation of developing countries, available at http://wto.org/english/docs_e/legal_e/enabling1979_e.htm (accessed 21 May 2012)

World Trade Organization (2011), Trade Policy Review Zimbabwe, WT/TPR/M/252, Geneva

Yin, R. K. (1989), Case Study Research, Design and Methods, London: Sage 


\section{Samenvatting}

Al van in de jaren '70, toen de eerste stappen in de Europese Politieke Samenwerking werden gemaakt, heeft de Unie herhaaldelijk bevestigd dat consistentie centraal moest staan in haar extern optreden. Die roep kwam sterker dan ooit terug toen het Verdrag van Lissabon een aantal institutionele innovaties introduceerde om het buitenlands beleid van de Unie consistenter te maken. Voorbeelden van zulke innovaties waren onder meer de oprichting van de Europese Dienst voor Extern Optreden (EDEO) en het samenvoegen van de functies van Hoge Vertegenwoordiger met die van de Unie voor Buitenlands- en Veiligheidsbeleid (HBVB) en vice-voorzitter van de Europese Commissie.

De manier waarop de EU poogt consistentie te brengen in de verschillende dimensies van haar extern optreden is het centrale onderwerp van dit proefschrift. De centrale onderzoeksvraag is in welke mate is het extern beleid consistent en wat zijn de voorwaarden onder dewelke er al dan niet consistentie is in concrete case studies. De focus van het onderzoek is toegespitst op twee aspecten. Eerst en vooral focust deze thesis zich op de Europese Commissie. Zij is reeds lang verantwoordelijk om de consistentie binnen de Unie te waarborgen, heeft een cruciale rol en expertise in handelsbeleid en ontwikkelingsbeleid, en heeft algemeen gesproken een belangrijke bijdrage in het extern beleid van de EU. Ten tweede spitst dit onderzoek zich toe op de kern van het extern beleid van de Unie, met name het extern handelsbeleid, ontwikkelingssamenwerking en het Gemeenschappelijk Buitenlands- en Veiligheidsbeleid (GBVB).

Dit onderzoek bestudeert Commissievoorstellen rond extern beleid, vanaf het moment van het eerste ontwerp tot aan hun aanname door het College van Commissarissen. Er worden twee cases bestudeerd: de maatregelen tegen Zimbabwe (met een focus op zowel het Commissievoorstel uit 2002 om 'gepaste maatregelen' te nemen, als het voorstel uit 2012 om deze te hernieuwen) en het voorstel van de Commissie uit 2011 betreffende de herziening van het algemeen preferentiestelsel (Generalised System of Preferences of GSP). Om de bespreking te structureren werden drie sub-vragen gesteld:

- Hoe en op welk niveau wordt de vereiste om consistent te zijn uitgedrukt en geïmplementeerd?

- In hoeverre is de output van het beleid consistent?

- Onder welke omstandigheden is coördinatie nuttig?

De consistentie van een voorstel van de Commissie wordt gedefinieerd als zijnde een voorstel dat geen contradicties bevat tussen de hoofddoelstelling van dat voorstel en de gedetailleerde bepalingen van het voorstel met betrekking tot de specifieke beleidsdomeinen. Dit onderzoek identificeert en definieert verschillende 
punten op het continuum tussen consistentie en inconsistentie (m.n. hoge consistentie, middelmatige consistentie, lage consistentie en inconsistentie). Deze schaal werd vervolgens toegepast op elke case study om de consistentie van de desbetreffende voorstellen te kunnen beoordelen.

Wat betreft de eerste sub-vraag heeft dit onderzoek een alomvattend kader ontwikkeld dat de verschillende niveaus op dewelke de consistentie-vereiste werd uitgedrukt en geïmplementeerd identificeert. Dit kader bestaat uit drie verschillende niveaus. Eerst en vooral het algemene kader voor consistentie in het extern optreden van de EU zoals vastgelegd door het Verdrag; ten tweede het beleidskader dat de consistentie-vereiste in een specifiek beleidsdomein specifieert; ten derde het interne proces van besluitvorming binnen de Commissie die de consistentie-vereiste implementeert. Dit drieledige kader definieert bijgevolg zowel de juridische, substantiele als procedurele richtlijnen die de activiteiten van de Commissie in haar extern beleid omlijnen, en omvat ook de doelstelling om een consistente beleidsoutput te hebben. en die ook de doelstelling om tot een consistente beleidsoutput te komen omvatten. Wat de tweede sub-vraag betreft, beargumenteert deze thesis dat ondanks het feit dat er juridische, substantiele en procedurele richtlijnen rond consistentie bestaan, de output van het Commissie-beleid niet systematisch consistent is. In het bijzonder zien we dat, hoewel er verschillende instrumenten voor coordinatie zijn, de coordinatie van verschillende beleidsdoelstellingen tijdens het ontwerpen van een voorstel toch kan mislukken zodat het uiteindelijke voorstel alsnog inconsistent is. Consistentie kan dus wel of niet de uitkomst zijn van coordinatie. Enkel wanneer coordinatie succesvol is, zien we ook dat de beleidsoutput consistent is. Op basis van deze overweging, beoordeelt dit onderzoek eerst de mate waarin het specifieke Commissievoorstel consistent is. Vervolgens, afhankelijk van de mate van consistentie, leidt dit onderzoek af of coordinatie meer of minder succesvol is geweest in deze gevallen (beperkt, gematigd of volledig succesvol). In de derde stap bespreekt dit onderzoek de voorwaarden onder dewelke coordinatie succesvol is.

In de twee onderzochte cases werden de voorstellen van de Commissie consistent bevonden, zij het wel in verschillende mate. Het voorstel uit 2002 dat voornamelijk gericht was op het herstellen van het zogenaamde 'essentiële elementen', had een lage tot gemiddelde consistentiegraad. Het voorstel uit 2012 dat gericht was op het hernieuwen van die maatregelen had daarentegen een gemiddelde tot hoge consistentiegraad. Deze resultaten zijn gelinkt met een 'beperkt' tot 'gematigd succesvolle' coördinatie in 2002, en een 'gematigd' tot 'volledig sucessvolle' coördinatie in 2012. Het Commissie voorstel uit 2011 met betrekking tot het herzien van het GSP had dan weer een hoge graad van consistentie in haar streven naar een herorientering van de import-preferenties richting die landen die dit het meeste nodig hebben. Dit kan gelinkt worden met een 'volledig succesvolle' coordinatie. 
Op basis van deze analyse kunnen we een aantal factoren identificeren die bijdroegen tot consistentie. Deze factoren zijn zowel extern als eigen aan de Commissie. Met betrekking tot de externe factoren heeft het onderzoek zich in eerste instantie gericht op de invloed van de internationale omgeving, bijvoorbeeld de aanwezigheid van een bindend kader van de Wereld Handelsorganisatie rond voorkeursvoorzieningen voor import. In de case study rond het GSP bleek de internationale factor een sleutelrol te spelen voor het vaststellen van de voorwaarden aan dewelke de gewijzigde voorzieningen dienden te voldoen. Deze factor beperkte de beleidskeuzes van de Commissie en beïnvloedde de standpunten van de actoren binnen de Commissie. In concreto werd het zeggenschap van de leidende DG en het leidende kabinet versterkt. In de case study rond Zimbabwe was de invloed van externe elementen eerder beperkt gezien er geen internationaal bindend kader omtrent sancties tegen Zimbabwe bestaat. Desondanks verengde de algemene veroordeling van Mugabe's misdrijven de opties die de EU had.

Externe factoren kunnen echter ook inter-institutioneel zijn, zoals bijvoorbeeld in de eerste case study, de strenge houding van een aantal lidstaten in de Raad met betrekking tot de situatie in Zimbabwe. Gezien de Commissie een voorstel moet doen dat zowel voor de Raad als het Europees Parlement aanvaardbaar is, zal ze rekening houden met hun voorkeuren. De Zimbabwe case toonde goed de invloed van de Raad op de besluitvorming van de Commissie aan: de aanwezigheid van hardliners in de Raad liet weinig keuze voor wat de gewenste actie tegen Mugabe's regime betrof, en stuurde bijgevolg het ontwerp van het Commissie voorstel in een welbepaalde richting.

Concluderend kunnen we stellen dat de case studies aantoonden dat externe factoren de opties van de Commissie verengen. Dit vergroot vervolgens de macht van sommige actoren terwijl het die van andere actoren - degenen wiens voorkeuren niet overeenstemmen met de politieke of juridische eisen die worden verwoord buiten het kader van de Commissie - doet afnemen. Op die manier wordt dan ook het coördinatie proces beïnvloed.

Interne factoren bleken echter ook een impact te hebben op de coördinatie tussen de verschillende doelstellingen in de voorstellen, en zijn dus ook van belang voor de consistentie van de voorstellen. Verschillende interne factoren hadden een invloed. Ten eerste, het soort besluit bepaalt het besluitvormingsproces en de stappen die de Commissie moet nemen tijdens het ontwerpen van een bepaald voorstel. Bij een crisisbesluit zal de Commissie haar voorstel ontwerpen volgens een vereenvoudigde procedure, in elke andere situatie wordt een hele resem coördinatie-instrumenten geactiveerd, die zowel de inhoud als het besluitvormingsproces aan controle onderwerpen. Dit geeft meer mogelijkheden 
om de verschillende dimensies van de actie te analyseren en succesvol te coördineren.

Ten tweede, kunnen interne factoren ook te maken hebben met intra-institutionele dynamieken. Zoals in elke organisatie lopen er scheidingslijnen doorheen de Commissie: de verschillende departementen en kabinetten, die verschillende doelstellingen voor ogen hebben en verschillende ideeën omtrent aanpak hebben. Zoals te verwachten bestaan er dus ook verschillende standpunten. De mate waarin uiteenlopende doelstellingen de overhand nemen wordt tijdens het coördinatieproces afgezwakt. Een van de 'afzwakkende' factoren is de bevoegdheid van de Commissie over het domein. In een domein met exclusieve EU bevoegdheid heeft de leidende DG het 'kapitaal' om te definiëren welke doelstellingen aanvaardbaar zijn, en welke niet. Hier komt bij dat het Verdrag van Lissabon in de eerste jaren na haar implementatie, de uitdagingen omtrent coördinatie in de Commissie verder heeft benadrukt door de vereiste in te voeren dat actoren binnen de Commissie dienen samen te werken met externe actoren in het opstellen van voorstellen, zoals de EDEO. Algemeen genomen heeft het Verdrag ook geen antwoord gegeven over wie de coordinatie van buitenlands beleid binnen de Commissie leidt, ondanks het feit dat de HVBV hiervoor een formeel mandaat heeft. Het feit dat men blijft hinder ondervinden om de verschillende coördinatieinstrumenten ten volle te gebruiken wijst erop dat de uitdagingen omtrent coördinatie en consistentie in de Commissie ook na het Verdrag van Lissabon de wereld niet uit zijn.

Over het geheel genomen hebben de case studies verschillende factoren aan het licht gebracht die het coördinatie proces beïnvloeden en op die manier ook de consistentie van de beleidsoutput mee bepalen. Het empirisch onderzoek was echter niet sluitend voor wat betreft de invloed die de verschillende factoren afzonderlijk hebben.

Concluderend kunnen we stellen dat om in een internationale omgeving multidimensionele, globale uitdagingen aan te gaan, de EU ernaar streeft om haar buitenlands beleid consistenter te maken. Haar effectiviteit, geloofwaardigheid en legitimiteit hangt er immers mee van af. Het is duidelijk dat de Commissie het potentieel van een aantal instrumenten rond het coördineren van buitenlands beleid en het bereiken van een consistente beleidsoutput nog niet ten volle heeft benut. Indien de EU er in de toekomst in slaagt om de consistentie van haar buitenlands beleid te versterken, zal ook haar internationale status vergroten. 


\section{Valorization}

This PhD has dealt with the consistency of EU external policies. A recurrent challenge for the EU for decades already, the consistency of external policies remains high on the political agenda. The research aimed to assess the consistency of the Commission's action in external policies and to explain this outcome. In so doing, the PhD focused in particular on the Commission's internal decision-making process, exploring the dynamics of intra-institutional coordination. Conducted in the framework of the multidisciplinary Initial Training Network (ITN-FP7) on Institutional Cooperation in the EU (INCOOP) (2010-14), this research contributed to the broader objective to get a better understanding of intra- and interinstitutional cooperation in the EU.

The valorisation of a $\mathrm{PhD}$ has gained a new prominence, as it is a constant challenge for the researcher to ensure the relevance of a topic and its utilisation in practice. Knowledge valorisation is the "process of creating value from knowledge, by making knowledge suitable and/or available for social (and/or economic) use and by making knowledge suitable for translation into competitive products, services, processes and new commercial activities" (Article 23, Regulation governing the attainment of doctoral degrees at Maastricht University, 2013). In the framework of this $\mathrm{PhD}$, valorisation has been effected through four activities, which will be successively discussed: publications, education, evaluation, as well as the formulation of policy recommendations and the provision of trainings.

\section{Publications}

To an academic audience, the publication of research is the main instrument of knowledge transfer. At Maastricht University, it is systematically pursued, as $\mathrm{PhD}$ candidates are required to present their book on the day of the defence. In addition to the book, publishing in various academic outlets is also encouraged throughout the PhD. I published both on my analytical framework and on my empirical research by way of conference publications, academic journal articles and a chapter in an edited volume. Some of these publications were the end products of papers first presented at conferences (UACES, ECPR and EUSA notably), revised on the basis of panel discussions. Publications also benefited in particular from the expertise shared in the INCOOP collaborative research network. Even though INCOOP has formally ended, collaboration continues as several INCOOP members and I are working on the publication of a special issue in the European Integration online Papers (EIoP). Building on a network of scholars working on consistency, I co-authored an article published in the peer-reviewed Journal of European Integration (JEI) - which we also presented at several conferences and research seminars. This theoretical article led to the creation of research group on "Coherence and public diplomacy in EU external action" following our successful 
panel proposal at the September 2014 UACES conference. This publication also serves as a stepping stone to another article (in preparation) which will be presented at this conference. Depending on the outcome of the conference, it is hoped that the contributions will form the skeleton for a joint publication such as a special issue. Overall, building on a $\mathrm{PhD}$ research and on the contacts made during the research opens up numerous opportunities for the valorisation of one's research: participating in different research networks allows to broaden the initial research focus, to think about it from different perspectives and to benefit from the synergies between different disciplines.

\section{Education}

The most logical step to transfer knowledge is education. On the basis of the $\mathrm{PhD}$ topic, two tracks may be pursued. The first one is policy-specific and relates to the substance of EU external action. Also building on my previous experience as teaching assistant at the College of Europe, Bruges, I contributed during the past academic year to a master's module on the "EU as a global actor" dealing with the EU's core external policies. When I was a PhD student, I exploited my expertise in external policies in teaching an undergraduate course entitled "Negotiation skills" that consisted of a series of simulation games, some of which dealing with the external dimension of EU action. The second track, which I am currently pursuing, builds on the institutional focus of my PhD. While dealing with the Commission's decision-making, I have acquired a detailed knowledge of Commission procedures that is applicable to any policy area. In my current position of research associate at Aston University, I aim at developing a large-scale simulation game targeting postgraduate students. In a domain outside of my traditional policy focus, I am working in collaboration with a former Commission official and a former Member of the European Parliament to set up a simulation of Commission and European Parliament decision-making. The demand for such a course is really strong. On the one side, students are very much interested in a hands-on approach to EU studies; on the other side, the University is keen to offer more practical courses as it is expected to valorise the curriculum and to increase the employability of students.

\section{Evaluation}

The assessment of the consistency of the Commission's action on the basis of extensive empirical research on the Commission's decision-making process is a novelty in the literature. The knowledge on an organisation serves to evaluate the functioning of this organisation and its capacity to meet the objectives it sets. As revealed by the interviews conducted with Commission officials (policy officers drafting proposals and policy coordinators), it is of practical relevance to evaluate the extent to which the Commission in particular and EU institutions in general meet the consistency objective. As the service responsible for overseeing 
coordination within the Commission and seeing after the consistency of the Commission proposals, the Secretariat General of the Commission evaluates on a daily basis the output of the decision-making process but operates on limited resources. The framework developed in this $\mathrm{PhD}$ research could be used to conduct a more systematic assessment of the consistency of Commission proposals and an evaluation of the institutional mechanisms aiming at consistency. In addition, the policy and institutional focus of the $\mathrm{PhD}$ can be expanded. The results can be generalised to all areas of Commission action - and not limited to external policies only. Eventually, policy recommendations can be drawn on the basis of the evaluation exercise, as will be mentioned below.

\section{Policy recommendations and Training}

The conceptual framework developed in this research was applied a few years after the entry into force of the Lisbon Treaty. The institutional innovations introduced by the new Treaty have led to the adaptation of the working methods and the accommodation of new actors in the Commission's decision-making process, especially in the field of external policies. The methodology used helps to provide an assessment of the functioning of the Commission with respect to the consistency objective. It is also relevant to other institutions and services, such as the European External Action Service. Other research conducted in the INCOOP network illustrated the relevance of the consistency concern across the range of EU institutions.

In turn, discussing Lisbon's innovation in the light of these results could lead to the formulation of policy recommendations to enhance coordination within the Commission, within other institutions and between institutions and to strengthen the consistency of the policy output. This option to valorise the research has already been realised both in the proposals put forward at the end of this dissertation and in a policy brief presented at the INCOOP dissemination colloquium (October 2013) organised in Brussels. The colloquium aimed at bridging the gap between academia and practitioners: the objective was to emphasise the practical relevance of the INCOOP PhD projects, to assess the current institutional arrangements, as well as to formulate and discuss concrete policy recommendations. Acting as the coordinator for the working group on intrainstitutional coordination, I contributed to the writing of a policy brief and presented it in front of an audience of more than 100 representatives of EU institutions, consultancies and scholars. Policy recommendations included, for instance, an increase in the resources of the coordinating bodies inside the EU institutions, a more systematic use of coordination instruments at the political level such as the External Relations Group of Commissioners within the Commission, a strengthening of the consistency requirement in the impact assessment process, as well as the development of trainings for EU officials to enhance the horizontality of policy-making and diffuse best practices in terms of coordination. This practitioner- 
oriented approach was aiming at directly transferring knowledge to a nonacademic audience and working towards the applicability of this knowledge.

Regarding the development of policy recommendations, I have already had the opportunity to pursue this track while I was still working on my $\mathrm{PhD}$. When I interned at the European Commission (DG Trade, March-April 2012), I acted i.a. as a policy coordinator, advising my unit with respect to coordination. For instance, I drafted position papers on the specific challenges that coordination and consistency represented for DG Trade, providing support to colleagues involved in intra- or inter-institutional conflicts and contributed to the resolution of these conflicts.

Interviewees expressed their interest in the development of training activities on consistency- and coordination-related issues within the Commission. this is explained not only by the need to ensure the smooth functioning of an institution always in flux, but also to maintain awareness of the challenges that consistency and coordination constitute. These activities would not be offered to Commission only but could be extended to the European External Action Service in the exercise of the responsibilities for which Commission decision-making applies. Indeed, given the turnover of officials and the variety of backgrounds of EEAS officials - for instance as they join the service seconded by their Member States - trainings represent a significant market opportunity.

To conclude, the valorisation of research contributes to the relevance of a PhD by ensuring that the knowledge created can be transferred to both academic and nonacademic audiences. Four options were discussed - publications, education, evaluation, policy recommendations and training. I am currently pursuing all of them in an effort to realise in a maximal way the potential of the PhD. 


\section{Curriculum vitae}

Anne-Claire Marangoni (1984) studied public administration and European affairs at Sciences Po Strasbourg (2002-2006). She spent one year as an Erasmus student at Birmingham University (2004) in international relations. She obtained a Master's degree in Public Administration from Sciences Po Strasbourg in 2007. She then completed the EU International Relations and Diplomacy Studies programme at the College of Europe in Bruges and graduated in 2008.

Upon graduation, Anne-Claire started working in Brussels as a junior consultant in public and European affairs. She returned to the College of Europe, Department of International Relations and Diplomacy Studies, as the senior academic assistant. In addition to research and teaching activities in the field of EU external action, she also worked as a trainer for the Belgian Presidency of the EU.

Anne-Claire took up a Ph.D. position at the faculty of Arts and Social Sciences, Maastricht University, in September 2010, funded by the European Commission under the Marie Curie Initial Training Network on Inter-institutional Cooperation in the EU (ITN-FP7). Her research deals with intra-institutional coordination within the European Commission in external policy-making. The findings of her research have been presented at international conferences (UACES, ECPR, EUSA) and published either as chapters in edited volumes or in academic journals (Journal of European Integration, EU External Affairs Review).

Besides her research, Anne-Claire has lectured and tutored in the course 'Negotiation Skills' at Maastricht University. She interned at the European Commission, DG Trade, providing expertise on intra- and inter-institutional coordination. She is currently a Research Associate at Aston University, Birmingham. 